\title{
Low-Pressure-Ratio Regenerative Exhaust-Heated Gas Turbine
}

\section{Final Report}

\author{
L.A. Tampe \\ R.G. Frenkel \\ D.J. Kowalick \\ H.M. Nahatis \\ S.M. Silverstein \\ D.G. Wilson
}

January 1991

Work Performed Under Contract No.: DE-AC21-89MC26051

For

U.S. Department of Energy

Office of Fossil Energy

Morgantown Energy Technology Center

Morgantown, West Virginia

By

Massachusetts Institute of Technology Department of Mechanical Engineering Cambridge, Massachusetts

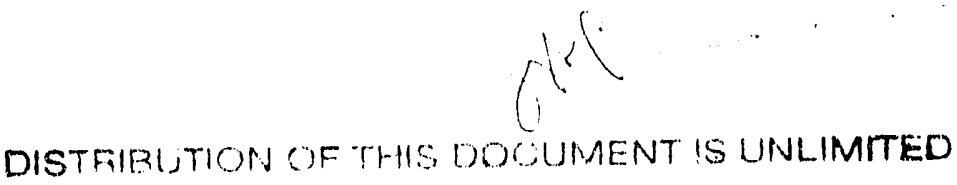




\section{DISCLAIMER}

This report was prepared as an account of work sponsered by an agency of the United States Government. Neither the United States Government nor any agency thereof, nor any of their employees makes any warranty, express or implied, or assumes any legal liability or responsibility for the accuracy, completeness or usefulness of any information, apparatus, product, or process disclosed, or represents that its use would not infringe privately owned rights. Reference herein to any specific commercial product, process, or service by trade name, trademark, manufacturer, or otherwise, does not necessarily constitute or imply its endorsement, recommendation, or favoring by the United States Government or any agency thereof. The views and opinions of authors expressed herein do not necessarily state or reflect those of the United States Government or any agency thereof.

This report has been reproduced directly from the best available copy.

Available to DOE and DOE contractors from the Office of Scientific and Technical Information, P.O. Box 62, Oak Ridge, TN 37831; prices available from (615)576-8401, FTS 626-8401.

Available to the public from the National Technical Information Service, U.S. Department of Commerce, 5285 Port Royal Rd., Springtield, VA 22161. 


\title{
Low-Pressure-Ratio Regenerative Exhaust-Heated Gas Turbine
}

Final Report

\author{
L.A. Tampe \\ R.G. Frenkel \\ D.J. Kowalick \\ H.M. Nahatis \\ S.M. Silverstein \\ D.G. Wilson
}

January 1991

Work Performed Under Contract No.: DE-AC21-89MC26051

For

U.S. Department of Energy

Office of Fossil Energy

Morgantown Energy Technology Center

P.O. Box 880

Morgantown, West Virginia 26507-0880

By

Massachusetts Institute of Technology

Department of Mechanical Engineering

77 Massachus s Avenue

Cambridge, Massachusetts 02139 
ABSTRACT

A design study of coal-burning gas-turbine engines using the exhaust-heated cycle and state-of-the-art components has been completed. In addition, some initial experiments on a type of rotary ceramic-matrix regenerator that would be used to transfer heat from the products of coal combustion in the hot turbine exhaust to the cool compressed air have been conducted. Highly favorable results have been obtained on all aspects on which definite conclusions could be drawn.

Preliminary designs were completed of four two-megawatt engines. They worked on two cycles: in one the compressor had no intercooler, and in the other one intercooler was employed. Two manifestations of the two cycles were examined. One used modifications of existing gas-turbine engines, and the other approach was that of a "clean-sheet" or "blue-sky" engine, designed from scratch.

The two blue-sky engines had design-point thermal efficiencies of from 45-51\%, for maximum cycle temperatures from $1144 \mathrm{~K}$ $(1600 \mathrm{~F})$ to $1373 \mathrm{~K}(2011 \mathrm{~F})$. The part-power performances were predicted to be outstandingly good: efficiencies were far better than those of current Diesel engines of similar design power, down to at least fifteen-percent power. The engines modified from existing "off-the-shelf" designs had efficiencies generally about five percentage points below these levels.

Life-cycle costs were predicted for all engines examined, and were found to be favorable.

A ceramic heat exchanger was incorporated into a test rig to investigate the effects of fouling from the products of coal com-bustion. The depositions that occurred in low-temperature tests were found to be easily removed by very-low-pressure "soot blowing". Preliminary tests of the deposition of high-temperature products of coal combustion in alumina tubes in a drop-tube furnace indicated that deposition problems should be manageable. The long-term viability of the heat exchanger in an exhaust-heated cycle is, however, the principal uncertainty that needs to be resolved before this promising coal-burning engine system can be recommended with complete confidence. 
ACKNOWLEDGEMENTS.

The work reported here was supported in part by the U.S. Department of Energy, Morgantown Energy Technology Centex, Morgantown, WV, under DOE contract DE-AC21-89MC26051. The project managers were Michael H. McMillian, for the first part of the work, and Edward I. Parsons, Jr. for the later part of the program. The research assistant throughout the program was Luis A. Tampe. Three graduate students performed their masters-thesis work while on fellowships, and therefore at no cost to the program: Richard G. Frenkel and Harry M. Nahatis, GE Fellows, and David J. Kowalick, US Navy Fellow. Seth M. Silverstein worked on the laboratory testing side of the program as an undergraduate researcher. Professor Janos M. Beer of the Chemical Engineering Department, MIT, gave continual guidance and advice, again at no cost to the program. Mr. Anthony $J$.

Modestino, Energy Laboratory, MIT, was of considerable help in our tests in the drop-tube furnace. We had considerable helpful advice from individual members of our advisory committee, who received our bi-monthly and other reports. The members were as follows.

David Aronson

David Aronson Associates (consulting engineers) 9 Riverview Drive, West UPPER MONTCLAIR, NJ 07043

Janos M. Beer

M.I.T. room 66-548

CAMBRIDGE, MA 02139

Ronald L. Bannister, Program Manager

Westinghouse Electric Corp.

4400 Alafaya Trail, MC 203

orlando, Florida 32826-2399

Michael Hayes

P.O. Box 1926, Toowoomba

Queensland 4350 AUSTRALIA

Paul G. LaHaye, President HAGUE INTERNATIONAL

3 Adams street

SOUTH PORTLAND, ME 04106

Thomas H. Lindsey

Program Manager

Allison Gas Turbine

P.O. Box 420, MS T-14

Indianapolis, IN 46206-0420
Colin F. McDonald, Manager

Mechanical Engineering

GA Technologies, Inc.

P.O. Box 85608,

San Diego, California 92138

Michael H. McMillian,

Project Manager

D.O.E. - M.E.T.C.

P.O. BOX 880

MORGANTOWN, WV 26506

Dr. Richard A. Newby

Prin.Engineer, Fossil Fuel

Westinghouse Electric Corp. 1310 Beulah Road

Pittsburgh, PA 15235

Edward L. Parsons, Jr. Project Manager

Coal Projects Management Div. DEPARTMENT OF ENERGY, METC

P.O. BOX 880

MORGANTOWN, WV 26507-0880

Peter B. Roberts, Manager

Combustion Engineering

Solar Turbines, Inc.

P.O. Box 85376

San Diego, CA $92138-5376$ 
Dr. James E. Staudt

Programs Manager,

FUEL TECH, INC.

61 Taylor Reed Place

STAMFORD, CT 06906

G. A. Richards

DOE/METC

P.O. BOX 880

MORGANTOWN, WV 26507-0880

Kon Logan

DOE/METC

P.O. BOX 880

MORGANTOWN, WV 26507-0880

We carried out the tests of the rotating ceramic regenerator in the MIT Heat Transfer Laboratory, with the permission of the director, Professor Peter Griffith. The secretary to the program was Mrs. Carolyn Beckman-stitson.

To all of these who contributed so substantially to the program the principal investigator gives his sincere thanks.

David Gordon Wilson 


\section{FINAL TOPICAL REPORT}

DOE Contract DE-AC21-89MC26051

Low-Pressure-Ratio Regenerative

Exhaust-Heated Gas Turbine

TABLE OF CONTENTS

Page

LIST OF FIGURES $\ldots \ldots \ldots \ldots \ldots \ldots \ldots \ldots \ldots \ldots \ldots \ldots \ldots \ldots \ldots$

LIST OF TABLES $\ldots \ldots \ldots \ldots \ldots \ldots \ldots \ldots \ldots \ldots \ldots \ldots \ldots \ldots \ldots \ldots$

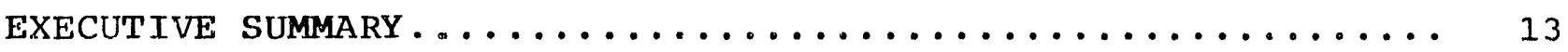

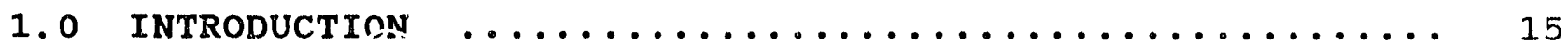

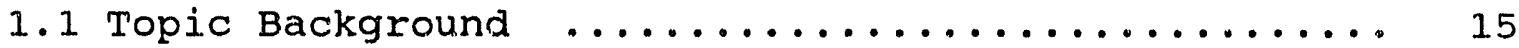

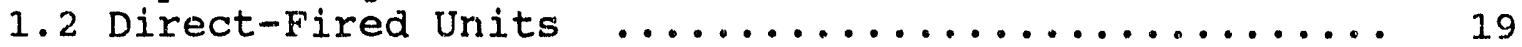

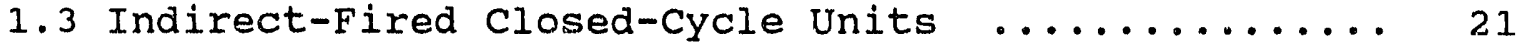

1.4 Indirect-Fired Exhaust-Heated Units ........... 21

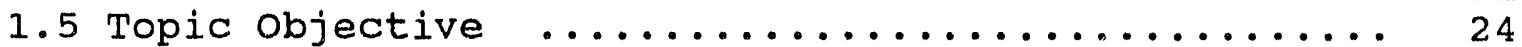

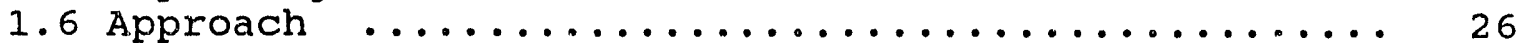

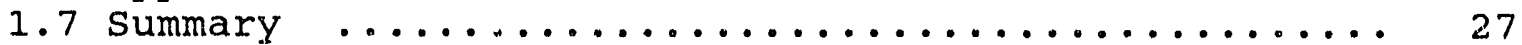

2.0 BACKGROUND TO GAS-TURBINE GEOMETRY \& THERMODYNAMICS $\ldots . .28$

2.1 Blade Geometry of Axial-Flow Turbines \& Compressors 28

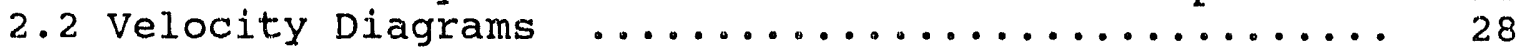

2.3 Efficiency of Turbines and Compressors ......... 32

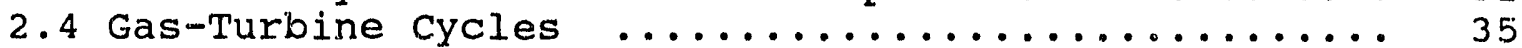

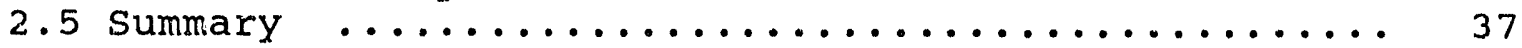

3.0 BACKGROUND TO ENGINE DESIGN AND PERFORMANCE ESTIMATION 40

3.1 Compressor and Turbine sizing .............. 40

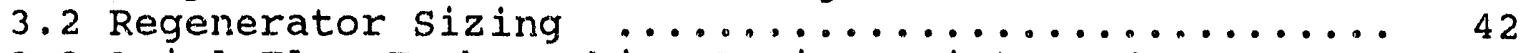

3.3 Axial-Flow Turbomachine Design-Point Performance

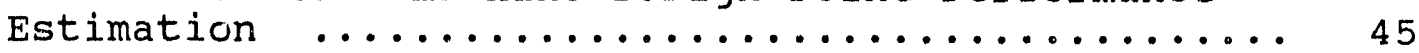

3.4 Axial-Flow Turbomachine off-Design Performance

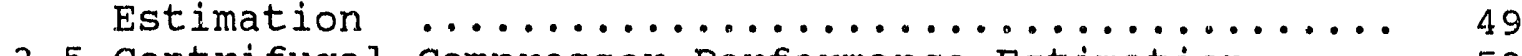

3.5 Centrifugal Compressor Performance Estimation .... 53

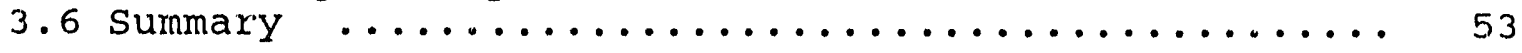

4. 0 PROCEDURE FOR CYCLE ANALYSIS AND ENGINE DESIGN $\ldots \ldots \ldots .54$

4.1 Background to Computer Cycle Analysis ........... 54

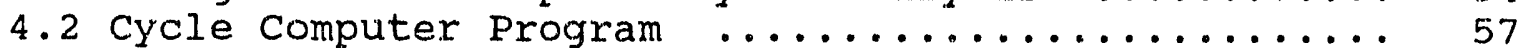

4.3 Turbine and compressor computer programs ........ 60

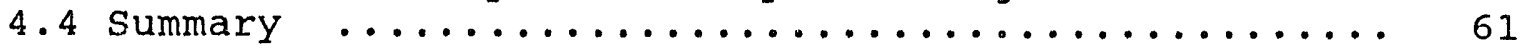

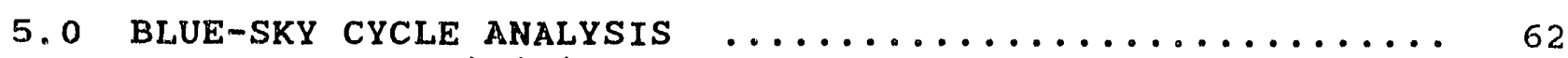

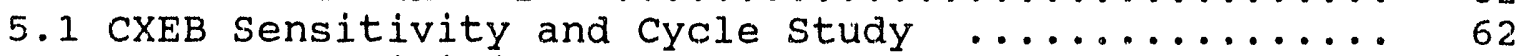

5.2 CICXEB Sensitivity and Cycle study ............ 70 


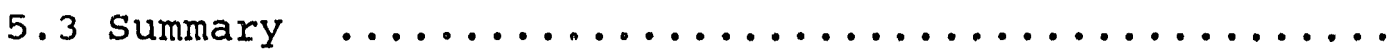

6.0 OFF-THE-SHELF ENGINE SELECTION AND CYCLE ANALYSIS $\ldots \ldots \quad 82$

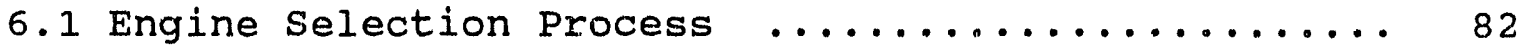

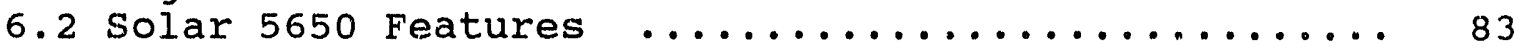

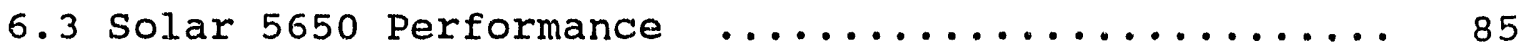

6.4 Analysis Overview of the Engine Conversions ..... 85

6.5 NIC Exhaust-Heated 5650 Cycle Analysis .......... 87

6.6 IC Exhaust-Heated 5650 Cycle Analysis ......... 89

6.7 summary $\ldots \ldots \ldots \ldots \ldots \ldots \ldots \ldots \ldots \ldots \ldots \ldots . \ldots \ldots . \ldots \ldots$

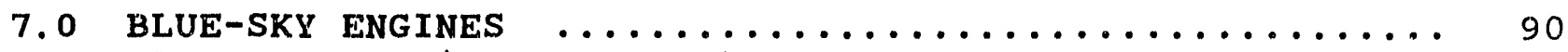

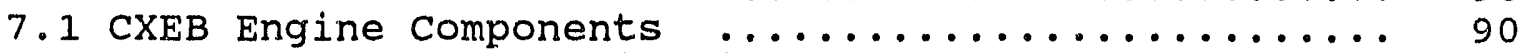

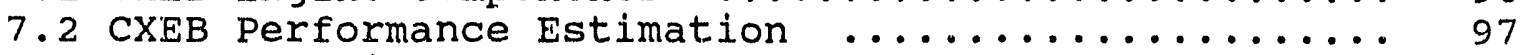

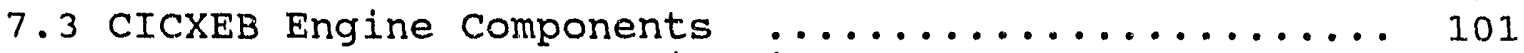

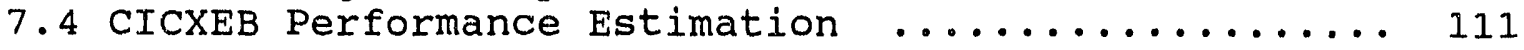

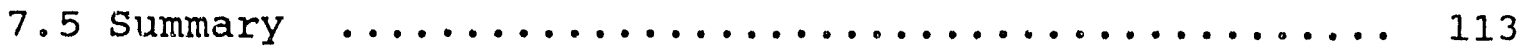

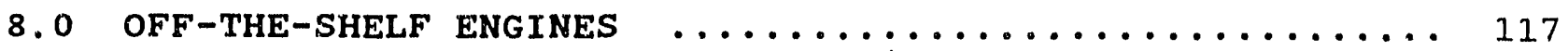

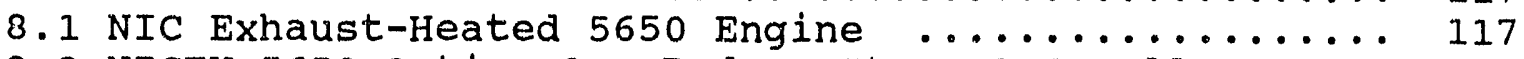

8.2 NICEH 5650 Option 1 - Reduce stage-1 Impeller

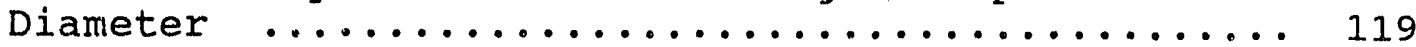

8.3 NICEH 5650 Option 2 - Redesign all Turbomachinery 122

8.4 NICEH 5650 option 3 - Run Existing Turbomachinery

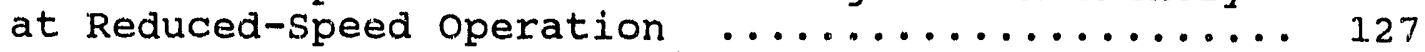

8.5 IC Exhaust-Heated 5650 Engine ................. 131

8.6 ICEH 5650 Option 1 - Run Engine at Original

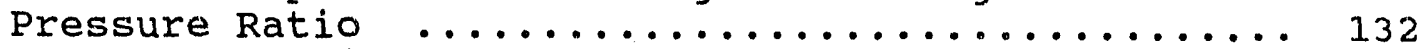

8.7 ICEH 5650 Option 2 - Redesign all Turbomachinery . 132

8.8 ICEH 5650 Option 3 - Run Existing Turbomachinery

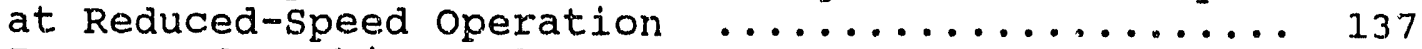

8.9 Increased Turbine-Inlet Temperature $\ldots \ldots \ldots \ldots \ldots 137$

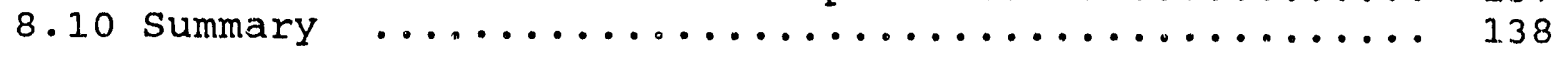

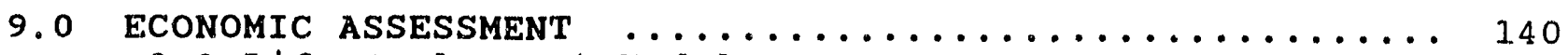

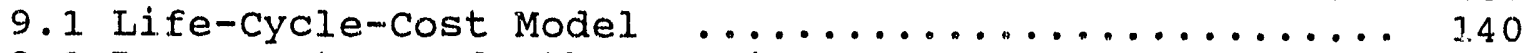

9.2 Regenerator and other Engine component Costs ..... 141

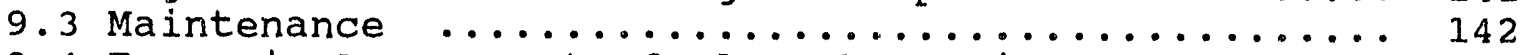

9.4 Economic Assessment of 3lue-sky Engines .......... 143

9.5 Economic Assessment of off-The-Shelf Engines ..... 149

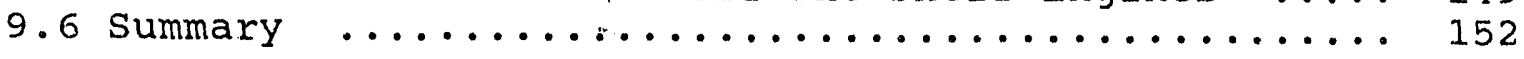

10.0 HEAT-EXCHANGER FOULING TESTS $\ldots \ldots \ldots \ldots \ldots \ldots \ldots \ldots \ldots$

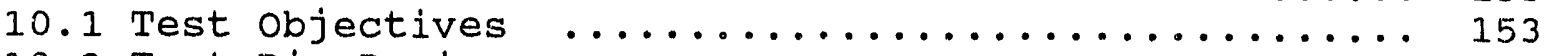

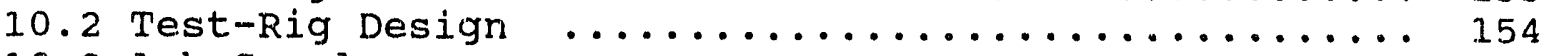

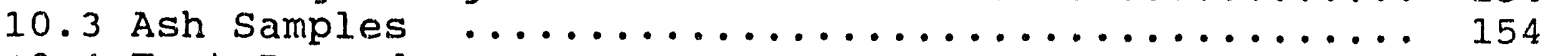

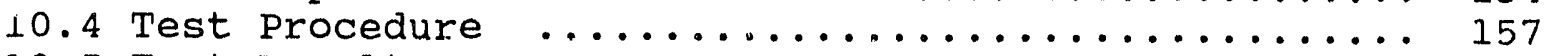

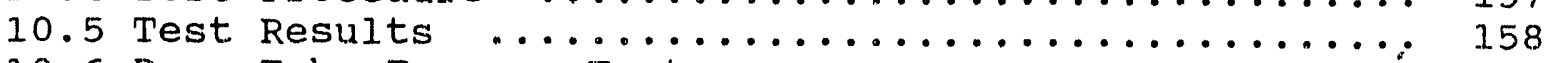

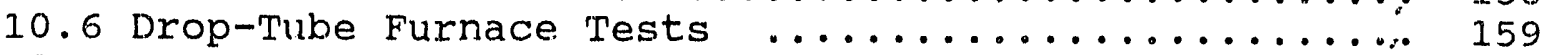

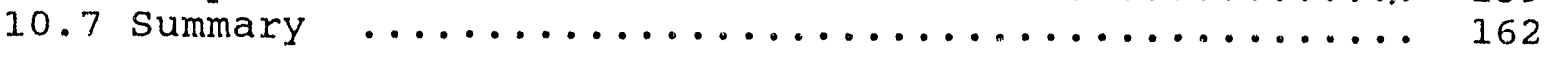

11.0 CONCLUSIONS AND RECOMMENDATIONS $\ldots \ldots \ldots \ldots \ldots \ldots \ldots$

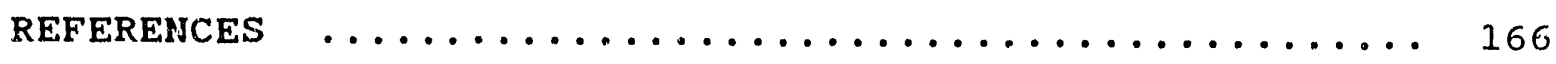

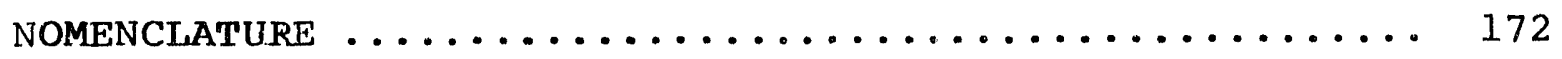




\section{LIST OF FIGURES}

Figures

Title

Page

1.1 DOE/METC SPONSORED SYSTEM DESCRIPTIONS 16

$\begin{array}{lll}1.2 & \text { DIRECT-FIRED COAL-BURNING GAS TURBINE } & 17\end{array}$

$1 . \therefore$ CLOSED-CYCLE COAL-BURNING GAS TURBINE 18

1.4 EXHAUST-HEATED COAL-BURNING GAS TURBINE 20

1.5 MORDELL'S EXHAUST-HEATED GAS TURBINE 23

1.6 ROTATING CERAMIC-MATRIX REGENERATOR 23

\begin{tabular}{l|l}
1.7 & SCHEDULE PLAN FOR PROJECT
\end{tabular}

2.1 MAJOR GEOMETRIC TURBINE-BLADE PARAMETERS 29

2.2 TABULATED COMPRESSOR-BLADE GEOMETRY 30

2.3 NACA COMPRESSOR-BLADE PERFORMANCE GRAPH 31

2.4 COMPRESSOR VELOCITY DIAGRAM 33

2.5 TURBINE VELOCITY DIAGRAM 33

2.6 T-S DIAGRAM OF IDEAL AND NON-IDEAL

$\begin{array}{lll}2.7 & \text { CBE CYCLE } & 34\end{array}$

2.8 CBEX CYCLE 36

2.9 CICBEX CYCLE 36

2.10 CXEB CYCLE 38

2.11 CICXEB CYCLE 39

3.1 AXIAL-FLOW-TURBINE STAGE EFFICIENCY VS 41

3.2 $f$ AND $j$ CURVES FOR CORE 503A 44

3.3 TURBINE LOSSES ALONG CONSTANT ENTROPY LINE 46

3.4 WILSON \& KORAKIANITIS PERFORMANCE CURVES 46 FOR A LPR COMPRESSOR 
3.5 WORK COEFFICIENT AND INCIDENCE ANGLE VS FLOW COEFFICIENT FOR THE COMPRESSOR

5.1 THERMAL EFFICIENCY VS SPECIFIC POWER FOR CXEB FOR $0.90,0.95$, AND 0.975 EFFECTIVENESS CXEB FOR POLYTROPIC-EFFICIENCY CONSTANTS 0.92 AND 0.90

5.3 THERMAL EFFICIENCY VS SPECIFIC POWER FOR CXEB FOR $T \max =1373 \mathrm{~K}, 1393 \mathrm{~K}$, AND $1413 \mathrm{~K}$ THERMAL EFFICIENCY VS SPECIFIC POWER FOR CXEB FOR Tmax $=1373 \mathrm{~K}, 1255 \mathrm{~K}$, AND $1144 \mathrm{~K}$ THERMAL EFFICIENCY VS SPECIFIC POWER FOR CXEB CYCLE

5.7 THERMAL EFFICIENCY VS SPECIFIC POWER FOR CXEB WITH REDUCED LEAKAGE

5.8 THERMAL EFFICIENCY VS SPECIFIC POWER FOR CXEB WITH PRESSURE-DROP REDUCTION

5.9 THERMAL EFFICIENCY VS SPECIFIC POWER FOR CICXEB FOR $0.90,0.95$, AND 0.975 EFFECTIVENESS

5.10 THERMAL EFFICIENCY VS SPECIFIC POWER FOR CICXEB FOR POLYTROPIC-EFFICIENCY CONSTANTS 0.92 AND 0.90

5.11 THERMAL EFFICIENCY VS SPECIFIC POWER FOR CICXEB FOR Tmax $=1373 \mathrm{~K}, 1393 \mathrm{~K}$, AND $1413 \mathrm{~K}$

5.12 THERMAL EFFICIENCY VS SPECIFIC POWER FOR CICXEB FOR Tmax $=1373 \mathrm{~K}$, $1255 \mathrm{~K}$, AND $1144 \mathrm{~K}$

5.13 THERMAL EFFICIENCY VS SPECIFIC POWER FOR CICXEB CYCLE

5.14 CICXEB CYCLE 79 $\begin{array}{ll}5.15 & \text { THERMAL EFFICIENCY VS SPECIFIC POWER FOR } \\ \text { CICXEB WITH REDUCED LEAKAGE } & 80\end{array}$

5.16 THERMAL EFFICIENCY VS SPECIFIC POWER FOR 


\begin{tabular}{|c|c|c|}
\hline 6.1 & SOLAR 5650 INDUSTRIAL GAS TURBINE & 84 \\
\hline 6.2 & SOLAR 5650 ENGINE CROSS SECTION & 84 \\
\hline 6.3 & $\begin{array}{l}\text { THERMAL EFFICIENCY VS SPECIFIC POWER FOR } \\
\text { NICEH } 5650\end{array}$ & 88 \\
\hline 6.4 & $\begin{array}{l}\text { THERMAI EFFICIENCY VS SPECIFIC POWER FOR } \\
\text { ICEH } 5650\end{array}$ & 88 \\
\hline 7.1 & $\begin{array}{l}\text { NACA 65-8-10 COMPRESSOR-BLADE PERFORMANCE } \\
\text { GRAPH }\end{array}$ & 92 \\
\hline 7.2 & CROSS-SECTIONAL SKETCH OF CXEB ENGINE & 96 \\
\hline 7.3 & CXEB SIX-STAGE COMPRESSOR MAP & 99 \\
\hline 7.4 & SAMPLE LPR TURBINE MAP & 100 \\
\hline 7.5 & OFF-DESIGN THERMAL EFFICIENCY OF CXEB & 106 \\
\hline 7.6 & OFF-DESIGN NET POWER OF CXEB & 107 \\
\hline 7.7 & CROSS-SECTIONAL SKETCH OF CICXEB ENGINE & 112 \\
\hline 7.8 & OFF-DESIGN THERMAL EFFICIENCY OF CICXEB & 114 \\
\hline 7.9 & OFF-DESIGN NET POWER OF CICXEB & 115 \\
\hline 8.1 & NICEH 5650 ENGINE CROSS SECTION & 118 \\
\hline 8.2 & NICEH 5650 COMPRESSOR STAGE 1 SCHEMATIC & 123 \\
\hline 8.3 & NICEH 5650 COMPRESSOR STAGE 2 SCHEMATIC & 123 \\
\hline 8.4 & NICEH 5650 REDESIGNED-TURBINE SCHEMATIC & 126 \\
\hline 8.5 & SOLAR 5650 COMPRESSOR OPERATING LINE & 128 \\
\hline 8.6 & SOLAR 5650 TURBINE OPERATING IINE & 129 \\
\hline 8.7 & NICEH 5650 REDUCED-SPEED OPERATION & 130 \\
\hline 8.8 & ICEH 5650 ENGINE CROSS SECTION & 130 \\
\hline 8.9 & ICEH 5650 COMPRESSOR SMAGE 1 SCHEMATIC & 133 \\
\hline 8.10 & ICEH 5650 COMPRESSOR STAGE 2 SCHEMATIC & 133 \\
\hline 8.11 & ICEH 5650 REDESIGNED-TURBINE SCHEMATIC & 136 \\
\hline 8.12 & REDUCED-SPEED OPERATION OF ICEH AND NICEH 5650 & 136 \\
\hline 8.13 & DESIGN PERFORMANCE OF ALL OPTIONS & 139 \\
\hline
\end{tabular}


9.1 LIFE-CYCLE COST VS THERMAL EFFICIENCY

9.3

LIFE-CYCLE COST VS MAINTENANCE COST 


\section{LIST OF TABLES}

Tables

Title

Page

3.1 SURFACE GEOMETRY FOR THREE CORES

$\begin{array}{lll}4.1 & \text { ULTIMATE ANALYSIS OF COAL } & 57\end{array}$

6.1 CANDIDATE GAS TURBINES 83

6.2 ENGINE DIMENSIONS

6.3 SOLAR 5650 DESIGN-POINT PERFORMANCE 85

6.4 COMPONENT PERFORMANCE OF THE NIC EXHAUST-HEATED 87

6.5 COMPONENT PERFORMANCE OF THE IC EXHAUST HEATED 89

7.1 MAJOR SIZING RESULTS OF THE CXEB COMPRESSOR 90

7.2 VELOCITY-DIAGRAM DATA FOR THE COMPRESSOR 91

7.3 MAJOR SIZING RESULTS FOR THE CXEB TURBINE 93

7.4 VELOCITY-DIAGRAM DATA FOR THE TURBINE 93

7.5 REGENERATOR SIZE FOR DIFFERENT CORE TYPES 94

7.6 EFFECT OF INCREASING HYDRAULIC DIAMETER ON THE 95 REGENERATOR DIAMETER AND THICKNESS FOR THE CXEB ENGINE

7.7 COMPRESSOR TOTAL-TO-TOTAL POLY EFFICIENCIES

7.8 TURBINE TOTAL-TO-TOTAL POLY EFFICIENCIES 98

7.9 HEAT-EXCHANGER RESULTS AT DESIGN POINT 102

$\begin{array}{lll}7.10 & \text { HEAT-EXCHANGER RESULTS AT OFF DESIGN } & 103\end{array}$

$\begin{array}{lll}7.11 & \text { OVERALL OUTFUT FOR DESIGN POINT } & 104\end{array}$

$\begin{array}{lll}7.1 .2 & \text { OVERALL OUTPUT FOR OFF DESIGN } & 105\end{array}$

7.13 MAJOR SIZING RESULTS FOR FIRST COMPRESSOR 208

7.14 MAJOR SIZING RESULTS FOR SECOND COMPRESSOR

7.15 VELOCITY-DIAGRAM DATA FOR FIRST COMPRESSOR 108 
7.16 VELOCITY-DIAGRAM DATA FOR SECOND COMPRESSOR

7.17 MAJOR SIZING RESULTS FOR THE CICXEB TURBINE

7.20 COMPRESSOR TOTAL-TO-TOTAL POLY EFFICIENCIES TUREI:. $\overline{-}$ TOTAL-TO-TOTAL POLY EFFICIENCIES

8.4 POWER-TURBINE GEOMETRY FOR TRIMMED-IMPELLER OPTION

8.5 MEAN-DIAMETER TURBINE VELOCITY-DIAGRAM DATA FOR TRIMMED-IMPELLER OPTION

8.6 OVERALL PERFORMANCE COMPARISON--TRIMMED VS CPTIMAL

8.8 COMPARISON OF REDESIGNED COMPRESSOR GEOMETRY FOR NICEH 5650 COMPRESSOR OPTION 


\begin{tabular}{|c|c|}
\hline 8.16 & REGENERATOR SIZE FOR DIFFERENT CORE TYPES \\
\hline 8.17 & $\begin{array}{l}\text { OVIERALL PERFORMANCE COMPARISON } \\
\text { IC } 5650 \text { VS ICEH } 5650\end{array}$ \\
\hline 8.18 & COMPRESSOR DESIGN PARAMETERS \\
\hline 8.19 & $\begin{array}{l}\text { COMPARISON OF REDESIGNED COMPRESSOR GEOMETRY } \\
\text { FOR ICISH } 5650\end{array}$ \\
\hline 8.20 & $\begin{array}{l}\text { REDESIGNED NICEH } 5650 \text { COMPRESSOR } \\
\text { VELOCITY-DIAGRAM DATA }\end{array}$ \\
\hline 8.21 & COMPRESSOR DESIGN INTENT VS PREDICTION \\
\hline 8.22 & $\begin{array}{l}\text { GAS-PRODUCER TURBINE GEOMETRY FOR REDESIGNED } \\
\text { COMPRESSOR OPTION }\end{array}$ \\
\hline 8.23 & $\begin{array}{l}\text { POWER-TURBINE GEOMETRY FOR REDESIGNED COMPRESSOR } \\
\text { OPTION }\end{array}$ \\
\hline 8.24 & $\begin{array}{l}\text { MEAN-DIAMETER TURBINE VELOCITY-DIAGRAM DATA FOR } \\
\text { REDESIGNED COMPRESSOR OPTION }\end{array}$ \\
\hline 8.25 & $\begin{array}{l}\text { DESIGN INTENT VS PREDICTED EFFICIENCY FOR } \\
\text { FOR TURBINES }\end{array}$ \\
\hline 8.26 & $\begin{array}{l}\text { OVERALL PERFORMANCE COMPARISON } \\
\text { OPTIMAL VS REDUCED-SPEED DESIGN }\end{array}$ \\
\hline 8.27 & $1339 \mathrm{~K}$ TIT CYCLE COMPARISON - NICEH ENGINE \\
\hline 8.28 & $1339 \mathrm{~K}$ TIT CYCLE COMPARISON - ICEH ENGINE \\
\hline 9.1 & $\begin{array}{l}\text { REGENERATOR CAPITAL COST FOR DIFFERENT CORE } \\
\text { TYPES }\end{array}$ \\
\hline 9.2 & LIFE-CYCLE CALCULATION PARAMETERS \\
\hline 9.3 & CAPITAL COST OF BLUE-SKY ENGINES \\
\hline 9.4 & LIFE-CYCLE COST SUMMARY \\
\hline 9.5 & SUMMARY OF ECONOMIC SENSITIVITY STUDY \\
\hline 9.6 & LIFE-CYCLE COST FOR VARYING COAL PRICES \\
\hline 9.7 & CAPITAL COST OF NICEH 5650 OPTIONS \\
\hline 9.8 & CAPITAL COST OF ICEH 5650 OPTIONS \\
\hline 9.9 & LIFE-CYCLE CALCULATION PARAMETERS \\
\hline
\end{tabular}


9.10 LIFE-CYCLE COST SUMMARY $\quad 151$

$\begin{array}{llll}10.1 & \text { SIZE } & 157\end{array}$

$\begin{array}{lll}10.2 & \text { RESULTS OBTAINED FROM TEST RIG } & 158\end{array}$ 
EXECUTIVE SUMMARY.

The exhaust-heated cycle involves modifying the standard gas-turbine cycle by transposing the combustor from its position before the turbine in the simple direct-fired unit to a location after the turbine. The hot, clean air from the turbine exhaust first passes into a coal-fired combustor, from then into some form of hot-gas cleanup, and then passes into a heat exchanger that heats the ccmpressed air leaving the compressor. The entire heat addition to the air entering the turbine, then, occurs in a heat exchanger.

The attractiveness of this cycle is that the products of combustion do not pass through the turbine. Thus, there will be no ash deposition, erosion, or corrcsion of the turbine blades. The designers' concern shifts from the highly stressed and criticaliy profiled turbine to the somewhat-less-sensitive heat exchanger. Modern turbine-inlet temperatures are well above the limit for any pussible metallic heat exchanger. Presently available choices for nonmetallic units are limited to ceramir. recuperators (fixed-surface heat exchangers) or periodic-flow regenerators. We selected the rotating-ceramic-matrix

regenerator from several possible types for initial study. In the ceramic regenerator, the two streams (the cumpressor-delivery air and the products of combustion) pass through different annular areas of the matrix (which contains small pores) in counterflow. While the disk is rotating the matrix absorbs heat from the hot stream and transfers it to the cold stream. This type of heat exchanger is normally self-cleaning since, as it rotates, the flory direction reverses and any dry deposits that might be formed as the exhaust gases pass through in one direction should be disiodged when the compressed air from the compressor flows in the opposite directior. The highest effectiveness of a heat exchanger of this type is slightIy over 0.95 in the Allison GT 404 engine. An effectiveness of 0.975 could be obtained on that unit by approximately doubling its current thickness, that is, by increasing the disk thickness from about $80 \mathrm{~mm}$ to about $160 \mathrm{~mm}$.

The exhaust-heated cycle also has some apparent disauvantages compared with the direct-heated coal-burning cycles. The combustor operates at about atmospheric pressure nd must be considerably larger than one working at compressor-delivery pressure. The heat exchanger may have a shorter life than one working in a direct-fired gas- or oil-fuelled gas turbine. However, a heat-exchanger cycle confers such major advantages in efficiency at full and part load that for engines that work on base load or for extended pexiods the heat exchanger itself cannot be considered disadvantageous. The heat exchanger in an exhaust-heated cycle covers a considerably larger temperature range than one in a direct-fired cycle because it must raise the compressed air to turbine-inlet, rather than combustor-inlet, temperature. Therefore, the duties imposed on the heat exchanger are doubly arduous: it must handle a very challengirig 
temperature range, and it must do so with a corrosive particle-laden gas stream. The success of the exhaust-heated cycle depends, therefore, on the viability of the heat exchanger.

The DOE-sponsored program reported here examined the exhaust-heated cycle with and without intercooling. The exhaust-heated engine without intercooling will be referred to as the CXEB (Compressor heat exchanger Expander Burner) cycle. The exhaust-heated engine with intercooling will be referred to as the CICXEb cycle, using similar rationale.

The conclusions reached from this program were as follows. The exhaust-heated gas-turbine cycle has a high potential for burning coal in an environmentally benign manner, with control over pollutants and, because of its high efficiency, with minimum production of carbon dioxide.

Desigr-point efficiencies can be over 50 percent if moderate maximum cycle temperatures $(1373 \mathrm{~K}$ or $2011 \mathrm{~F})$ can be used, and over 45 percent if the heat-exchanger-inlet temperatures must be reld to lower values, such as $1145 \mathrm{~K}(1600 \mathrm{~F})$.

The highly regenerated low-pressure-ratio version of the exhaust-heated cycle has a very favorable part-load performance, giving efficiencies better than thuse of current Diesel engines of similar power output down to at least fifteen percent of design power.

The lowest life-cycle cost of the engines examined is estimated t.o be a "blue sky" or "clean-sheet" engine having an intercooled axial-flow six-stage compressor of four-to-one overall pressure ratio; a rotary ceramic matrix regenerator having an effectiveness of 0.975 ; a three-stage axial-flow turbine with an inlet temperature of $1367 \mathrm{~K}$ (2000F); and a combustor burning dry micronized coal with a hot-gas-cleanup system. An engine that would require less investment but that would result in a life-cycle cost a little higher would involve modifying the Caterpillar solar 5650 gas-turbine engine to work on the intercooled exhaust-heated cycle.

Cold-flow and coal-combustion experiments on a ceramic regenerator and on alumina tubes have given preliminary favorable indications that a ceramic-matrix regenerator would operate successfully and with an acceptable life in the harsh environment of cooling coal-combustion gases. However, considerable testing is required before this indication can be confirmed. 


\subsection{INTRODUCTION}

This chapter presents a description of the topic background and objective. A review is given of the various tasks accomplished in this project. Other alternatives to the exhaust-heated cycle for coal burning in gas turbines are explained and compared to the exhaust-heated cycle. Ample references are included for the interested reader to consult.

\subsection{TOPIC BACKGROUND}

Studies have been underway for the past fifty yiars or so to develop feasible coal-burning gas turbines. In 1982 the increasing price gap between coal and other forms of fossil fuels and the inevitable depletion of petroleum-based fuels prompted the Department of Energy (DOE) to revive research in coal-burning heat engines [1]. The types of heat engines being looked into by DOEsponsored researchers include gas turbines and Diesel engines. since the United States possesses enormous coal reserves it is likely that a decrease in this country's dependence on foreign petroleum-based fuels would occur with new developments in coalfired engines. Clearly, there would be great advantages to the development of new forms of coal-fired power generation and propulsion systems incorporating stringent pollution controls. These reasons, coupled with the gas turbine's advantages of compact size, potential low cost, and relative ease of control [2] make coal-fired gas turbines extremely attractive.

DOE has awarded contracts to GE, Westinghouse, Allison/Gas Turbines, and Solax Turbines for development of integrated coalfired gas-turbine systems. The research by these companies has concentrated primarily on one type of engine arrangement: the direct-fired unit as shown in Figure 1.1. Another type of engine configuration which has received less attention is the indirectfired gas turbine. Indirect-fired gas turbines can be subdivided further into two types: those using the closed cycle and those employing the exhaust-heated cycle $[3,4]$.

The direct-fired units have combustion of the compressed air with coal prior to entering the turbine. The air is first compressed in a compressor and then fed to a coal combustor incorporating some form of hot-gas cleaning. The products of combustion then enter the expander, perform work, and are rejected back into the atmosphere after further pollutant removal, or are directed toward a waste-heat boiler. Figure 1.2 illustrates the basic direct-fired unit.

The indirect-fired closed-cycle gas turbine operates with the working fluid completely encased in a separate circuit froll the fuel. Thus the products of combustion and the working fluid never mix. Figure 1.3 shows the closed-cycle gas turbine. 


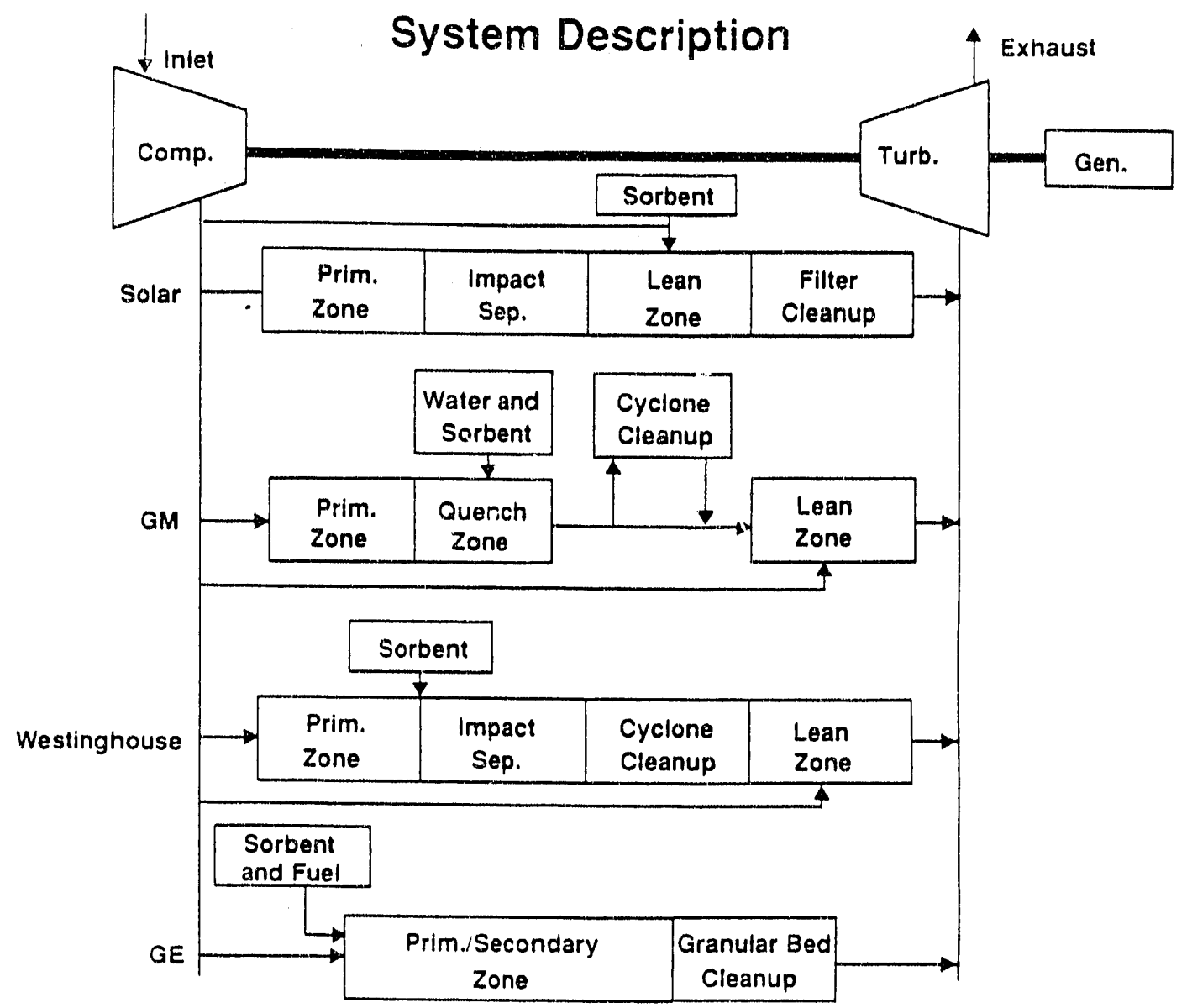

FIGURE 1.1 DOE/METC SPONSORED SYSTEM DESCRIPTIONS [1] 


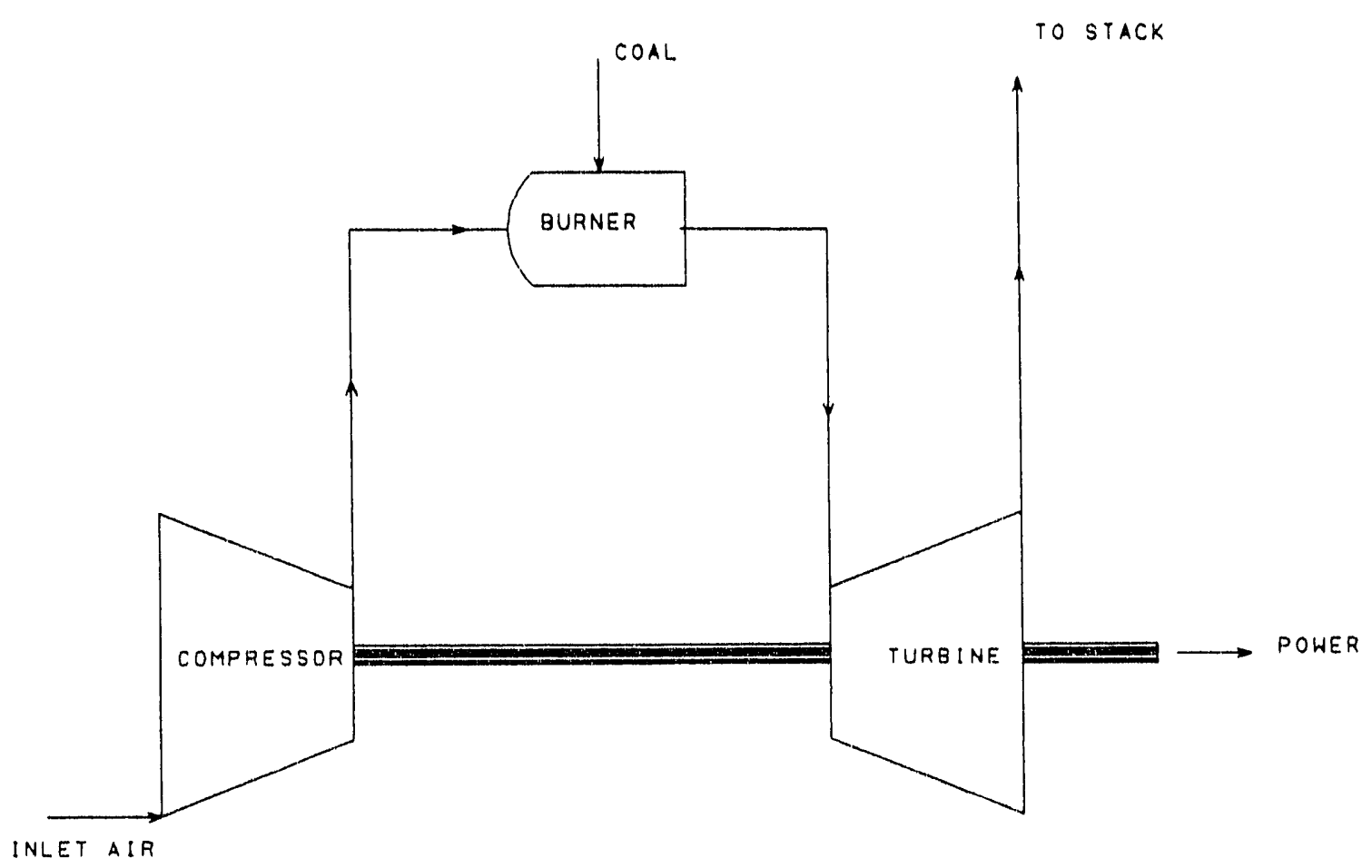

FIGURE 1.2 DIRECT-FIRED COAL-BURNING GAS TURBINE 


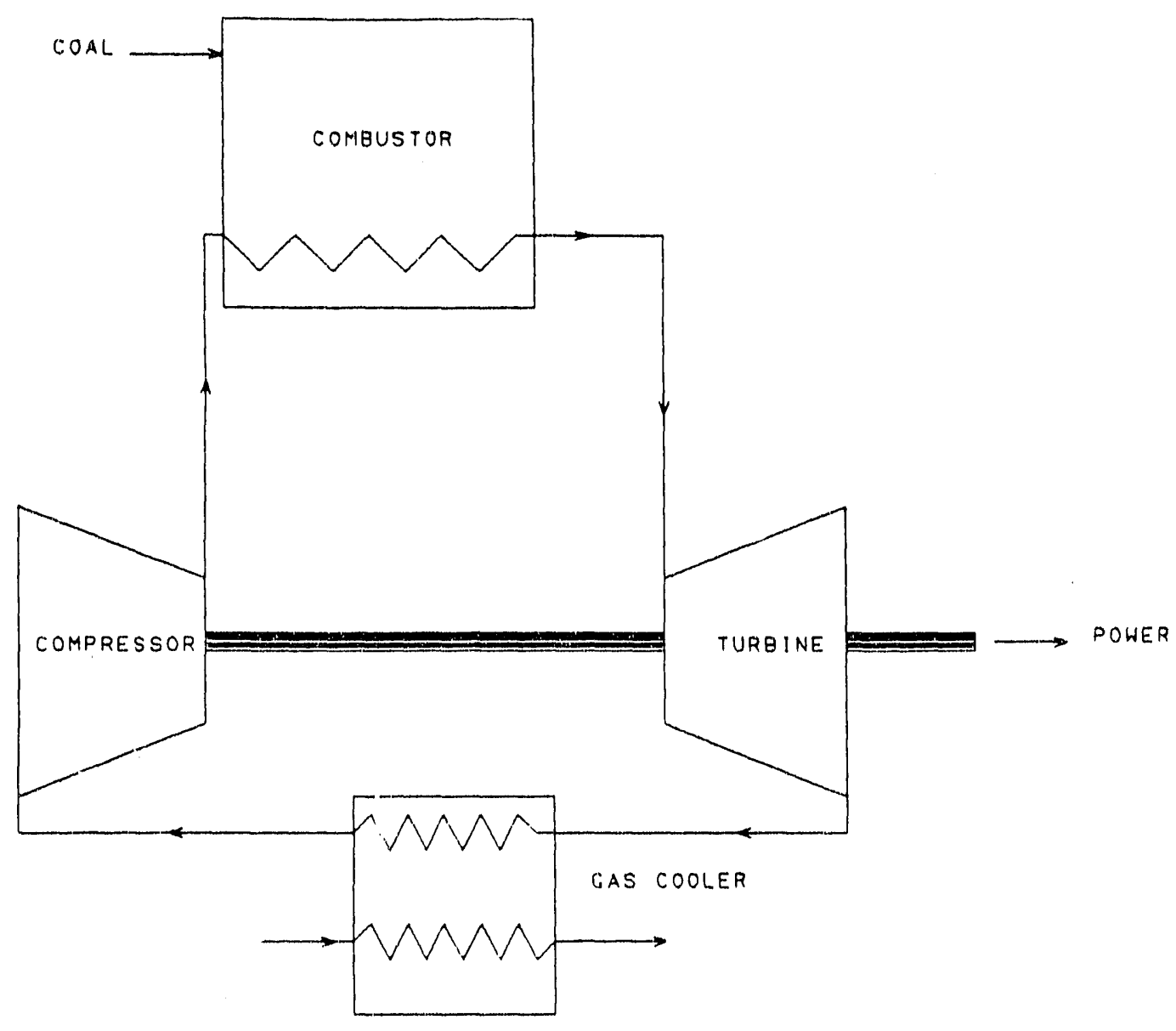

FIGURE 1.3 CLOSED-CYCLE COAL-BURNING GAS TURBINE 
The exhaust-heated cycle involves transposing the combustor from its position in the simple direct-fired unit to a location after the turbine. The entire heat addition to the air entering the expander, then, occurs in a heat exchanger as shown in Figure 1.4 .

The contract given to MIT by the DOE was for the investigation of the coal-fired exhaust-heated gas-turbine cycle. The next sections of this chapter will describe and contrast the different coal-fired gas-turbine cycles that have been presented and point out some of the advantages of the exhaust-heated cycle for coal burning in gas turbines. Following this a short summary is made of the different tasks accomplished as outlined in [5].

\subsection{DIRECT-FIRED UNITS}

Many variations, such as the addition of a heat exchanger to decrease the amount of coal required to heat the air, or the addition of an intercooler in the compressor, can be made to the simple direct-fired unit. Changes can also be made to the way in which the coal is combusted in the cycle. The direct-fired unit can also be linked to a separate steam-cycle to use, efficiently, any excess heat produced in the combustor. All these modifications are, of course, designed to increase the overall efficiency of the cycle [6].

Direct-fired units face a number of difficulties. The coalcombustion process always results in ash-laden gas and, depending on the efficiency of the combustion, unburnt coal particles. The ash alone has a powerful erosive effect on the turbine blades; large particles (as, say, an unburnt piece of coal) have damaging effects on the turbine blades [7]. Moreover, the ash tends to form over time a deposit around the blades that has deleteriolis aerodynamic effects on their performance. In addition, ash has corrosive constituents that actually attack the parent metal of turbine blades $[8,9]$.

As far as the combustion process is concerned it poses some more challenges since it involves feeding and burning coal at higher-than-atmospheric pressures. The past experience of two reputable companies involved in coal-fired turbine research indicates that there is no adequate method for uniformly injecting dry micronized coal (DMC) into a pressurized combustor [1]. All of the companies involved in the current DOE-sponsored research have focused on coal water slurry (CWS) as a more feasible alternative. However, for power-generating facilities below about $15 \mathrm{MW}$ it is more economical to use dry micronized coal [1]. Westinghouse working with AVCO Textron have also been burning pulverized coal (PC), which has a substantially lower price than DMC, experimentally.

Much research has been done in the hope of solving blems faced by coal-burning direct-fired gas-turbine possible solutions that have been investigated include

the proengines. reducing 


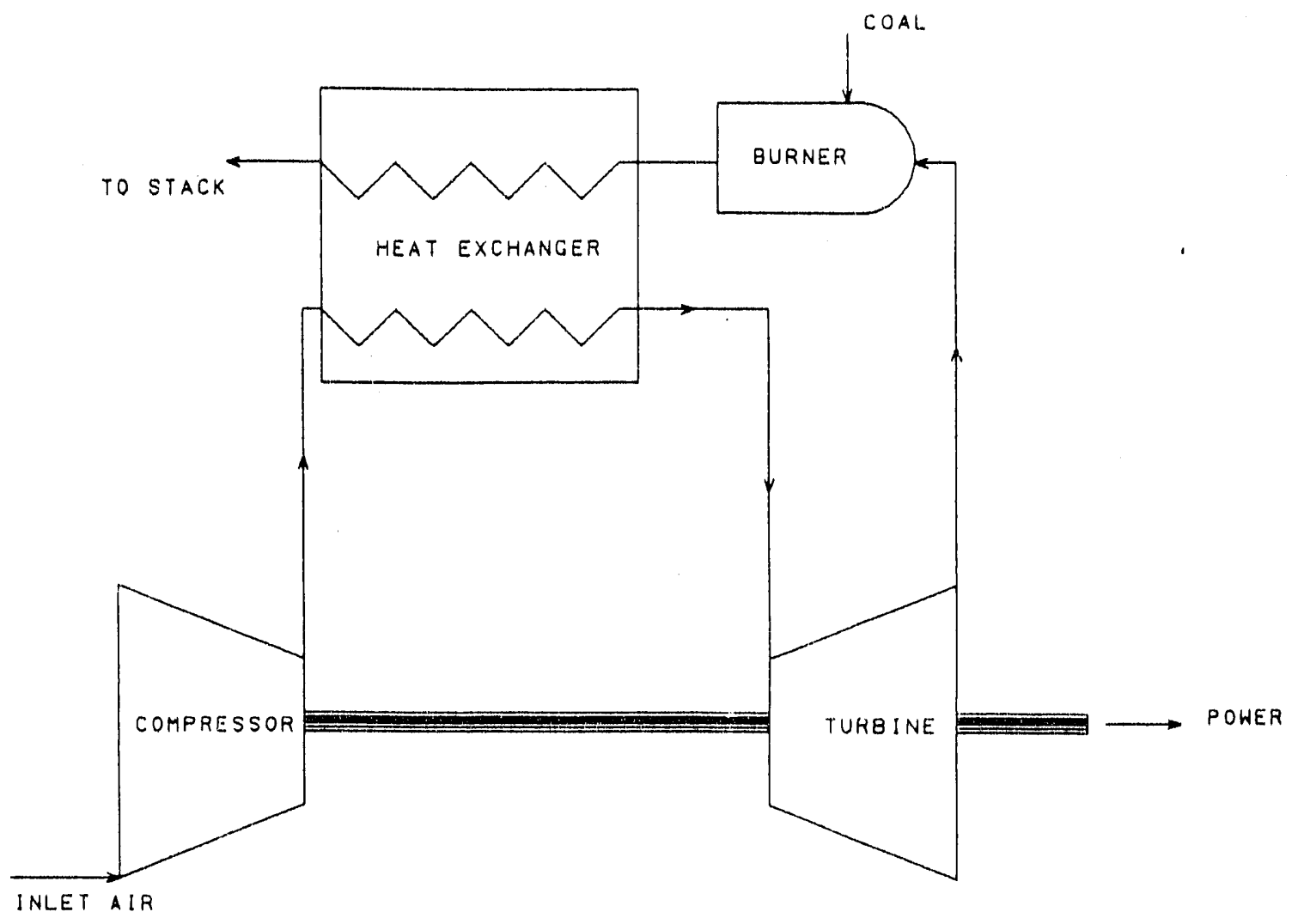

FIGURE 1.4 EXHAUST-HEATED COAL-BURNING GAS TURBINE 
the concentration and size of the solids in the flow, selecting blade alloys for erosion resistance, designing appropriate aerodynamic blade profiles to minimize the effects of gas-borne solids, the incorporation of additives to reduce the deposition rate of ash, and maintaining a suitably low blade-surface temperature $[3,10,11,12]$. The solutions that have been outlined above have been studied resulting in some progress and in a few more setbacks. Two examples of the setbacks encountered are that researchers in Australia found that by reducing the concentration of coarser ash particles with cyclone separators the ash deposition rate in the blades rose by 70 percent [13] and that researchers at DOE METC have found that when the amount of deposition was lowered the deposited material became much more strongly bonded to the metal surface (i.e., a trade off exists) [11,12]. Clearly, more research and development is required to make direct-fired units feasible for commercial use.

\subsection{INDIRECT-FIRED CLOSED-CYCLE UNITS}

One of the great advantages of closed-cycle units is that the working fluid, which is not limited to air (helium, hydrogen and argon are among other possibilities), can be pressurized leading to very compact sizes for the principal components of the engine [14]. Efficiencies between 45 and 55 percent have been calculated for the closed-cycle gas turbine, but actual units in operation have achieved only between 28 to 30 percent [15].

closed-cycle engines are currently the only commercially available coal-fired gas turbines. These units have very good part-power efficiencies but suffer from the fact that the highpressure gas must be heated through a heat-exchanger wall. This limits the maximum temperature to which the working fluid can be heated. With present technology this means the maximum working fluid temperature is around $1200 \mathrm{~K}(1700 \mathrm{~F})$. The recuperative heat exchangers have relatively low heat-exchanger effectivenesses, limiting the thermal efficiency of the cycle. Also, when compared to ordinary direct-fired units, these engines become much more complex [2]. In particular, a large additional heat exchanger, the gas cooler, is required (see Figure 1.3).

\subsection{INDIRECT-FIRED EXHAUST-HEATED UNITS}

The exhaust-heated cycle was studied extensively by the late Professor D.I. Mordell of McGill University from 1949 until about 1957. His preliminary analysis indicated that a heat-exchanger effectiveness of at least 75 percent is necessary to make the cycle attractive. Compared to a conventional open-cycle gasturbine with the same temperature ratio (turbine-inlet temperature divided by the compressor-inlet temperature), pressure ratio (compressor-outlet pressure divided by the compressor-inlet pressure), and component efficiencies, the exhaust-heated cycle will yield the same specific power. The thermal efficiencies of both cycles would be equivalent for the above case only if the heat-exchanger effectiveness of the exhaust-heated cycle were 100 percent. 
Professor Mordell constructed an exhaust-heated gas turbine using a Rolls Royce Dart gas turbine, a slagging cyclone combustor, and a specially designed shell-and-tube heat exchanger. Mordell's test-rig is shown in Figure 1.5. Mordell discovered that dry-ash fouling of the heat-exchanger surface was not nearly as critical as he at first had thought [16]. The slagging cyclone furnace proved to be extremely well suited for combustion of coal at atmospheric pressure and the high turbine-exit air temperatures. A screw-type coal feeder showed good results in metering the required amounts of fuel into the combustor (this is in contrast to direct-fired engines where higher-than-atmospheric pressures make a simple screw feeder impractical) [17]. The major problems Mordell noted were the clogging of the combustor, which he thought could be dramatically improved by re-designing it, and high pressure losses $i n$ the heat exchanger. The heat-exchanger tubes also showed some corrosion due to sulphur condensation. Despite the very low effectiveness of his heat exchanger, Mordeli's unit demonstrated that the exhaust-heated cycle is a practical way of burning coal in the gas turbine.

The attractiveness of this cycle is that the products of combustion do not pass through the turbine. Thus, there will be no ash deposition, erosion, or corrosion of the turbine blades. our concerns shift from the turbine to the heat exchanger. We selected the rotating ceramic matrix as a possible heat exchanger for the exhaust-heated gas turbine. In the ceramic regenerator, shown in Figure 1.6, the two streams (the compressor air and the products of combustion) pass through the annular area of the matrix (which contains small pores about 500 microns in diameter) in counterflow. While the disk is rotating the matrix absorbs heat from the hot stream and transfers it to the cold stream. This type of heat exchanger is normally "self-cleaning" since, as it rotates, the flow direction reverses and any dry deposits that might be formed as the exhaust gases pass through in one direction should be dislodged when the compressed air from the compressor flows in the opposite direction. This regenerator generally has two types of seals: circumferential seals which cover the outer and inner circumference formed by the annular area, and the radial seals which act along a radius connecting the two circumferential seals.

The rotating ceramic matrix is one of only a few heat exchangers suitable for high temperatures in a low-pressure-ratio cycle [18]. The highest effectiveness of a heat exchanger of this type is slightly over 0.95 in the Allison GT 404. An effectiveness of 0.975 could be obtained on that unit by approximately doubling its current thickness [18].

The exhaust-heated cycle also has some apparent disadvantages compared with the direct-heated coal-burning cycles. The combustor operating at about atmosphexic pressure must be considerably larger than one working at compressor-delivery pressure. The use of a heat exchanger may be a penalty. However, a heat-exchanger cycle confers such major advantages in efficiency at full and part 


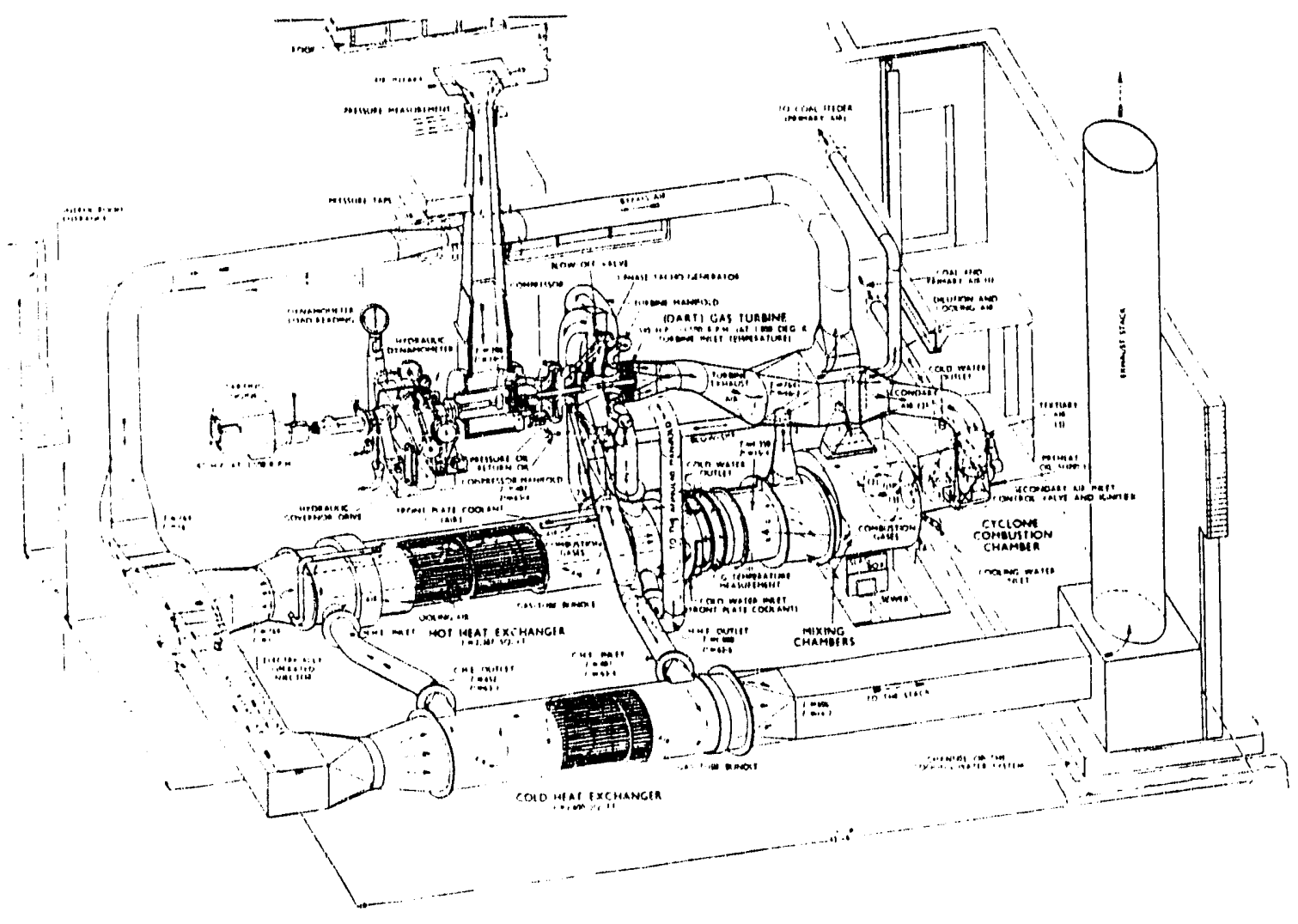

FIGURE 1.5 MORDELL'S EXHAUST-HEATED GAS TURBINE [16]

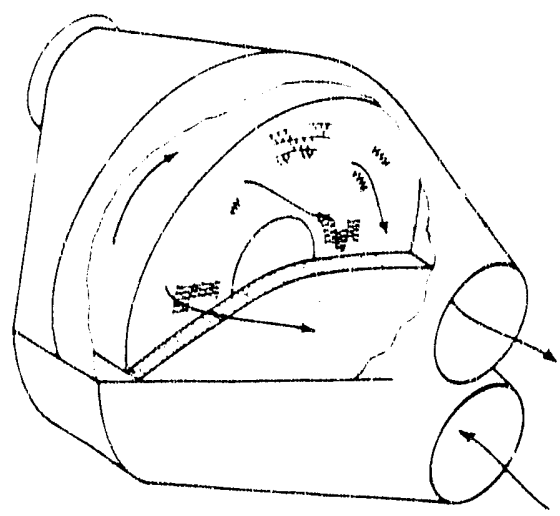

DISK - TYPE ROTARY

PERIODIC - FLOW REGENERATOR

FIGURE 1.6 ROTATING CERAMIC-MATRIX REGENERATOR [6] 
load that for engines that work on base load or for extended periods the heat exchanger itself cannot be considered disadvantageous. The heat exchanger in an exhaust-heated cycle covers a considerably larger temperature range than one in a direct-fired cycle, because it must raise the compressed air to turbine-inlet temperature. Therefore, the duties imposed on the heat exchanger are doubly arduous: it must handle a very challenging temperature range, and it must do so with a corrosive particle-laden gas stream. The success of the exhaust-heated cycle depends, therefore, on the viability of the heat exchanger.

\subsection{TOPIC OBJECTIVE}

The overall topic objective of the proguam was to investigate the feasibility of a coal-fired exhaust-heated gas turbine. The program is divided into two phases, the first of which has been completed. Phase I included the theoretical analysis of various gas-turbine power cycles and the construction of a test rig to visualize the effects ash particles have when impacting the proposed regenerator. The optional. Phase II (to be funded, if DOE so determined, from the fall of 1990) would involve the design and construction of a coal combustor and a rig whereby the products of coal combustion could be passed through a rutating ceramic matrix [5]. Phase II would then presumably provide extensive information on the performance of the regenerator in a coal-combustion environment.

Phase I was divided into six tasks; the objective of each task is discussed in the list below. Figure 1.7 shows the time schedule followed in performing the tasks.

\section{TASK OBJECTIVE}

1. The contractor performed cycle studies of the lowpressure-ratio exhaust-heated engine and recommended four units: two optimized or "blue-sky" designs (one with intercooling and the other without) and two off-the-shelf designs, that is, designs based on commercially available components (one with intercooling and the other without).

2. The contractor performed the preliminary desicn of the engines discussed in task 1 and presented two topical reports (on for the blue-sky designs and the other for the off-the-shelf engines).

3. The contractor estimated the design- and offdesign-point performance of the four engines (the results were also included in the tivo topical reports of task 2).

4. The contractor performed economic assessments on the four units and compared them with some competing engines. 


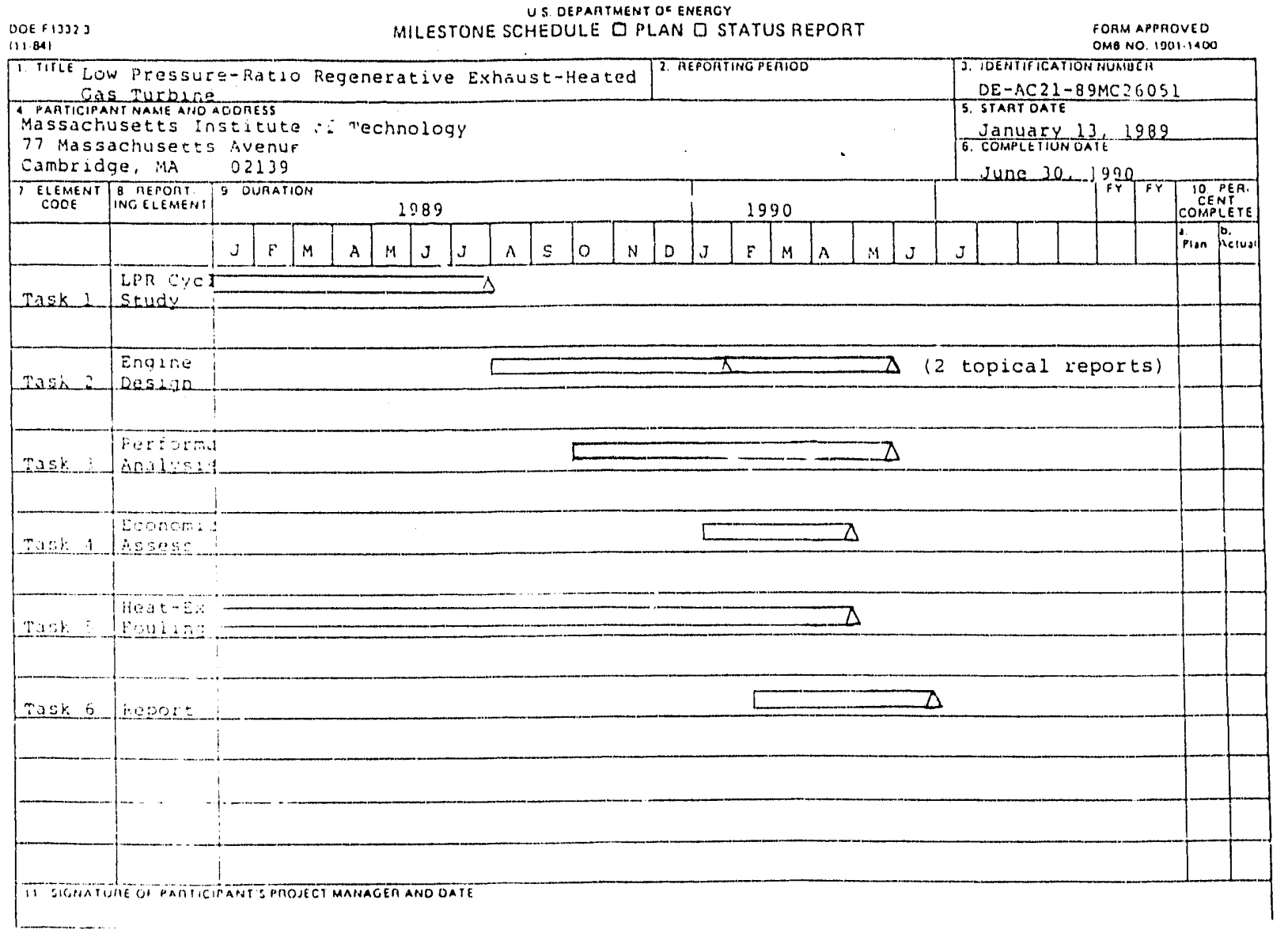

FIGURE 1.7 SCHEDULE PLAN FOR PROJECT 
5. Preliminary experiments were performed in a test rig to determine the regenerator's fouling and deposition tendencies in a simulated coal-combustion environment.

6. The contractor prepared this final topical report which summarizes all the major results of the other tasks.

This report contains the preliminary design and performance estimations of the blue-sky and off-the-shelf engines we proposed to the DOE, the economic assessment of the engines we designed, and the results obtained from the test-rig. More detailed information on the method employed in obtaining the blue-sky engines is found in $[19,20,21]$ and in obtaining the off-the-shelf designs in $[22,23]$.

As in any design process the approach taken to arrive at the results described here was iterative. This explains the discrepancies that the reader may find between the data found here and in other references written by the authors on the same topic.

Chapters two and three of this report contain some brief background information on turbomachinery design trat the reader may find helpful. Chapter four describes the basic algorithm followed by the CYCLE computer program which was written to perform the cycle analysis of the various engines. Chapters five and six present the cycle analysis of the blue-sky and off-the-shelf engines, respectively. Chapters seven and eight describe the proposed blue-sky and off-the-shelf designs, respectively. The economic assessment of the various engines is included in chapter nine while the heat exchanger fouling tests are in chapter ten. Finally, chapter eleven contains the conclusions and recommendations.

\subsection{APPROACH}

The general approach followed in both the blue-sky designs and the off-the-shelf designs was basically the same. The offthe-shelf designs required an extra step at the beginning whereby the best candidate engine available commercially was identified. As soon as the preliminary design of the engines (both blue-sky and off-the-shelf) was completed (tasks 1 and 2) the performance estimation (task 3) was undertaken. The design-point performance estimation of the turbomachine components was the most critical because if a substantial difference was found between the selected component efficiency and that calculated a new design would have to be made based on the calculated efficiency. Once the engine designs and performance estimations were completed the economic assessment could be done (task 4). The heat-exchanger fouling tests (task 5) were being performed concurrently with tasks 1 through 4. The next few paragraphs outline briefly the procedure followed in obtaining the preliminary design of the engines.

Once the basic thermodynamic cycle for the engines was established, the optimum pressure ratio (compressor-outlet pressure 
divided by the compressor-inlet pressure) and temperature ratio (turbine-inlet temperature divided by the compressor-inlet temperature) could be determined through a cycle analysis. The cycle analysis yielded the required thermodynamic properties of the working fluid (air) at the various locations of interest (inlet and exit of the compressor, of the turbine, of the regenerator, and of the intercooler where applicable). With this information it was possible to size these components. The process was iterative in that the sizing of the turbomachine components, as was described above, required the selection of its working efficiency which was later verified in the performance estimation.

The cycle analysis of the blue-sky designs was accomplished with a BASIC computex program written by the group which we shall refer to as CYCLE. This program also sizes the regenerator and calculates the air leakages through its seals. The cycle analysis for the preliminary design of the off-the-shelf engines was made with a modified version of CYCLE as will be explained in this report.

\subsection{SUMMARY}

A fairly comprehensive review of the various gas-turbine cycles that may be suitable for coal-burning was presented. The exhaust-heated cycle seems to be a simple and feasible solution to the many problems related to ash deposition, corrosion, and erosion of the turbine blades characteristic of direct-fired gas turbines. The exhaust-heated cycle has problems of its own related to the heat exchanger, but not enough research has been done on this cycle to identify clearly what those problems are, much less point out possible solutions. A summary has also been presented of the main objectives of this DOE sponsored program and of the organization of this report. 


\subsection{BACKGROUND TO GAS-TURBINE GEOMETRY \& THERMODYNAMICS}

This chapter presents the major geometric parameters found in turbines and compressors. Some thermodynamic concepts and relations important for understanding the working principle of gas turbines are also presented.

\subsection{BLADE GEOMETRY OF AXIAL-FLOW TURBINES \& COMPRESSORS}

Figure 2.1 shows the major axial-flow-turbine-blade parameters. Among the blade-geometry parameters used in the turbine performance estimation are the following.

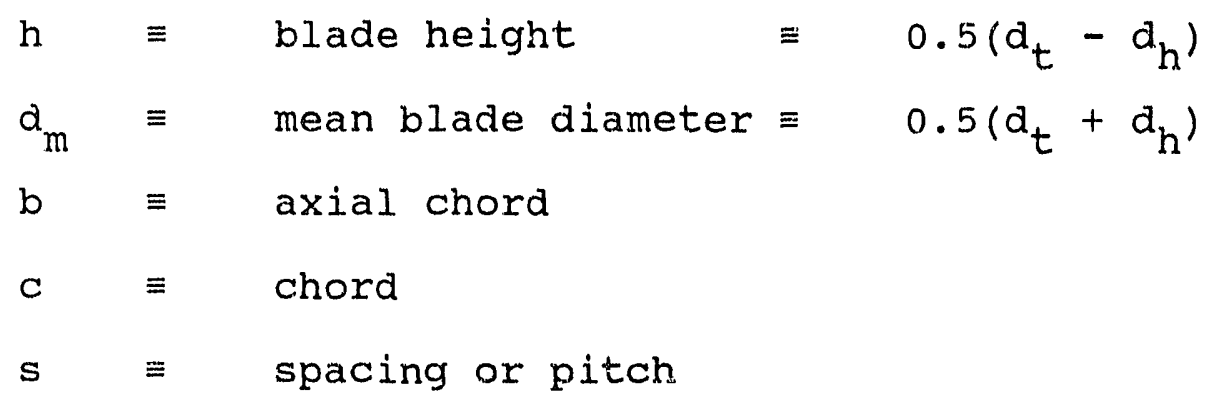

Here, $d_{t}$ is the tip diameter and $d_{h}$ is the hub diameter.

The turbine-blade profile is determined by the chosen flow inlet and outlet angles. With this information, and a few other selections (discussed in chapters three and four) the blade profile can be drawn following suggestions in [6].

Axial-flow-compressor blades, unlike turbine blades, are designed not from first principles but are rather selected (in preliminary design) from a group of tabulated compressor-blade configurations and performance graphs, such as those shown in Figures 2.2 and 2.3. Figure 2.3 indicates the region in which a particular blade (designated in the figure) will deflect the flow without causing flow separation (in compressor blade rows the flow decelerates while passing through the blade--too much deceleration can cause flow separation [6]).

\subsection{VELOCITY DIAGRAMS}

The flow across the turbine or compressor stationary blades (the stators) is described with absolute velocities while in the moving blades (the rotors) it is described with relative angles and velocities. The relative velocities and angles are used in order to include the velocity component imposed on the flow by the moving blades. Velocity diagrams are a concise means of presenting all the velocities and angles of a particular turbine or compressor stage. Velocity diagrams are used in determining the profile of the blades, the size of the annular-flow space, and the design- and off-design-point performance estimations. Typical velocity diagrams for a compressor and turbine are shown in 


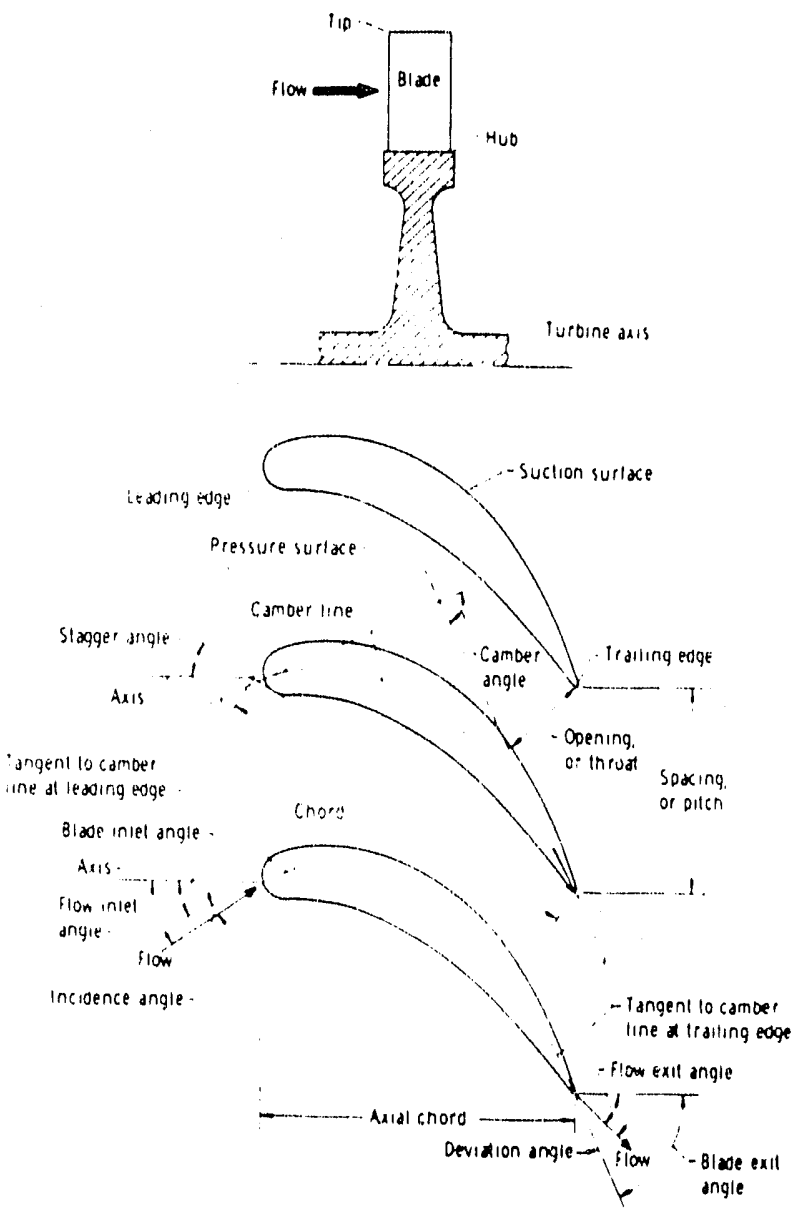

FIGURE 2.1 MAJOR GEOMETRIC TURBINE-BLADE PARAMETERS [ 45 ] 


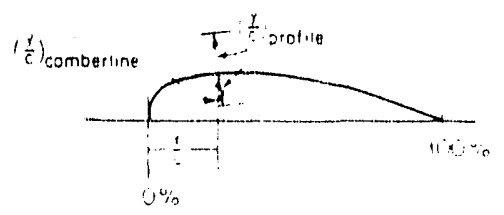

Coordinates of NACA 65 -series artoils

NACA 65-series compressor-blade base profile

\begin{tabular}{|c|c|c|c|}
\hline \multirow[b]{2}{*}{$\begin{array}{l}\text { Station, } x / c \\
\text { (percent) }\end{array}$} & \multirow{2}{*}{$\begin{array}{l}\text { Base protile. } \\
\pm\left(y / c^{\prime}\right)_{\text {pro }} \\
\text { (percent) }\end{array}$} & \multicolumn{2}{|c|}{$\begin{array}{l}\text { Ordinates and slope of mean line } \\
\text { (camber line) for } C_{\mathrm{L} . \mathrm{th}}=1.0\end{array}$} \\
\hline & & $\begin{array}{l}\text { Ordinate, } .1 / c \\
\text { (percent) }\end{array}$ & Slope, $d y d x$ \\
\hline 0 & () & 1) & \\
\hline 0.5 & 0.772 & 0.250 & $0 .+2120$ \\
\hline 0.75 & 0.932 & 0.350 & 0.38875 \\
\hline 1.25 & 1.169 & 0.535 & $0.347 \% 0$ \\
\hline 25 & 1.574 & 19930 & 0. 29153 \\
\hline 5.0 & 2.177 & 1.580 & 0.234 .30 \\
\hline 7.5 & $2.6+7$ & 2.120 & 0.19995 \\
\hline 10.0 & $3 .(1)+()$ & 2.585 & 0.17485 \\
\hline 15.0 & 3.666 & 3.365 & 0.13805 \\
\hline 20.0 & +.14 .3 & 3.980 & 0.11030 \\
\hline 25.0 & 4.5() .3 & 4.475 & $0.087+5$ \\
\hline $3(0.1)$ & +.760 & $4.860)$ & $0.067+5$ \\
\hline 35.0 & 4.92 .4 & 5.150 & 0.04925 \\
\hline 40.1$)$ & 4.996 & 5.355 & 0.03225 \\
\hline 45.0 & +.963 & 5.475 & 01.01595 \\
\hline 50.0 & +.812 & 5.515 & 0 \\
\hline 55.1$)$ & 4,530 & 5.475 & $-(0.01595$ \\
\hline 60.0 & 4.146 & 5.355 & -0.133225 \\
\hline 65.0 & $3.68: 2$ & 5.150 & -10.04925 \\
\hline $7(0,0)$ & 3.156 & 4.860 & $-0.067+5$ \\
\hline 75.0 & 2.584 & 4.475 & $-0.087+5$ \\
\hline 80.0 & 1.987 & 3.980 & -0.11030 \\
\hline 850 & 1.385 & 3.365 & -0.13805 \\
\hline 90.0 & 0.810 & 2.585 & -0.17485 \\
\hline y5.1) & 0.306 & 1.580 & -0.23430 \\
\hline 100.0 & 0 & 0 & \\
\hline Leading-edge radius & 0.687 & & \\
\hline
\end{tabular}

FIGURE 2.2 TABULATED COMPRESSOR-BLADE GEOMETRY [6] 


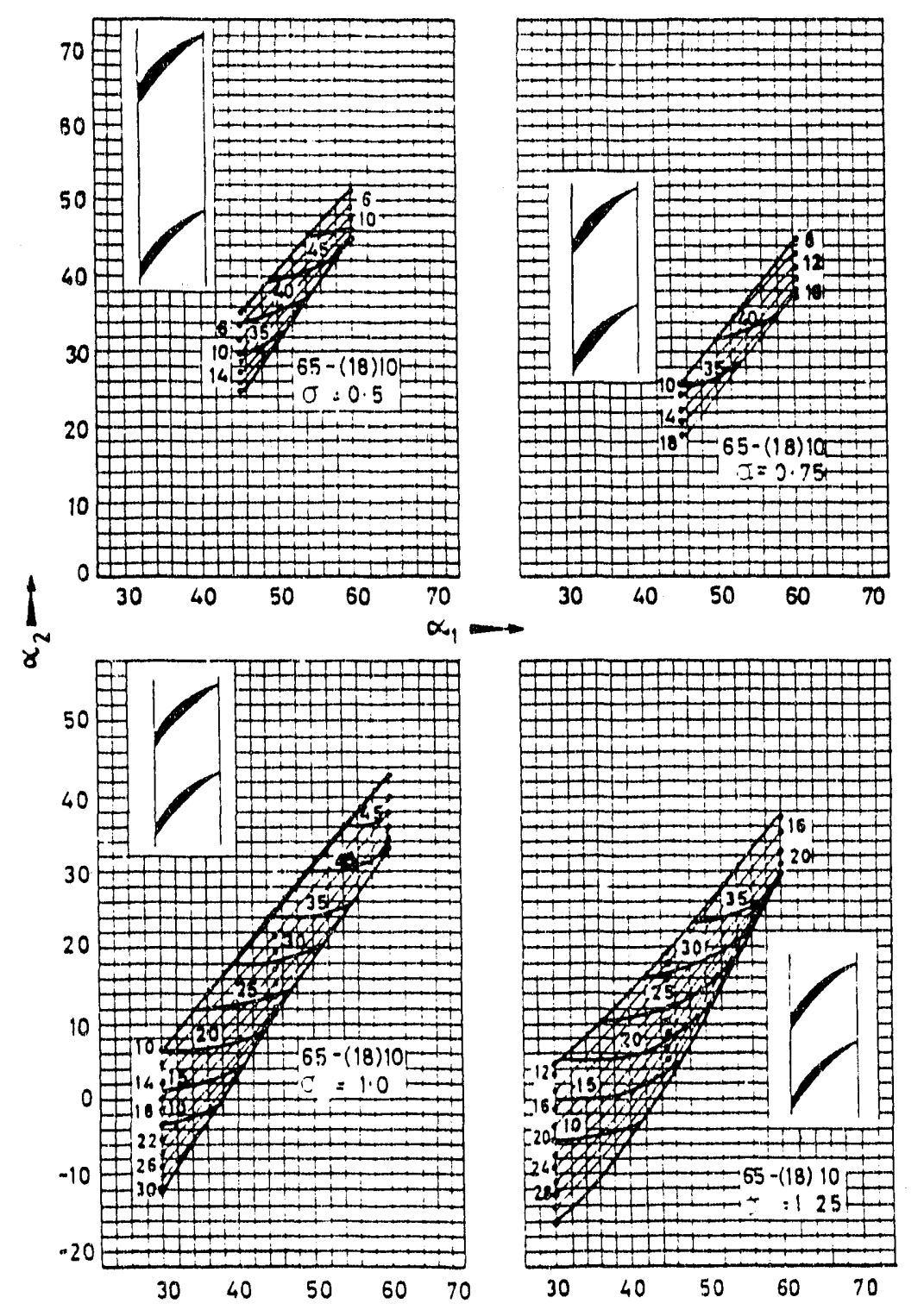

FIGURE 2.3 NACA COMPRESSOR-BLADE PERFORMANCE GRAPH [76] 
Figures 2.4 and 2.5 , respectively.

An important design specification that can be made concerning the flow entering and leaving a blade (either stator or rotor) is that the axial component of its velocity (i.e., parallel to the axis of rotation of the turbine or compressor) remains constant. When such a selection is made and it is further assumed that the streamlines crossing the blade are relatively straight and parallel to the axis of rotation, then the velocity diagram is referred to as a "simple" velocity diagram. Referring to Figure 2.4 we note that, for the simple velocity diagram we would have the following.

$$
c_{z 2}=C_{z 1} \equiv \text { axial velocity component }
$$

Simple velocity diagrams can be described completely by three dimensionless parameters: the reaction ( $R n)$, the work coefficient $(\psi)$, and the flow coefficient $(\phi)$. The definitions, based on a simple diagram, are shown below.

$$
\begin{aligned}
& \mathrm{Rn} \equiv \frac{\text { static enthalpy change in the rotor }}{\text { total enthalpy change }} \equiv 1-\frac{\mathrm{C}_{\theta 1}+\mathrm{C}_{\theta 2}}{2 \mathrm{u}} \\
& \psi \equiv-\frac{\mathrm{C}_{\theta 2}-\mathrm{C}_{\theta 1}}{\mathrm{u}} \\
& \phi \equiv \frac{\mathrm{C}_{\mathrm{z}}}{\mathrm{u}}
\end{aligned}
$$

The work coefficient is positive for turbines and negative for compressors. More detailed information on velocity diagrams can be found in $[6,24,25,26]$.

$C_{1}$ is the air absolute velocity at the stator exit (rotor inlet) and $\mathrm{C}_{2}$ is the air absolute velocity at the stator inlet (rotor exit). This convention, however, is not used in performance estimation where the subscript 1 indicates an inlet property (for stators and rotors) and the subscript 2 indicates an exit property (for stators and rotors) [6].

\subsection{EFFICIENCY OF TURBINES AND COMPRESSORS}

Figure 2.6 shows on a T-s diagram a comparison between an ideal (perfect) compressor and turbine and the real (less than $100 \%$ efficient) compressor and turbine. The inefficiency results in an increase in entropy for both the compressor and turbine. A number of different types and definitions for efficiency exist. We shall here restrict ourselves to polytropic efficiency of the compressor and turbine. Since we shall also be dealing with total or stagnation inlet and outlet properties of the compressor and turbins, the efficiency is more specifically a total-to-total 


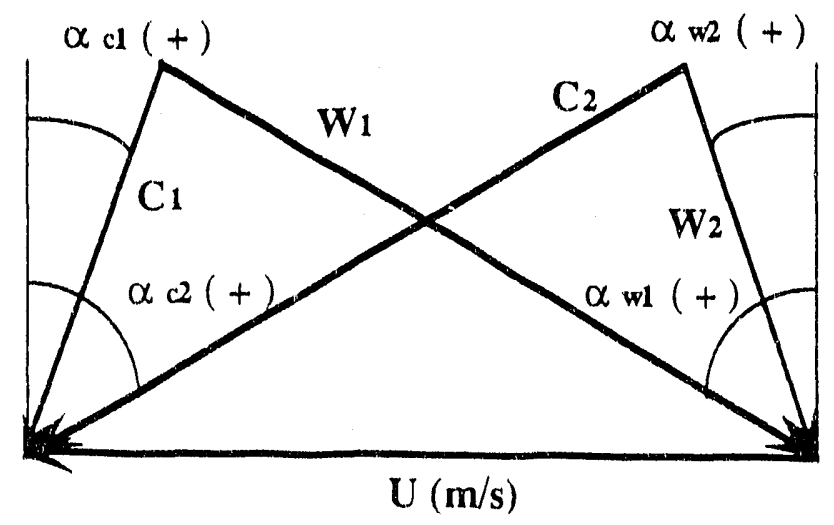

FIGURE 2.4 COMPRESSOR VELOCITY DIAGRAM

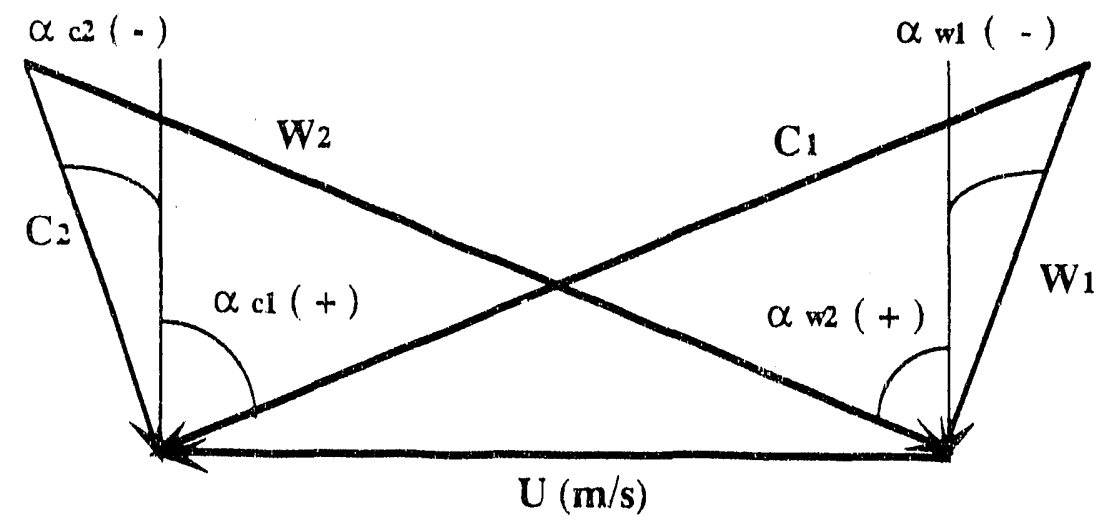

FIGURE 2.5 TURBINE VELOCITY DIAGRAM 


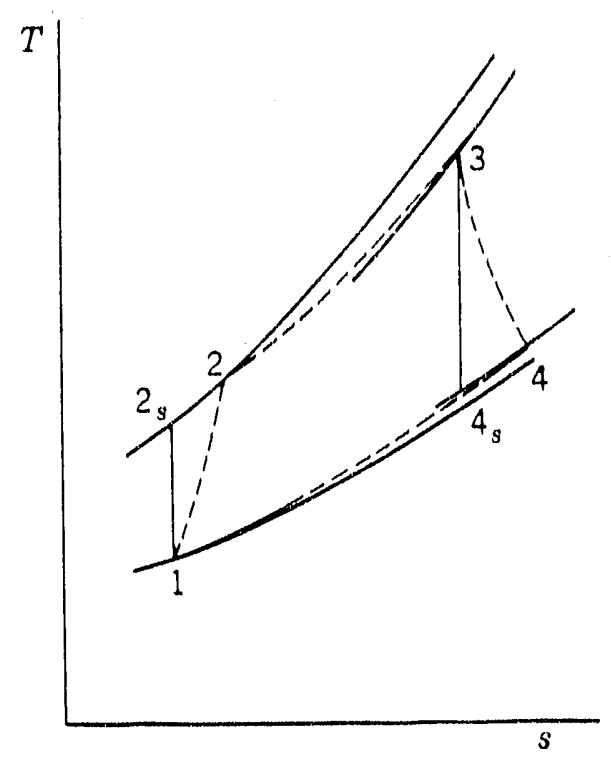

FIGURE 2.6 T-S DIAGRAM OF IDEAL AND NON-IDEAL COMPRESSOR AND TURBINE PERFORMANCES [77]

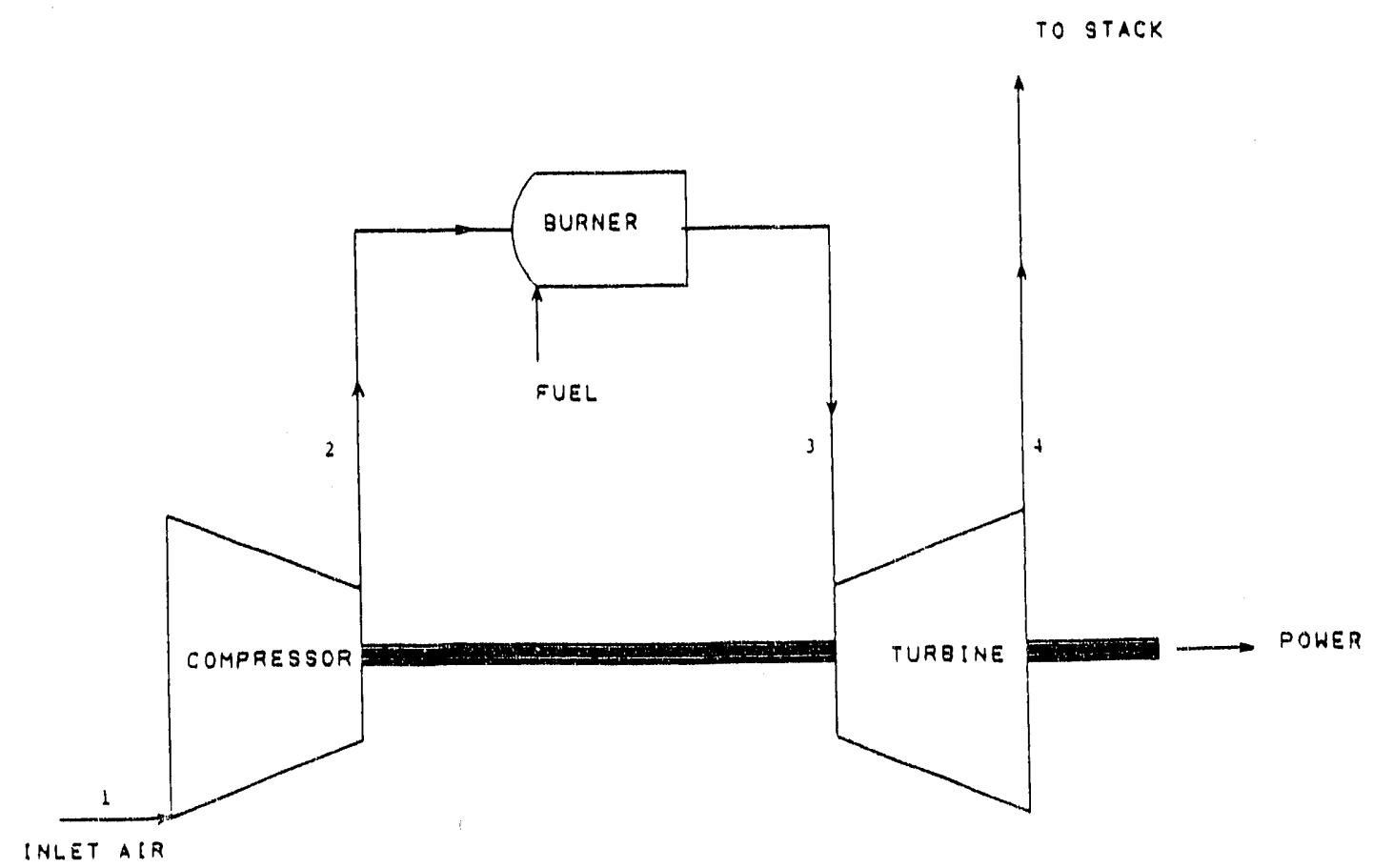

FIGURE 2.7 CBE CYCLE 
polytropic efficiency. The polytropic total-to-total efficiency can be defined as shown below.

$$
\eta \equiv \begin{gathered}
\text { actual work transfer } \\
\text { work transfer in an ideal process } \\
\text { total temperature to the defined } \\
\text { outlet total pressure }
\end{gathered}
$$

The following two equations relate the turbine and compressor inlet and outlet stagnation properties.

$$
\begin{aligned}
& \frac{\mathrm{T}_{\text {Tout }}}{\mathrm{T}_{\text {Tin }}}=\left[\frac{\mathrm{P}_{\text {Tout }}}{\mathrm{P}_{\text {Tin }}}\right]^{\frac{\mathrm{R}}{\mathrm{C}_{\mathrm{p}} \eta_{\mathrm{p}}, \mathrm{c}}} \\
& \frac{\text { (Compressor) }}{\mathrm{T}_{\text {Tout }}}=\left[\frac{\mathrm{P}_{\text {Tout }}}{\mathrm{P}_{\text {Tin }}}\right]^{\frac{\mathrm{R} \eta_{\mathrm{p}}, \mathrm{e}}{\mathrm{C}_{\mathrm{p}}}}
\end{aligned}
$$

Here $\eta_{p, c}$ and $\eta_{p, e}$ are the total-to-total polytropic efficiencies of the compressor and expander (turbine) respectively.

Depending on the method being used in carrying out the performance estimation of the gas turbine it was sometimes necessary to calculate the total-to-total isentropic efficiency of the turbine or compressor. The polytropic efficiency is actually derived from the isentropic efficiency by taking the pressure ratio to a limit of one [6].

\section{4 GAS-TURBINE CYCLES}

Chapter 1 describes a few of the existing gas-turbine cycles. Most of the existing gas turbines use the direct-fired cycle, with a petroleum-based "clean" fuel in the combustor. In order to reach higher thermal efficiencies (and higher power outputs) in these engines it is necessary to increase the turbine inlet temperature and the pressure ratio [6]. This cycle, following the guidelines in wilson [6], can be referred to as a compressorBurner-Expander ( $C B E$ ) cycle and is shown in Figure 2.7.

The fuel flow in the CBE cycle can be reduced by transferring back energy that would otherwise be lost in the turbine discharge with a heat exchanger. This engine, the compressor-BurnerExpander-heat exchanger (CBEX) cycle, can produce much higher thermal. efficiencies at lower pressure ratios than the CBE cycle [6]. A diagram of the CBEX cycle can be seen in Figure 2.8 . 


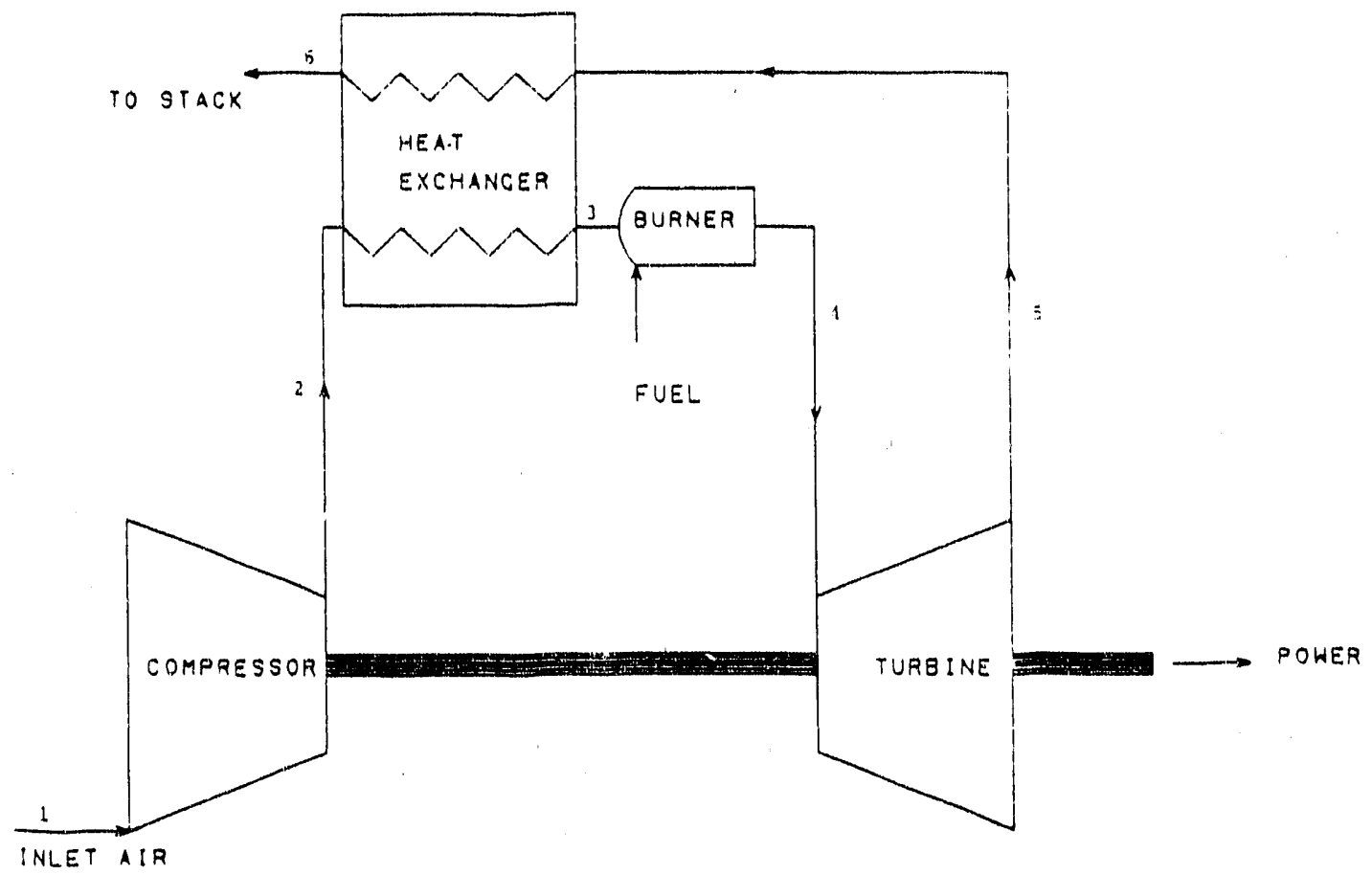

FIGURE 2.8 CBEX CYCLE

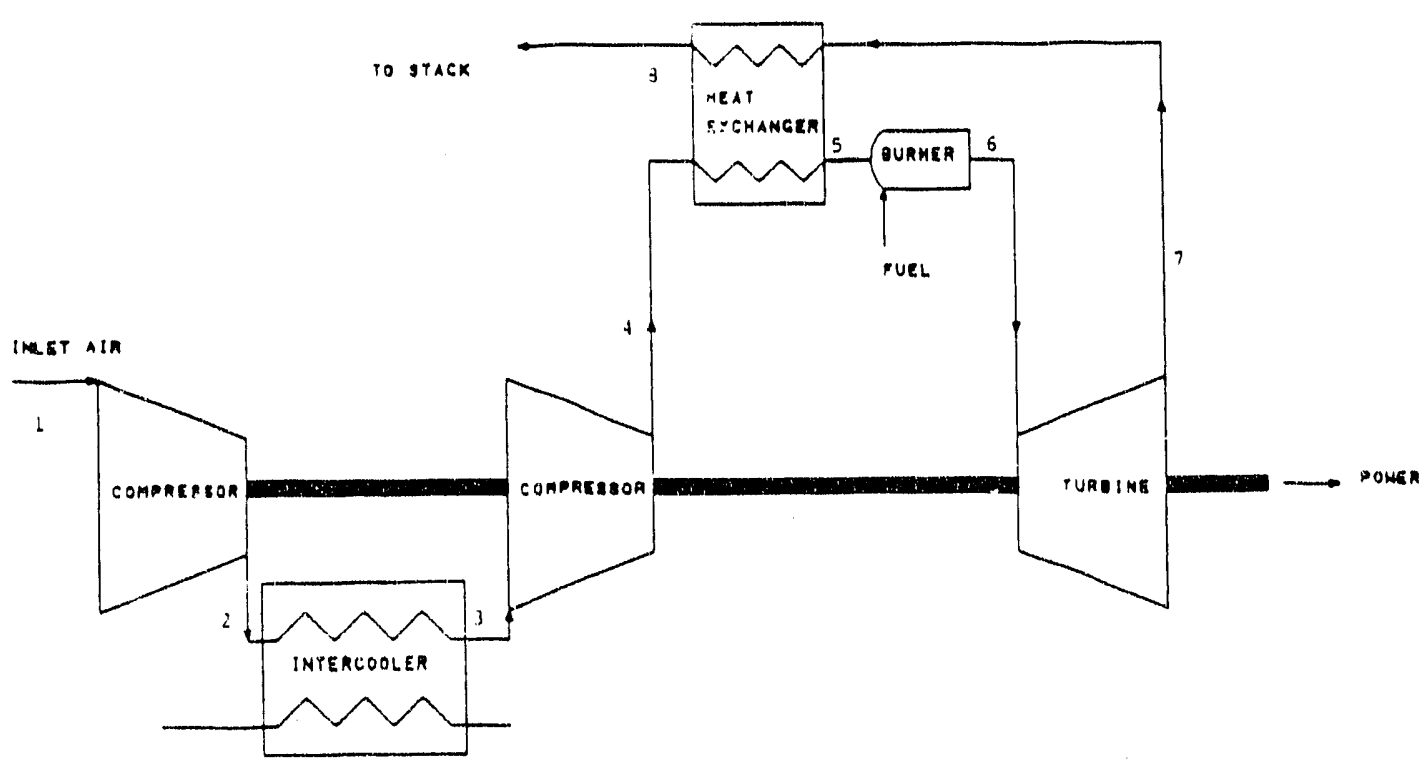

FIGURE 2.9 CICBEX CYCLE 
The power required to compress the working fluid is proportional to the initial temperature. Therefore, if the compression process could be split into two or more segments and the fluid cooled down between them the overall power required to compress the air would be reduced. This, coupled with a heat exchanger, would naturally increase the overall thermal efficiency. This gas-turbine cycle, the Compressor-Intercooler-Compressor-BurnerExpander-heat exchanger (CICBEX) cycle, is shown in Figure 2.9 .

The exhaust-heated cycle with and without intercooling were studied [5] in this DOE-sponsored program. The exhaust-heated engine without intercooling will be referred to as the compressorheat exchanger-Expander-Burner (CXEB) cycle. The exhaust-heated engine with intercooling will be referred to as the compressorIntercooler-Compressor-heat exchanger-Expander-Burner (CICXEB). Figures 2.10 and 2.11 illustrate the CXEB and the CICXEB Cycle respective $y$.

\subsection{SUMMARY}

A brief introduction to gas turbines has been made. The major thermodynamic and geometric parameters have been identified; those parameters which play an important role in the performance estimation of the compressor and turbine have also been pointed out. 

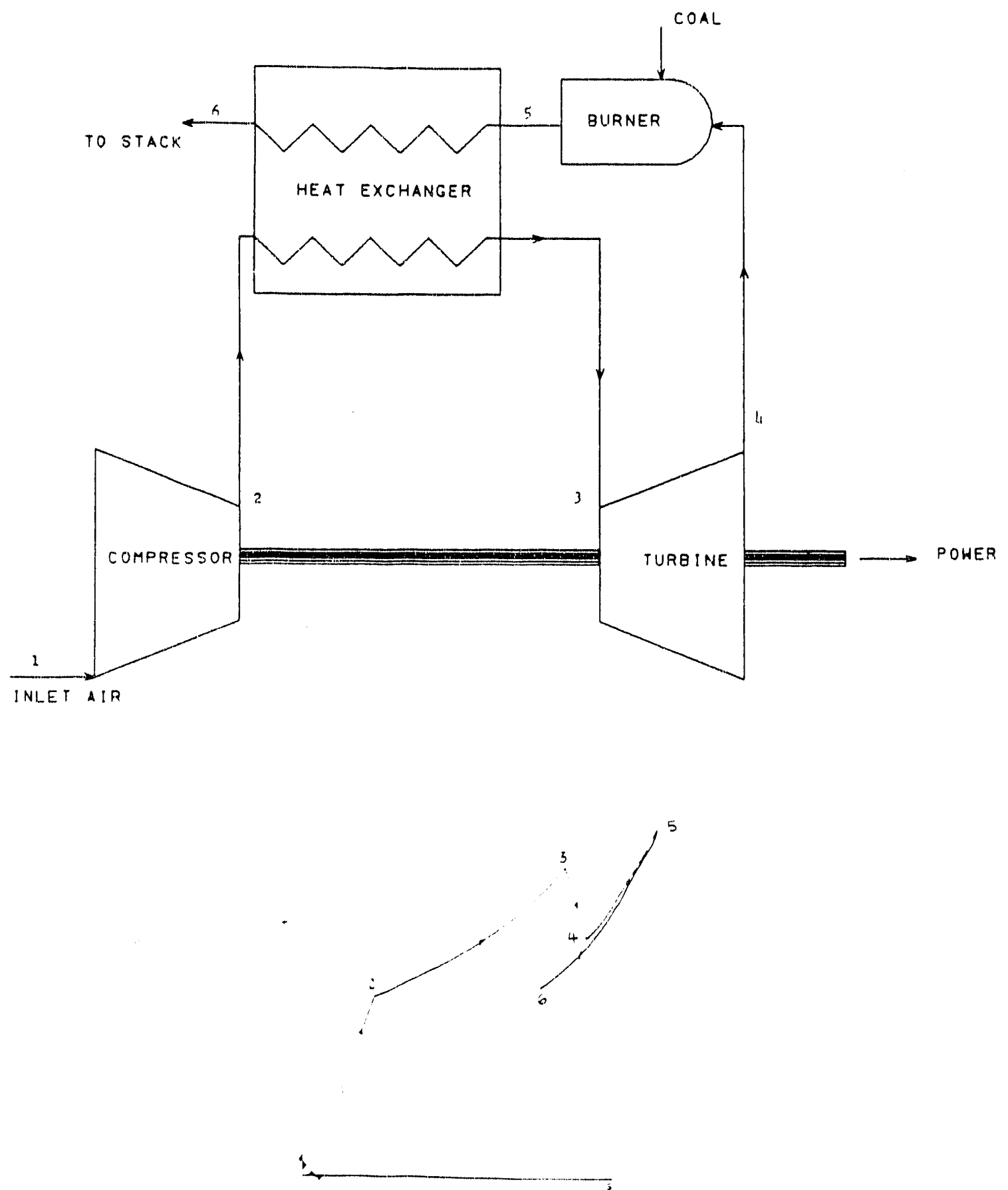

FIGURE 2.10 CXEB CYCLE 

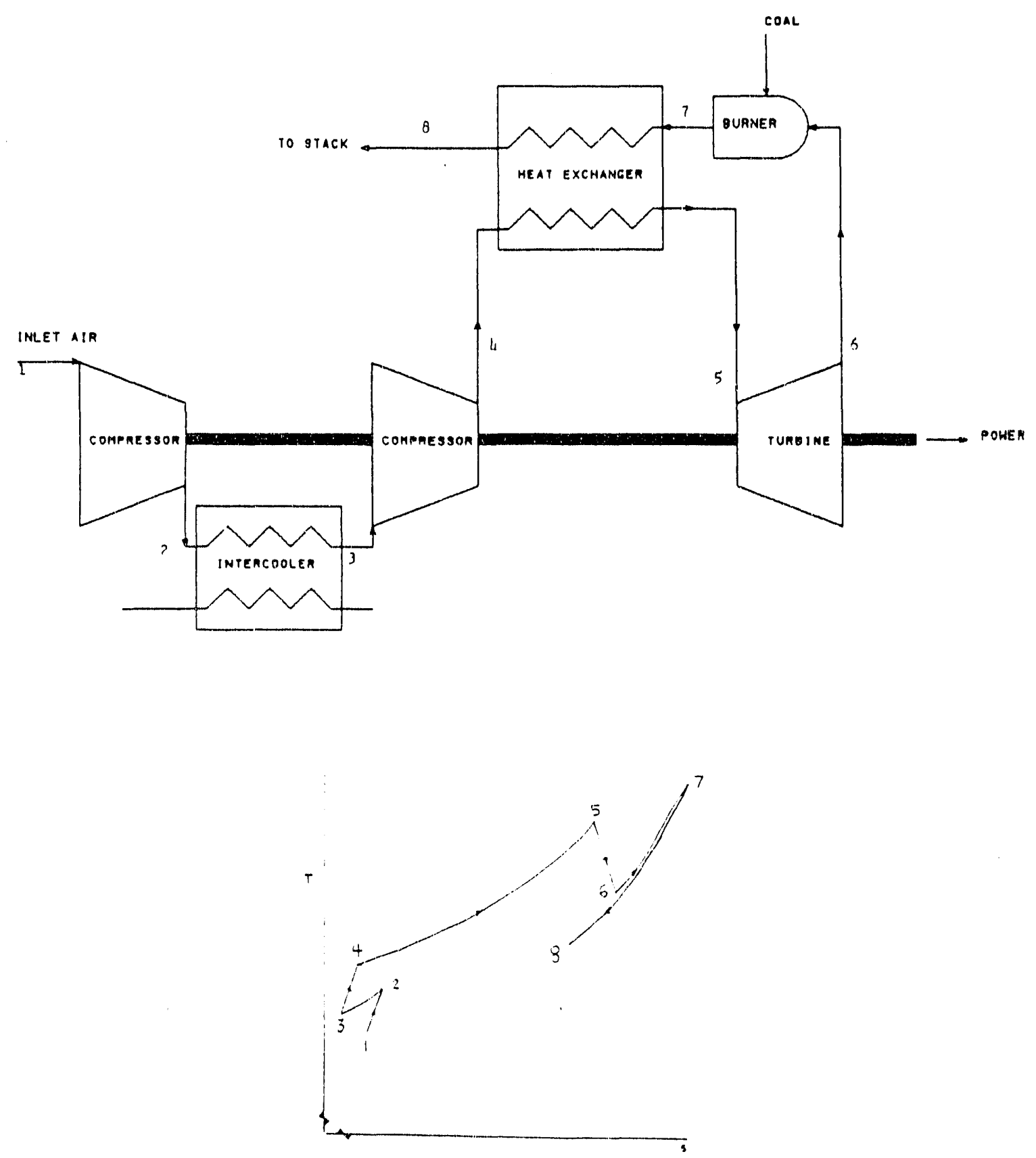

FIGURE 2.11 CICXEB CYCLE 


\subsection{BACKGROUND TO ENGINE DESIGN AND PERFORMANCE ESTIMATION}

This chapter explains briefly how the axial-flow turbine and compressor sizing were done. The procedure outlined here for the compressor and turbine were turned into two BASIC computer programs. This sizing procedure was used both for the blue-sky designs and for calculating the turbomachine modifications required in the off-the-shelf designs. This chapter also explains briefly the three methods used for the design-point performance estimation of the axial-flow turbines, the method used for determining the performance of the axial-flow compressors, and briefly discusses how the performance of the centrifugal compressors (for the offthe-shelf designs) were estimated.

\subsection{COMPRESSOR AND TURBINE SIZING}

Before sizing of the gas-turbine components can be made an operating pressure ratio, temperature ratio and power output must be selected for the engine. To perform the cycle analysis it is also necessary to specify efficiencies for the turbine and compressor. Once the latter is done, the temperatures and pressures at the inlet and exit of all the major components can be calculated, as well as the required air mass-flow rate.

The sizing procedure of an axial-flow compressor or turbine begins by selecting the annulus area configuration (i.e., constant hub diameter, or constant tip diameter, etc.), the reaction, the work coefficient, the flow coefficient, the number of stages (two adjacent rows of stators and rotors form a stage), and the initial hub-to-tip ratio $(\lambda)$. Wilson $[6,27]$ shows that for maximum efficiency a reaction of around fifty percent should be selected for both the turbine and compressor. A work coefficient of around 1.0 and a flow coefficient of about 0.6 are optimum at this reaction for a turbine as seen from Figure 3.1. These considerations as well as recommendations of the hub-to-tip ratio for the compressor and turbiie as found in [27] were used as an initial starting point in the designs.

Once initial selections of the velocity diagrams were made, it was a matter of moving from stage to stage calculating the pressures and temperatures based on selected stage efficiencies. The derived pressures and temperatures resulted in densities which in turn, combined with the selected air mass flow rate from the cycle analysis and the continuity principle (i.e., the mass flow rate of a fluid entering and leaving a control surface is conserved), yielded the required annulus areas of the turbine and compressor. That is, this produced the various blade geometry parameters such as height, tip diameter, and hub diameter.

The centrifugal compressor preliminary designs that were performed for the off-the-shelf engines used procedures outlined in Wilson [6] and in lectures by MIT Professor A.D. Carmichael [28]. 

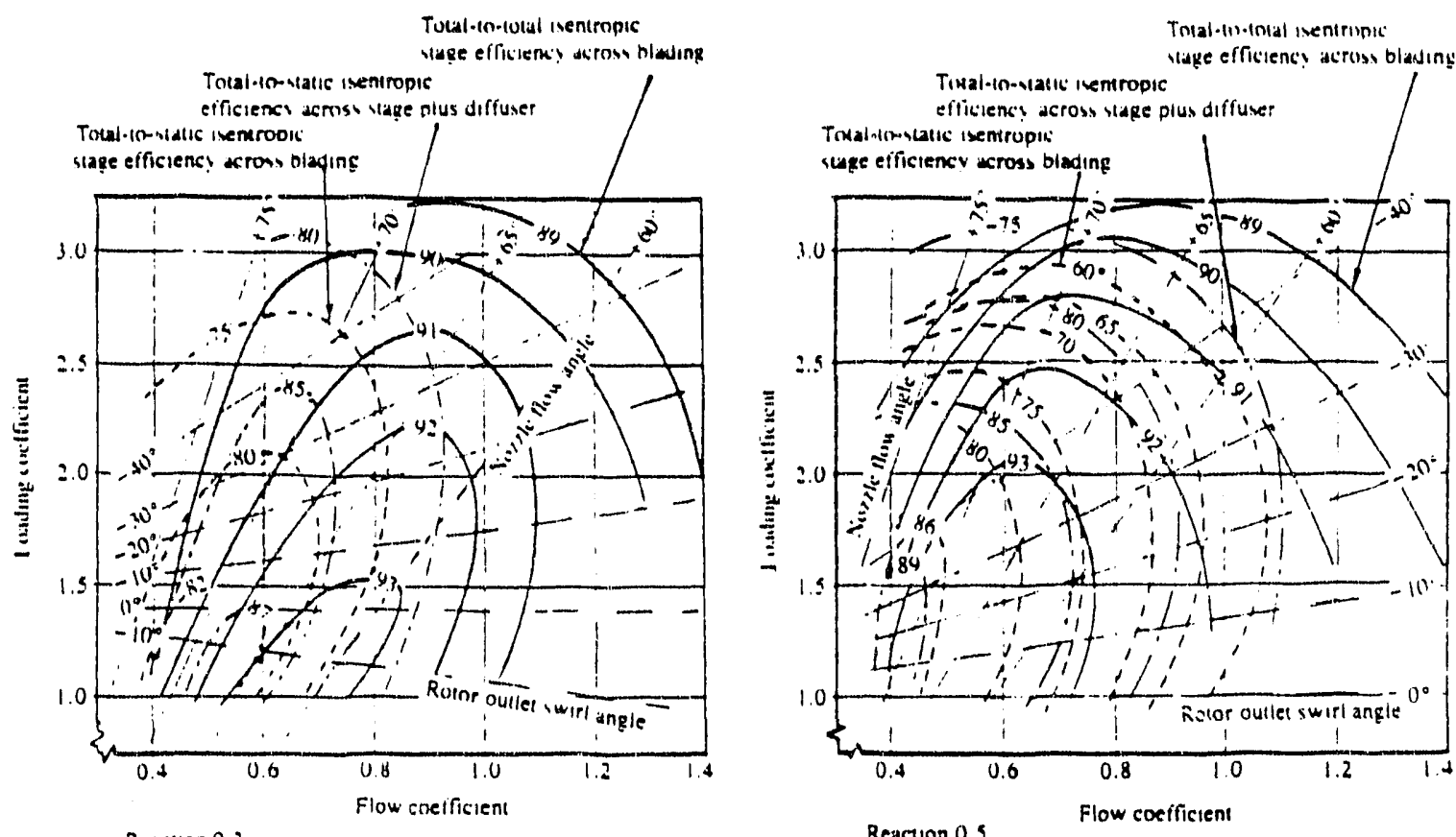

Reaction 0.3

Reaction 0.5
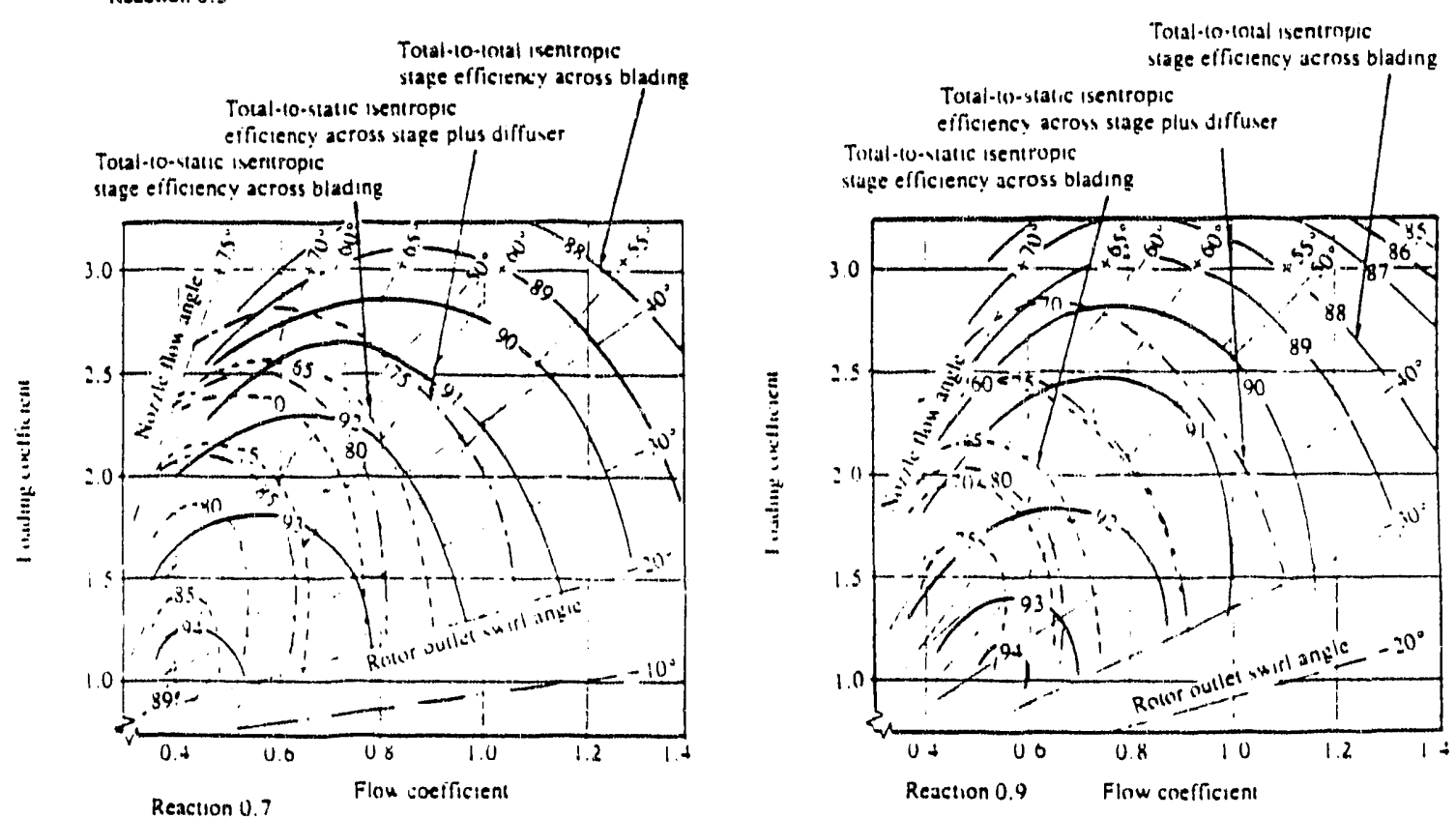

\section{FIGURE 3.1 AXIAL-FLOW-TURBINE STAGE EFFICIENCY VS LOADING AND FLOW COEFFICIENTS [2.7]}


The impeller shape-calculation algorithms were developed by Ganley [29].

\subsection{REGENERATOR SIZING}

The ceramic regenerator is a periodic-flow heat exchanger, as is described in Kays \& London [30]. The sizing procedure for this type of heat exchanger, as for any other, involves using two characteristic curves, the $f$ and $j$ curves, obtained through experimentation $[6,28,30,31]$. The $f$ curve describes how the friction factor varies with the Reynolds number while the $j$ curve describes how the Colburn factor varies with the Reynolds number. The friction factor is a dimensionless measure of the skin-friction tangential stress at the wall, while the colburn factor is a dimensionless measure of the heat-transfer coefficient. The mathematical definitions of these factors is given below.

$$
\begin{aligned}
f & \equiv \frac{\tau_{w}}{\left[\frac{\rho_{T} C_{S}^{2}}{2 g_{C}}\right]} \\
j & \equiv s t(P r)^{2 / 3}
\end{aligned}
$$

Here $\tau_{w}$ is the skin-friction tangential stress at the wall, $\operatorname{Pr}$ is the Prandtl number, st is the stanton number defined by the following.

$$
s t \equiv \frac{h_{t}}{\rho C_{p} C_{s}}
$$

$\mathrm{C}_{\mathrm{s}}$ is the free-stream velocity of the fluid and $\mathrm{h}_{t}$ is the heattransfer coefficient [6].

London et al. obtained the $f$ and $j$ curves for three different ceramic-matrix cores. The different matrix geometries are designated as core numbers 505A, 503A, and 504A from a stanford University study [31]. Table 3.1 below summarizes the surface geometry

\begin{tabular}{|c|c|c|c|}
\hline Core No. (Stanford) & $505 \mathrm{~A}$ & $503 A$ & $504 \mathrm{~A}$ \\
\hline $\begin{array}{l}\text { Passage Count, No./in }{ }^{2} \\
\text { Hydraulic diameter, } \mu \mathrm{m} \\
\text { Area density, } \mathrm{m} 2 / \mathrm{m} 3 \\
\text { Porosity } \\
\text { Solid density, } \mathrm{kg} / \mathrm{m}^{3}\end{array}$ & $\begin{array}{r}526 \\
753 \\
4216 \\
0.794 \\
2259\end{array}$ & $\begin{array}{r}1008 \\
511 \\
5551 \\
0.708 \\
2259\end{array}$ & $\begin{array}{r}2215 \\
327 \\
7864 \\
0.644 \\
2259\end{array}$ \\
\hline
\end{tabular}
of each core.

TABLE 3.1 SURFACE GEOMETRY FOR THREE CORES 
Figure 3.2 contains t'le $f$ and $j$ curves for core 503A. The analysis of this and other similar figures for the other cores reveals that the $f$ and $j$ curves can be characterized, for all three cores, by the very simple equations shown below.

$$
\begin{array}{ll}
f \equiv \frac{3.0}{\operatorname{Re}} & (\operatorname{Re}<1000) \\
j \equiv \frac{14.0}{\operatorname{Re}} & (\operatorname{Re}<1000)
\end{array}
$$

Suggestions by Hagler $[32,33]$ were used to optimize the regenerator design. Hagler developed her own design parameters based on Equations 3.4 and 3.5. We have not used Hagler's parameters but instead developed a computer subroutine that sizes the regenerator following the procedure used in an example in Wilson [6]. The developed computer program also calculates the mass-flow-rate leakage across the heat-exchanger seals using equations developed by Hagler [32].

Wilson uses the NTU method of heat-exchanger design to size the regenerator. This method is discussed briefly in the following paragraphs.

The effectiveness, $\varepsilon$, is a measure of the thermal performance of a heat exchanger. It is defined as the ratio of the actual heat transferred to the maximum amount of heat that can be transferred. The maximum amount of heat that can be transferred in a two-fluid heat exchanger would occur if the outlet temperature of the fluid with the smaller heat capacity, $\left(\dot{m} c_{p}\right)_{m i n}$ were to reach the inlet temperature of the other fluid [6]. The governing equation is, then, as shown below.

$$
\varepsilon \equiv \frac{\dot{\mathrm{Q}}}{\dot{\mathrm{Q}}_{\operatorname{miax}}}
$$

Here the following apply.

$$
\begin{aligned}
& \dot{\mathrm{Q}}_{\max }=\left(\dot{\mathrm{m}} \mathrm{C}_{\mathrm{P}}\right)_{\min } \Delta \mathrm{T}_{\max } \\
& \dot{\mathrm{Q}}=\mathrm{UA}_{\mathrm{h}} \Delta \mathrm{T}_{\text {mean }}
\end{aligned}
$$

Here $\Delta \mathrm{T}_{\max }$ is the temperature difference between the inlets of the hot and cold fluids, $\mathrm{UA}_{\mathrm{h}}$ is the product of the average heattransfer coefficient and area, and $\Delta T_{\text {mean }}$ is some prescribed mean temperature difference between the two fluids (e.g., this can be the log-mean temperature difference [32]). Combining Equations $3.7,3.8$, and 3.6 results in the following. 


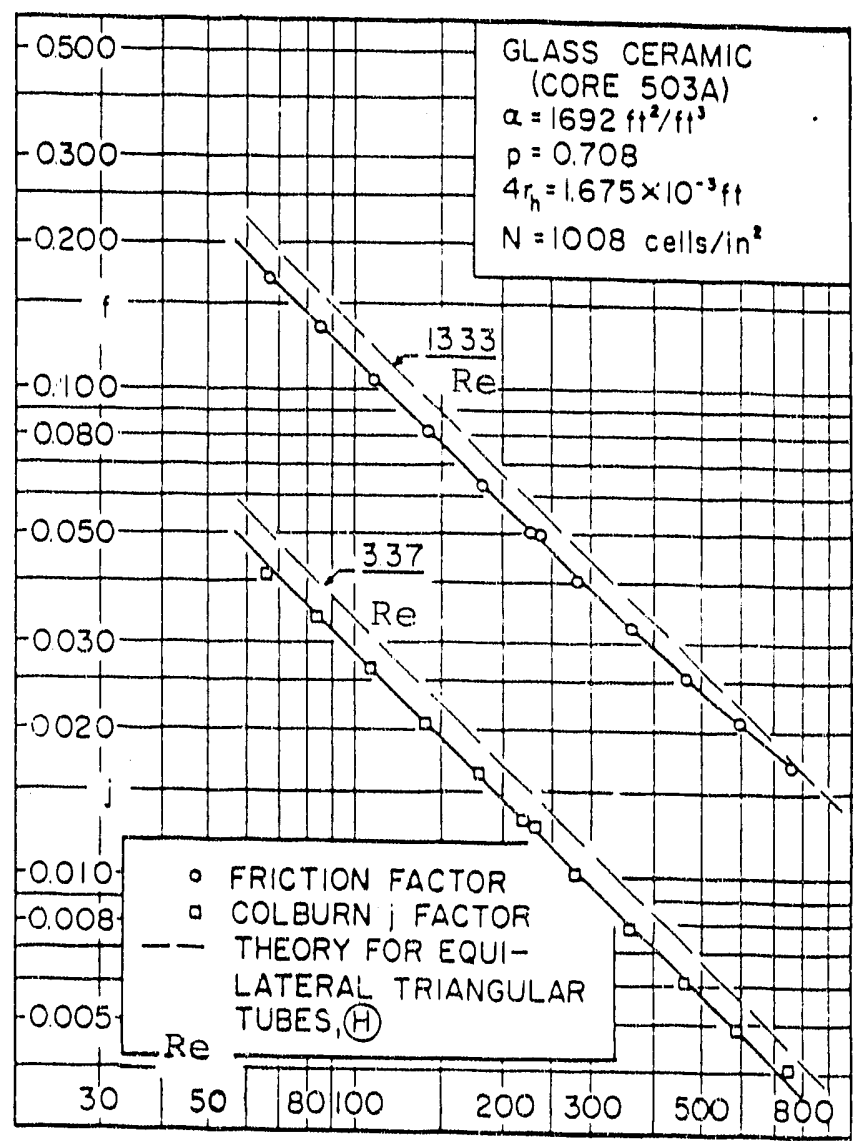

FIGURE 3.2 $f$ AND $j$ CURVES FOR CORE 503A [31] 


$$
\varepsilon \equiv\left[\frac{U A_{h}}{\left(\dot{m} C_{p}\right)_{\text {min }}}\right] \cdot\left[\frac{\Delta T_{\text {mean }}}{\Delta T_{\text {max }}}\right]
$$

The first term on the right side of Equation 3.9, the dimensionless heat-exchanger size, is called the "number of transfer units" or NTU. Therefore, the definition of NTU is as shown below.

$$
\mathrm{NTU} \equiv \frac{\mathrm{UA}_{\mathrm{h}}}{\left(\dot{\mathrm{m}} \mathrm{C}_{\mathrm{p}}\right)_{\min }}
$$

The ratio of the mean to the maximum temperature difference depends on the flow arrangement (i.e., counterflow, crossflow, etc.), the NTU or effectiveness, and the ratio of the smaller heat-capacity rate to the larger, $C_{\text {rat' }}$ as defined below.

$$
c_{\text {rat }} \equiv \frac{\left(\dot{m} c_{p}\right)_{\text {min }}}{\left(\dot{m} c_{p}\right)_{\max }}
$$

Charts and tables of effectiveness versus NTU with $C_{\text {rat }}$ as a parameter are included in Kays and London [30]. In periodic-flow heat exchangers an extra parameter, the switching rate $\left(C_{\text {rot--defined }}\right.$ below), is also necessary.

$$
C_{\text {rot }} \equiv \frac{\left(M \omega C_{p}\right)_{\text {matrix }}}{\left(\dot{m} C_{p}\right)_{\text {min }}}
$$

Here $M$ is the mass of the matrix and $\omega$ is the rotational speed $(\mathrm{rev} / \mathrm{s})$ of the matrix. Hagler determined that the optimum $\mathrm{C}_{\text {rot }}$ is about $3.0[32]$.

\subsection{AXIAL-FLOW TURBOMACHINE DESIGN-POINT PERFORMANCE ESTIMATION}

The design-point performance estimation calculates the losses experienced in a turbine or compressor, as designed, and calculates the component efficiencies. Three different methods were used to estimate the performance of the turbine: Wilson's exact form $[6,35,36,37]$, Wilson's trimmed binomial form (as discussed in Bazan [35]), and a GE method as found in [38]. The estimation of the compressor was accomplished by following the method suggested in wilson [6]. Our discussion will focus first on turbines and later on compressors.

Energy losses in turbines can be modeled as entropy increases along a constant temperature line on a $T-s$ diagram as shown in Figure 3.3. These entropy increases can be, in turn, described as 


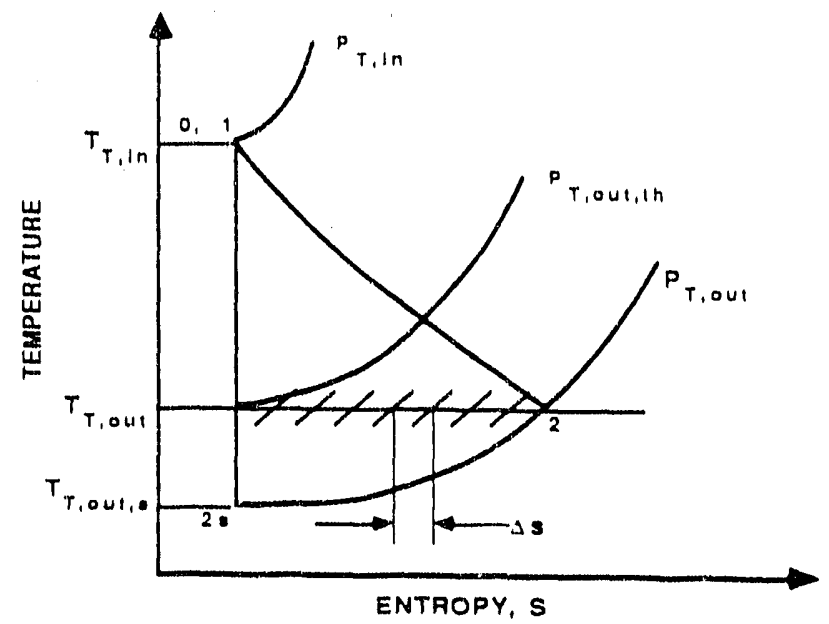

FIGURE 3.3 TURBINE LOSSES ALONG CONSTANT ENTROPY LINE [35]

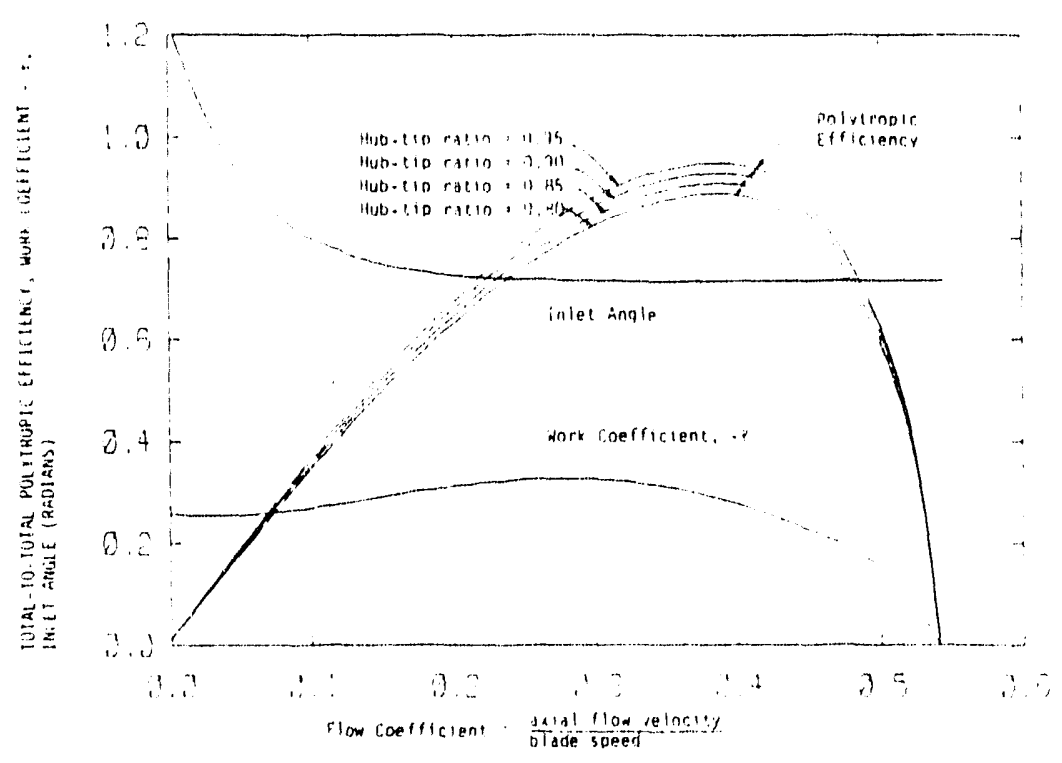
$\begin{array}{ll}\text { FIGURE } 3.4 & \text { WILSON \& KORAKIANITIS PERFORMANCE CURVES } \\ & \text { FOR A LPR COMPRESSOR [42] }\end{array}$ 
pressure losses $[6,35]$. All three turbine performance-estimation methods used convert calculated loss coeffloients into pressure losses. Once the pressure losses are obtalned the turbine efficlency can be calculated. Most of the loss coefficients are found using the diagrams found in craig and Cox [37]. Some of the loss coefficients accounted for include the following.

$\mathrm{X}_{\mathrm{Re}} \equiv$ Reynolds number (Re) loss coefficient. Flow deviations from the blade metal surfaces caused by boundary-layer growth produce losses. The boundary-layer growth can be related to the Reynolds number, based on the bladethroat length.

$\mathrm{x}_{\text {tcl }} \equiv$ Tip-clearance loss coefficlent. Air that leaks through the small gap between the rotor tip and the turbine casing does not produce any work and thus results in a loss.

$x_{\text {pro,te }} \equiv$ Profile/trailing-edge loss coefficient. This loss occurs also due to boundary-layer growth produced by the blade contour and to flow dissipation in the blade wake.

$x_{\text {sl }} \equiv$ Secondary loss coefficient. These losses are due to the interaction of the blade ends on the boundary layer and to frictional effects at the end walls.

Once the loss coefficients for a blade row are obtained they can be converted to a pressure loss by either the exact form of the loss-conversion equation or the first-order binomial-expansion form (binomial) which is an approximation of the first. A comparison of the two forms for a rotor is shown below.

Exact form:

$$
\frac{\Delta P}{P}=-\left[\Sigma X_{i}\right] \operatorname{rot}\left[1-\left[1+\frac{w_{2}^{2}}{2 g_{C} c_{p} T_{T 2}-C_{2}^{2}}\right]^{\frac{-C_{p}}{R}}\right]
$$

Binomial form:

$$
\frac{\Delta \mathrm{p}}{\mathrm{P}}=-\left[\Sigma \mathrm{x}_{i}\right] \operatorname{rot}\left[\frac{-\left[\frac{\mathrm{C}_{\mathrm{p}}}{\mathrm{R}}\right] \mathrm{W}_{2}^{2}}{2 \mathrm{~g}_{\mathrm{C}} \mathrm{C}_{\mathrm{p}} \mathrm{T}_{\mathrm{T} 2}-\mathrm{C}_{2}^{2}}\right]
$$

Here,

$$
\begin{array}{lll}
\Sigma \mathrm{X}_{\mathrm{i}} & \equiv \text { sum of loss coefficients } \\
\mathrm{T}_{\mathrm{T} 2} & \equiv \text { Rotor-exit total temperature }
\end{array}
$$




$\begin{array}{lll}\mathrm{C}_{2} & \equiv \text { Air absolute exit velocity } \\ \mathrm{W}_{2} & \equiv \text { Air relative exit velocity } \\ \mathrm{C}_{\mathrm{p}} & \equiv \text { Specific heat of the air } \\ \frac{\Delta \mathrm{P}}{\mathrm{P}} & \equiv \quad \text { Fraction of pressure loss }\end{array}$

Bazan [35] found that the prediction ability of the exact form of the loss-conversion equation was not very good with multistage axial turbines. She found the method underpredicted by as much as 6 percentage points the efficiencies of multi-stage turbines--thus, the method seems to be too pessimistic for such turbines. The exact form, however, does predict very accurately (within two percent) the performance of single-stage axial turbines $[35,36]$. Bazan determined that the binomial form of the pressure-loss equation was better than the exact form at predicting the performance of multi-stage turbines when the loss coefficients were multiplied by constant reducing factors (or trimming factors). The trimming factors found by Bazan to improve the performance prediction for multi-stage turbines were 0.7 for the secondary loss coefficient, and 0.67 for the Reynolds No. loss coefficient, the profile/tralling-edge loss coefficient, and the tip-clearance loss (as calculated in Dunham \& Came [39]).

The GE method for axial-turbine performance prediction uses trimming factors. This method also accounts for secondary losses and profile/trailing-edge losses directly by way of loss coeficients. The method differs from the others in that it treats tipclearance losses indirectly by multiplying the turbine isentropic efficiency calculated by only considering secondary and profile/trailing-edge losses by a reducing factor $(0.975$ for a mean reaction of 0.5 ).

The method used to obtain the design-point performance of the axial-flow compressors is that outlined in wilson [6]. This method accounts for blade-profile losses and end-wall losses (which include the rotor-blade tip-clearance effects). The end-wall losses are accounted for by multiplying the stage free-stream isentropic efficiency with a reducing factor. The reducing factor is a function of the rotor tip clearance and the selected blade type. The resulting isentropic efficiency can then easily be converted to a polytropic efficiency.

Compressors are occasionally designed with inlet and outlet guide vanes. These vanes are designed to accelerate (inlet guide vanes) or decelerate (outlet guide vanes) in a smooth manner--that is, they are used when the flow would go through an abrupt change that might produce too many losses. The compressor design-point performance estimation ignored the effects the inlet guide vanes and the outlet guide vanes would have on the efficiency. 


\subsection{AXIAL-FLOW TURBOMACHINE OFF-DESIGN PERFORMANCE ESTIMATION}

The off-design performance of a gas-turbine engine is determined by considering the part-load performance of each component individually. For the compressor and turbine, many researchers have developed methods of accurately predicting component efficiencies based on loss coefficients. Craig \& Cox [37] and Dunham \& Came [39] have already been referred to as good examples. While their papers have been shown to correlate design-point performance very well, a recent paper by Moustapha \& Kacker [40] implies that these luss-coefficient prediction methods do not correlate well for off-design performance. Wilson [6] suggests the use of component maps; however, these maps must somehow be derived from existing theory if no cascade tests are to be performed.

An early study by Ainley \& Mathieson [41] correlated offdesign turbomachinery performance to incidence-angle losses. This principle has been referred to by many subsequent studies of offdesign performance. All studies agree that for a given geometry, there is an ideal blade incidence angle which produces minimum losses and maximum efficiency. Wilson and Korakianitis [42] used this relation to generate a graph of efficiency vs. flow coefficient. Horlock [43] derived a elationship between work coefficient and flow coefficient; Wilson and Korakianitis also used this relationship.

Figure 3.4 shows the graph used by wilson and Korakianitis in the study of the off-design performance of their compressor. At low values of the flow coefficient the incidence angle has a sharp decrease and then, for higher values of the flow coefficient, becomes practically constant. There also is a slight depression in the work-coefficient curve. These characteristics can be attributed to a compressor stall at low flow coefficients. Results of axial-flow compressor cascade tests reported in wilson [6] also support these performance curves.

Curves of work coefficient and incidence angle vs. flow coefficient and efficiency vs. flow coefficient are derived from theory. Figure 3.5 and Figure 3.6 show the curves used in the sixstage CXEB compressor. To develop these curves into a compressor map, a method proposed by Korakianitis [44] was used. First, based on a given mass flow rate, pressure ratio, and power requirement from the CYCLES program, the compressor is sized using the performance curves. A first-stage mean value of blade speed, UMDP, is assumed. Given flow coefficient, incidence angle, blade speed, and inlet total pressure and temperature, the compressor geometry can be determined. Based on the work coefficient, blade speed, and efficiency, the overall pressure ratio of the compressor is also determined. The initial guess of UMDP is then adjusted until the selected pressure ratio is reached. A fixed geometry compressor now exists; its size is compared to values generated in the design stage. 


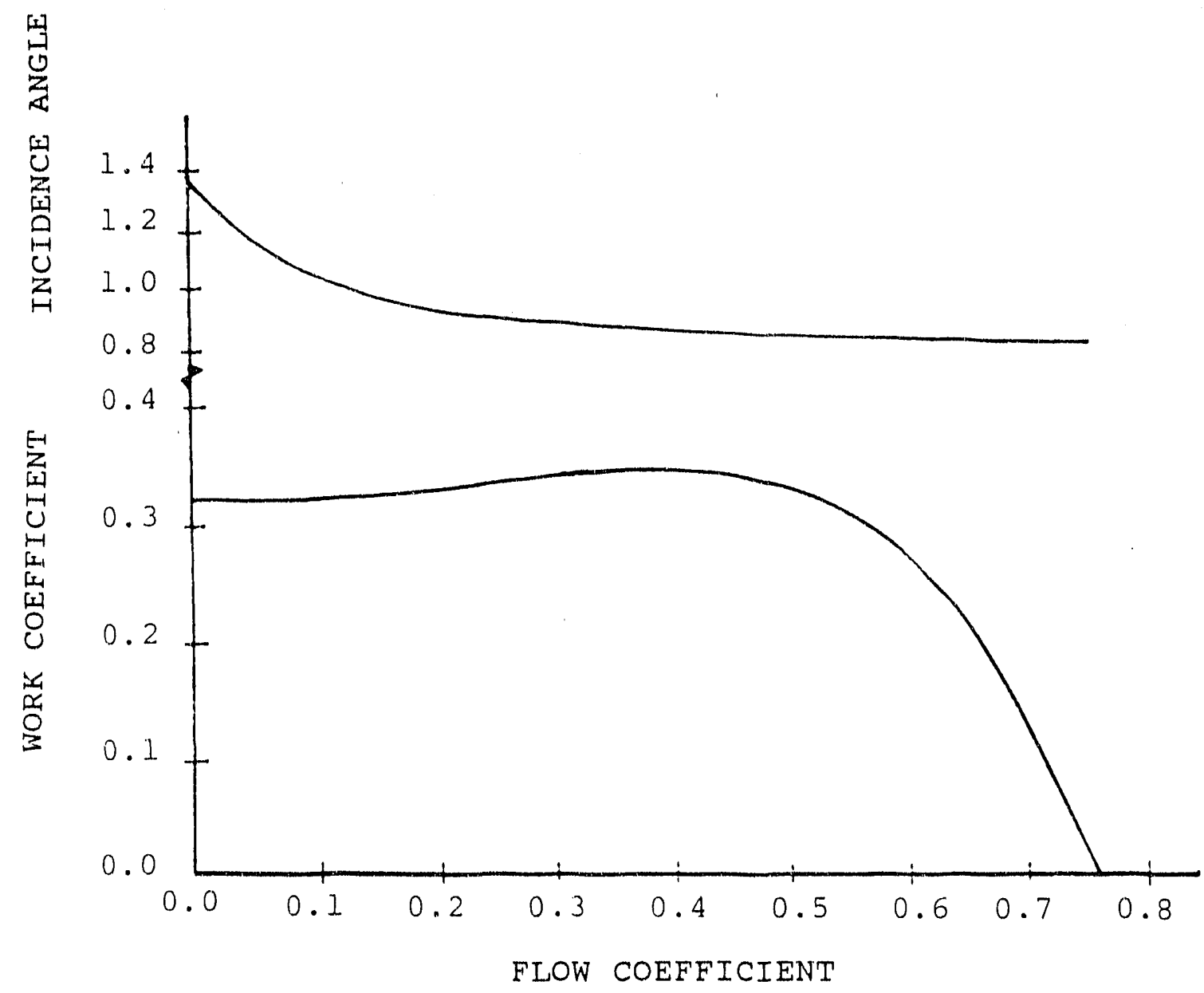

FIGURE 3.5 WORK COEFFICIENT AND INCIDENCE ANGLE VS FLOW COEFFICIENT FOR THE COMPRESSOR 


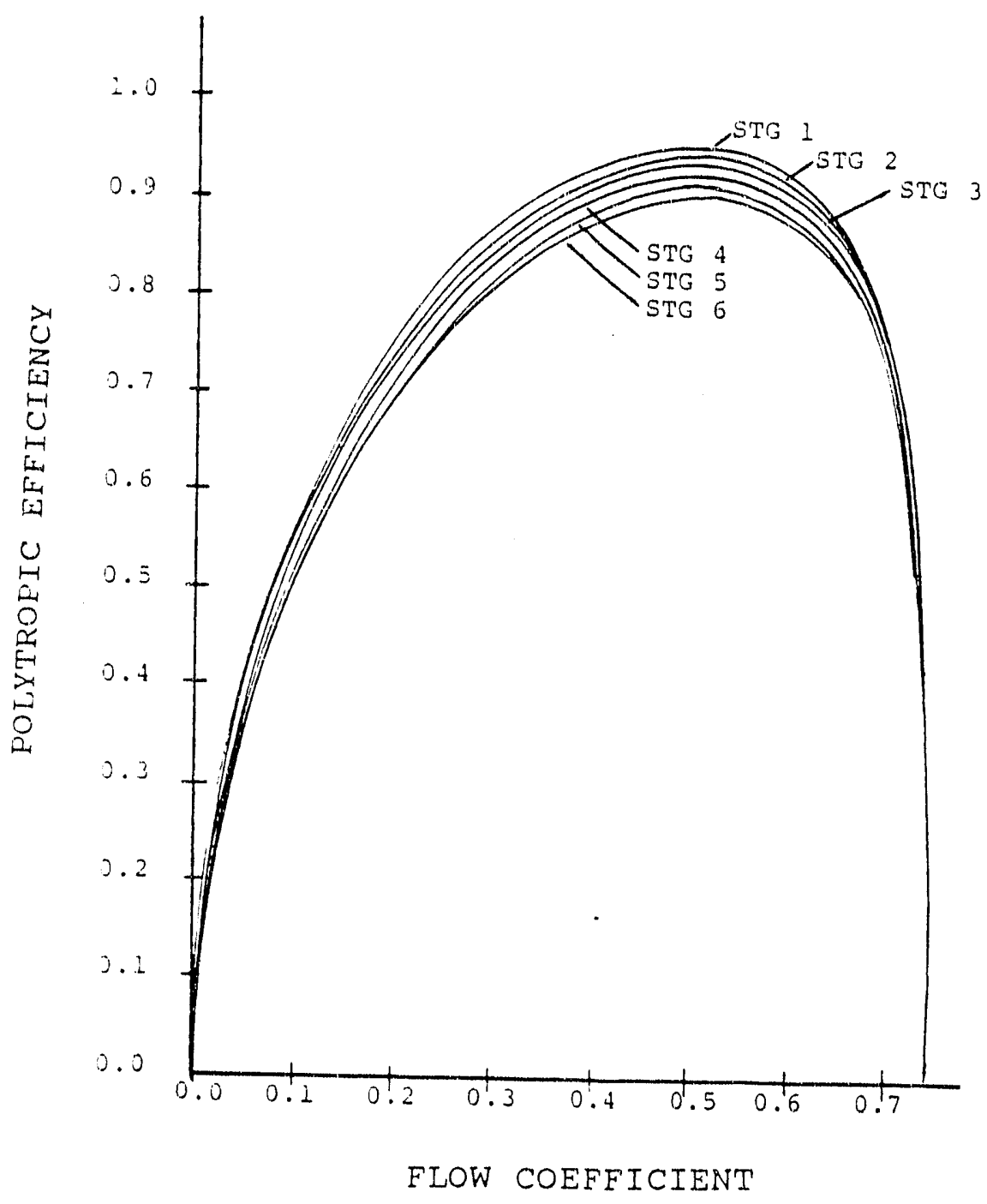

FIGURE 3.6 EFFICIENCY CHARACTERISTICS FOR THE COMPRESSOR 
Since the performance curves of Figures 3.5 and 3.6 were used to size the compressor, then in off-design analysis, the compressor performance will match the CYCLES program at the design point. At off-design, since the geometry is fixed, the only unknowns to determine the overall compressor performance at a given mass flow rate are the results from the performance characteristic curves. Wilson [6] has a good example of compressor off-design performance and flow-coefficient variation.

Two computer programs in BASIC were written to carry out the sizing and off-design performance analysis of the compressor. since this is a single-shaft gas-turbine engine, an equilibrium line on the compressor map can be selected, as suggested by cohen, Rogers, \& Saravanamuttoo [26]. This line is selected so it passes through the region of maximum efficiency.

According to the work of Kays \& London [30] the rotating heat exchanger becomes more effective at lower mass flow rates, at an off-design condition. An extensive review of the work of Kays \& London as well as other heat-exchanger souxces was performed by Carla Hagler [32]. Hagler developed equations describing mass flow leakages in the heat exchanger, in both the radial and circumferential directions. Effectiveness-NTU relationships developed by Kays \& London and the heat-exchanger leakage and performance equations developed by Hagler were combined in a computer program which generated results for the off-design performance of the ceramic rotary regenerator.

Next, the off-design performance of the turbine is considered. A computer program could have been generated to do this, but results from actual cascade testing were found in a paper by Szanca and Schum [45]. Their turbine was a low-pressure-ratio turbine, and Korakianitis [44] successfully scaled the turbine map to use in off-design performance. Since the results from the turbine-map scaling appear reasonable, it was decided to rescale Szanca \& Schum's map for this engine.

Finally, the off-design performance characteristics of the entire engine are considered. For a given input mass flow rate, the equilibrium running line determines the compressor-map characteristics, which in turn fixes the turbine-map performance. Hagler's equation directs how the heat exchanger performs at off design. plots of performance such as flow vs. power, efficiency vs. power, etc., can subsequently be produced.

As a footnote, the combustor was not modeled to act differently in off-design operation. Its efficiency was assumed to be constant over all mass flow rates. In addition, for the CICXEB cycle, the off-design performance methods are identical to those of the CXEB cycle. The intercooler is also assumed to be fixed in efficiency and not to vary at off-design conditions. 


\subsection{CENTRIFUGAL COMPRESSOR PERFORMANCE ES'TIMATION}

The off-the-shelf designs required a method of centrifugalcompressor-performance prediction. After consulting many references $[46,47,48,49,50]$, Dallenbach's method of off-designcentrifugal-compressor-performance prediction was selected [51]. Dallenbach presents equations and a well-structured procedure for calculating the losses and pressures in the various parts of a single-stage centrifugal compressor. The losses represent the total pressure losses due to the non-isentropic flow processes.

The Dallenbach method accounts for the following losses: impeller internal and external, vaneless diffuser, vaned diffuser, scroll and exit losses. The impeller internal losses consist of skin friction, diffusion and blade loading, blade incidence, and shock wave loss. The sources of impeller external losses are disk friction and recirculation. The vaneless diffuser has only skinfriction loss but the vaned diffuser has skin friction, diffusion and blade loading, blade incidence and shock-wave losses. Skin friction is the only scroll loss while the exit adds kineticenergy losses. For a given stage geometry, mass flow, speed and inlet condition, the Dallenbach method will calculate stage efficiency and pressure ratio.

Although the Dallenbach method can be used to predict the off-design performance of a centrifugal compressor, the compressor-performance map for the solar 5650 (the selected off-the-shelf engine) found in [52] was used.

\subsection{SUMMARY}

A brief introduction on the sizing and performance estimation of the engines has been presented. More detailed information on the sizing and performance estimation of axial-flow turbines and compressors can be found in $[6,19,35,36]$. Tampe [19] presents, in detail, the procedure used for the preliminary design of the blue-sky engines. Nahatis [22] presents, in more detail, the off-the-shelf design procedure. 


\subsection{PROCEDURE FOR CYCLE ANALYSIS AND ENGINE DESIGN}

A computer program written in BASIC (the CYCLE program) was developed to calculate the thermal efficiency of both the CXEB and the CICXEB cycles for varying pressure ratios. In addition, the computer program sized the required ceramic regenerator(s) and calculated the mass-flow-rate leakage across the heat-exchanger seals using equations developed by Hagler [32]. Two computer programs were also developed to size the turbine and compressor. This proved to be invaluable since the design process is iterative, meaning that both the turbine and compressor had to be sized more than once when a parameter was changed. The modifications made to the CYCLE program for the off-the-shelf design are explained briefly.

\subsection{BACKGROUND TO COMPUTER CYCLE ANALYSIS}

To reduce the ash stickiness the maximum cycle temperature in both the CXEB and the CICXEB units was selected at $1373 \mathrm{~K}(2000 \mathrm{~F})$ (current industrial turbines often use higher temperatures, e.g., $1560 \mathrm{~K}--2350 \mathrm{~F})$. The maximum cycle temperature for the off-theshelf unit was selected such that the turbine inlet temperature (TIT) would be approximately $1241 \mathrm{~K}(1774 \mathrm{~F})$, which is the current design TIT of the solar 5650 (the off-the-shelf engine). The maximum cycle temperature for the off-the-shelf designs was thus around $1265 \mathrm{~K}(1818 \mathrm{~F})$. The maximum cycle tempexature will of course occur at the combustor exit. The remaining variables in the cycle studies were thus the pressure ratio, the heat-exchanger effectiveness, and the component efficiencies.

The cycle analysis for the blue-sky designs allows for $2.5 \%$ of the compressor flow to cool the first stage of the three-stage expander (the engine designs are explained in chapter seven and eight). (The blade speeds are low, so that a ceramic stage or stages could be substituted for the cooled metallic blades with high confidence, increasing the overall efficiency through reducing the loss of compressor air). The off-the-shelf unit model used a cooling flow of $2.5 \%$ for the gas-proaucer turbine and $0.8 \%$ for the power turbine, as specified for the base engine by solar in $[52]$.

Hagler [32] developed equations for calculating the massflow-rate leakage across the seals of the regenerator. Hagler's approach accounts for both the radial and circumferential seal leakages. These leakages are proportional to the pressure ratio of the gas turbine, $r$, and to the size of the regenerator. obviously, the larger the percentage or proportional leakage, the more the thermal efficiency will be penalized since less flow is available to pass through the expander. Hagler's correlations are somewhat pessimistic: they predict a considerably greater leakage than has been measured in some actual rotary regenerators ${ }^{1}$. In

i. Hagler's model was compared to actual data printed in [78] and
found to pedict leakages approximatel y 50 percent larger. 
addition, MIT is applying for patent protection on a sealing system for rotary regeerators that promises to cut current leakage rates by more than 90 percent. Therefore whjle Hagler's correlations show qualitative leakage trends accurately, we believe that we are being conservate in taking the values predicted by this model in our analysis.

In order to present the data we obtained from the CYCLE program a number of graphs were prepared showing thermal efficiency versus specific power for various pressure ratios. Here specific power has been defined as shown in Equation 4.1 .

$$
\dot{\mathrm{w}}^{\prime} \equiv \frac{\dot{\mathrm{w}}_{\text {net }}}{\mathrm{c}_{\mathrm{p}} \dot{\mathrm{m}}_{\mathrm{i}} \mathrm{T}_{\mathrm{T} i}}
$$

Here $\quad \dot{w}_{\text {net }} \equiv$ net cycle rate of work

$c_{p} \equiv$ specific heat of inlet air

$\dot{\mathrm{m}}_{i} \equiv$ inlet mass flow rate

$\mathrm{T}_{\mathrm{Ti}} \equiv$ inlet total air temperature

Here by inlet we are referring to the inlet to the cycle, that is, the compressor.

The expander and compressor polytropic efficiencies were specified to vary with pressure ratio according to the following equations, which are intended to model attainable component performances at design point [53].

expander polytropic efficiency $\equiv \eta_{p, e} \equiv A-\frac{(r-1)}{300}$

compressor polytropic efficiency $\equiv \eta_{p, c} \equiv A-\frac{(r-1)}{500}$

Here $A$ is an appropriate constant. This parameter was set equal to 0.90 and 0.92 in the blue-sky designs. For the off-the-shelf designs $A$ was determined by matching the compressor and turbine efficiency obtained from Equations 4.2 and 4.3 with those reported by the manufacturer of the selected off-the-shelf engine.

For the intercooled cycle, the overall pressure ratio is divided equally between the two compressors (i.e., the pressure ratio across each compressor is $\sqrt{r}$ ). Therefore, Equation 4.3 changes as shown below for the intercooled engine. 


$$
\eta_{p, c} \equiv A-\frac{(\sqrt{r}-1)}{500}
$$

Also for the intercooled engine the intercooler effectiveness was set at 0.90 for all the calculations (blue-sky and off-the-shelf engines).

The cycle thermal efficiency is defined as usual.

$$
\text { thermal efficiency } \equiv \frac{\dot{W}_{\text {net }}}{\text { Heat Added }}
$$

The net cycle rate of work or power, $\dot{w}_{\text {net, includes mechanical }}$ losses in the shaft, the power required to supply the coal (assumed to be $1 / 3 \mathrm{hp}$ ), the power needed for the turbine oil pump (assumed to be about $3 \mathrm{hp}$ ), and the power needed to rotate the regenerator. The latter was obtained by multiplying the angular speed of rotation of the matrix with the required torque. Data found in Hagler [32] resulted in Equation 4.6 that calculates the required torque based on the diameter, $D$, in meters of the matrix.

required torque in $\mathrm{KNm}=-0.7468 \cdot \mathrm{D}+2.7914 \cdot \mathrm{D}^{2}$

Equation 4.6 is probably most accurate when used for matrix diameters between 0.5 and 3 meters.

The heat added in Equation 4.5 is obtained from Equation 4.7 .

$$
\text { heat added }=\frac{\text { heat needed by the air }}{0.95}
$$

A value of 0.95 is used to account for heat losses through the furnace wall and for losses due to unburnt coal particles [53]. The value of 0.95 is conservative enough to account for the turbine-blade cooling flow desribed previously for the blue-sky engines. (The cycle analysis of the blue-sky engines, unlike the cycle analysis of off-the-shelf units, did not account for the cooling flow directly but did so by using a conservative combustion efficiency). The combustion efficiency is, after account is made of $2.5 \%$ loss in the compressor flow to cool the first stage of the turbine, approximately 0.987 .

The amount of coal required is calculated by assuming a near adiabatic heat transfer between the coal and the air. Therefore, the required coal rate is obtained by simply dividing Equation 4.7 by the higher heating value (HHV) of the coal, as illustrated in Equation 4.8 . 


$$
\text { coal required }=\frac{\text { heat needed by the air }}{0.95 \cdot(\text { HHV })}
$$

The properties of the coal used in the analysis are of a West Virginia low-volatile, bituminous coal [54]. The ultimate analysis is shown in Table 4.1. The higher heating value of the coal used

TABLE 4.1 ULTIMATE ANALYSIS OF COAL

\begin{tabular}{l|ccccccc}
\hline species & Moisture & $\mathrm{C}$ & $\mathrm{H}$ & $\mathrm{S}$ & $\mathrm{O}$ & $\mathrm{N}$ & $\mathrm{A}$ \\
\% composition & 2.7 & 84.7 & 4.3 & 0.6 & 2.2 & 1.5 & 4.0 \\
\hline
\end{tabular}

is $34,262 \mathrm{~kJ} / \mathrm{kg}(14,730 \mathrm{Btu} / \mathrm{lb})$.

The cycle pressure losses used in the program were assigned as follows (the selections are conservative) [53]. For the CXEB cycle with a heat-exchanger effectiveness of 0.975 the pressure losses were 9 percent plus whatever pressure drop was calculated for the regenerator (usually of the order of 4 percent). For the CICXEB cycle with an effectiveness of 0.975 the losses were 11 percent plus the calculated regenerator pressure drop (as before these were of the order of 4 percent). The pressure losses for the off-the-shelf engines were about 13 percent plus the pressure drop calculated for the regenerator for the nonintercooled version and approximately 16 percent plus the pressure drop calculated for the regenerator for the intercooled engine (in both cases the regenerator pressure drop was of the order of 4 percent).

\subsection{CYCLE COMPUTER PROGRAM}

The CYCLE program iterates in a number of different places to obtain the average specific heat needed in the calculation (e.g., in calculating the exit total temperature of the compressor and turbine). The program operates under three nested iteration loops. The first loop adjusts a variable called MFRAC, which will be explained later, until it is within a selected tolerance. MFRAC accounts for the air-flow leakages in the regenerator. The second loop adjusts the initial guess of $\mathrm{C}_{\text {rat }}$ that is made by the user. Finally, the third and outer loop adjusts the air mass-flow rate to obtain the desired power output. Before we can explain these loops in any more detail it is necessary to discuss the sizing procedure of the regenerator.

In order to size the regenerator and calculate its air leakages the inlet and exit temperatures of the compressed air and of the exhaust gases must be known [6,32]. The total temperature of the air leaving the compressor and entering the regenerator and the temperature of the gases entering the regenerator from the combustor are known. The remaining two unknown temperatures are the exit temperature of the compressed air from the regenerator and the exit temperature of the exhaust gases from the regenera- 
tor. Since the effectiveness of the regenerator is selected, it is generally the case that the exit temperature of the compressed air from the regenerator can be calculated easily. This is done by simply applying Equations 3.6 and 3.7 and a modified version of Equation 3.8. Equations 3.6, 3.7, and 3.8 are shown below, for convenience, as Equations $4.9,4.10$, and 4.11 respectively.

$$
\begin{aligned}
& \varepsilon \equiv \frac{\dot{\mathrm{Q}}}{\dot{\mathrm{Q}}_{\max }} \\
& \dot{\mathrm{Q}}_{\max }=\left(\dot{\mathrm{m}} \mathrm{C}_{\mathrm{P}}\right)_{\min } \Delta \mathrm{T}_{\max } \\
& \dot{\mathrm{Q}}=\mathrm{UA}_{\mathrm{h}} \Delta \mathrm{T}_{\text {mean }}
\end{aligned}
$$

Equation 4.11, as explained in chapter three, is the heat transferred in the regenerator. A usual assumption in heat-exchanger design is that there are no heat losses in the heat-transfer process (i.e., all the heat lost by the hot fluid is gained by the cold fluid) [34]. Mathematically this means that $\dot{Q}$ can be expressed as shown in Equation 4.12 .

$$
\dot{\mathrm{Q}}=\left(\dot{\mathrm{m}} \mathrm{C}_{\mathrm{p}}\right)_{\min } \Delta \mathrm{T}_{1}=\left(\dot{\mathrm{m}} \mathrm{C}_{\mathrm{p}}\right)_{\max } \Delta \mathrm{T}_{2}
$$

Here $\Delta T_{1}$ is the temperature change in the fluid with the smaller heat-capacity rate and $\Delta \mathrm{T}_{2}$ is the temperature change in the fluid with the larger heat-capacity rate. Combining Equations 4.9, 4.10 , and 4.12 results in Equation 4.13 .

$$
\varepsilon=\frac{\Delta \mathrm{T}_{1}}{\Delta \mathrm{T}_{\max }}
$$

Generally the fluid with the smaller heat-capacity rate is the compressed air from the compressor. Since $\Delta \mathrm{T}_{\max }$ is the difference between the compressed air and exhaust gas inlet temperatures (both known quantities), it is obvious that the exit temperature of the compressed air is the only unknown in Equation 4.13. To determine the remaining unknown temperature, the exit temperature of the exhaust gases, Equation 4.12 is rearranged as shown below.

$$
\frac{\left(\dot{m} C_{p}\right)_{\min }}{\left(\dot{m} C_{p}\right)_{\max }}=\frac{\Delta T_{2}}{\Delta T_{1}}
$$

Applying the definition of $c_{\text {rat }}$ to Equation 4.14 results in Equation 4.15 . 


$$
C_{\text {rat }}=\frac{\Delta \mathrm{T}_{2}}{\Delta \mathrm{T}_{1}}
$$

From Equation 4.15 it is clear that an initial guess of $\mathrm{C}_{\text {rat }}$ must be made in order to calculate the exit temperature of the exhaust gases from the regenerator, the only remaining unknown in Equation 4.15 .

Once the inlet and exit temperatures of the compressed air and of the exhaust gases are known the regenerator can be sized. With the regenerator size known the leakages can be calculated using Hagler's equations. (Hagler has a copy of the computer program that calculates the leakages she developed in [32]; a subroutine in CYCLE uses the same solution procedure as she did with one minor correction). It is assumed that half of the air-mass-flowrate leakages occur at the regenerator inlet and the other half when the air exits the regenerator. MFRAC, then, is a multiplier used to reduce the air-mass flow rate in the regenerator by exactly half the amount of the leakage. Since at first the leakages are unknown an initial guess must be made of MFRAC. Once the leakages have been calculated the guess of MFRAC can be modified and the sizing procedure of the regenerator and the leakage calculation is done again. This procedure is repeated until the change of MFRAC from one iteration to the next falls within a certain tolerance specified in the CYCLE program (this tolerance was specified as 0.0001 in the program).

In guessing a value of $\mathrm{C}_{\text {rat }}$ the mass-flow rate of the exhaust gases is automatically specified (see Equation 3.12). The massflow rate of the exhaust gases obtained from the $c_{\text {rat }}$ guess may or may not be the same as that calculated based on the compressed-air mass flow rate, the leakages, and the amount of fuel added in the combustor. The error between the two exhaust-gas flow rates, ERRMA, can be calculated from Equation 4.16 .

$$
\text { ERRMA } \equiv \text { MAIRHT - (MAIRCT - LEAKAGES + FUEL) }
$$

Here MAIRHT $\equiv$ total exhaust-gas mass flow rate

MAIRCT $\equiv$ total compressed-air mass flow rate

LEAKAGES $\equiv$ total leakages in the regenerator

FUEL $\equiv$ fuel mass flow rate added in combustor

The CYCLE program continues iterating on $C_{\text {rat }}$ (i.e., changing the value of $\mathrm{C}_{\text {rat }}$ used in the computations) until ERRMA is smaller than a specified tolerance (a value of 0.002 was used).

The final loop iterates on the air-mass flow rate until the selected power output is obtained. The program begins with an initial guess of the air mass flow rate $(10 \mathrm{~kg} / \mathrm{s})$. Using the ini- 
tial guess of flow rate and after the cycle has been calculated completely (i.e., the correct MFRAC and $C_{\text {rat }}$ have been obtained) the program calculates the specific power. Using the definition of specific power and the required power output the appropriate air mass flow rate can be calculated. The program performs all the calculations again using the new air mass flow rate. This process may need to be repeated three to five times since the leakages vary with air mass flow rate and alter the specific power of the cycle.

\subsection{TURBINE AND COMPRESSOR COMPUTER PROGRAMS}

TWO computer programs, COMPRESSOR and TURBINE, were developed for the sizing of the axial-flow compressor and turbine, respectively.

The inputs required by both programs are the temperatures and pressures obtained by the cycle study, the load coefficient, the reaction, the hub-to-tip ratio (all the latter three at the selected reference station along the blade height), and the number of stages.

A constant-hub-diameter configuration was selected for the turbine. Thus the turbine sizing is done by "jumping" from blade row to blade row at the hub diameter. once the program reaches the last stage it will have all the major dimensions of each blade row in the turbine. With the obtained mean and tip diameters for each blade row the simple-radial-equilibrium (SRE) equation is used by the program to calculate the velocity diagrams at these other blade-height stations. The SRE equation adjusts the velocity diagrams along the blade height to obtain a constant enthalpy (or energy) change at every station along the blade height. Thus the program goes through the stages of the turbine twice--the first time to size the annular area at each stage and the second time to get the velocity diagrams at two other radial stations. The turbine sizing program also calculates the Mach number at the stator hub $\left(C_{1}\right.$ is largest at the stator hub) and the relative Mach number at the rotor tip $\left(\mathrm{w}_{2}\right.$ is largest at the rotor tip). The interested reader is referred to Wilson [6] and Tampe [19] for a more detailed explanation of the SRE equation and its role in the development of the velocity diagrams at different locations along the blade height.

The COMPRESSOR program operates in much the same way as does the TURBINE program. A compressor of constant-tip-diameter configuration was selected. Thus, the sizing of the compressor was accomplished at the blade tip of each stage. The program subsequently calculates, with the obtained stage dimensions, the velocity diagrams at the mean and hub diameters with the SRE equation. As with the TURBINE program the compressor sizing program calculates the Mach number at the stator hub $\left(C_{2}\right.$ is largest at the stator hub) and the relative Mach number at the rotor tip ( $W_{1}$ is lar- 
gest at the rotor tip). In addition the program also verifies if the flow will separate at the hub, mean, and tip radial stations for both stators and rotors. This is done by calculating the ratio of the outlet air velocity to the inlet air velocity for a particular streamline. This value, called the de Haller ratio, must be greater than about 0.71 to avoid flow separation $[6,19]$.

The use of both programs was iterative. The reaction, load coefficient, and the hub-to-tip ratio were varied until reasonable results were obtained. Because we chose to use subsonic designs, we desired the Mach number in both the turbine and compressor to be less than 0.9. For the compressor the de Haller ratio had to be met.

\subsection{SUMMARY}

The three primary BASIC computer programs used in the design process were discussed. The CYCLE program was used to perform the cycle analysis; it was used to select the operating pressure ratio of the blue-sky CXEB and CICXEB CYcle engines. With a few modifi-cations it was also used to perform the cycle analysis of the offthe-shelf engine (both intercooled and nonintercooled). The TURBINE and COMPRESSOR programs were used to size and determine the velocity diagrams at various radial stations for each blade row for the axial-flow turbine and compressor, respectively. All three programs were used in $G W$ BASIC and can also be used in MICROSOFT QUICKBASIC. 


\subsection{BLUE-SKY DESIGN CYCLE ANALYSIS}

The CXEB and the CICXEB CYCLE programs were run with a desired power output of $2 \mathrm{MW}$; a heat-exchanger effectiveness of 0.975 , a maximum cycle temperature of $1373 \mathrm{~K}$, and the pressure losses as described in chapter four. A sensitivity study was also done on both cycles by varying those parameters. Finally, design-point pressure ratios of 3.0 and of 4.0 were selected for the CXEB and the CICXEB cycles respectively.

\subsection{CXEB SENSITIVITY AND CYCLE STUDY}

Since the thermal efficiency is strongly dependent on the regenerator effectiveness, $\varepsilon$, the CXEB CYCLE computer program was run for three cases: $\varepsilon=0.90, \varepsilon=0.95$, and $\varepsilon=0.975$. For all cases the constant of Equations 4.2 and 4.3 was set at $A=0.92$ and the maximum cycle temperature was set at $1373 \mathrm{~K}$. Figure 5.1 shows the results obtained. The pressure ratio was varied from 2 to 4.2 in increments of 0.1 . The maximum thermal efficiency increases from about 39 percent to about 50 percent as the effectiveness is increased from 0.90 to 0.975 . Since an effectiveness of 0.975 results in a heat-exchanger size that is not unreasonable (see section 1.4), we have selected it for both the CXEB and the CICXEB CYcle.

To evaluate the effect of the constant $A$ on the thermal efficiency of the gas turbine a different run was made with the same effectiveness of 0.975 but changing A from 0.92 to 0.90 . Figure 5.2 shows the results obtained from the program. A decrease of about 1.5 points is obtained from changing $A$. Actual turbine and compressor polytropic efficiencies show that setting $A=0.90$ is perhaps too conservative. Thus the value of 0.92 was retained as final.

Figure 5.3 shows the effects of increasing the maximum cycle temperature from $1373 \mathrm{~K}$ to $1393 \mathrm{~K}(2011 \mathrm{~F}$ to $2048 \mathrm{~F}$ ) and then again to $1413 \mathrm{~K}(2084 \mathrm{~F})$. A total increase of about 2 percent in the maximum thermal efficiency is obtained by increasing the maximum cycle temperature by 3 percent. For our case, however, we will retain the original maximum cycle temperature which already shows a very attractive performance.

As will be explained in chapter ten there may be some difficulties in using a ceramic regenerator in the coal-fired exhaustheated cycle. These difficulties have to do with the degradation of ceramics in coal products of combustion environments. As a possible alternative we have suggested the use of a metalflexible-band regenerator. The use of such a heat exchanger would limit the maximum temperature to a range between $1144 \mathrm{~K}$ and $1255 \mathrm{~K}$ $(1600 \mathrm{~F}$ to $1800 \mathrm{~F})$. Figure 5.4 shows the effects on the CXEB Cycle if the maximum temperature is lowered first to $1255 \mathrm{~K}$ and then to $1144 \mathrm{k}$. For this latter run the leakages were reduced by a 


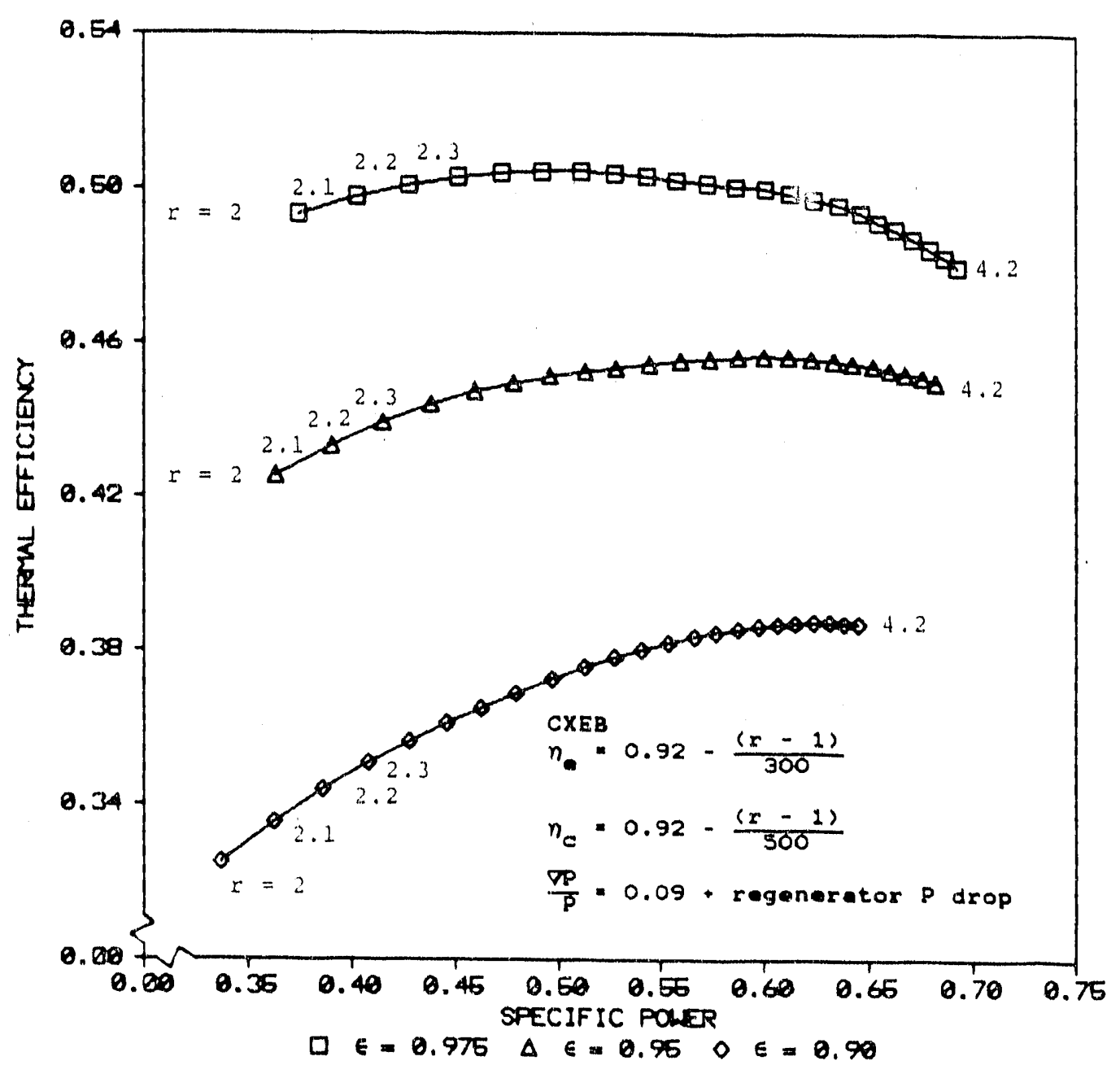

FIGURE 5.1. THERMAL EFFICIENCY VS SPECIFIC POWER FOR CXEB FOR $0.90,0.95$, AND 0.975 EFFECTIVENESS 


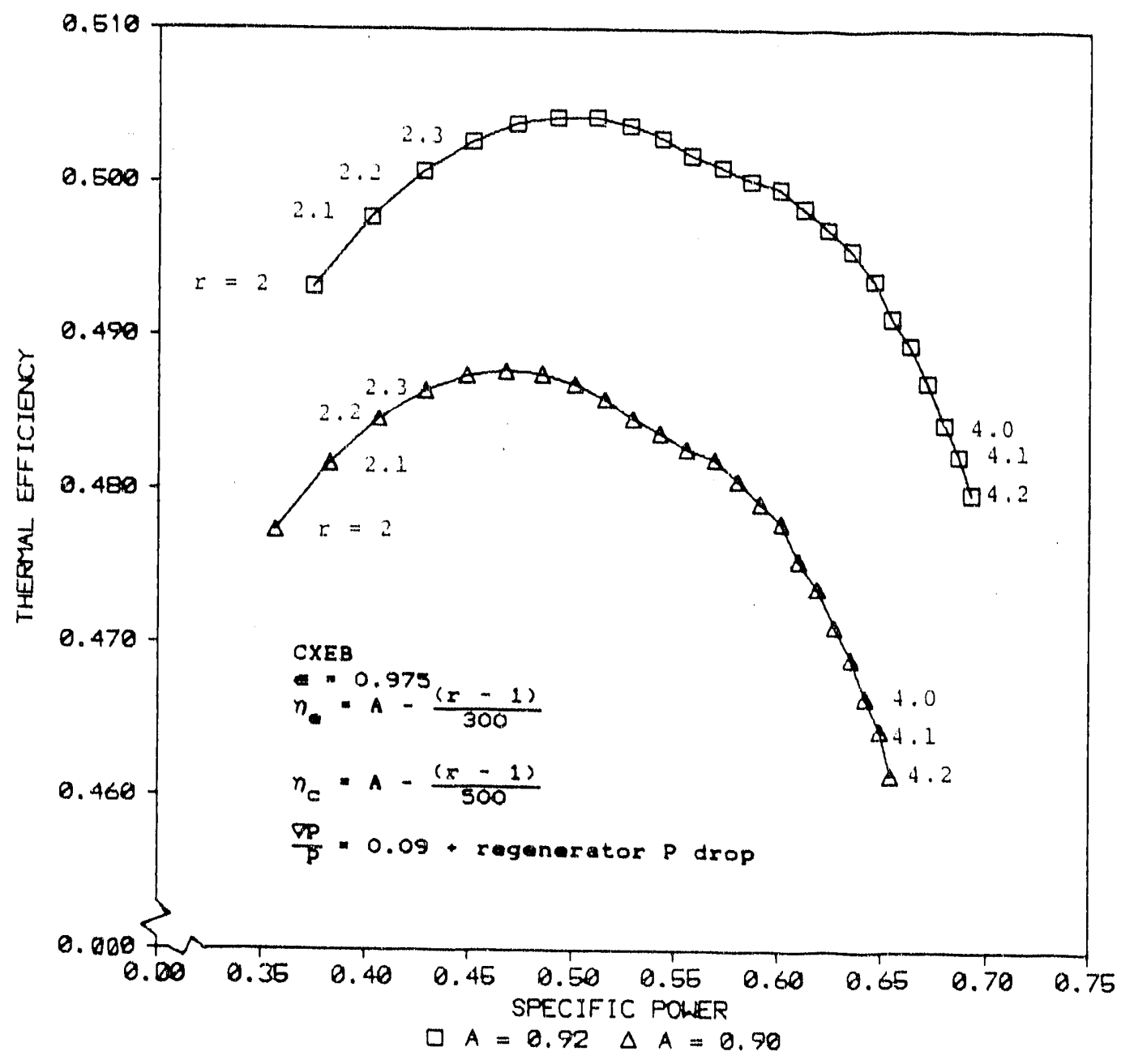

FIGURE 5.2 THERMAL EFFICIENCY VS SPECIFIC POWER FOR CXEB FOR POLYTROPIC-EFFICIENCY CONSTANTS 0.92 AND 0.90 


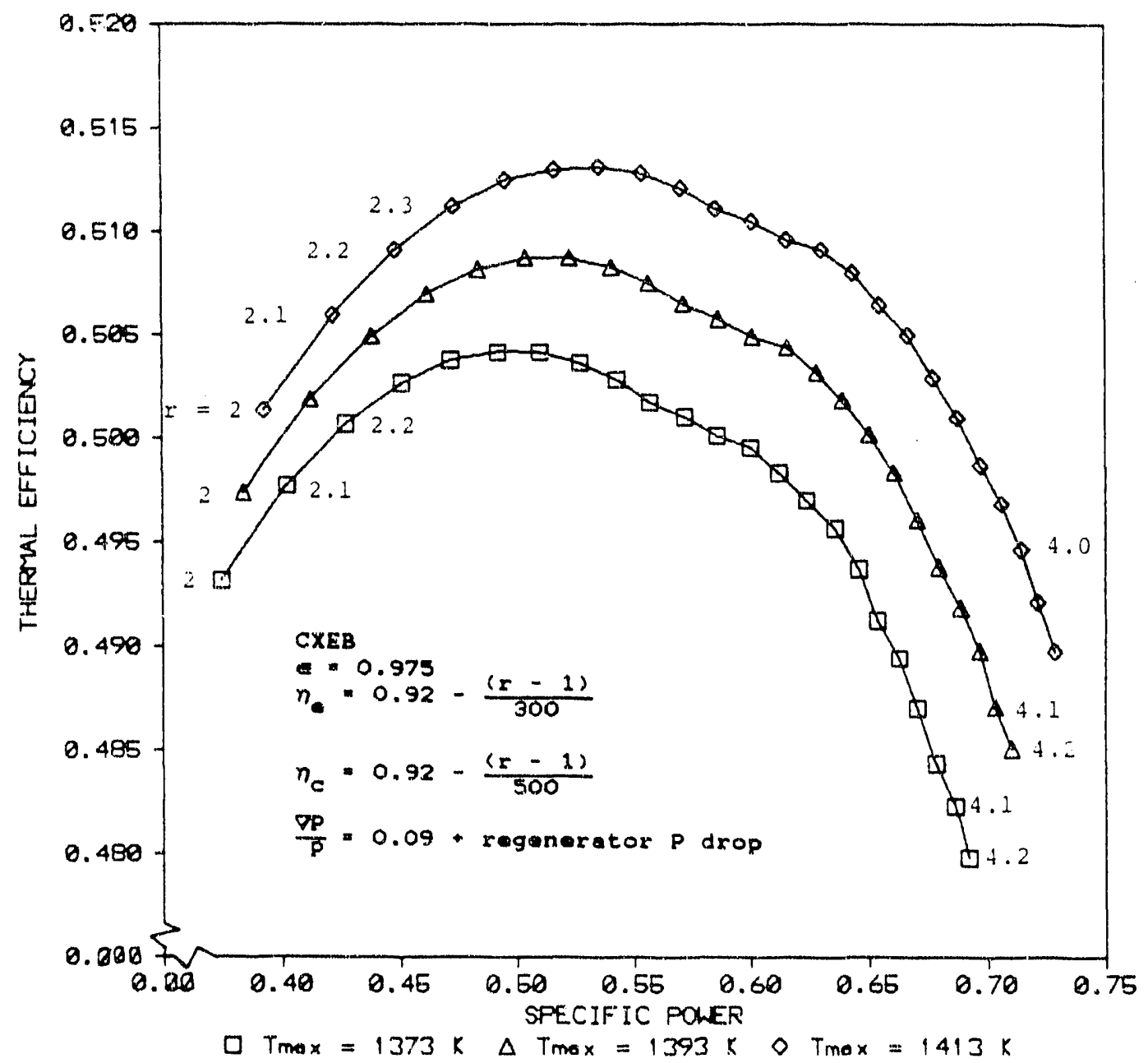

FIGURE 5.3 THERMAL EFFICIENCY VS SPECIFIC POWER FOR CXEB FOR Tmax $=1373 \mathrm{~K}, 1393 \mathrm{~K}$, AND $1413 \mathrm{~K}$ 


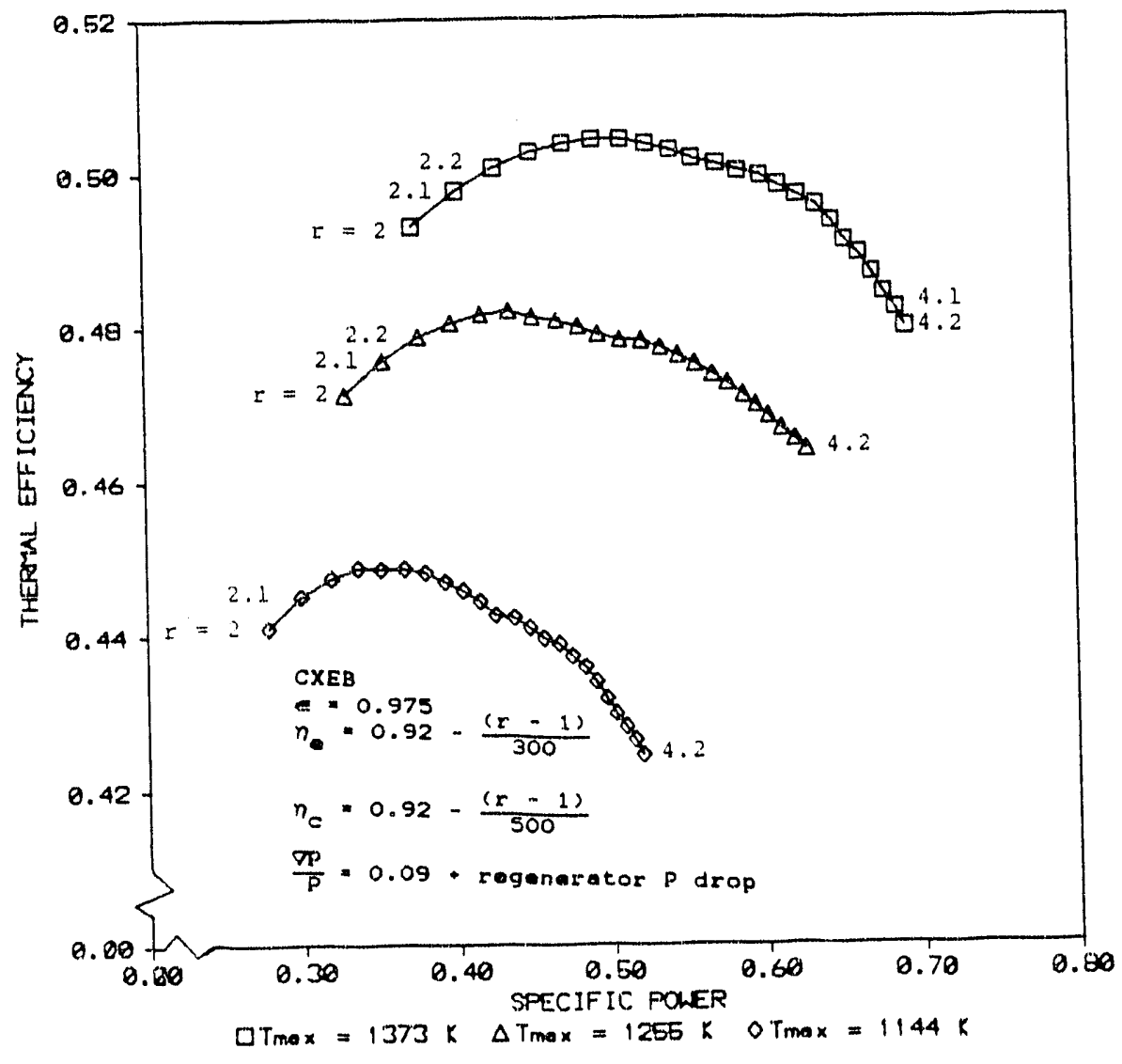

FIGURE 5.4 THERMAL EFFICIENCY VS SPECIFIC POWER FOR CXEB FOR Tmax $=1373 \mathrm{~K}, 1255 \mathrm{~K}$, AND $1144 \mathrm{~K}$ 
factor of 10 since the metallic heat exchanger would probably have little or no leakages. The performance of the engine at these lower temperatures is still quite good: a thermal efficiency of about 48 percent at $1255 \mathrm{~K}$ and of about 45 percent at $1144 \mathrm{~K}$.

Once the mass-flow rate (by way of the selected power output), the component efficiencies, and the regenerator effectiveness were selected we needed to choose only an appropriate pressure ratio. Figure 5.5 shows the performance of the gas-turbine engine for pressure ratios ranging from 2 to 12 in increments of 0.5. The maximum thermal efficiency, equal to 0.504 , occurs at a pressure ratio of 2.5 and has a specific power of 0.492 . The cycle having maximum specific power, equal to 0.756 , occurs at a pressure ratio of 7 and has a thermal efficiency of 0.414 . As the pressure ratio increases mass-flow losses in the regenerator seals also increase; for the two cases above the leakage increases from 2.1 percent to 6.3 percent, using Hagler's model [32].

The pressure drop across the compressed-air side of the regenerator decreases with increasing pressure ratio. If the pressure drop is allowed to become too small the flow entering the regenerator from that side will not distribute evenly over the entire face area, thus leading to a decrease in the heat that is transferred. For the two extreme cases discussed in the previous paragraph the compressed-air pressure drop across the regenerator falls from about 1 percent to about 0.2 percent. We are not recommending the latter case. If we were, we would recommend flowdistribution devices for the compressed-air side of the regenerator.

The pressure ratio of the CXEB cycle was chosen at a value higher than that giving maximum thermal efficiency, it being our judgment that an economic optimurn would be reached with a somewhat higher specific power. The resulting CXEB cycle is as shown in the 1 ist below.

air mass-flow rat
pressure ratio
thermal efficien
mass-flow leakag
specific power
net power output
pressure losses
coal consumption
$\mathrm{T}_{\mathrm{T} 1}=\quad 300 \mathrm{~K}$
$\mathrm{~T}_{\mathrm{T} 2}=422 \mathrm{~K}$
$\mathrm{~T}_{\mathrm{T} 3}=1349 \mathrm{~K}$

$=11.6 \mathrm{~kg} / \mathrm{s}$
$=3.0$
$=0.50$
$=2.5 \mathrm{percent}$
$=0.572$
$=2.0 \mathrm{MW}$
$=13.0 \mathrm{percent}$
$=0.12 \mathrm{~kg} / \mathrm{s}$
$\mathrm{T}_{\mathrm{T} 4}=1090 \mathrm{~K}$
$\mathrm{~T}_{\mathrm{T} 5}=1373 \mathrm{~K}$
$\mathrm{~T}_{\mathrm{T} 6}=450 \mathrm{~K}$

Here $\mathrm{T}_{\mathrm{T}}$ is the total or stagnation temperature at a particular 


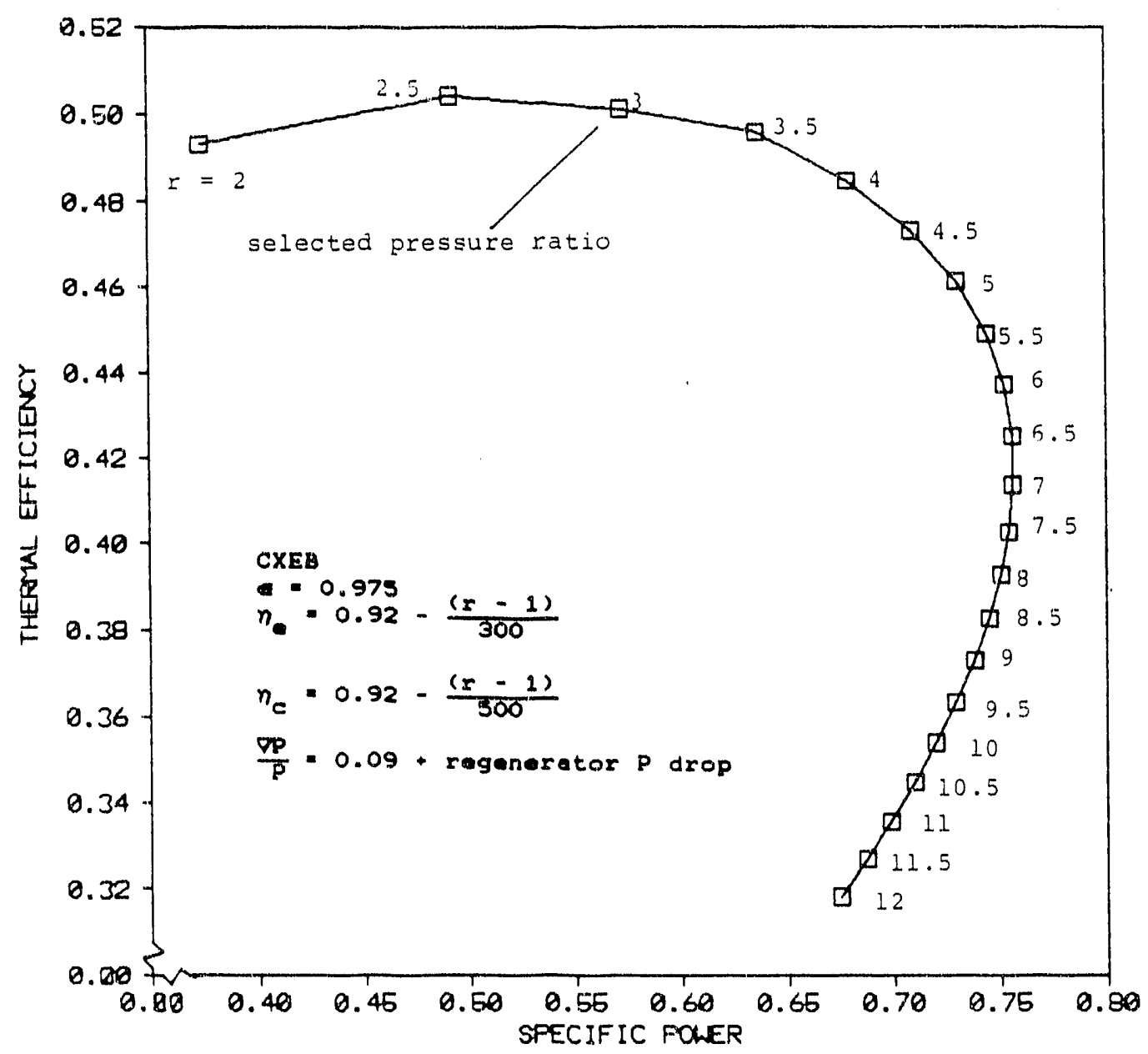

FIGURE 5.5 THERMAL EFFICIENCY VS SPECIFIC POWER FOR CXEB CYCLE 


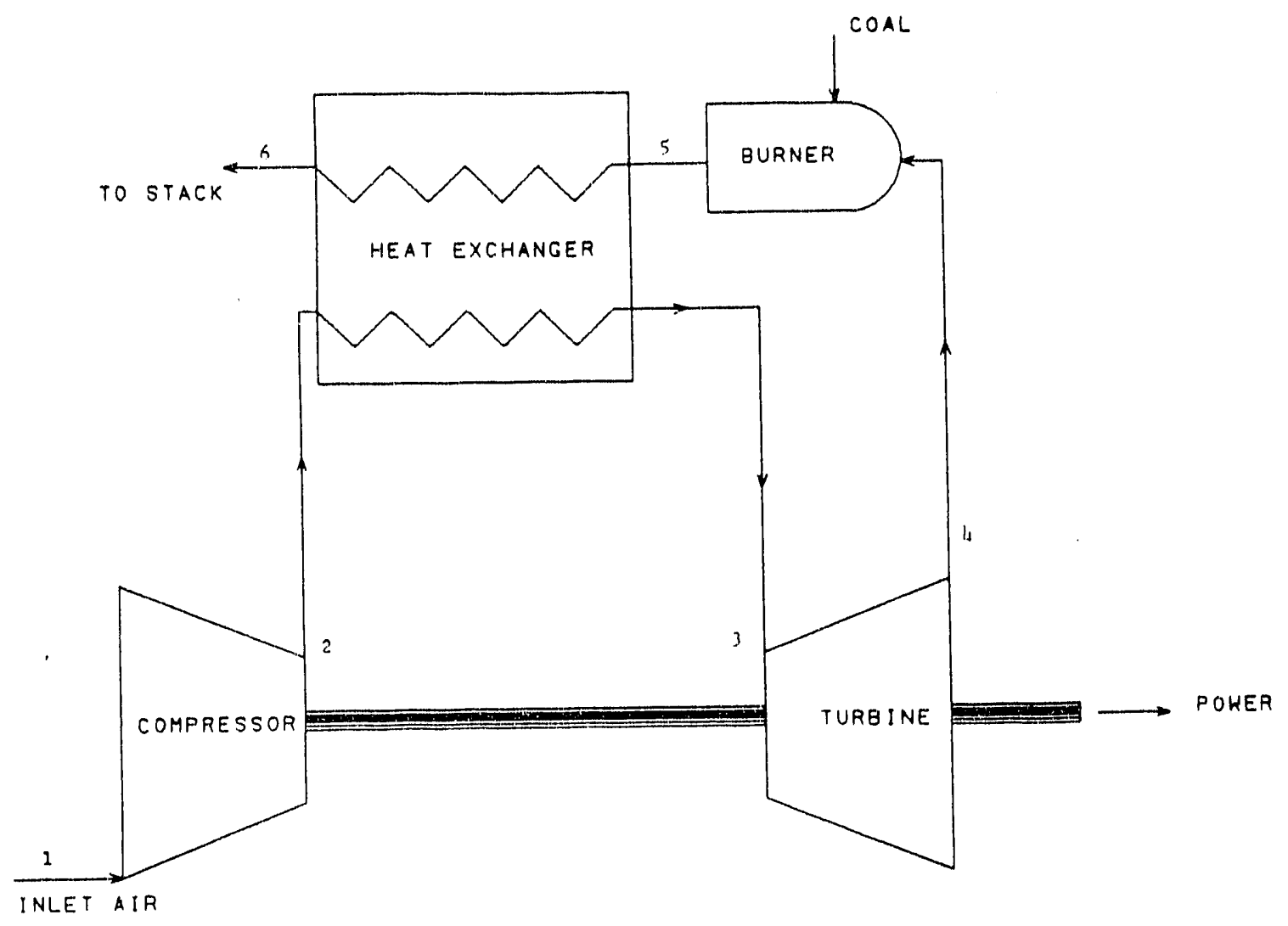

FIGURE 5.6 CXEB CYCLE 
location designated by the subscript number in the cycle (see Figure 5.6$)$.

As was mentioned previously, the leakages obtained from Hagler's equations are somewhat pessimistic (see chapter four). They are based on arbitrarily selected gap widths between the seals and the matrix surface. We thus reduced the leakages obtained from Hagler's model by a factor of 2 . The results are included in Figure 5.7. As can be seen, the thermal efficiency increases about one point due to the leakage reduction. This confirms the obvious fact that the efficiency is very sensitive to mass-flow losses.

Through a careful design of ducting the pressure losses may be reduced from our value of 0.09 (plus the drop in the regenerator). In order to determine the effect a reduction in the pressure drop has on the cycle efficiency we decreased the losses from 0.09 to 0.07 . The CYCLE program was run with this new pressure loss. The obtained result is shown in Figure 5.8. As can be seen, the maximum thermal efficiency increases about two percent, or one percentage point.

\subsection{CICXEB SENSITIVITY AND CYCLE STUDY}

As in the CXEB case the CICXEB Cycle was run with heatexchanger effectivenesses of $0.90,0.95$, and 0.975 . The result is included in Figure 5.9. Figure 5.10 shows the effect of decreasing $A$ from 0.92 to 0.90 . The effectiveness of the intercooler, unless noted otherwise, was always 0.90 .

Figure 5.11 shows the effect of increasing the cycle maximum temperature from $1373 \mathrm{~K}$ to $1393 \mathrm{~K}$ and then again to $1413 \mathrm{~K}$. Figure 5.12 shows the effect of decreasing the cycle maximum temperature from $1373 \mathrm{~K}$ to $1255 \mathrm{~K}$ and then again to $1144 \mathrm{~K}$. The original maximum cycle temperature was retained for the rest of the analysis.

Figure 5.13 contains the result of varying the overall pressure ratio from 2 to 12 . The maximum thermal efficiency of 0.52 occurs at a pressure ratio of 3.2 , with a specific power of 0.613 . The mass flow leakage at this pressure ratio is predicted to be 3.0 percent. The maximum specific power of 0.852 occurs at a pressure ratio of 9 ; the mass leakage for the latter is 8.2 percent.

As in the CXEB cycle, the final pressure ratio was selected by judgment between the pressure ratios for maximum thermal efficiency and for maximum specific power. The obtained CICXEB cycle is summarized below. 


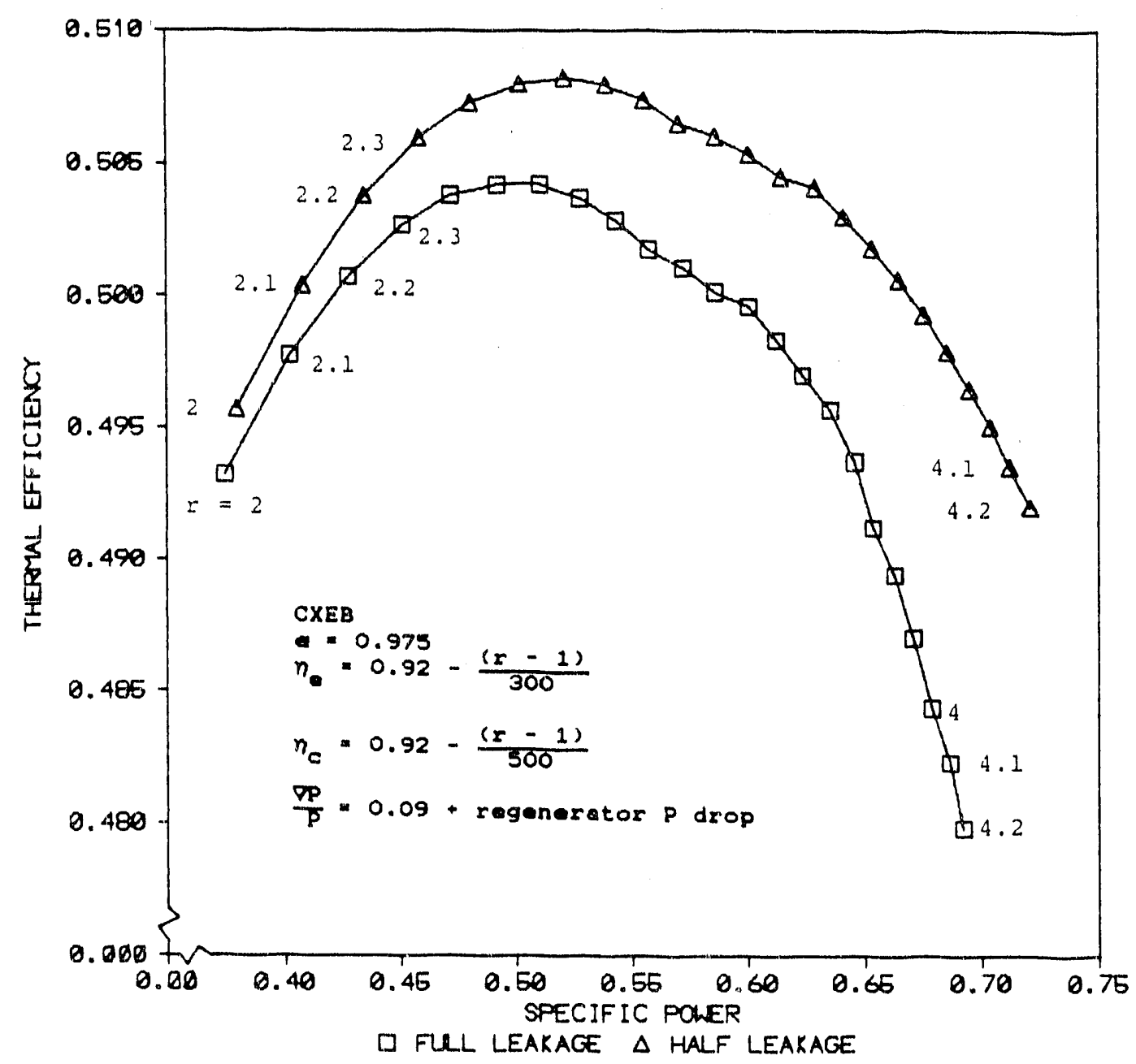

FIGURE 5.7 THERMAL EFFICIENCY VS SPECIFIC POWER FOR CXEB WITH REDUCED LEAKAGE 


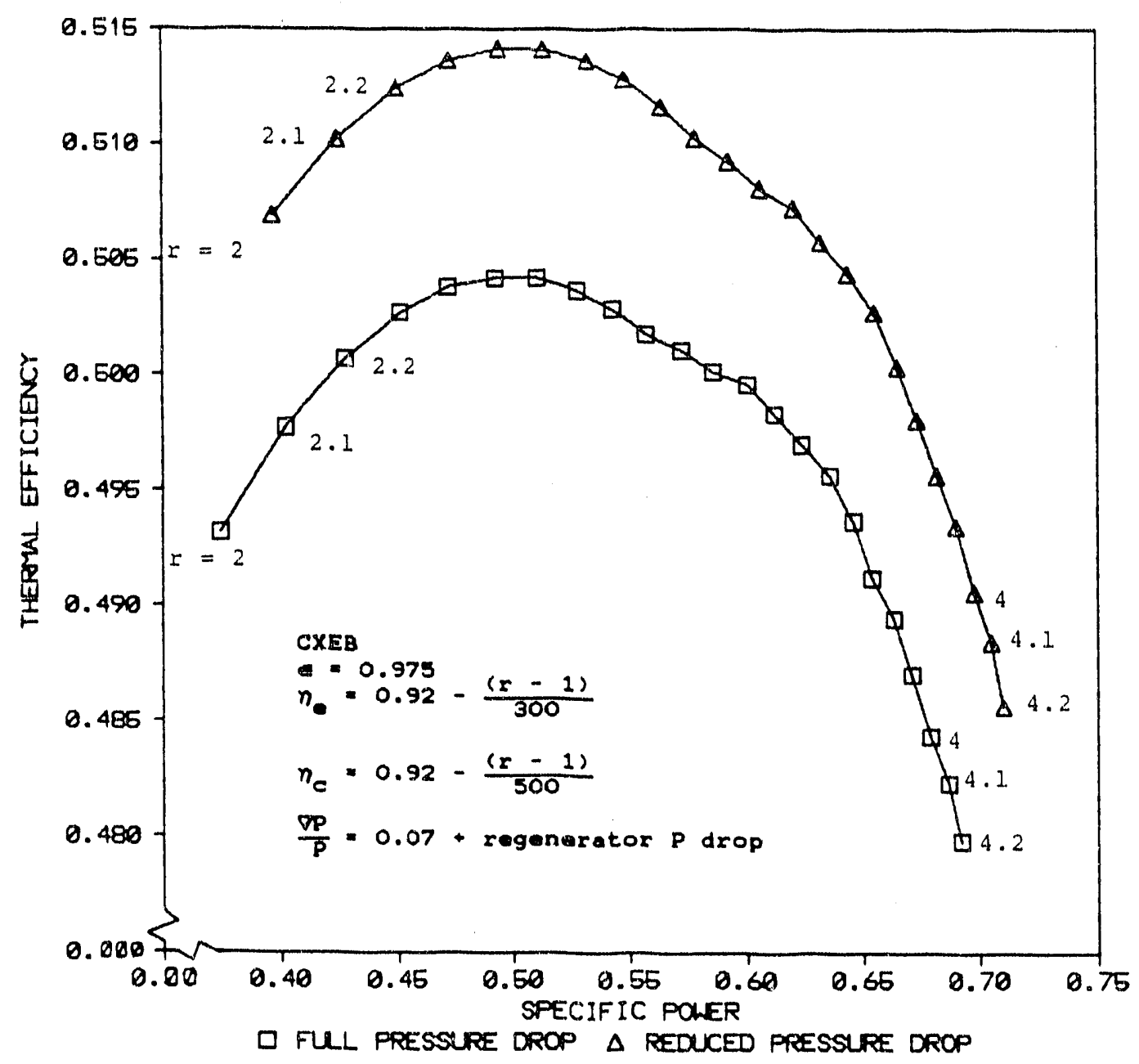

FIGURE 5.8 THERMAL EFFICIENCY VS SPECIFIC POWER FOR CXEB WITH PRESSURE-DROP REDUCTION 


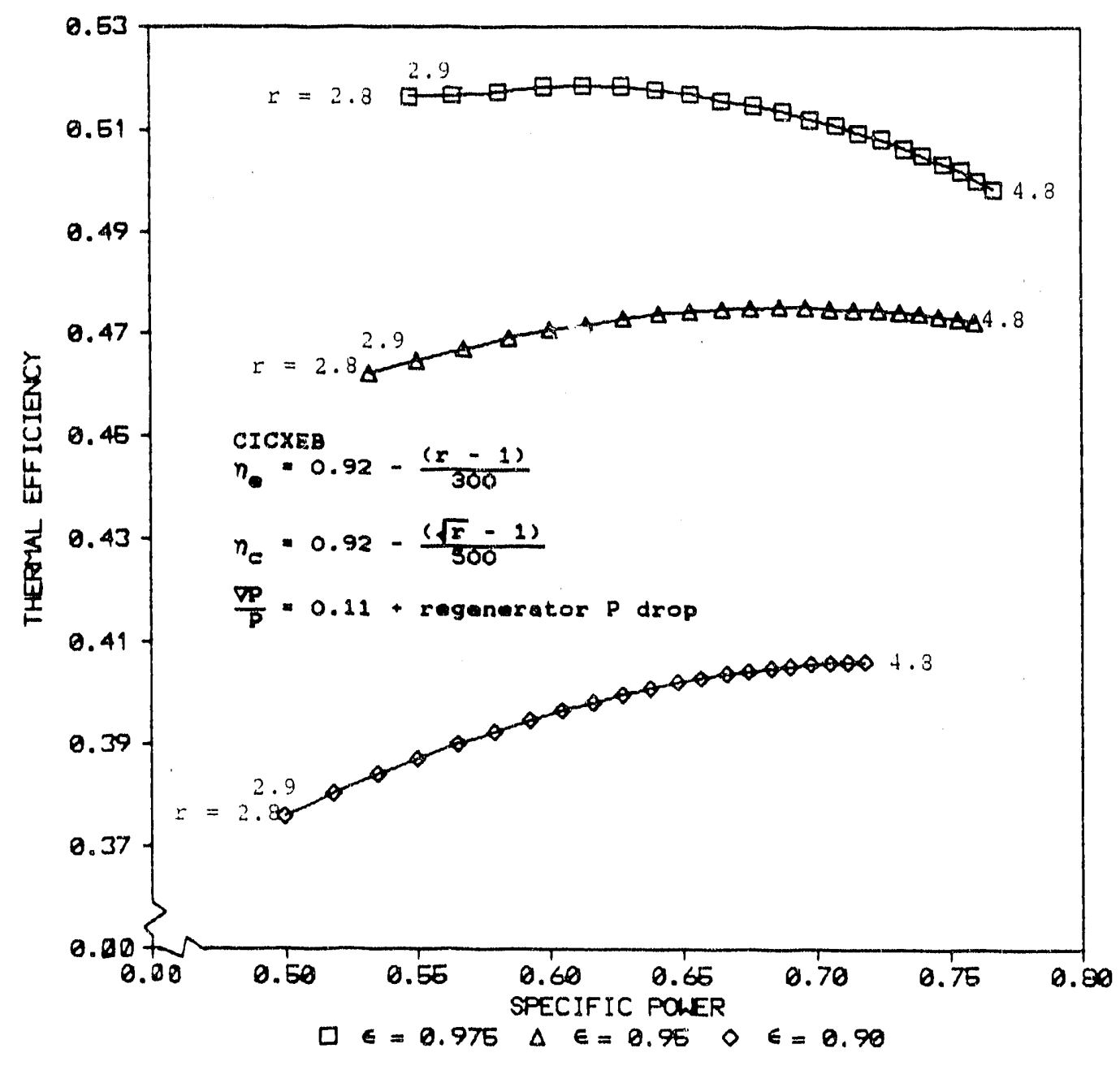

FIGURE 5.9 THERMAL EFFICIENCY VS SPECIFIC POWER FOR CICXEB FOR $0.90,0.95$, AND 0.975

EFFECTIVENESS 


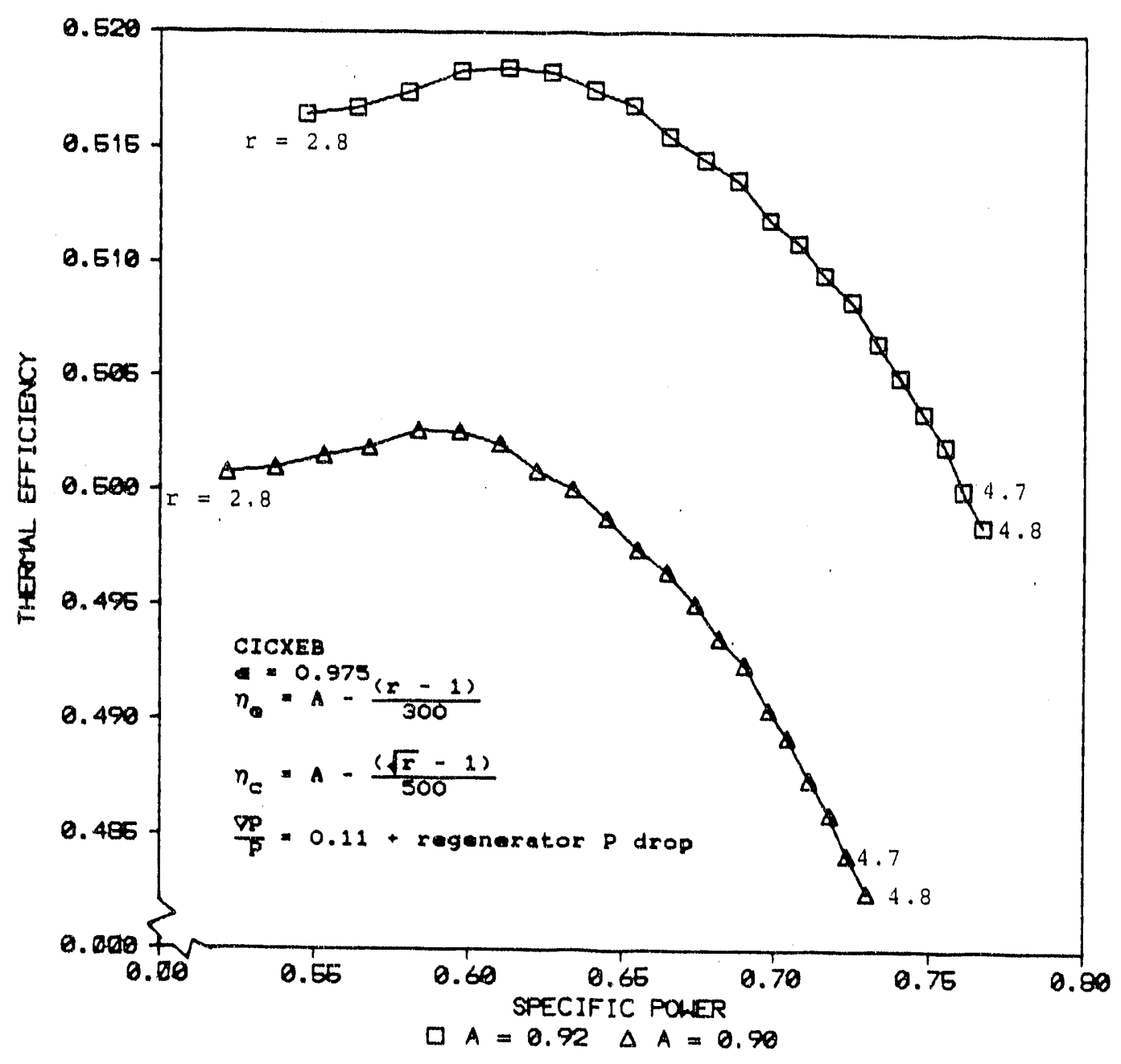

FIGURE 5.10 THERMAL EFFICIENCY VS SPECIFIC POWER FOR
CICXEB FOR POLY'ROPIC-EFFICIENCY CONSTANTS
0.92 AND 0.90 


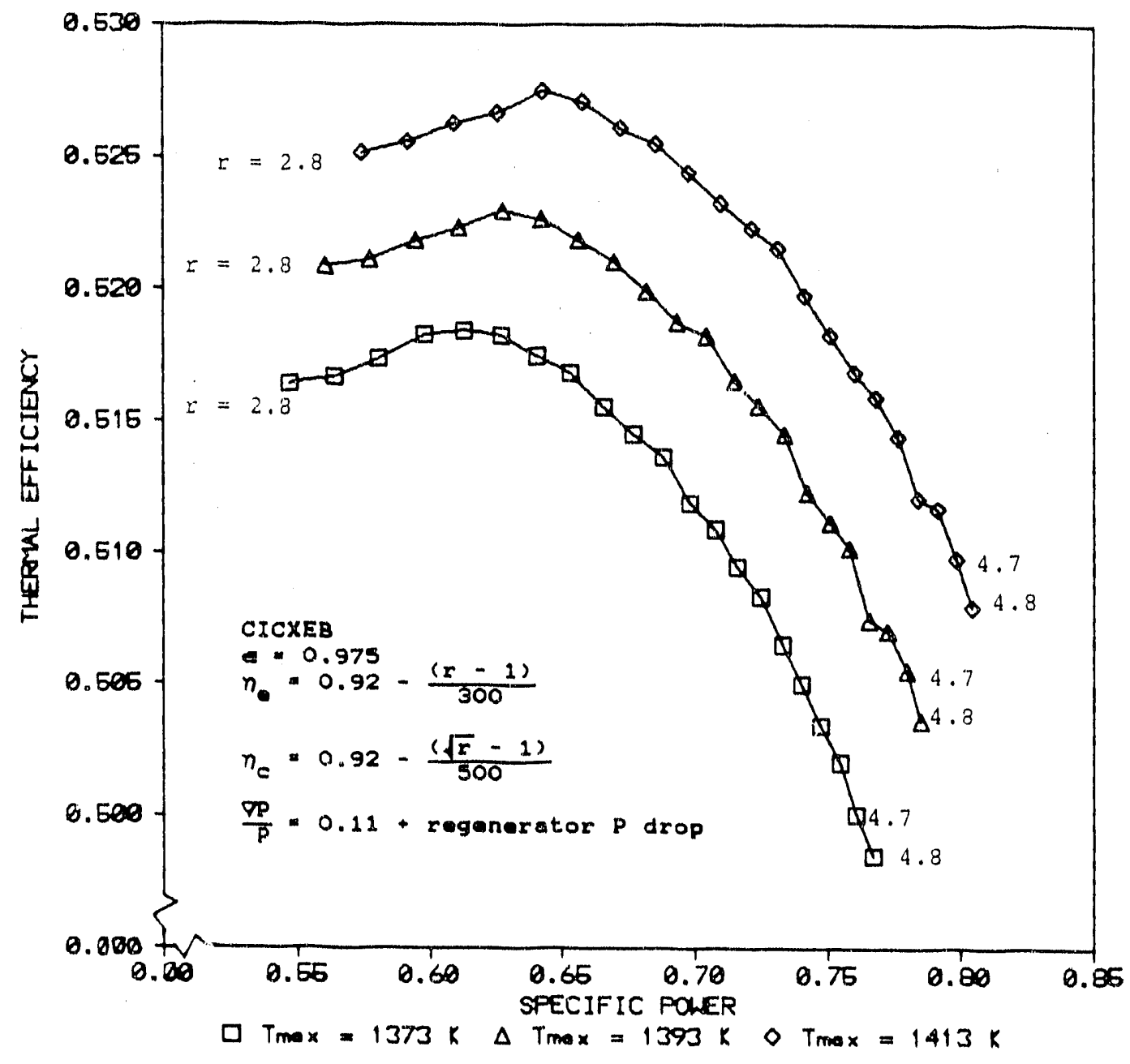

FIGURE 5.11 THERMAL EFFICIENCY VS SPECIFIC POWER FOR CICXEB FOR $T \max =1373 \mathrm{~K}, 1393 \mathrm{~K}$, AND $1413 \mathrm{~K}$ 


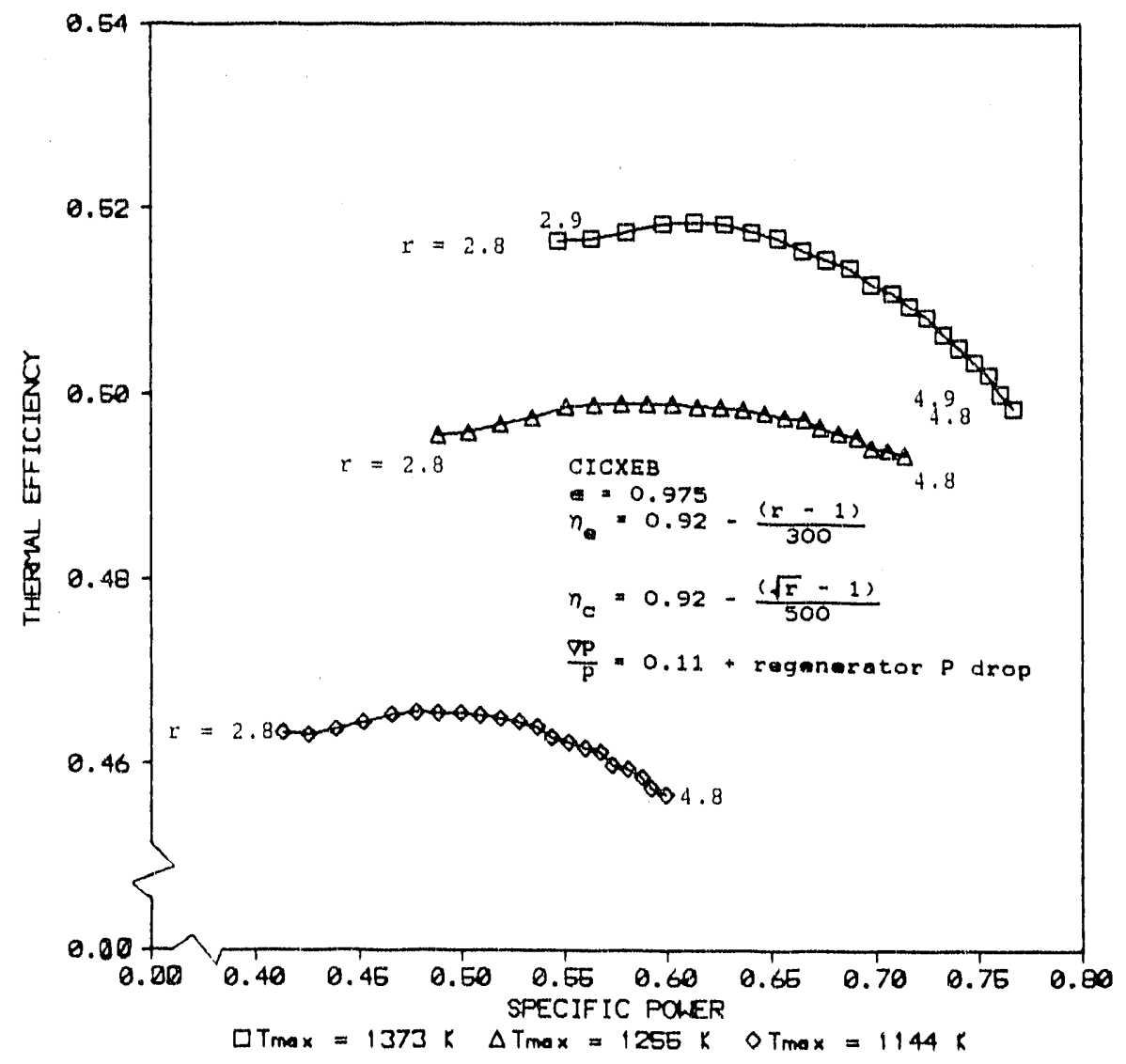

FIGURE 5.12 THERMAI EFFICIENCY VS SPECIFIC POWER FOR CICXEB FOR $T \max =1373 \mathrm{~K}, 1255 \mathrm{~K}$, AND $1144 \mathrm{~K}$ 


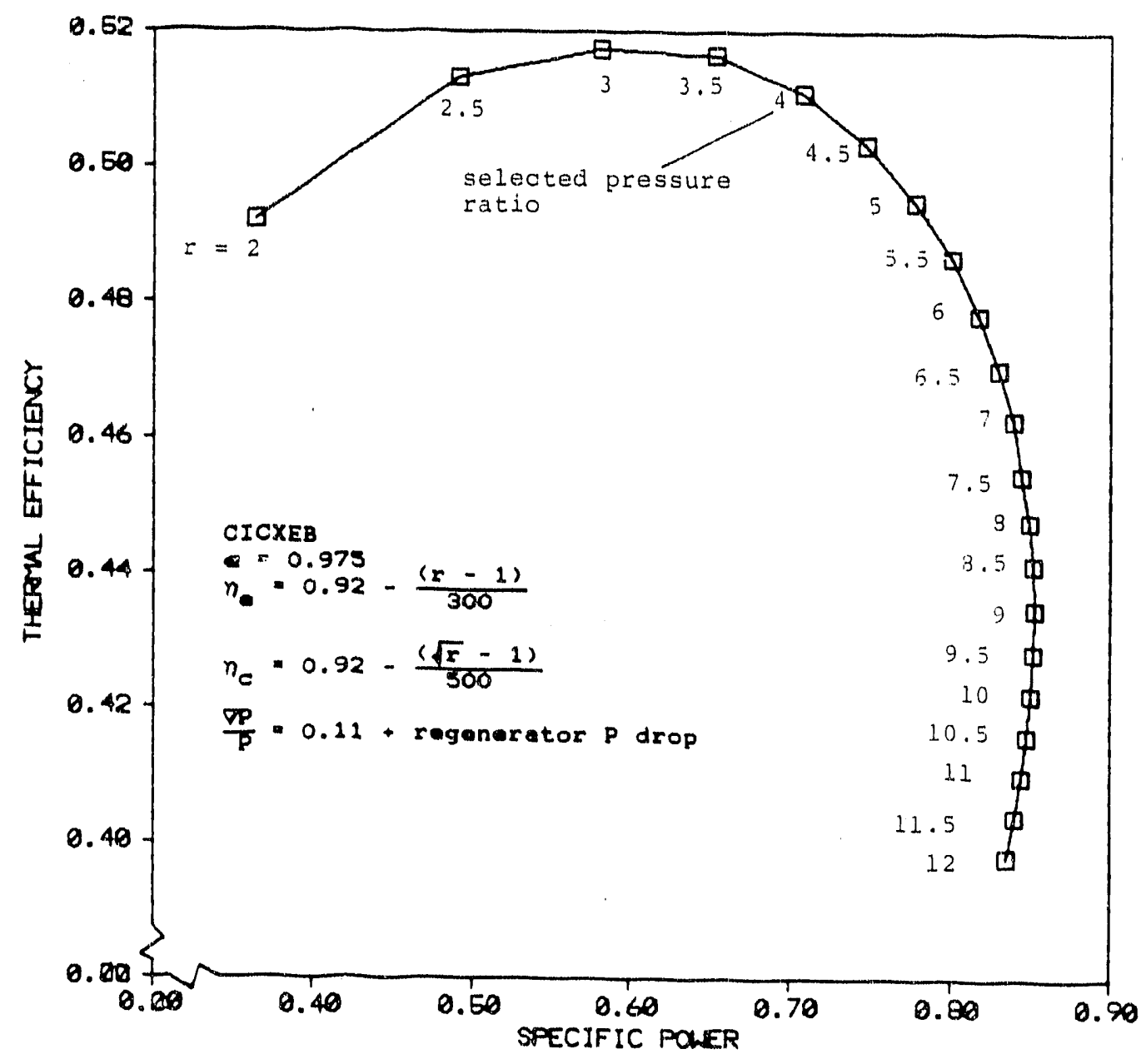

FIGURE 5.13 THERMAL EFFICIENCY VS SPECIFIC POWER FOR CICXEB CYCLE 


$\begin{array}{lll}\text { air mass-flow rate } & = & 9.4 \mathrm{~kg} / \mathrm{s} \\ \text { pressure ratio } & = & 4.0 \\ \text { thermal efficiency } & = & 0.51 \\ \text { mass-flow leakages } & = & 4.0 \text { percent } \\ \text { specific power } & =0.708 \\ \text { net power output } & = & 2.0 \mathrm{MW} \\ \text { pressure losses } & = & 14.6 \text { percent } \\ \text { coal consumption } & = & 0.11 \mathrm{~kg} / \mathrm{s} \\ \mathrm{T}_{\mathrm{T} 1}=300 \mathrm{~K} & \mathrm{~T}_{\mathrm{T} 5}=1345 \mathrm{~K} \\ \mathrm{~T}_{\mathrm{T} 2}=372 \mathrm{~K} & \mathrm{~T}_{\mathrm{T} 6}=1024 \mathrm{~K} \\ \mathrm{~T}_{\mathrm{T} 3}=307 \mathrm{~K} & \mathrm{~T}_{\mathrm{T} 7}= \\ \mathrm{T}_{\mathrm{T} 4}=381 \mathrm{~K} & \mathrm{~T}_{\mathrm{T} 8}=\end{array}$

Figure 5.14 shows a diagram of the CICXEB cycle with the different locations of interest numbered.

Figure 5.15 shows the result of reducing the mass-flow leakages by a factor of 2. An increase of about 2.4 percent, 1.2 points, occurs in the maximum thermal efficiency of the cycle. Figure 5.16 shows the effect of reducing the pressure losses from 0.11 (plus the drop through the regenerator) to 0.09 . The thermal efficiency increases again by about 2 percent ( 1 point). clearly, there is a tremendous incentive to reduce both pressure losses and, particularly, mass leakages in both the CXEB and the CICXEB cycles.

\subsection{SUMMARY}

We have selected the design pressure ratio for both the CXEB cycle and the CICXEB cycle. The choices made in both cases concerning component efficiencies and regenerator effectiveness are reasonable and should be possible within our present state of technology. A short stindy was also made to determine the effect the leakages, the component efficiencies, the maximum cycle temperature, the pressure drop, and the regenerator effectiveness have on the overall thermal efficiency. 


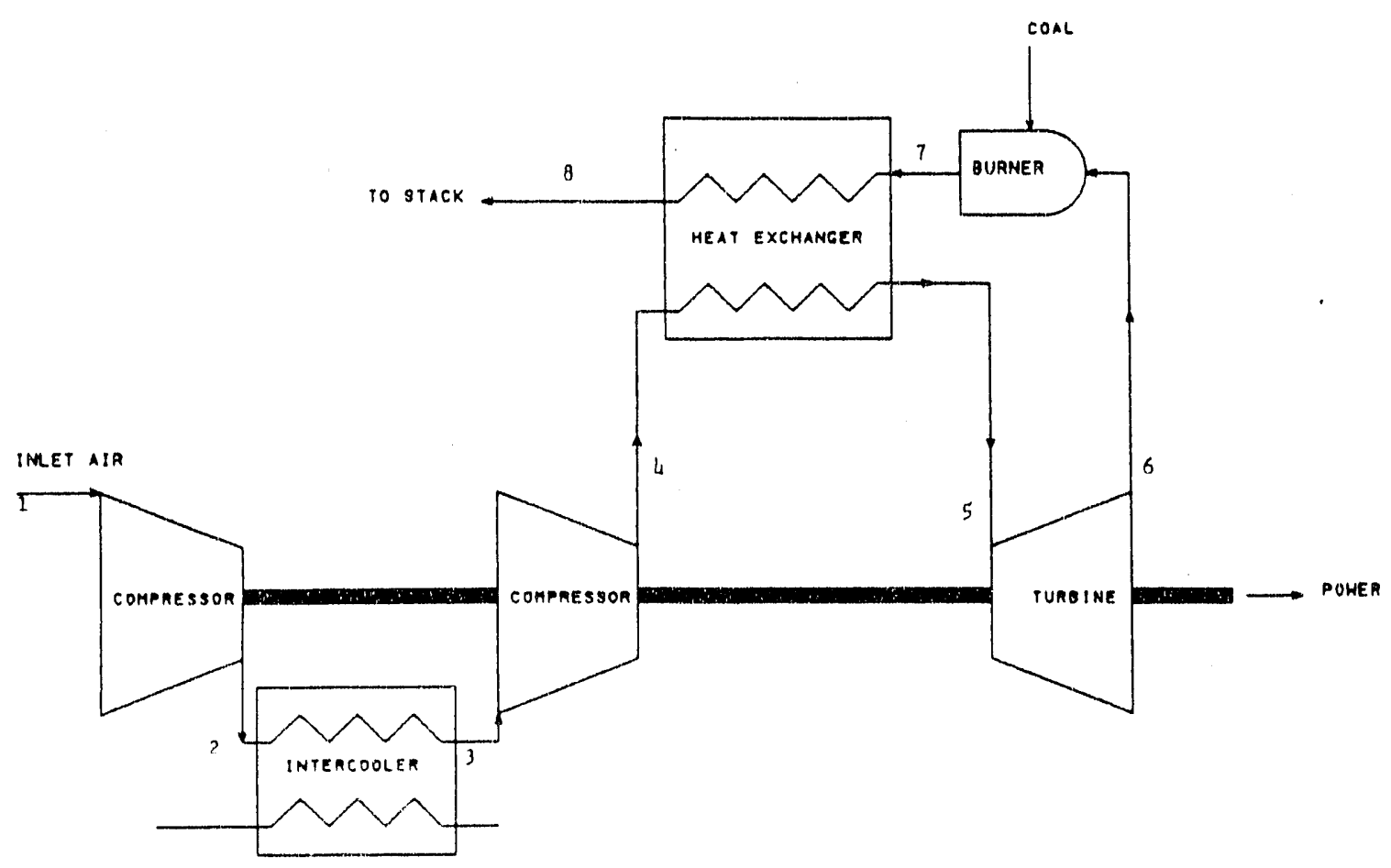

FIE"RE 5.14 CICXEB CYCLE 


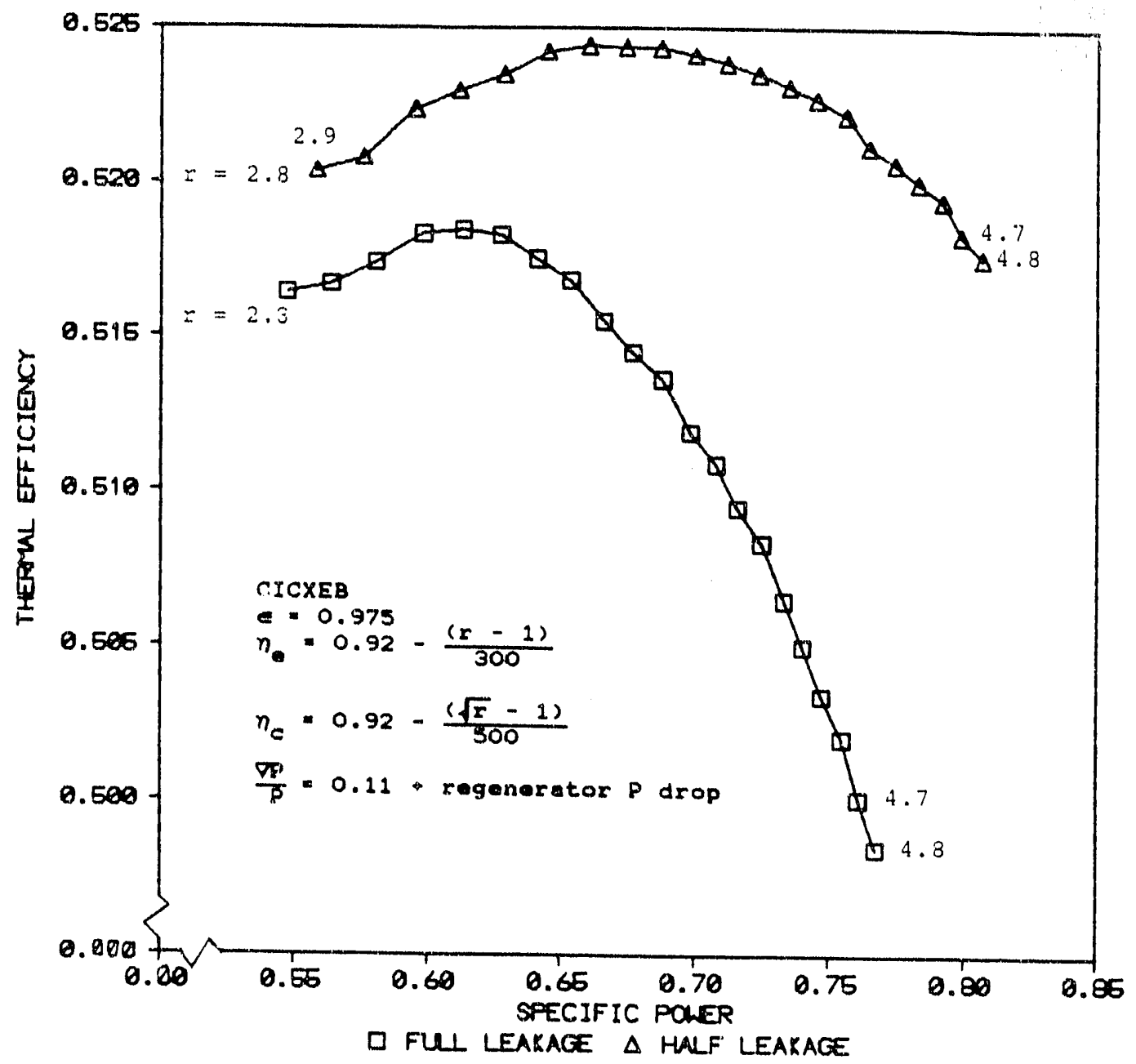

FIGURE 5.15 THERMAL EFFICIENCY VS SPECIFIC POWER FOR CICXEB WITH RFDUCED LEAKAGE 


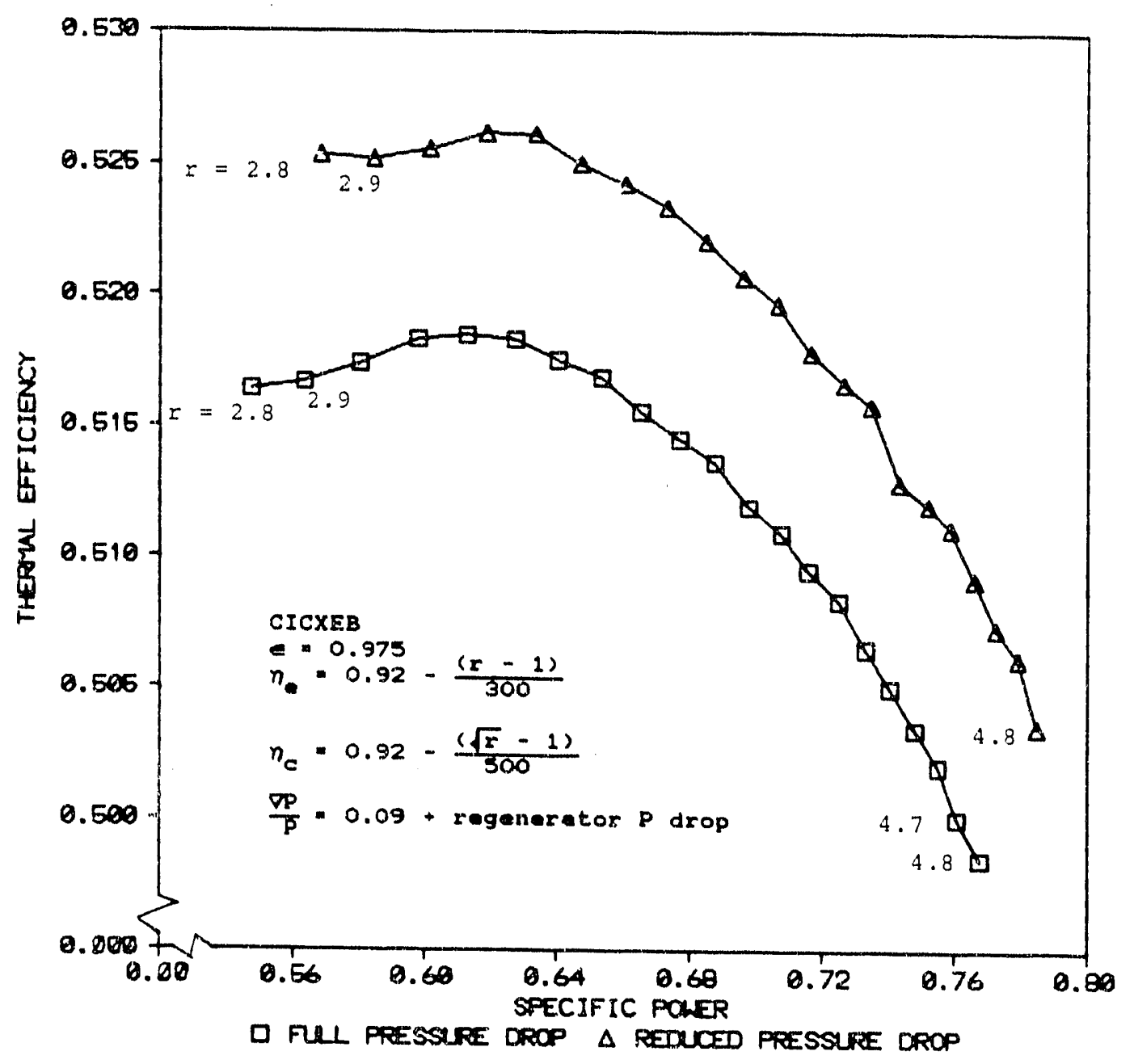

FIGURE 5.16 THERMAL EFFICIENCY VS SPECIFIC FOWER FOR CICXEB WITH PRESSURE-DROP REDUCTION 


\subsection{OFF-THE-SHELF ENGINE SELECTION AND CYCLE ANALYSIS}

The engine selected for conversion to a coal-fired exhaustheated cycle is the solar 5650 industrial gas turbine. This section outlines the engine-selection process, the engine features and performance, and the cycle analysis performed on the nonintercooled (NIC) and intercooled (IC) exhaust-heated versions of the Solar 5650. The selected effectiveness for the regenerators of the NIC and the IC exhaust-heated versions of the Solar 5650 was 0.975 for all the calculations.

\subsection{ENGINE SELECTION PROCESS}

Several criteria were established to narrow down the number of candidate engines to a manageable size. The criteria are based on requirements used to size the blue-sky engines [19] and minimize the conversion expense. The criteria are:

1. the power output must be approximately $2 \mathrm{MW}$,

2. the turbine-inlet temperature should be about $1300 \mathrm{~K}$ for high thermal efficiency with low ash stickiness,

3. performance and relevant design information must be readily available,

4. a low-pressure-ratio cycle is preferred,

5. a two-stage centrifugal compressor would facilitate intercooling, and

6. the engine must be developed or in production.

The matrix of candidate engines and their basic features shown in Table 6.1 was created from [55] and [56]. Numerous other engines were eliminated from consideration for various reasons. The Solar 5650 emerged as the clear choice for conversion to an exhaust-heated, coal-burning engine since few production engines are specifically designed for industrial, low-pressure-ratio operation. Although solar was reluctant to provide design and performance details, several non-proprietary reports were discovered to contain all the relevant information needed to carry out this preliminary design study. 
TABLE 6.1 CANDIDATE GAS TURBINES $[55,56]$

\begin{tabular}{|c|c|c|c|c|c|c|}
\hline $\begin{array}{l}\text { Manufacturer } \\
\text { model }\end{array}$ & $\begin{array}{c}\text { output } \\
(\mathrm{kW})\end{array}$ & $\begin{array}{l}\text { pressure } \\
\text { ratio }\end{array}$ & $\begin{array}{c}\text { flow } \\
(\mathrm{kg} / \mathrm{s})\end{array}$ & $\begin{array}{l}\text { TIT } \\
(\mathrm{K})\end{array}$ & $\begin{array}{l}\eta_{\text {th }} \\
\left(\frac{o}{8}\right)\end{array}$ & $\begin{array}{l}\text { speed } \\
(\text { rpm) }\end{array}$ \\
\hline $\begin{array}{l}\text { AVCO-Lycoming } \\
\text { TF25 }\end{array}$ & 1865 & 6.9 & 9.6 & -- & 23.0 & 14500 \\
\hline $\begin{array}{l}\text { Ruston } \\
\text { TA2500 }\end{array}$ & 1865 & 5.1 & 12.9 & 1124 & 21.2 & 7950 \\
\hline $\begin{array}{l}\text { IHI } \\
\text { IM } 100-4 \mathrm{G}\end{array}$ & 1110 & 8.4 & 6.4 & .1018 & 23.0 & 19500 \\
\hline $\begin{array}{l}\text { Kawasaki } \\
\text { M1A-03 }\end{array}$ & 1470 & 9.2 & 9.1 & -- & 20.1 & 22000 \\
\hline $\begin{array}{l}\text { Dresser-kand } \\
\text { KG2 }\end{array}$ & 1550 & 4.0 & 13.1 & 1100 & 16.7 & 18100 \\
\hline $\begin{array}{l}\text { Solar Gas Turbine } \\
\text { Centaur } \\
5650\end{array}$ & $\begin{array}{l}2945 \\
2768\end{array}$ & $\begin{array}{l}9.0 \\
6.5\end{array}$ & $\begin{array}{l}17.3 \\
17.2\end{array}$ & $\begin{array}{l}1150 \\
1241\end{array}$ & $\begin{array}{l}25.0 \\
33.5\end{array}$ & $\begin{array}{l}15700 \\
10620\end{array}$ \\
\hline $\begin{array}{l}\text { Yanmar } \\
\text { AT270C }\end{array}$ & 2400 & 8.1 & 15.4 & 1173 & -- & 1800 \\
\hline $\begin{array}{l}\text { Pratt \& Whitney } \\
\text { SPW } 124\end{array}$ & 1790 & 13.7 & 7.7 & -- & -- & 20000 \\
\hline $\begin{array}{l}\text { General Electric } \\
\text { LM500 }\end{array}$ & 3730 & -- & 15.0 & -- & -- & 7000 \\
\hline
\end{tabular}

\subsection{THE SOLAR 5650 FEATURES}

The Solar 5650 industrial gas turbine has been in development for twenty years. Solar and its parent company, caterpillar Tractor, designed the 5650 to compete with large diesel engines. Although the 5650 is not in full-scale produstion, several pilot sites currently use the 5650 for full or part-time power generation [57]. Figure 6.1 is a photograph of the solar 5650 engine.

The 5650 is a twin-shaft, low-pressure-ratio, recuperated gas turbine with multiple unique features. The overall dimensions of the engine are listed in Table 6.2. The modular engine components consist of a primary-surface recuperator, a two-stage centrifugal compressor, an annular combustor, a single-stage air-cooled gasproducer turbine, and a single-stage power turbine with variable inlet vanes (see Figure 6.2). The modular primary-surface foldedsheet-metal recuperator is the most innovative feature. The elements of the high-effectiveness recuperator can slide relative to each other thus avoiding thermal stress and strain. Unfortunately, this engine component cannot economically be used in the exhaust-heated design because it cannot withstand operation at turbine-inlet (rather than the usual turbine-exit) temperatures. Intercooling can be readily added to the two-stage centrifugal compressor. The variable-area power-turbine nozale allows guick 


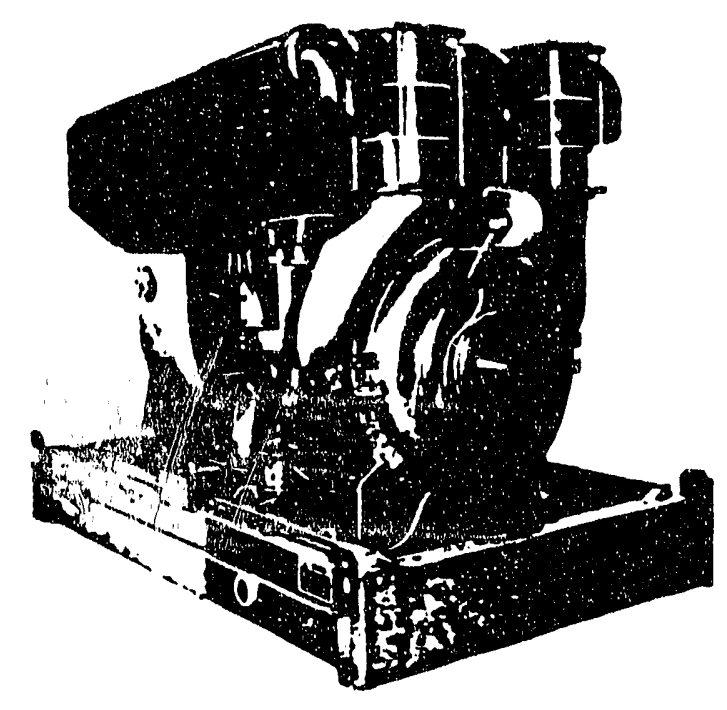

FIGURE 6.1 SOLAR 5650 INDUSTRIAL GAS TURBINE [58]

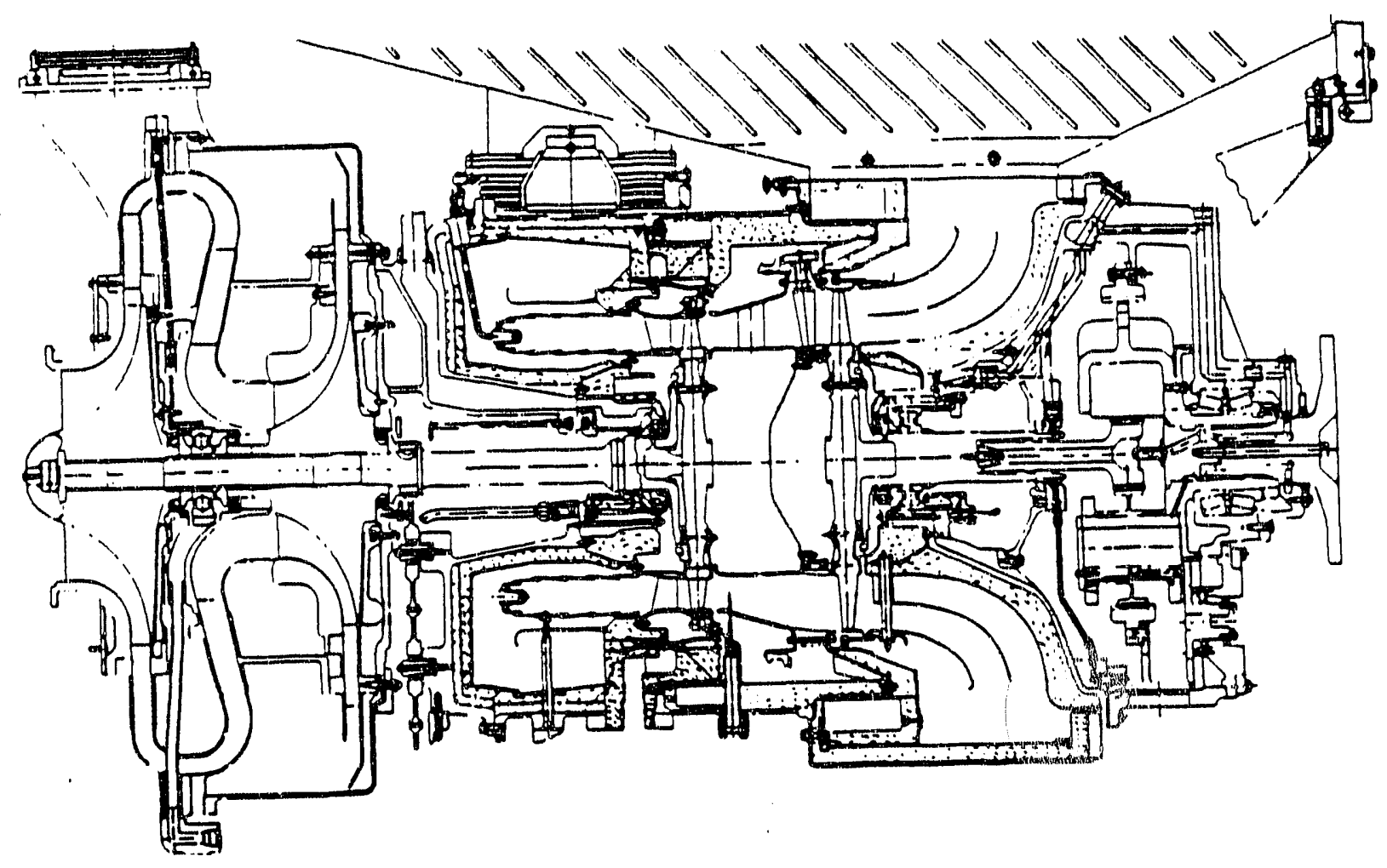

FIGURE 6.2 SOLAR 5650 ENGINE CROSS SECTION [59] 
load response and high part-power thermal efficiency. The turbine-inlet temperature is hot enough to attain high thermal efficiency yet low enough to reduce ash stickiness in the regenerator. The manufacturer claims that with improved turbine-blade cooling the 5650 is capable of a 98 degrees $K$ increase in turbine-inlet temperature while still meeting the 100,000-hour design life [57].

TABLE 6.2 ENGINE DIMENSIONS [59]

\begin{tabular}{ccc}
\hline physical dimensions & engine & $\begin{array}{c}\text { engine including } \\
\text { base }\end{array}$ \\
\hline length $(\mathrm{m})$ & 2.896 & 3.659 \\
width $(\mathrm{m})$ & 1.930 & 2.090 \\
height $(\mathrm{m})$ & 2.235 & 2.730 \\
weight $(\mathrm{kg})$ & 7,264 & 10,215 \\
\hline
\end{tabular}

\subsection{SOLAR 5650 PERFORMANCE}

Several sources of quoted design-point performance of the Solar 5650 appear to be in conflict $[52,57,59]$. The minor inconsistencies are attributed to the fact that the 5650 is currently not in production and is constantly undergoing new performance evaluations. The engine performance in Table 6.3 is believed to be from the most recent testing. The performance information on the intercooled version of the solar 5650 resulted from a recent study [52] on the effects intercooling would have on this engine and thus are the outcome of a mathematical analysis only, since no prototype intercooled engine has ever been built.

TABLE 6.3 SOLAR 5650 DESIGN-POINT PERFORMANCE $[52,57,59]$

\begin{tabular}{lcc}
\hline & NIC 5650 & IC 5650 \\
\hline thermal efficiency (\%) & 33.5 & 36.3 \\
power output (kW) & 2768 & 3520 \\
specific fuel consumption (kW/kg-hr) & 0.2506 & 0.2312 \\
mass flow (kg/s) & 17.22 & 18.77 \\
compressor pressure ratio & 6.37 & 6.96 \\
compressor speed (rpm) & 13,100 & 13,100 \\
turbine inlet temperature (K) & 1241.3 & 1241.3 \\
power-turbine speed (rpm) & 10620 & 10620 \\
\hline
\end{tabular}

\subsection{ANALYSIS OVERVIEW OF THE ENGINE CONVERSIONS}

The analytical procedure used to modify the NIC and the I.C base 5650 engines to become a NIC and an IC coal-fired exhaustheated engines, respectively, involved two primary tasks: the cycle analysis and the turbomachinery preliminary design. The cycle analysis determined the overall pexformance of the modified engines and set. the thermodynamic requirements to which the turbomachinery hach to be designed. A brief summaxy of the steps followed to carry out these tasks is included here. 
1. The design-point performance of the NIC 5650 and the predicted design-point performance of the IC 5650 were matched with the performance calculated by two modified versions of the CYCLE program, respectively [22].

2. The modified CYCLE programs were modified again to simulate the NIC and IC exhaust-heated coal-burning solar 5650 engines (NICEH 5650 and ICEH 5650 engines, respectively).

3. The optimal compressor pressure ratios for the NIC and the IC exhaust-heated coal-fired solar 5650 engines were determined.

4. Three alternatives to achieve the optimal performance of the NIC exhaust-heated 5650 were examined. The options are:

1. reduce the diameter of the stage-1 compressor impeller,

2. design al1-new turbomachinery, or

3. make no turbomachinery modifications, just decrease engine speed.

5. Three alternatives to achieve the optimal performance of the IC exhaust-heated 5650 were examined. The options are:

1. run the modified engine at its baseline pressure ratio,

2. design all-new turbomachinery, or

3. make no turbomachinery modifications, just decrease engine speed.

The first two tasks are explained in great detail in $[22,23]$. The results from the off-the-shelf design cycle analysis (the third task in the list above) are examined briefly in the next sections. The results obtained from examining the various options in tasks four and five are discussed in chapter eight.

The proposed conversion from the NIC and IC base 5650 engines to the NIC and IC exhaust-heated coal-burning 5650 engines would consist of five basic steps:

1. remove the existing annular combustor and insert smooth ducting in its place;

2. remove the primary-surface recuperator;

3. insert two ceramic rotary regenerators in parallel between the compressor and gas-producer turbine;

4. connect the inlet of a slagging combustor to the powerturbine exhaust and the outlet of the combustor to the rotary regenerator hot-side inlet; and 
5. duct the compressor-exit air into the regenerator coldside.

\subsection{NIC EXHAUST-HEATED 5650 CYCLE ANALYSIS}

The optimal cycle pressure ratio occurs between the points where thermal efficiency and specific power are near their peak values. These parameters cannot be maximized simultaneously, but they can be optimized approximately by constructing a curve of thermal efficiency versus specific power and choosing the pressure ratio at which the percentage decrease in thermal efficiency is greater than the percentage increase in specific power. Each point on this curve represents the design point of a different engine, but each engine has the same turbine-inlet temperature and mass flow rate.

Figure 6.3 shows the thermal efficiency versus specific power for the NIC exhaust-heated 5650 at different pressure ratios. The optimum pressure ratio for this engine was selected as 4.0 . The thermal efficiency at this pressure ratio is about $39 \%$ and the power output is around $2.5 \mathrm{MW}(2.491 \mathrm{MW})$ with an air mass-flow rate of $17 \mathrm{~kg} / \mathrm{s}$. Table 6.4 below summarizes the important thermodynamic properties of the air at different locations of interest.

TABLE 6.4 COMPONENT PERFORMANCE OF THE NIC EXHAUST-HEATED
SOLAR 5650 ENGINE




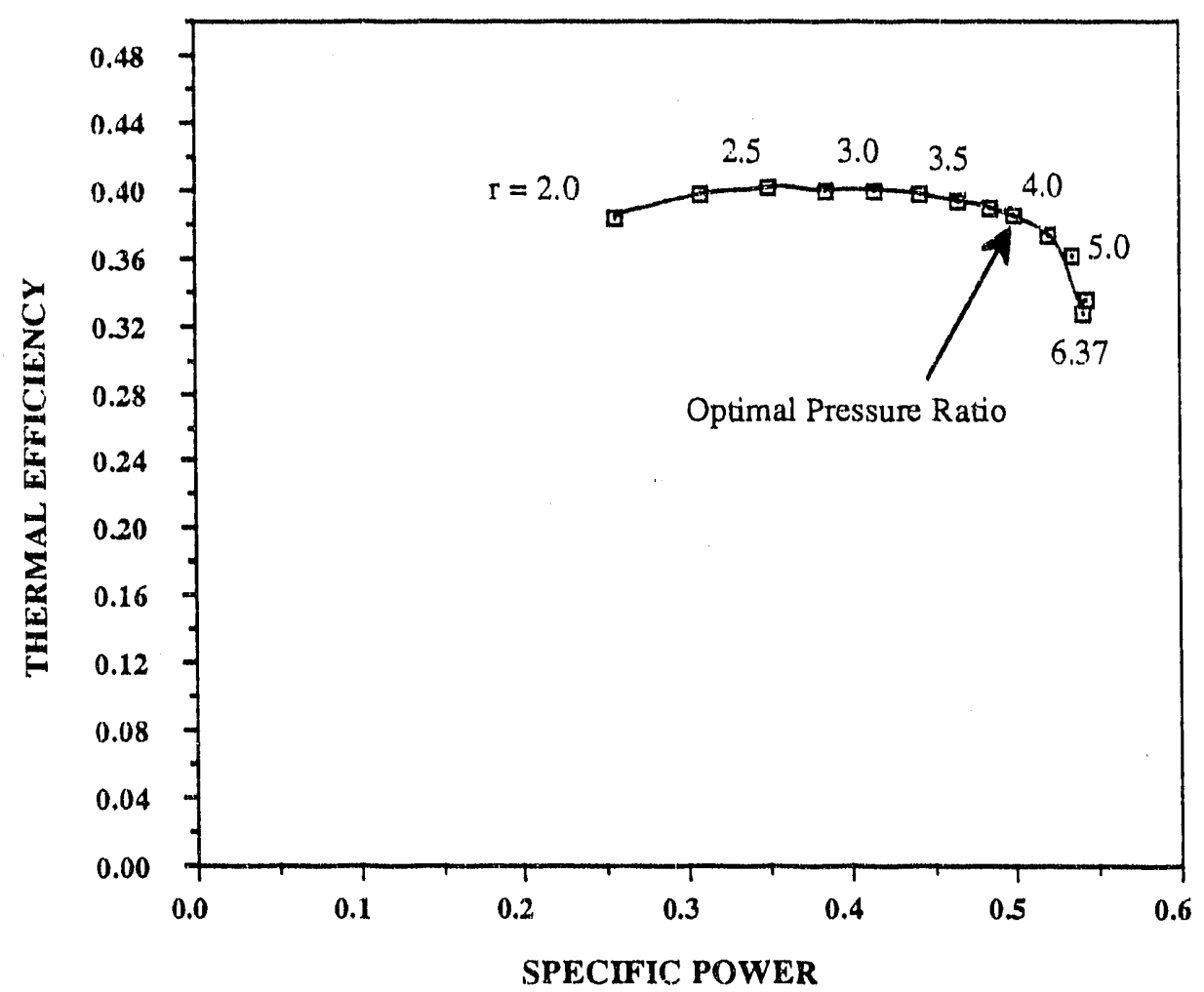

FIGURE 6.3 THERMAL EFFICIENCY VS SPECIFIC POWER FOR NICEH 5650

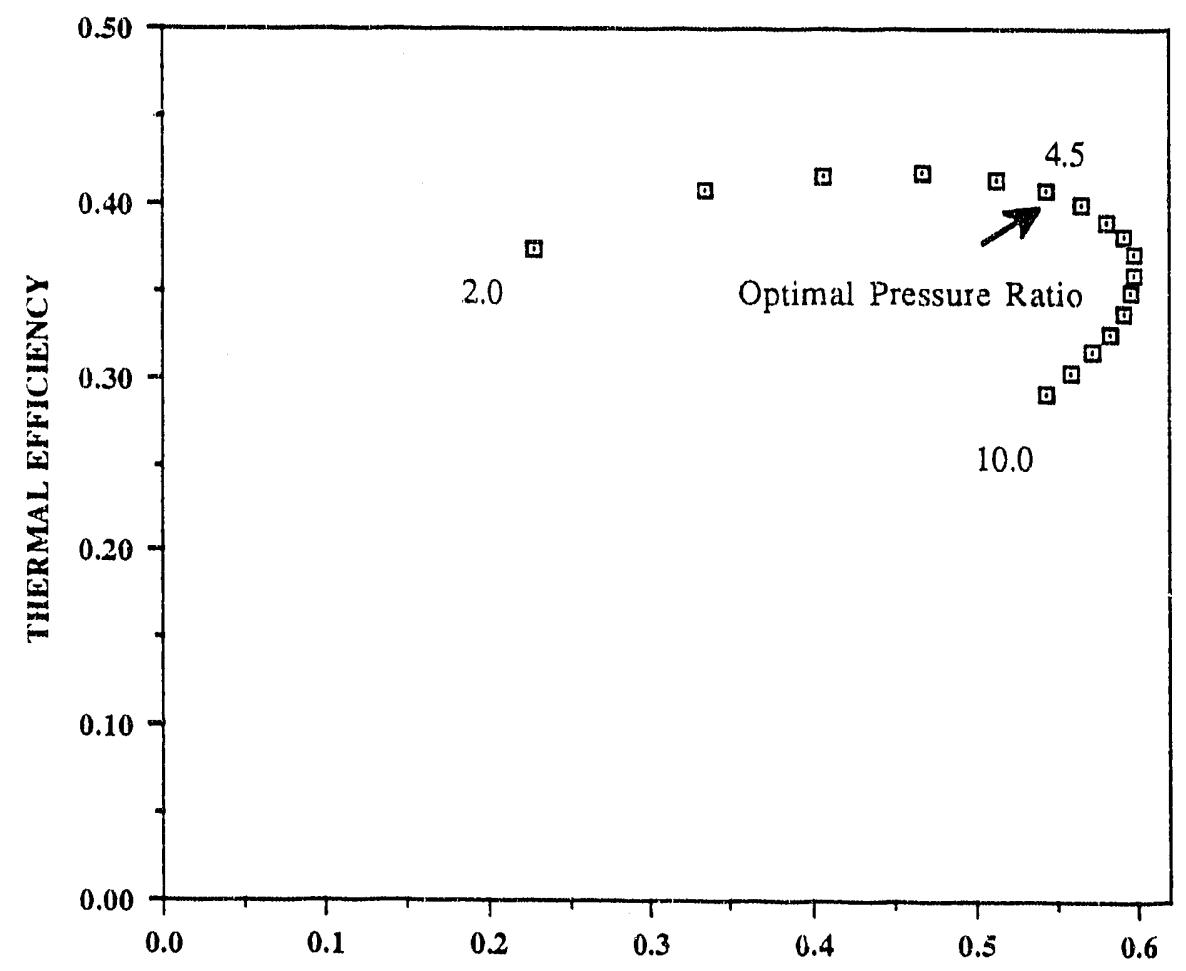

SPECIFIC POWER

FIGURE 6.4 THERMAL EFFICIENCY VS SPECIFIC POWER FOR ICERT 5650 
Referring to Table 6.3 it is evident that the thermal efficlency of the exhaust-heated NIC 5650 is about five percentage points higher than the NIC 5650, but the power output is approximately 11 percent smaller.

\subsection{IC EXHAUST-HEATED 5650 CYCLE ANALYSIS}

Figure 6.4 shows the thermal efficiency versus specific power for the IC exhaust-heated 5650 at different pressure ratios. The optimum pressure ratio for this engine was selected as 4.5 . The thermal efficiency at this pressure ratio is about $41 \%$ and the power output is around 3.0 MW (2.961 MW) with an air mass-flow rate of $19 \mathrm{~kg} / \mathrm{s}$. Table 6.5 below summarizes the important thermodynamic properties of the air at the inlet and exit of the various components.

TABLE 6.5 COMPONENT PERFORMANCE OF THE IC EXHAUST-HEATTED SOLAR 5650 ENGINE

\begin{tabular}{lrr}
\hline & inlet & exit \\
Compressor & & \\
total temperature (K) & 288.0 & 373.7 \\
flow (kg/s) & 18.77 & 18.77 \\
pressure (kPa) & 101.3 & 455.9 \\
Intercooler & & \\
total temperature (K) & 373.7 & 309.4 \\
Heat-Exuhanger Cold Side & & \\
total temperature (K) & 395.6 & 1243.3 \\
Combustor & & \\
total temperature (K) & 940.1 & 1265.0 \\
flow (kg/s) & 18.24 & 1086.1 \\
Gas-Producer Turbine & & 18.09 \\
total temperature (K) & 1243.3 & 234.5 \\
flow (kg/s) & 17.62 & \\
pressure (kPa) & 436.9 & 940.1 \\
Power Turbine & & 18.24 \\
total temperature (K) & 1075.4 & \\
flow (kg/s) \\
pressure (kPa)
\end{tabular}

\subsection{SUMMARY}

The cycle analysis and the engine selection process used for the off-the-shelf designs has been explained. The various options which have been listed for achieving the required optimum pressure ratio in the conversion of the 5650 to an exhaust-heated cycle shall be examined in some detail in chapter eight. 


\subsection{BLUE-SKY ENGINES}

Following the procedures outlined in the previous chapters, and using the data obtained from the CYCLE program the CXEB and CICXEB (the two blue-sky engines) compressors and turbines were sized. The design- and off-design-point performance for these components were estimated using the methods described in chapter three. We present here the major results obtained for the engine designs and performance estimations.

\subsection{CXEB ENGINE COMPONENTS}

\section{COMPRESSOR}

The compressor designed is an axial, six-stage unit, rotating at $18,400 \mathrm{rpm}$. The compressor requires about $1.4 \mathrm{MW}$ of power to operate. A constant-tip-diameter configuration was chosen $\left(d_{t}=\right.$ $332 \mathrm{~mm}$ ) with a reaction at the mean diameter near 0.5 (the changing blade height from stage to stage changes the reaction at mean diameter in the different blade rows since the SRE equation is used). Table 7.1 below shows the major results obtained in the compressor sizing.

TABLE 7.1 MAJOR SIZING RESULTS FOR THE CXEB COMPRESSOR

\begin{tabular}{l|c|c|c|c|c}
\hline Blade row & $\begin{array}{c}\text { Blade } \\
\text { height } \\
(\mathrm{mm})\end{array}$ & $\begin{array}{l}\text { Mean } \\
\text { diameter } \\
(\mathrm{mm})\end{array}$ & $\begin{array}{l}\text { Hub } \\
\text { diameter } \\
(\mathrm{mm})\end{array}$ & $\begin{array}{c}\text { Blade } \\
\text { chord } \\
(\mathrm{mm})\end{array}$ & $\begin{array}{c}\text { Number of } \\
\text { blades } \\
(--)\end{array}$ \\
\hline IGV & 80 & 264 & 173 & 40 & 21 \\
First rotor & 77 & 266 & 177 & 39 & 14 \\
First stator & 69 & 272 & 193 & 35 & 16 \\
Second rotor & 63 & 276 & 207 & 31 & 19 \\
Second stator & 57 & 281 & 218 & 28 & 21 \\
Third rotor & 52 & 284 & 228 & 26 & 23 \\
Third stator & 48 & 288 & 236 & 24 & 25 \\
Fourth rotor & 44 & 291 & 243 & 22 & 28 \\
Fourth stator & 41 & 294 & 250 & 21 & 30 \\
Fifth rotor & 38 & 296 & 256 & 19 & 33 \\
Fifth stator & 36 & 298 & 298 & 18 & 35 \\
Sixth rotor & 33 & 300 & 265 & 17 & 38 \\
Sixth stator & 31 & 302 & 270 & 16 & 41 \\
OGV & 30 & 304 & 272 & 15 & 64 \\
\hline
\end{tabular}

Table 7.2 below summarizes the velocity-diagram information for each blade row at the mean diameter for the CXEB compressor. 
TABLE 7.2 VELOCITY-DIAGRAM DATA FOR THE COMPRESSOR

\begin{tabular}{|c|c|c|c|c|c|c|}
\hline \multirow[t]{2}{*}{ Blade row } & \multirow{2}{*}{$\begin{array}{l}\text { Inlet } \\
\text { angle } \\
\text { (deg) }\end{array}$} & \multirow{2}{*}{$\begin{array}{l}\text { outlet } \\
\text { angle } \\
\text { (deg) }\end{array}$} & $C_{z 1}$ & $c_{z 2}$ & \multirow{2}{*}{$\begin{array}{l}\mathrm{Rn} \\
(--)\end{array}$} & \multirow{2}{*}{$\begin{array}{l}\psi \\
(--)\end{array}$} \\
\hline & & & \multicolumn{2}{|c|}{$(\mathrm{m} / \mathrm{s})$} & & \\
\hline IGV & 0 & 24 & 183 & 190 & --- & -- \\
\hline First rotor & 42 & 27 & 190 & 194 & .50 & -.32 \\
\hline First stator & 40 & 24 & 194 & 188 & --- & --- \\
\hline Second rotor & 44 & 30 & 188 & 192 & .52 & -.30 \\
\hline second stator & 39 & 24 & 192 & 187 & $-\cdots$ & ---- \\
\hline Third rotor & 46 & 32 & 187 & 191 & .54 & -.29 \\
\hline Third stator & 39 & 24 & 191 & 187 & --- & --- \\
\hline Fourth rotor & 47 & 34 & 187 & 190 & .56 & -.26 \\
\hline Fourth stator & 39 & 24 & 190 & 186 & --- & ---- \\
\hline Fifth rotor & 48 & 35 & 186 & 189 & .57 & -.25 \\
\hline Fifth stator & 39 & 24 & 189 & 186 & --- & --- \\
\hline Sixth rotor & 48 & 37 & 186 & 188 & .58 & -.25 \\
\hline sixth stator & 39 & 24 & 188 & 185 & --- & --- \\
\hline OGV & 24 & 0 & 185 & 183 & -- & ---- \\
\hline
\end{tabular}

Table 7.2 shows the inlet and outlet angles to each blade row at the mean diameter (the angles are absolute for the stators and relative for the rotors--the sign convention being used is as shown in Figure 2.4). The axial velocity going through the blades $\left(C_{z}\right.$ ) changes from inlet to outlet (i.e., it is not a simple vector diagram) because of the way the compressor was sized and because the blade height decreases slightly from blade inlet to outlet (the data presented in Table 7.1 are average values). Since simple velocity diagrams were used at the compressor tip and the SRE equation was used to obtain the velocity diagrams at the mean diameter and at the hub the resulting velocity diagrams everywhere except at the tip are therefore not of the simple type.

The selected blade type from the Mellor-NASA charts (as shown in [6]) is 65-8-10 with a solidity (blade spacing divided by blade chord) of 1.5 for all the blade rows. Figure 7.1 shows the Mellor chart for blade 65-8-10.

\section{TURBINE}

The chosen turbine configuration is a three-stage unit having a mean-diameter reaction and load coefficient near 50 percent and 1.0 respectively. The turbine produces about 3.4 MW of gross power. A constant-hub-diameter configuration was chosen $\left(d_{h}=331\right.$ $\mathrm{mm})$. The turbine is designed to rotate, at design point, at $18,400 \mathrm{rpm}$.

Table 7.3 below summarizes a few main reslilts obtained in the turbine sizing. 


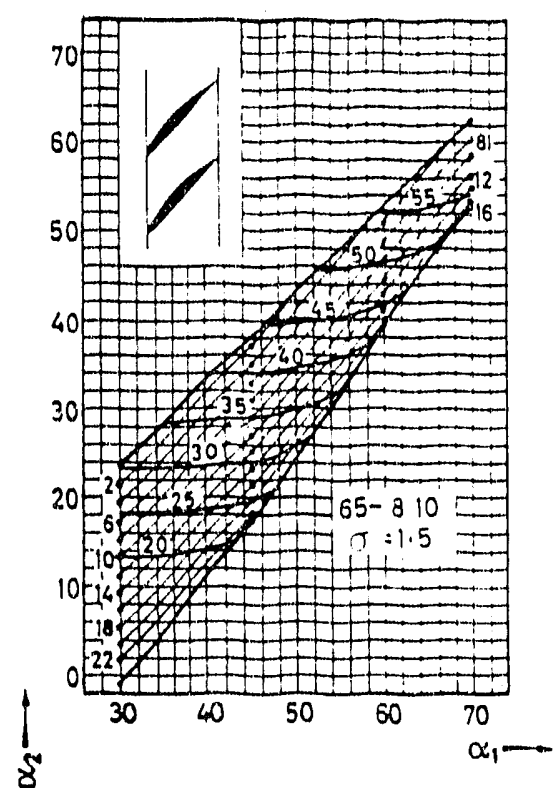

FIGURE 7.1 NACA 65-8-10 COMPRESSOR-BI_ADE PERFORMANCE GRAPH [76] 
TABIJE 7.3 MAJOR SIZING RESULTS FOR THE CXEB TURBINE

\begin{tabular}{l|c|c|c|c|c}
\hline Blade row & $\begin{array}{c}\text { Blade } \\
\text { height } \\
(\mathrm{mm})\end{array}$ & $\begin{array}{l}\text { Mean } \\
\text { diameter } \\
(\mathrm{mm})\end{array}$ & $\begin{array}{l}\text { Tip } \\
\text { diameter } \\
(\mathrm{mm})\end{array}$ & $\begin{array}{c}\text { Blade } \\
\text { chord } \\
(\mathrm{mm})\end{array}$ & $\begin{array}{c}\text { Number of } \\
\text { blades }\end{array}$ \\
\hline First stator & 44 & 378 & 419 & 15 & 106 \\
First rotor & 49 & 383 & 429 & 16 & 87 \\
Second stator & 55 & 390 & 44.2 & 18 & 65 \\
Sacond rotor & 62 & 397 & 454 & 21 & 65 \\
Third stator & 69 & 406 & 469 & 23 & 53 \\
Third rotor & 78 & 416 & 486 & 26 & 49 \\
\hline
\end{tabular}

Table 7.4 below summarizes the velocity-diagram information for each blade row in the turbine.

TABLE 7.4 VELOCITY-DIAGRAM INFORMATION FOR THE TURBINE

\begin{tabular}{l|c|c|c|c|c|c}
\hline Blade row & $\begin{array}{c}\text { Inlet } \\
\text { angle }\end{array}$ & $\begin{array}{l}\text { outlet } \\
\text { angle }\end{array}$ & $C_{z 1}$ & $C_{z 2}$ & $R n$ & $\psi$ \\
\cline { 4 - 5 } & (deg) & (deg) & \multicolumn{2}{|c|}{$(\mathrm{m} / \mathrm{s})$} & $(--)$ & $(--)$ \\
\hline First stator & 0 & 47 & 351 & 331 & --- & --- \\
First rotor & 3 & 41 & 331 & 347 & .48 & 0.7 \\
Second stator & 12 & 46 & 347 & 327 & --- & --- \\
Second rotor & 7 & 42 & 327 & 346 & .51 & 0.7 \\
Thirä stator & 12 & 46 & 346 & 321 & --- & --- \\
Third rotor & 11 & 44 & 321 & 345 & .56 & 0.6 \\
\hline
\end{tabular}

Table 7.4 shows the inlet and outlet angles to each blade row at the mean diameter (the angles are absolute for the stators and relative for the rotors).

The use of three stages resulted in a rather low blade speed which in turn reduces the steady-state stresses and the potential of damage from foreign objects as was specified in [5]. The low stresses experienced by the blades opens the possibility of using new blade materials, such as ceramics, lith higher reliability tilan would be achieved at more normal blade speeds.

\section{CERAMIC REGENERATOR}

As mentioned earlier the CYCLES program sized the ceramic regenerator required to transfer the necessary heat. The arrangement selected is two regenerators in parallel: thus each would receive half of the air flow from the compressor and half of the gas flow from the combustor. Core 503A has been arbitrarily selected from the three available core types. However, as will be shown later, sizing calculations were done for all three cores to 
compare and contrast them.

The list below summarizes the sizing data obtained from the CYCLE program for each 503A regenerator in the CXEB cycle:

$\begin{array}{ll}\text { Diameter : } & 3.1 \mathrm{~m} \\ \text { Thickness: } & 0.16 \mathrm{~m} \\ \text { Cold-side annular area : } & 1.47 \mathrm{~m}^{2} \\ \text { Hot-side annular area : } & 4.32 \mathrm{~m}^{2} \\ \text { Mass : } & 756 \mathrm{~kg} \\ \text { Rotation : } & 1.26 \mathrm{rpm} \\ \text { Motor Power : } & 3.2 \mathrm{~kW} \\ \text { Radial seal leakage : } & 0.2 \mathrm{~kg} / \mathrm{s} \\ \text { Circumferential seal leakage : } & 0.09 \mathrm{~kg} / \mathrm{s}\end{array}$

The regenerator outer circumference is surrounded by a gear that is driven by a pinion attached to an electric motor. The gear and pinion would have a tungsten-carbide coating for wear resistance [32]. The supporting of the heat exchanger could be as described in Hagler [32] with two geared rollers at the base 30 degrees apart from the vertical with an additional roller immediately opposite the first two to help locate the regenerator.

Table 7.5 below describes the data obtained at design-point for the three different regenerator core types.

TABLE 7.5 REGENERATOR SIZE FOR DIFFERENT CORE TYPES

\begin{tabular}{lc|c|c|c}
\hline core No. & $(--)$ & $503 \mathrm{~A}$ & $504 \mathrm{~A}$ & $505 \mathrm{~A}$ \\
\hline mass & $(\mathrm{kg})$ & 756 & 413 & 1044 \\
diameter & $(\mathrm{m})$ & 3.1 & 3.2 & 2.9 \\
thickness & $(\mathrm{m})$ & 0.16 & 0.06 & 0.35 \\
time of rotation & $(\mathrm{s})$ & 48 & 26 & 66 \\
\hline
\end{tabular}

Core 504A has the smallest mass since it has the smallest hydraulic diameter $(327 \mu \mathrm{m}$ compared to $511 \mu \mathrm{m}$ and $753 \mu \mathrm{m}$ for cores $503 \mathrm{~A}$ and 505A respectively). However, as can be seen from Table 7.5, the diameter is slightly larger and, what may be worse, the thickness is very small for the 504A. The only way to increase the thickness of the regenerator using this core type would be to allow the pressure drops on the cold and hot sides to increase which woulit penalize the overall thermal efficiency.

A better selection for the final design would probably be core 505A since it has a larger hydraulic diameter. The larger hydraulic diameter may be beneficial in prolonging the life of the regenerator in the presence of sticky coal-fly-ash particles. With this ir mind we generatea theoretically other core geometries with larger hydraulic diameters [60] (Core 505A has one of the largest hydraulic diameters available commercially). Table 7.6 
below summarizes the sizes obtained at design-point for each of the theoretical matrix-core geometries in the CXEB engine.

TABLE 7.6 EFFECT OF INCREASING HYDRAULIC DIAMETER ON THE REGENERATOR DIAMETER AND THICKNESS FOR THE CXEB ENGINE

\begin{tabular}{ll|c|c|c}
\hline hydraulic diameter & $\begin{array}{c}\text { regenerator } \\
\text { outer diam } \\
(\mathrm{m})\end{array}$ & $\begin{array}{c}\text { regenerator } \\
\text { thickness } \\
(\mathrm{m})\end{array}$ & porosity \\
\hline $504 \mathrm{~A})$ & 0.327 & 3.25 & 0.065 & 0.644 \\
$503 \mathrm{~A}$ & 0.511 & 3.10 & 0.158 & 0.708 \\
$505 \mathrm{~A}$ & 0.753 & 2.93 & 0.347 & 0.794 \\
& 1.000 & 3.11 & 0.608 & 0.700 \\
1.100 & 3.11 & 0.736 & 0.700 \\
1.200 & 3.11 & 0.876 & 0.700 \\
& 1.500 & 3.11 & 1.368 & 0.700 \\
2.000 & 3.11 & 2.432 & 0.700 \\
2.250 & 3.11 & 3.078 & 0.700 \\
5.000 & 3.11 & 15.201 & 0.700 \\
\hline
\end{tabular}

The data in Table 7.6 suggests that the largest feasible hydraulic diameter for the regenerator is probably between 1 and $2 \mathrm{~mm}$. For this preliminary design we a:e recommending the core 505A, which exists commercially. Most of the analysis, however, was done using core 503A. Thus the drawings of the engines that are included in this report show a regenerator size based on the results obtained for core 503A.

\section{COAL COMBUSTOR}

When this work was proposed it was stated that "the engine and cycle as described can use the best available technology for both combustion and sulfur removal", and these aspects were considered to be outside the scope of the work proposed.

We are, however, suggesting the use of a combustor similar to the Allison/Westinghouse or Solar slagging-combustors plus hotgas-cleanup systems, also funded by DOE/METC. These promise to produce an outlet stream substantially free of particulates and with greatly reduced alkali content. For the economic assessment we have assumed the exhaust-heated units (both blue-sky and offthe-shelf) are burning pulverized coal (PC).

\section{CXEB GAS-TURBINE ENGINE}

Figure 7.2 shows the CXEB engine cross section. As is usual, only one side of the engine is shc a since it is symmetric with respect to the center line. Only one of the regenerators is shown in the figis:--the flows are divided equally between the two heat: 


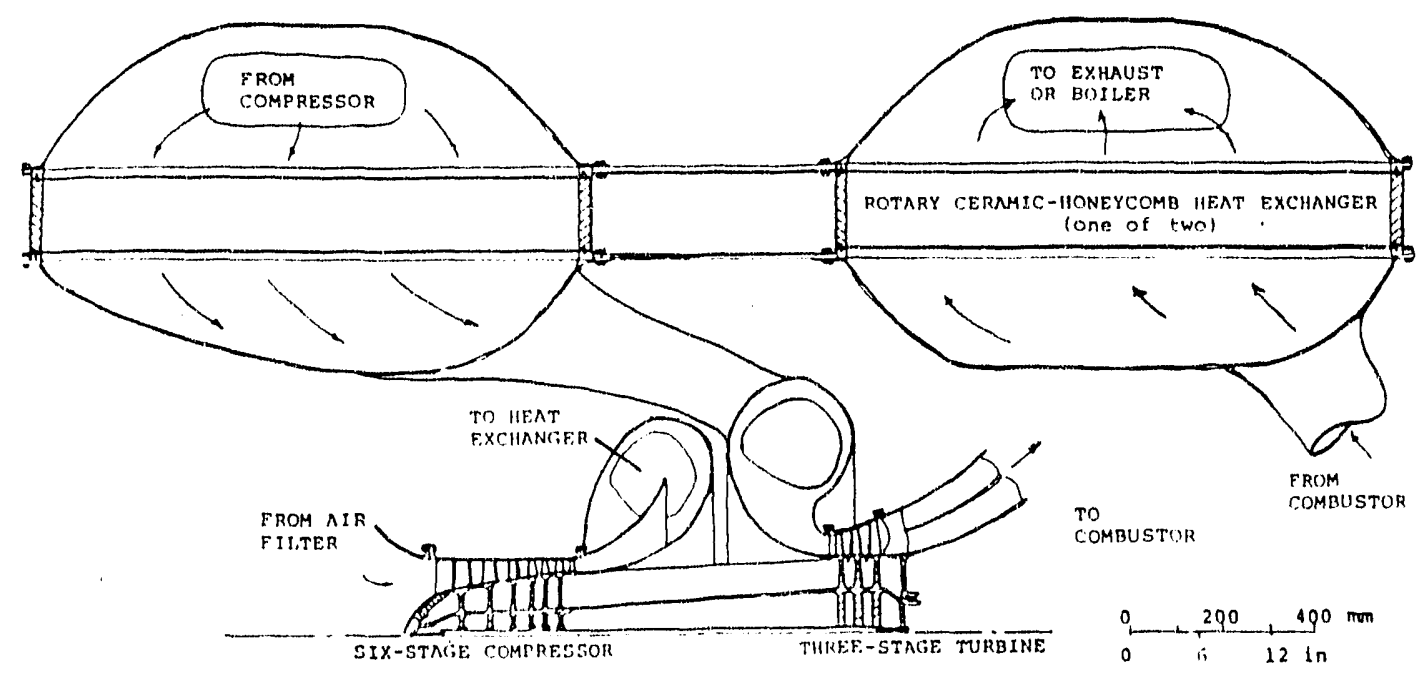

FIGURE 7.2 CROSS-SECTIONAL SKETCH OF CXEB ENGINE 
exchangers. If a smaller heat exchanger is desired more than two regenerators can be used, e.g. four, six, etc. This would, however, increase the losses due to leakages. The regenerator matrix shown is core 503A.

The weight of the CXEB engine was estimated using a modified version of the method outlined in [61] to be about $1,712 \mathrm{~kg}(3,774$ 1b). The method in [61] gives very low values of engine weight for small units. In a previous study [62] a multiplying factor of 14.7 was used to match the weight of the F-14 engine, and we used this factor here. The weight of the unit including the two core $505 \mathrm{~A}$ regenerators would be around $3,800 \mathrm{~kg}(8,377 \mathrm{lb})$.

\subsection{CXEB PERFORMANCE ESTIMATION}

The compressor total-to-total polytropic efficiency, it turns out, depends strongly on the selected rotor-tip clearance. Three different tip clearances $(1.0 \mathrm{~mm}, 0.5 \mathrm{~mm}$, and $0.25 \mathrm{~mm})$ were selected to compare the resulting efficiencies. Table 7.7 summarizes the obtained results.

TABLE 7.7 COMPRESSOR TOTAL-TO-TOTAL POLYTROPIC EFFICIENCIES

\begin{tabular}{lcc}
\hline Compressor & Rotor tip clearance & $\begin{array}{c}\text { Efficiency } \\
(\mathrm{mm})\end{array}$ \\
\hline CXEB & 1.00 & 0.906 \\
& 0.50 & 0.916 \\
& 0.25 & 0.923 \\
\hline
\end{tabular}

A usual value for the blade tip clearance is about 1 percent of the blade height $[35,36]$. From this we see that the blade tip clearance can be around $0.25 \mathrm{~mm}$ resulting in a fairly high efficiency for the compressor. Since the IGV and OGV were not accounted for in the analysis the polytropic efficiency should be slightly lower than as shown above (perhaps, at most, a percentage point lower). The obtained polytropic efficiency is close enough to the assumed efficiency in the design calculation of 0.916 (obtained from Equation 4.3) that an iteration was not necessary. Had there been a large difference between the selected efficiency used in the compressor sizing and that obtained through the performance estimation (a difference of, say, three or more points) then the sizing of the compressor would have had to been done again using the efficiency obtained from the performance estimation.

The three design-point performance-estimation methods were applied to the CXEB turbine. Table 7.8 below summarizes the results obtained. 
TABLE 7.8 RESULTS FROM THE CXEB TURBINE PERFORMANCE PREDICTION

\begin{tabular}{c|c|c|c}
\hline Cycle & rpm & Method & $\begin{array}{l}\text { Predicted poly efficiency } \\
\text { (total-to-total) }\end{array}$ \\
$(--)$ & $(--)$ & $(--)$ & $(--)$ \\
\hline \multirow{4}{*}{ CXEB } & \multirow{2}{*}{18,400} & Wilson (E) & 0.868 \\
& & Wilson (B) & 0.894 \\
& GE & 0.904 \\
\hline
\end{tabular}

Wilson (E) $\equiv$ Wilson's exact form

Wilson (B) $\equiv$ Wilson's binomial form

As mentioned earlier, Wilson's exact form is probably too pessimistic for multi-stage axial turbines. Wilson's binomial form and the GE method seem to give fairly similar results (a total-tototal polytropic efficiency of about 0.90). The predicted efficiency of the turbine is close enough to the assumed value of 0.913 (from equation 4.2 ) that an iteration was not necessary.

To generate the off-design characteristics of the six-stage compressor, Figures 3.5 and 3.6 were used. Initially, the flow coefficient and shaft speed were selected, and the corresponding mass flow rate, pressure ratio, and polytropic efficiency were found. This established one point on the compressor map. By varying the inlet flow coefficient until stall or choke was reached, a speed line on the compressor map was completed. Eight speed lines were run to define the entire compressor map, as seen in Figure 7.3. The $x$-axis of the map is a variable called the "mass flow function". This is the mass flow rate, multiplied by the square root of the inlet total temperature, and divided by the inlet total pressure. For $11.6 \mathrm{~kg} / \mathrm{s}, 300 \mathrm{~K}$, and 1 atm conditions, the design-point mass flow function is approximately 0.00196 . The design point is clearly marked as "D.P." on the map in Figure 7.3. The equilibrium running line was selected to pass through the design point and through the region of maximum compressor efficiency.

The sample turbine map is shown in Figure 7.4. Given a percent speed and pressure ratio from the compressor map, the turbine efficiency is easily found. For example, for a pressure ratio of 3.0 at design point $100 \%$ shaft speed, the turbine map in Figure 7.4 shows an isentropic efficiency of 93.5 percent. However, calculations show that a polytropic turbine efficiency of 90.9 percent is needed at design point in order for the net work to be $2000 \mathrm{~kW}$, as in the CYCLE program. Therefore, the turbine map is scaled based on the design-point requirements. The map in Figure 7.4 is the map used by Korakianitis [44]. The rescaled version is not in this report. 


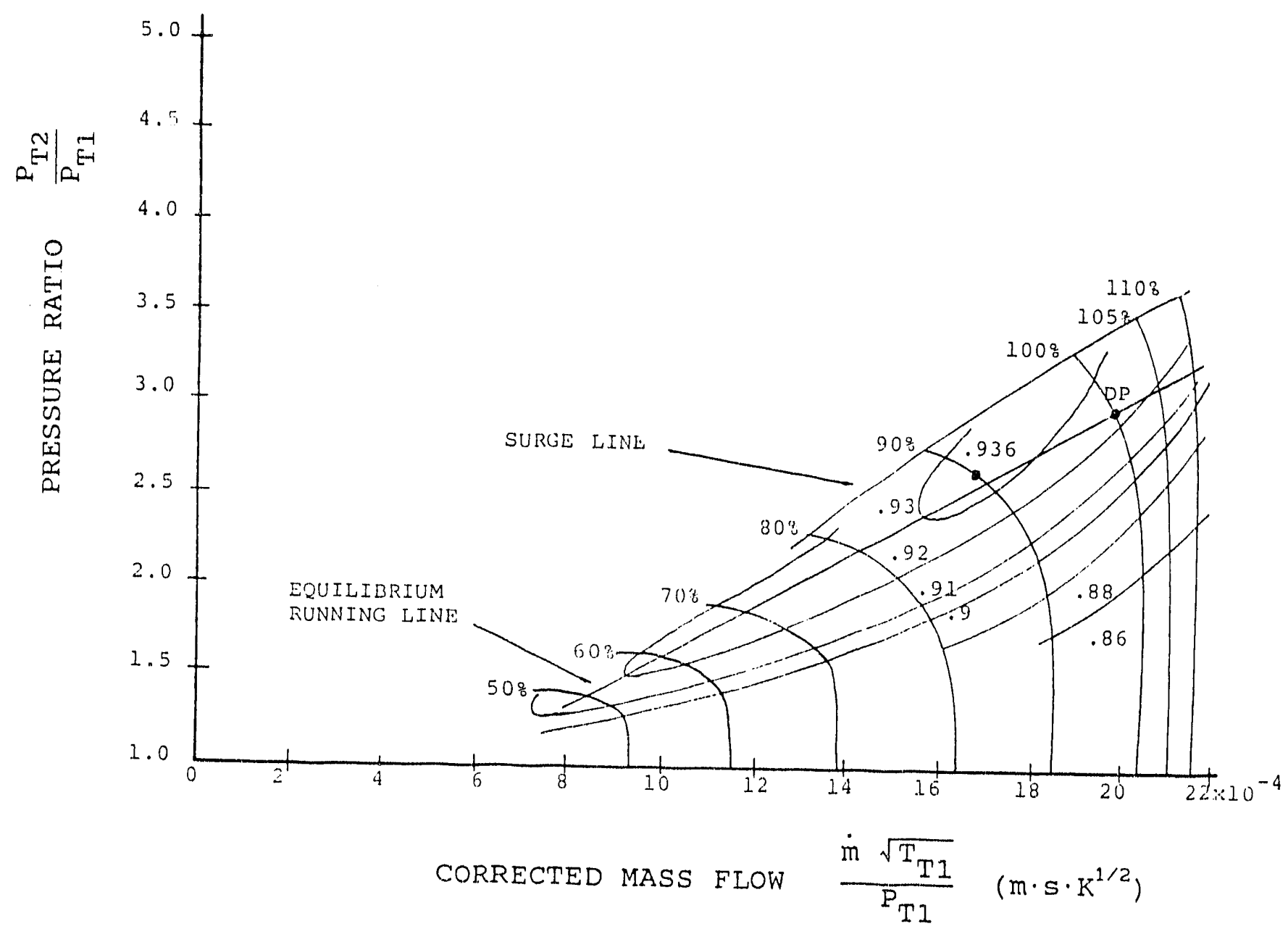

FIGURE 7.3 CXEB SIX-STAGE COMPRESSOR MAP 


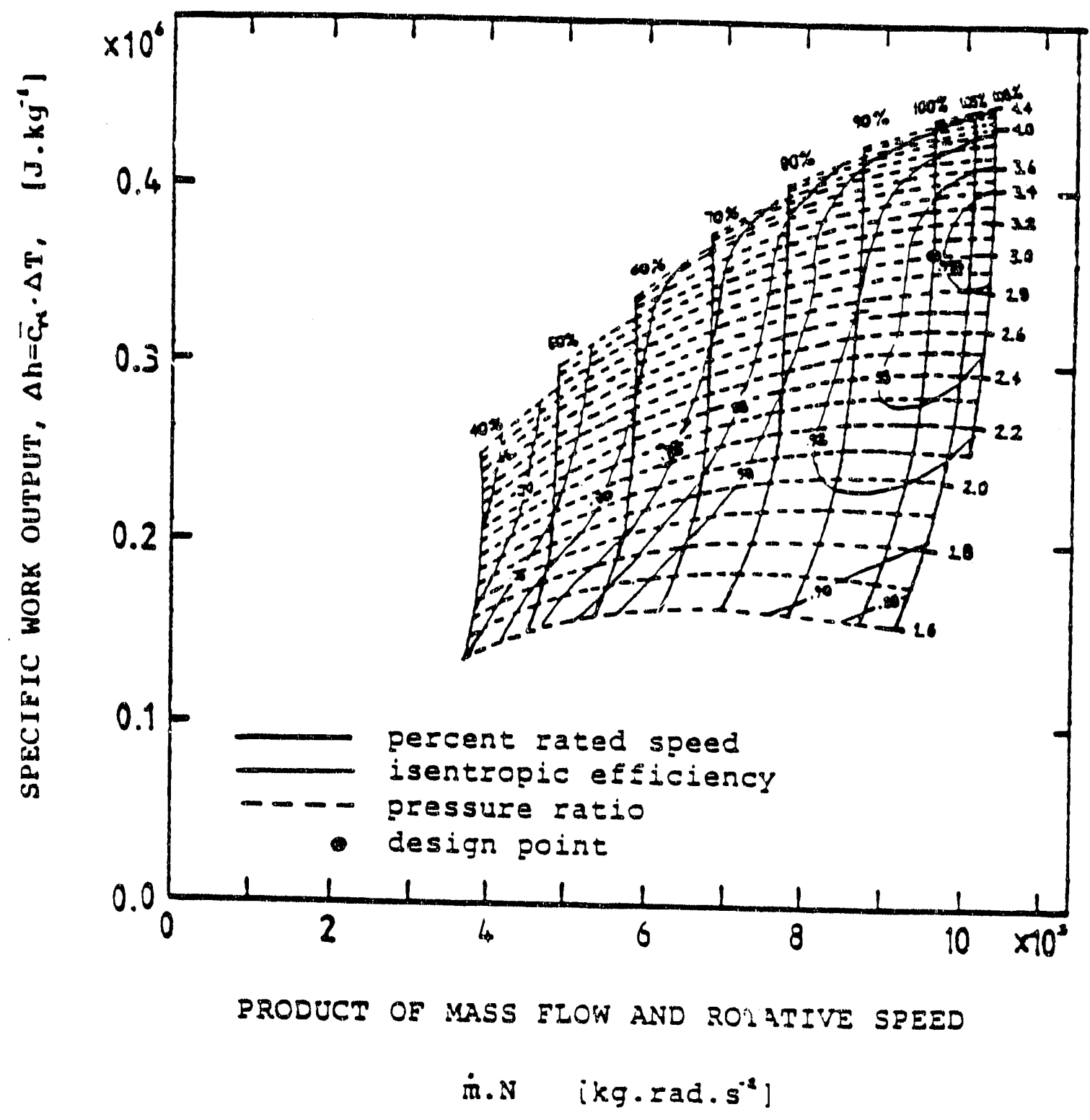

FIGURE 7.4 SAMPLE LPR TURBINE MAP [6] 
Now that compressor and turbine off-design results are established, modified Kays \& London and Hagler equations produred offdesign results for the heat exchanger. The effectiveness of the heat exchanger at design point had been fixed at 0.975 in the CYCLE program. Table 7.9 shows the heat-exchanger off-design results at design point. The effectiveness of the heat exchanger had to be adjusted because analysis showed that the original effectiveness caused a slight continuity error (conservation of mass in and out of the heat-exchanger control volume was not observed). Table 7.10 shows another output, at $10 \mathrm{~kg} / \mathrm{s}$. It is seen that the leakages have decreased and the effectiveness increased.

The overall off-design results were simple to generate once the cff-design characteristics of the individual components were established. Table 7.11 shows the off-design results at design point. The net work was calculated to be $2000 \mathrm{~kW}$, with a thermal efficiency of 50.3 percent. On this output sheet, all of the important mass flow, pressure, temperature, work, and efficiency parameters are reported. Another output sheet, Table 7.12, illustrates the results at part-power. At $9.3 \mathrm{~kg} / \mathrm{s}$, the shaft speed is $85 \%$ of design value, and the net work has decreased to about $65 \%$ of design value. The thermal efficiency has remained almost constant.

A graph of thermal efficiency vs. net output power is seen in Figure 7.5. For values of output as low as $700 \mathrm{~kW}$, the overall thermal efficiency of the cycle remains within a percentage point of 50 percent. This is attributed to the fact that as turbomachinery efficiencies decrease, the heat exchanger becomes more effective and initially the compressor efficiency increases.

Figure 7.6 shows how net power increases with air mass flow rate; the relationship is almost linear. Figures 7.5 and 7.6 illustrate the advantages of the regenerated cycle at off-design. While net work can be regulated by adjusting the inlet mass flow rate, the overall cycle thermal efficiency remains relatively constant, saving on fuel costs. Usually the efficiency drops off at part power rather quickly, causing the need for more fuel (coal in this case).

\subsection{CICXEB ENGINE COMPONENTS}

\section{COMPRESSORS}

The two compressors designed will be rotating at designpoint, at $20,500 \mathrm{rpm}$ and have a constant tip diameter of $306 \mathrm{~mm}$. Both compressors of the intercooled engine require about 0.8 MW of power each. The intercooler used has not been specified but an effectiveness of 0.90 has been used in the cycle calculations. Each compressor has three stages and produces a pressure ratio of 2. Tables 7.13 and 7.14 below summarize the major results obtained when both compressor were sized. 
SOLUTIONS TO HEAT EXCHANGER OFF-DESIGN AT DESIGN-POINT MASS ELOW FOR HX EEFECTIVENESS OF .9755 AND COMPRESSOR EFFICIENCY OE .9257

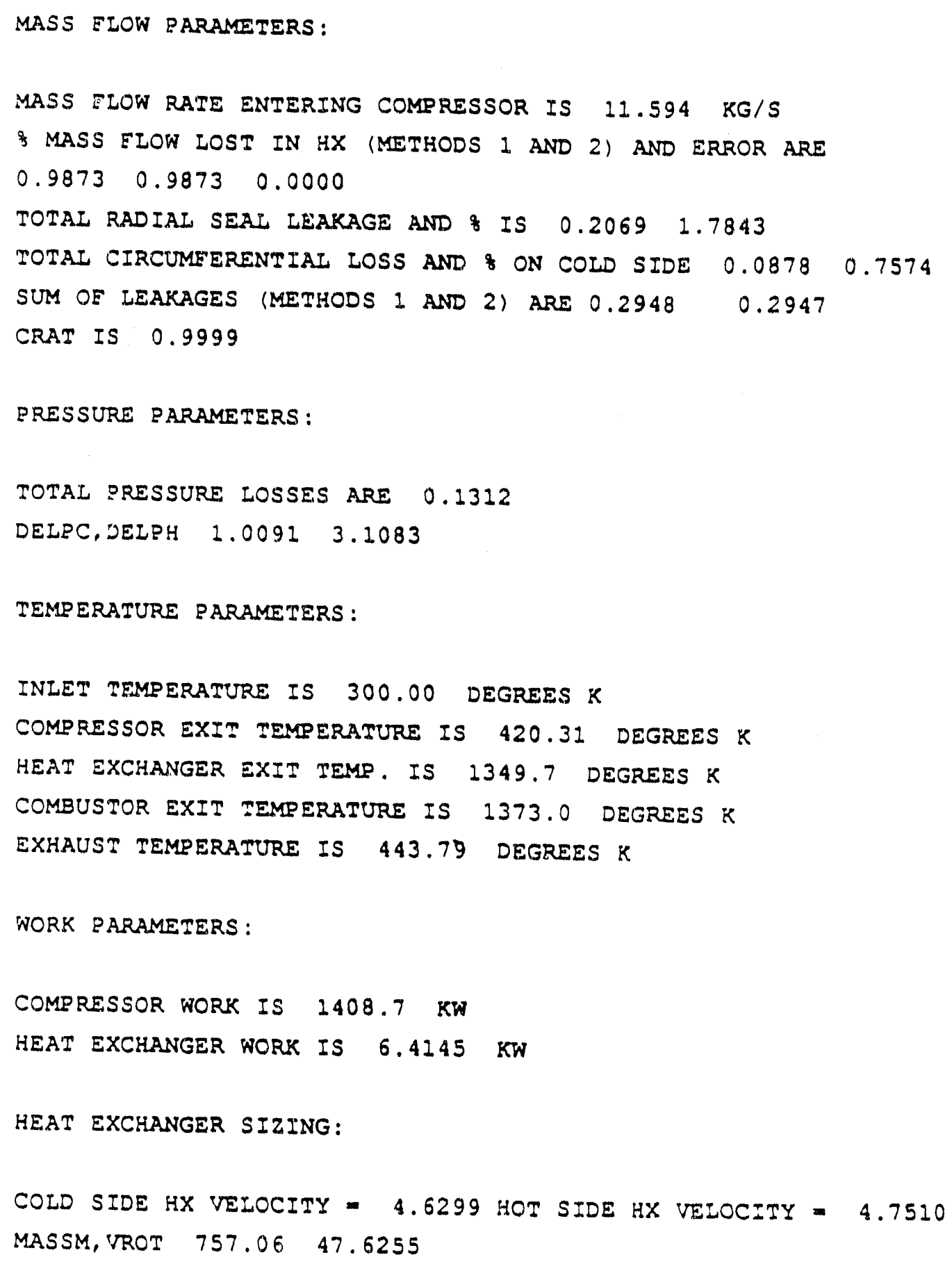


SOLUTIONS TO HEAT EXCHANGER OFF-DESIGN

FOR HX EEFECTIVENESS OF .9786 AND COMPRESSOR EFFICIENCY OF .934

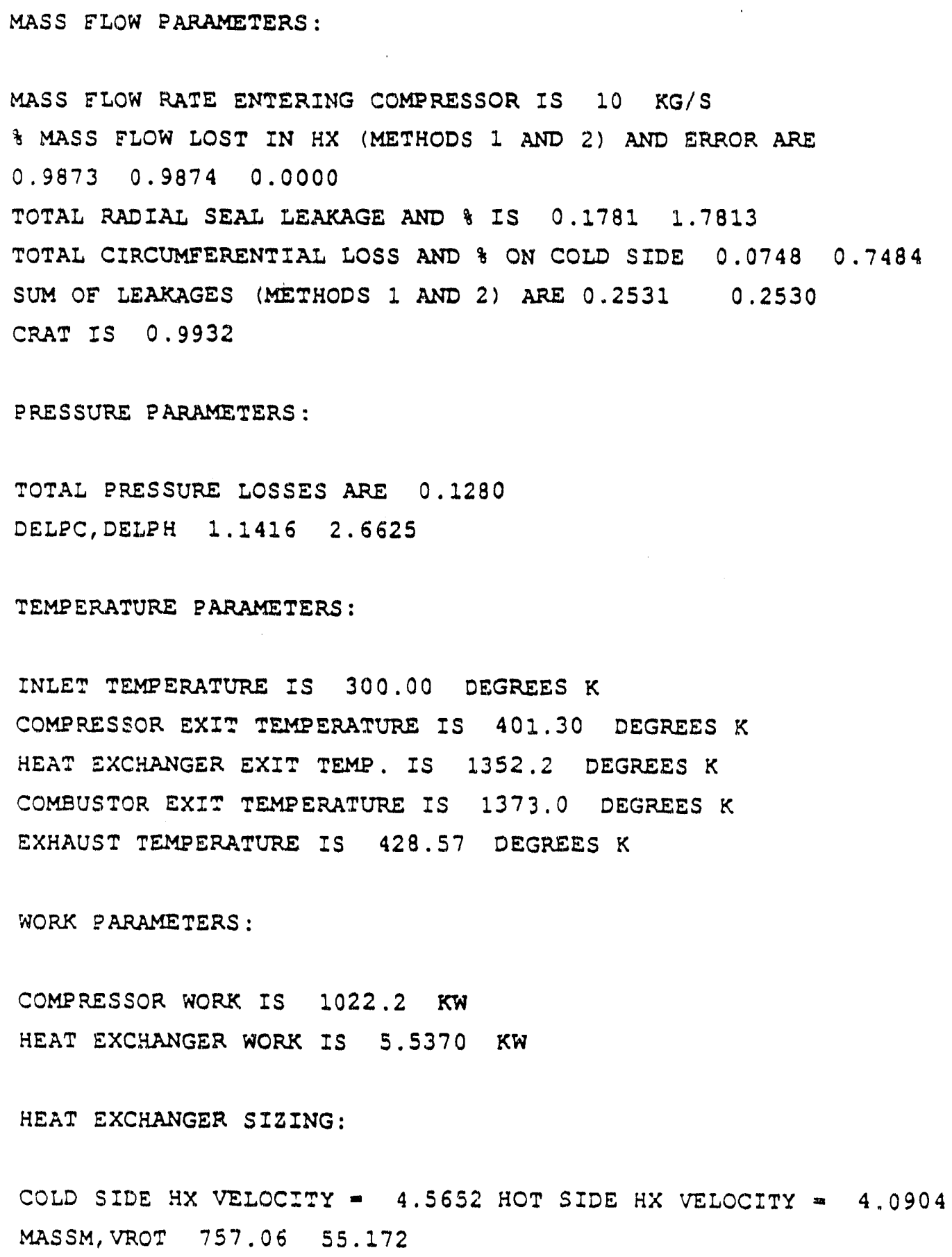


TABLE 7.11 OVERALL OUTPUT FOR DESIGN POINT

SOLUTIONS TO OFE-DESIGN PERFORMANCE AT DESIGN-POINT MASS FLOW RATE

MASS ELOW PARAMETERS:

MASS FLOW RATE ENTERING COMPRESSOR IS $11.594 \mathrm{kG} / \mathrm{S}$

\% MASS FLOW LOST IN HX (METHODS 1 AND 2) AND ERROR ARE

$0.9875 \quad 0.9875 \quad-0.0000$

TOTAL RADIAL SEAL LEAKAGE AND \& IS 0.204001 .7595

TOTAL CIRCUMFERENTIAL LOSS AND \& ON COLD SIDE $0.08647 \quad 0.74582$

SUM OF LEARAGES (METHODS 1 AND 2) ARE $0.29044 \quad 0.29047$

CRAT IS 1.0027

PRESSURE PARAMETERS:

TOTAL PRESSURE LOSSES ARE 0.13196

DELPC, DELPH $1.0316 \quad 3.1642$

TEMPERATURE PARAMETERS :

INLET TEMPERATURE IS 300.00 DEGREES $K$

COMPRESSOR EXIT TEMPERATURE IS 420.31 DEGREES $K$

HEAT EXCHANGER EXIT TEMP. IS 1348.7 DEGREES K

TURBINE EXIT TEMPERATURE IS 1092.1 DEGREES $\mathrm{K}$

COMBUSTOR EXIT TEMPERATURE IS 1373.0 DEGREES K

EXHAUST TEMPERATURE IS 442.07 DEGREES K

WORK PARAMETERS :

COMPRESSOR WORK IS $1408.7 \mathrm{KW}$

HEAT EXCHANGER WORK IS 6.4578 KW

TURBINE WORK IS $3431.2 \mathrm{~kW}$

NET WORK IS $1999.0 \mathrm{KW}$

EEEICIENCY PARAMETERS:

COMPRESSOR EEEICIENCY IS $92.57 \%$

HEAT EXCHANGER EFFECTIVENESS IS 97.45 \&

TURBINE EEEICIENCY IS 90.90 \%

COAL RATE REQUIRED IS $0.11592 \mathrm{KG} / \mathrm{S}$

THERMAL EEEICIENCY OF CYCIE IS $50.333 \%$

HEAT EXCHANGER SIZING:

COLD SIDE HX VELOCITY = 4.7717 HOT SIDE HX VELOCITY $=4.8784$ MASSM, VROT $728.83 \quad 45.836$ 
TABLE 7.12 OVERALL OUTPUT FOR OFF DESIGN

SOLUTIONS TO OEF-DESIGN PEREORMRNCE

MASS ELOW PARAMETERS:

MASS ELOW RATE ENTERING COMPRESSOR IS $9.3 \mathrm{KG} / \mathrm{S}$

8 MASS FLOW LOST IN HX (METHOES 2. AND 2) AND ERROR AYLE 0.987490 .98749

0.00000

TOTAL RADIAL SEAI LEAKAGE AND \& IS 0.164061 .7641

TOTAL CIRCUMEERENTIAL LOSS AND \& ON COLD STDE 0.068540 .7370

SUM OF LEAKAGES (METHODS I AND 2) ARE $0.23264 \quad 0.23260$

CRAT IS 0.99375 AND ERRMA IS 0.05781 AND $N$ IS 85.4

PRESSURE PARAMETERS :

TOTAL PRESSURE LOSSES ARE 0.12735

DELRC, DELPH $\quad 2.2 \% 26 \quad 2.5127$

TEMPERATURE PARAMETERS:

INLET TEMPERATURE IS 300.00 DEGREES $K$

COMPRESSOR EXI: TEUPERATURE IS 394.10 DEGREES $\mathrm{K}$

HEAT EXCHANGER EXIT TEMP. IS 2352.7 DEGREES K

TURBINE, EXIT TEMPERATURE IS 1150.0 DEGREES $X$

COMBUSTOR EXI: TEMPERATURE IS 1373.0 DEGREES K

EXHAUS: TEMEERATURE IS 430.40 DEGREES $K$

WORK PARAMEFERS:

COMPRESSOR WORK IS $882.75 \mathrm{KW}$

HEAT EXCHANGER WORK IS $5.2859 \mathrm{KW}$

TURBINE WORK IS $2: 83.9 \mathrm{KW}$

NE'? WORK IS $1294.3 \mathrm{KW}$

EFEICIENCY PARAMETERS:

COMPRESSOR EFE:CEENCY IS $93.140 \%$

HEAT EXCHANGER EESECTIVENESS IS $97.925 \%$

TURBINE EETICIENC" IS 88.800 \%

COAL RATE REQUTRED IS $0.07446 \mathrm{KG} / \mathrm{S}$

THERMAL EEFICIENCY OF CYCEE IS 50.342 \%

HEAT EXCHANGER SIZING:

COLD STDE HX VELOCITY = 4.6413 HOT SEDE HX VELOCITY = 3.9009 MASSM, VROT 728.33 57.077 
Thermal Efticiency vs. Power

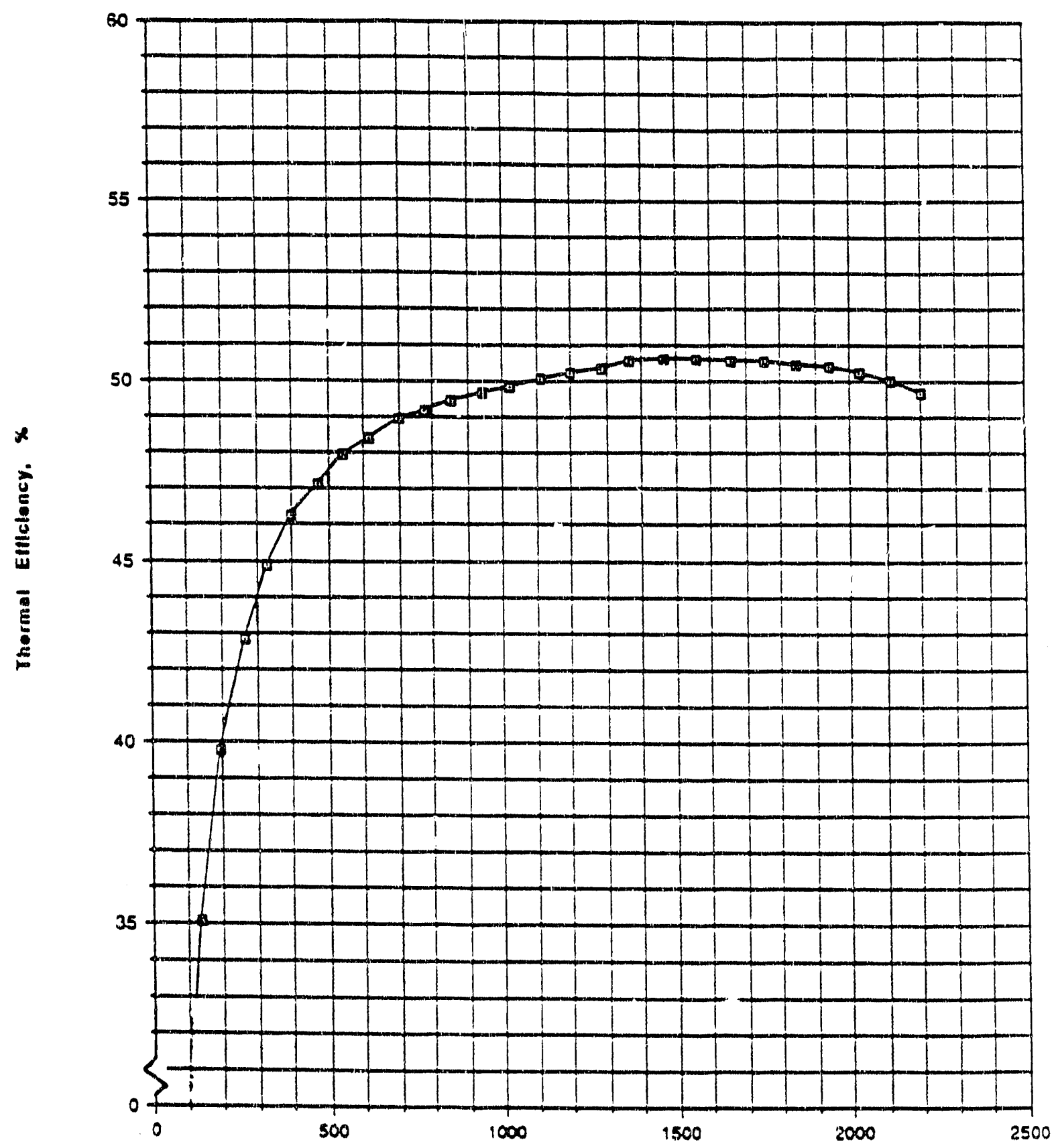

Power, KW

FIGURE 7.5 OFF-DESIGN THERMAL EFFICIENCY OF CXEB 
Air Mass Fiow Rate vs. Power Output

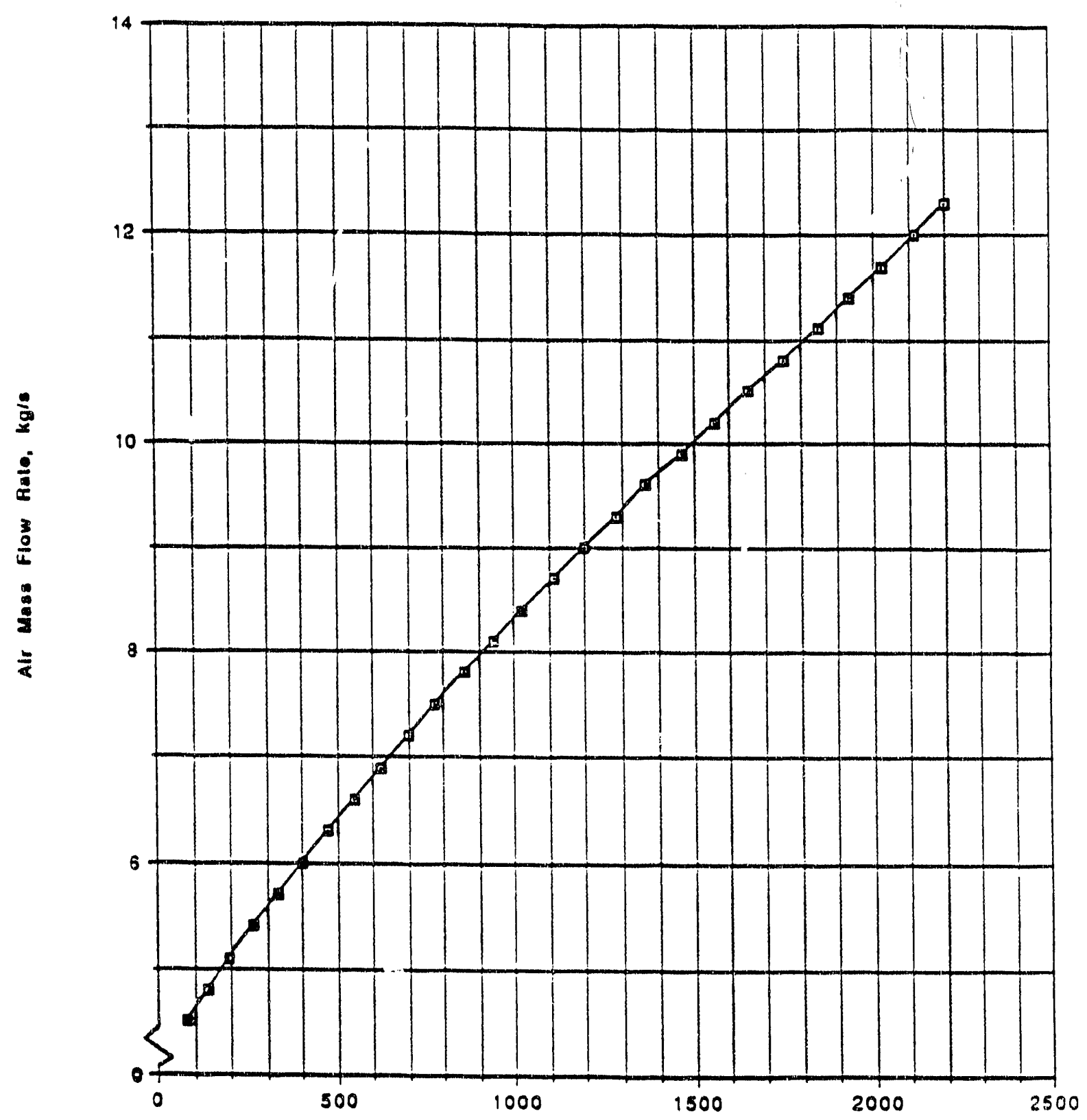

Power, kw

FIGURE 7.6 OFF-DESIGN NET POWER OF CXEB 
TABLE 7.13 MAJOR SIZING RESULTS FOR THE FIRST CICXEB COMPRESSOR

\begin{tabular}{l|c|c|c|c|c}
\hline Blade row & $\begin{array}{c}\text { Blade } \\
\text { height } \\
(\mathrm{mm})\end{array}$ & $\begin{array}{c}\text { Mean } \\
\text { diameter } \\
(\mathrm{mm})\end{array}$ & $\begin{array}{l}\text { Hub } \\
\text { diameter } \\
(\mathrm{mm})\end{array}$ & $\begin{array}{c}\text { Blade } \\
\text { chord } \\
(\mathrm{mm})\end{array}$ & $\begin{array}{c}\text { Number of } \\
\text { blades }\end{array}$ \\
\hline IGV & 65 & 247 & 168 & 34 & 23 \\
First rotor & 66 & 249 & 173 & 33 & 16 \\
First stator & 59 & 254 & 189 & 29 & 18 \\
Second rotor & 52 & 259 & 201 & 26 & 2.1 \\
Second stator & 47 & 263 & 212 & 24 & 23 \\
Third rotor & 43 & 267 & 220 & 21 & 26 \\
Third stator & 39 & 270 & 228 & 3.9 & 29 \\
OGV & 37 & 272 & 233 & 18 & 47 \\
\hline
\end{tabular}

TABLE 7.14 MAJOR SIZING RESULTS FOR THE SECOND CICXEB COMPRESSOR

\begin{tabular}{l|c|c|c|c|c}
\hline Blade row & $\begin{array}{c}\text { Blade } \\
\text { height } \\
(\mathrm{mm})\end{array}$ & $\begin{array}{l}\text { Mean } \\
\text { diameter } \\
(\mathrm{mm})\end{array}$ & $\begin{array}{l}\text { Hub } \\
\text { diameter } \\
(\mathrm{mm})\end{array}$ & $\begin{array}{c}\text { Blade } \\
\text { chord } \\
(\mathrm{mm})\end{array}$ & $\begin{array}{c}\text { Number of } \\
\text { blades }\end{array}$ \\
\hline IGV & 38 & 271 & 230 & 19 & 45 \\
First rotor & 37 & 272 & 232 & 18 & 31 \\
First stator & 33 & 275 & 239 & 17 & 35 \\
Second rotor & 30 & 277 & 246 & 15 & 39 \\
Second stator & 28 & 280 & 251 & 14 & 43 \\
Third rotor & 25 & 282 & 256 & 13 & 47 \\
Third stator & 23 & 284 & 260 & 12 & 52 \\
OGV & 22 & 285 & 263 & 11 & 82 \\
\hline
\end{tabular}

Tables 7.15 and 7.16 below summarize the velocity-diagram information for each blade row at the mean diameter for both compressors.

TABLE 7.15 VELOCITY-DIAGRAM DATA FOR THE FIRST COMPRESSOR

\begin{tabular}{|c|c|c|c|c|c|c|}
\hline \multirow[t]{2}{*}{ Blade row } & \multirow{2}{*}{$\begin{array}{l}\text { Inlet } \\
\text { angle } \\
\text { (deg) }\end{array}$} & \multirow{2}{*}{$\begin{array}{l}\text { outlet } \\
\text { angle } \\
\text { (deg) }\end{array}$} & $c_{21}$ & $C_{z 2}$ & \multirow{2}{*}{$\begin{array}{l}\mathrm{Rn} \\
(--)\end{array}$} & \multirow{2}{*}{$\begin{array}{l}\psi \\
(--)\end{array}$} \\
\hline & & & \multicolumn{2}{|c|}{$(\mathrm{m} / \mathrm{s})$} & & \\
\hline $\begin{array}{l}\text { IGV } \\
\text { First rotor } \\
\text { First stator } \\
\text { Second rotor } \\
\text { Second stator } \\
\text { Third rotor } \\
\text { Third stator } \\
\text { OGV }\end{array}$ & $\begin{array}{r}0 \\
45 \\
41 \\
47 \\
41 \\
48 \\
41 \\
23\end{array}$ & $\begin{array}{l}23 \\
28 \\
23 \\
31 \\
23 \\
34 \\
23 \\
0\end{array}$ & $\begin{array}{l}181 \\
187 \\
1.93 \\
186 \\
190 \\
185 \\
189 \\
184\end{array}$ & $\begin{array}{l}187 \\
193 \\
186 \\
190 \\
185 \\
189 \\
184 \\
181\end{array}$ & $\begin{array}{l}--- \\
.51 \\
-.5 \\
.54 \\
-.- \\
.56 \\
\cdots-- \\
---\end{array}$ & $\begin{array}{l}---- \\
-.35 \\
--.- \\
-.32 \\
--.- \\
-.30 \\
---\overline{-} \\
---\overline{-}\end{array}$ \\
\hline
\end{tabular}


I'ABLE 7.16 VELOCITY-DIAGRAM DATA FOR THE SECOND COMPRESSOR

\begin{tabular}{l|c|c|c|c|c|c}
\hline Blade row & $\begin{array}{l}\text { Inlet } \\
\text { angle }\end{array}$ & \multirow{2}{*}{$\begin{array}{l}\text { Outlet } \\
\text { angle }\end{array}$} & $\mathrm{C}_{z 1}$ & $\mathrm{C}_{z 2}$ & $\mathrm{Rn}$ & $\psi$ \\
\cline { 4 - 5 } & (deg) & (deg) & \multicolumn{2}{|c|}{$(\mathrm{m} / \mathrm{s})$} & $(--)$ & $(--)$ \\
\hline IGV & 0 & 33 & 141 & 148 & --- & --- \\
First rotor & 53 & 37 & 148 & 152 & .51 & -.30 \\
First stator & 50 & 33 & 152 & 147 & --- & --- \\
Second rotor & 54 & 39 & 147 & 150 & .53 & -.28 \\
Second stator & 50 & 33 & 150 & 145 & --- & --- \\
Third rotor & 55 & 41 & 146 & 149 & .54 & -.27 \\
Third stator & 50 & 33 & 149 & 145 & --- & --- \\
OGV & 33 & 0 & 145 & 141 & -- & --- \\
\hline
\end{tabular}

As before, the angles to each blade row are at the mean diameter; the angles are absolute for the stators and relative for the rotors.

The selected blade type from the Melior-NASA charts [6] for both compressors is 65-8-10 (as in the CXEB case) with a solidity of 1.5 for all the blade rows.

TURBINE

The chosen turbine configuration is a three stage unit having a mean-diameter reaction and load coefficient near 50 percent and 1.0 respectively. A constant-hub-diameter configuration was chosen $\left(d_{h}=270 \mathrm{~mm} ;\right.$. The turbine is designec. to rotate: at design point, at $20,500 \mathrm{rpm}$.

Table 7.17 below summarizes a few main results obtained in the turbine sizing.

TABLE 7.17 MAJOR SIZING RESULTS FOR THE CICXEB TURBINE

\begin{tabular}{l|c|c|c|c|c}
\hline Blade row & $\begin{array}{c}\text { Blade } \\
\text { height } \\
(\mathrm{mm})\end{array}$ & $\begin{array}{l}\text { Mean } \\
\text { diameter } \\
(\mathrm{mm})\end{array}$ & $\begin{array}{l}\text { Pip } \\
\text { diameter } \\
(\mathrm{mm})\end{array}$ & $\begin{array}{c}\text { Blade } \\
\text { chord }\end{array}$ & $\begin{array}{c}\text { Number of } \\
\text { blades }\end{array}$ \\
\hline First stator & 35 & 306 & 339 & 12 & 107 \\
First rotor & 39 & 312 & 349 & 15 & 104 \\
Second stator & 45 & 319 & 361 & 15 & 89 \\
Second rotor & 52 & 326 & 374 & 17 & 85 \\
Third stator & 61 & 336 & 391 & 20 & 65 \\
Third rotor & 70 & 348 & 411 & 24 & 59 \\
\hline
\end{tabular}

Table 7.18 below summarizes the velocity-diagram information for each blade row in the turbine. 
TABLE 7.18 VELOCITY-DIAGRAM INFORMATION FOR THE TURBINE

\begin{tabular}{l|c|c|c|c|c|c}
\hline Blade row & $\begin{array}{l}\text { Inlet } \\
\text { angle }\end{array}$ & \multirow{2}{*}{$\begin{array}{l}\text { Outlet. } \\
\text { angle }\end{array}$} & $\mathrm{C}_{z 1}$ & $\mathrm{C}_{z 2}$ & $\mathrm{Rn}$ & $\psi$ \\
\cline { 3 - 6 } & (deg) & $($ deg) & \multicolumn{2}{|c|}{$(\mathrm{m} / \mathrm{s})$} & $(--)$ & $(--)$ \\
\hline First stator & 0 & 51 & 330 & 310 & --- & --- \\
First rotor & -9 & 45 & 310 & 330 & .47 & 1.1 \\
Second stator & 1 & 51 & 330 & 304 & --- & -- \\
Second rotor & -4 & 46 & 304 & 330 & .52 & 1.0 \\
Third stator & 2 & 50 & 330 & 296 & $-5-$ & -- \\
Third rotor & 2 & 48 & 296 & 330 & .58 & 0.9 \\
\hline
\end{tabular}

Table 7.13 shows the inlet and outlet angles to each blade row at the mean diameter (the angles are absolute for the stators and relative for the rotors)

As in the CXEB case the low stresses experienced by the blades opens the possibility of using new blade materials, such as ceramics, at high reliability.

\section{CERAMIC REGENERATOR}

The configuration selected, as in the CXEB case, is two regenerators in parallel. The list below summarizes the sizing data obtained for each regenerator using core 503A.

$\begin{array}{ll}\text { Diameter : } & 2.8 \mathrm{~m} \\ \text { Thickness: } & 0.16 \mathrm{~m} \\ \text { Cold-side annular area : } & 1.16 \mathrm{~m}^{2} \\ \text { Hot-side annular area : } & 3.42 \mathrm{~m}^{2} \\ \text { Mass : } & 605 \mathrm{~kg} \\ \text { Rotation : } & 1.26 \mathrm{rpm} \\ \text { Motor Power : } & 2.5 \mathrm{~kW} \\ \text { Radial seal leakage : } & 0.3 \mathrm{~kg} / \mathrm{s} \\ \text { Circumferential seal leakage : } & 0.11 \mathrm{~kg} / \mathrm{s}\end{array}$

The drive arrangement for the regenerator is as explained in the CXEB case. Table 7.19 below compares the data obtained at design point for the three different regenerator core types.

TABLE 7.19 REGENERATOR SIZE FOR DIFFERENT CORE TYPES

\begin{tabular}{lc|c|c|c}
\hline Core No. & $(--)$ & $503 \mathrm{~A}$ & $504 \mathrm{~A}$ & $505 \mathrm{~A}$ \\
\hline mass & $(\mathrm{kg})$ & 605 & 339 & 825 \\
diameter & $(\mathrm{m})$ & 2.8 & 2.9 & 2.6 \\
thickness & $(\mathrm{m})$ & 0.16 & 0.07 & 0.36 \\
time of rotation & $(\mathrm{s})$ & 48 & 27 & 65 \\
\hline
\end{tabular}


As was explained for the CXEB engine, core 505A may be more appropriate to use because of its larger hydraulic diameter.

\section{CICXEB GAS-TURBINE ENGINE}

Figure 7.7 shows the CICXEB engine cross section. Only one side of the engine is shown since it is symmetric with respect to the center line. The cooling fluid in the intercooler can be water, which would be ideal for a ship design. The regenerator matrix shown is core $503 \mathrm{~A}$.

The weight of the engine, using the method in [61], was estimated to be about $1,363 \mathrm{~kg}(3,005 \mathrm{lb})$. Assuming the mass of the intercooler is around $600 \mathrm{~kg}$ (a conservative assessment) the weight of the engine including both regenerators (core 505A) and the intercooler would be about $3,613 \mathrm{~kg}(7,965 \mathrm{lb})$.

\subsection{CICXEB PERFORMANCE ESTIMATION}

Three different tip clearances were selected for both compressors $(1.0 \mathrm{~mm}, 0.5 \mathrm{~mm}$, and $0.25 \mathrm{~mm})$ to compare the efficiencies. Table 7.20 below summarizes the efficiencies obtained for both compressors.

TABLE 7.20 COMPRESSOR TOTAL-TO-TOTAI POLYTROPLC EFFICIENCIES

\begin{tabular}{lcc}
\hline Compressor & $\begin{array}{c}\text { Rotor tip clearance } \\
(\mathrm{mm})\end{array}$ & $\begin{array}{c}\text { Efficiency } \\
(--)\end{array}$ \\
\hline CICXEB first compressor & 1.00 & 0.897 \\
& 0.50 & 0.914 \\
& 0.25 & 0.923 \\
CICXEB second compressor & 1.00 & 0.891 \\
& 0.50 & 0.909 \\
& 0.25 & 0.921 \\
\hline
\end{tabular}

A representative tip clearance for both compressors is probably around $0.25 \mathrm{~mm}$, as it was for the compressor in the CXEB cycle. The calculated polytropic efficiencies are close enough to the assumed design efficiencies of 0.918 (obtained from Equation 4.4) for both compressors that an iteration was not necessary.

Table 7.21 summarizes the results obtained with the three design-point performance-estimation methods on the CICXEB turbine. 


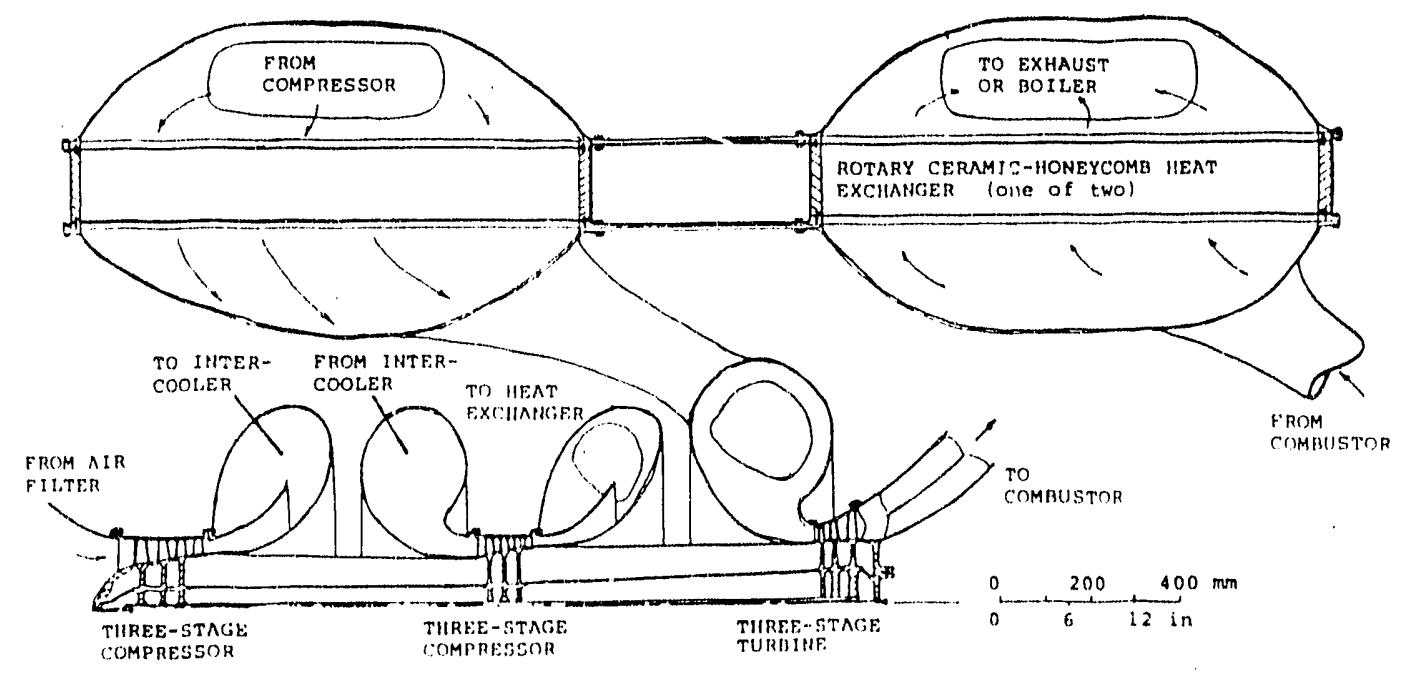

FIGURE 7.7 CROSS-SECTIONAL SKETCH OF CICXEB ENGINE 
TABLE 7.21 RESULTS FROM THE CICXEB TURBINE PERFORMANCE PREDICTION

\begin{tabular}{|c|c|c|c|}
\hline $\begin{array}{l}\text { Cycle } \\
(--)\end{array}$ & $\begin{array}{l}\mathrm{rpm} \\
(--)\end{array}$ & $\begin{array}{l}\text { Method } \\
(--)\end{array}$ & $\begin{array}{l}\text { Predicted poly efficiency } \\
\text { (total-to-total) } \\
\text { (--) }\end{array}$ \\
\hline CICXEB & 20,500 & $\begin{array}{l}\text { Wilson (E) } \\
\text { Wilson (B) } \\
\text { GE }\end{array}$ & $\begin{array}{l}0.881 \\
0.909 \\
0.912\end{array}$ \\
\hline
\end{tabular}

Wilson (E) $\equiv$ Wilson's exact form Wilson (B) $\equiv$ Wilson's binomial form

The predicted efficiency of the turbine (around 0.91) is close enough to the assumed value of 0.91 (from Equation 4.2) that an iteration was not necessary.

The CICXEB off-design performance was calculated by methods similar to the CXEB cycle. In this case, however, component maps for two compressors with pressure ratios of 2.0 were found and integrated into the overali results. The off-design of the heat exchanger remained the same, as did the selection of the turbine map. Inspection of the turbine map mentioned previously (Figure 7.4) reveals that the lines of constant pressure ratio include the overall pressure ratio of the CICXEB Cycle, 4.0. Rather than search for a turbine with an identical design point, it was decided to use the same map.

The results from the overall off-design performance analysis of the CICXEB cycle are seen in Figures 7.8 and 7.9. Figure 7.8 shows the thermal efficiency vs. net output power. At design point, the efficiency of the CICXEB cycle is approximately $1 \%$ higher than the CXEB cycle. The advantage of the intercooled cycle is that at off-design, the efficiency is much "flatter"; a higher efficiency remains at net output power from design point down to a much lower power output.

Figure 7.9 displays air mass flow rate vs. net output power. Note that at a constant air mass flow rate $(e . g .10 \mathrm{~kg} / \mathrm{s})$, the intercooled cycle gives out more work than the nonintercooled cycle (e.g. $2150 \mathrm{~kW}$ vs. $1450 \mathrm{~kW}$ ). More work for less flow is another advantage of using an intercooled cycle.

\subsection{SUMMARY}

We have explained the major results obtained during the compressor, turbine, and heat-exchanger sizing for the CXEB and CICXEB cycle. The design- and off-design-point performance estimations for the compressors and turbines have also been calculated. The intercooled cycle presents two advantages over the nonintercooled engine: 
Thermal Efticiency vs. Power

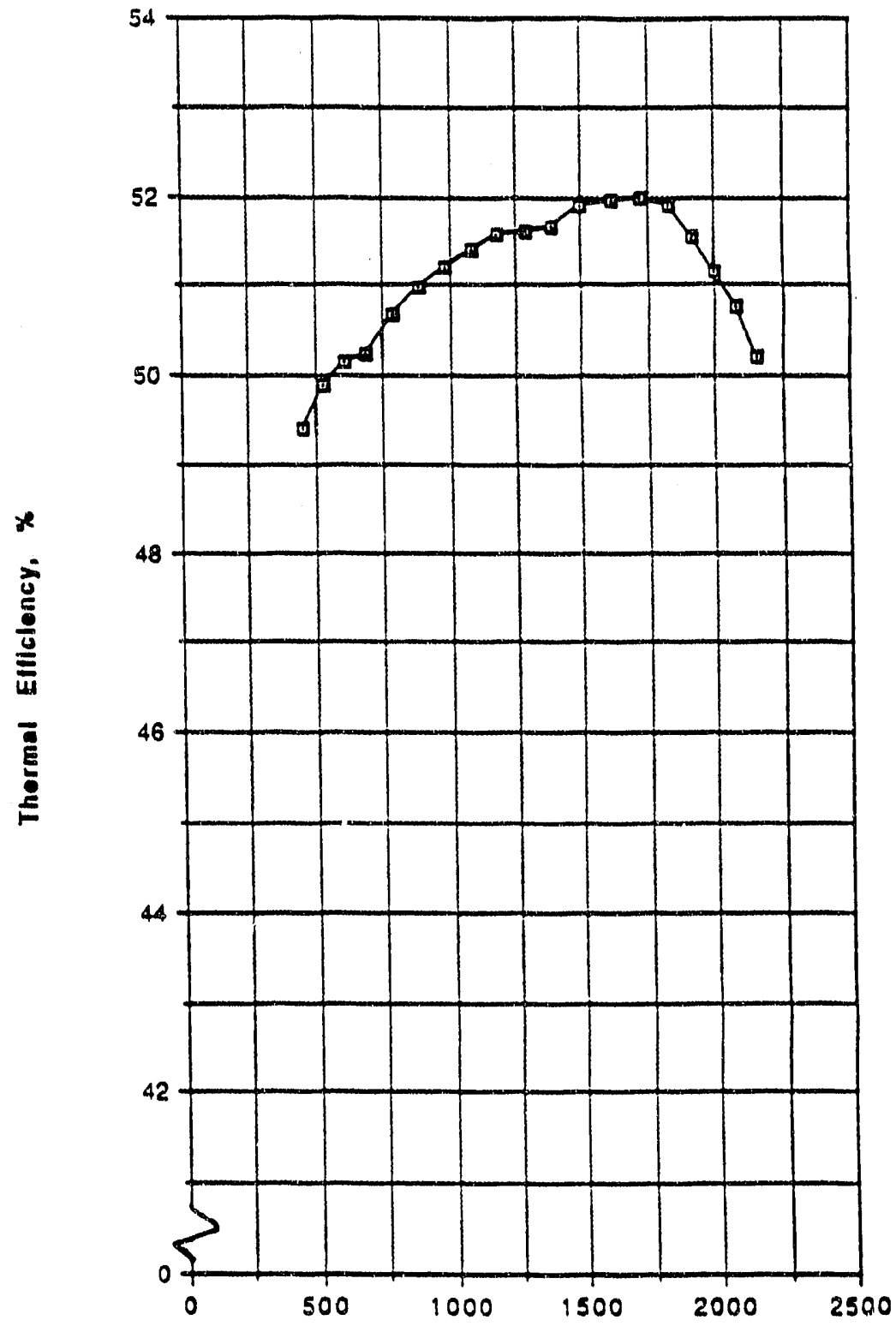

Power, kW

FIGURE 7.8 OFF-DESIGN THERMAL EFFICIENCY OF CICXEB 
Air Mass Flow Rate vs. Power

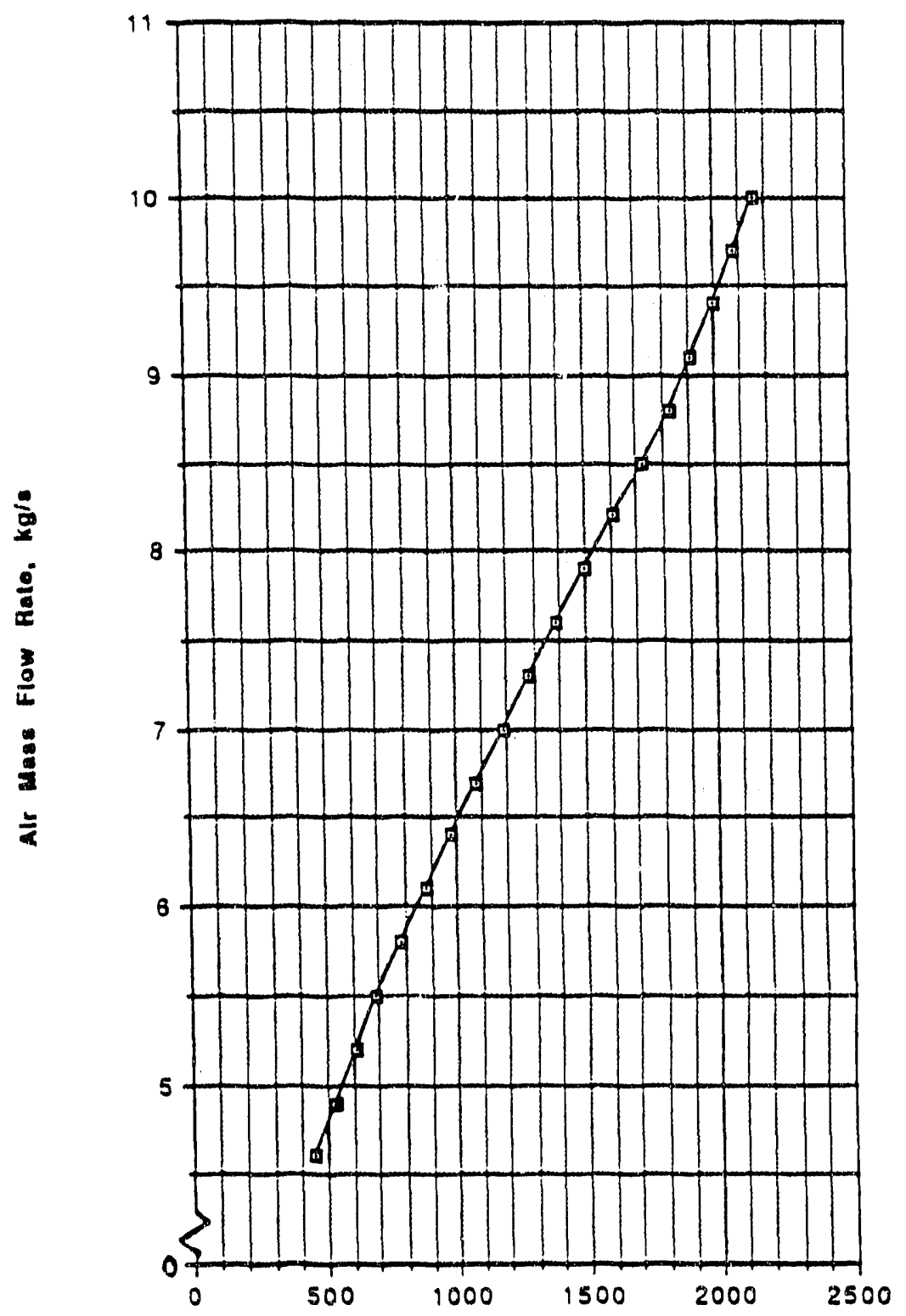

Power, KW

FIGURE 7.9 OFF-DESIGN NET POWER OF CICXEB 
1. a better turn-down performance, and

2. smaller component sizes for the same power output.

More detailed information on the off-design-point performance of the blue-sky engines can be found in Frenkel [20]. 


\subsection{OFF-THE-SHELF ENGINES}

The three alternatives previously stated to configure the NIC 5650 engine to run with a compressor-pressure ratio of 4.0 in exhaust-heated coal-burning arrangement are examined in this section. The options are listed below.

$$
\begin{aligned}
& \text { 1. reduce the diameter of the stage-1 compressor impeller; } \\
& \text { 2. design all-new turbomachinery; or } \\
& \text { 3. make no turbomachinery modifications: just decrease the } \\
& \text { engine speed. }
\end{aligned}
$$

Three alternatives were also considered to modify the IC 5650 engine to become an exhaust-heated coal-burning unit. Two of these options provide the optimal pressure ratio of 4.5 (identified in chapter six), while the third keeps the original design pressure ratio. All three options are presented in this section and are listed below.

1. run the modified engine at the existing pressure ratio;

2. design all-new turbomachinery; or

3. make no turbomachinery modifications: just decrease the engine speed.

In what follows the NIC exhaust-heated 5650 engine will be abbreviated as the NICEH 5650 engine and the IC exhaust-heated 5650 engine will be abbreviated as the ICEH 5650 engine.

\subsection{NIC EXHAUST-HEATED 5650 ENGINE}

The major dimensions of the base 5650 engine have already been presented in chapter six. In that same chapter the major thermodynamic properties of the air at different locations throughout the engine were also presented. Figure 8.1 is a schematic drawing of the NIC exhaust-heated 5650 using a core 503A (designed with an effectiveness of 0.975 ) for the regenerator matrix. The list below summarizes the major dimensions of this regenerator. As explained previously, this engine would have two such disks in parallel mounted in a similar way as in the blue-sky engines. 


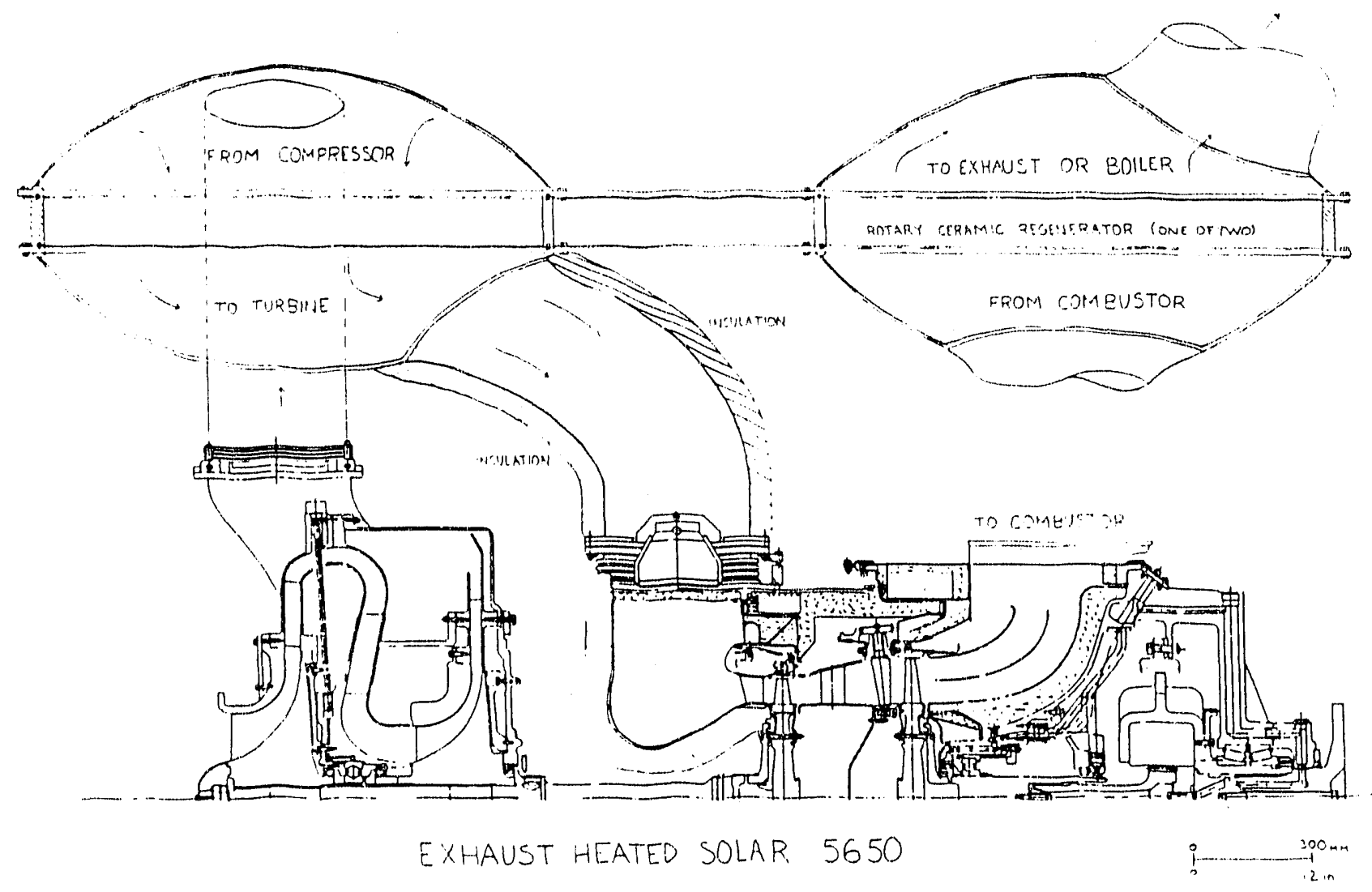

FIGURE 8.1 NICEH 5650 ENGINE CROSS SECTION 
Diameter :

Thickness:

Cold-side annular area :

Hot-side annular area :

Mass

Rotation :

Motor Power :

Radial seal leakage :

Circumferential seal leakage :
$3.4 \mathrm{~m}$

$0.13 \mathrm{~m}$

$1.75 \mathrm{~m}^{2}$

$5.10 \mathrm{~m}^{2}$

$724 \mathrm{~kg}$

$1.89 \mathrm{rpm}$

$11.6 \mathrm{~kW}$

$0.29 \mathrm{~kg} / \mathrm{s}$

$0.13 \mathrm{~kg} / \mathrm{s}$

Table 8.1 below describes the data obtained at design-point for the three different regenerator core types.

TABLE 8.1 REGENERATOR SIZE FOR DIFFERENT CORE TYPES

\begin{tabular}{lc|c|c|c}
\hline core No. & $(--)$ & $503 A$ & $504 \mathrm{~A}$ & $505 \mathrm{~A}$ \\
\hline mass & $(\mathrm{kg})$ & 724 & 394 & 997 \\
diameter & $(\mathrm{m})$ & 3.4 & 3.5 & 3.2 \\
thickness & $(\mathrm{m})$ & 0.13 & 0.05 & 0.28 \\
time of rotation & $(\mathrm{s})$ & 32 & 17 & 44 \\
\hline
\end{tabular}

\subsection{NICEH 5650 OPIION 1 - REDUCE STAGE-1 IMPELLER DIAMETER}

Reducing the compressor stage-1. impeller diameter decreases the pressure rise across that stage. The magnitude of the pressure rise in an impeller is approximately proportional to the square of the impeller tip speed. If the rotational speed of the impelier is constant then the only way to decrease the pressure ratio is to reduce the impeller diameter. The advantage to this method of changing the compressor pressure ratio is that very little modifications must be done to the compressor. The blading of the first stage must be tximmed leaving the impeller disk intact but the diffuser and the entire second stage can remain untouched. Both turbines, however, must be re-bladed to accommodate the reduced power required to drive the compressor. In addition, the performance of the compressor is typically adversely affected by the impeller trimming [63].

The result expected at the outset of this exercise was that the overall performance of the engine would be compromised due to a low post-impeller-trimming compressor efficiency. The cost of a poorly performing engine would then be weighed against the savings gained by leaving the compressor essentially intact.

The stage-1 impeller was picked to modify due to the unequal pressure-ratio split between the two stages in the base 5650 . The pressure ratio of stage 1 is 3.33 and the stage 2 pressure ratio is 1.98 . The overall pressure ratio, including duct losses between stages, is 6.37 [52]. To decrease the overall pressure ra- 
tio to 4.0 , the stage-1 pressure ratio must be decreased to approximately 2.02 .

The performance impact on the compressor of any geometric modification can be easily made by the Dallenbach method [22]. A more detailed explanation of the actual procedure for using Dallenbach's method of centrifugal-compressor performance estimation can be found in Nahatis $[22,23]$. The final dimensional changes and performance of the trimmed stage-1 impeller are listed in Table 8.2. The efficiencies in the table are isentropic.

TABLE 8.2 NICEH 5650 TRIMMED-IMPELLER RESULTS

\begin{tabular}{lcc}
\hline & $\begin{array}{c}\text { base } 5650 \\
\text { stage } 1 \text { impeller }\end{array}$ & $\begin{array}{c}\text { trimmed } \\
\text { impeller }\end{array}$ \\
tip diameter (mm) & 673.5 & 573.0 \\
blade-outlet angle & 40.0 & 35.0 \\
blade-outlet width (mm) & 29.0 & 38.0 \\
efficiency (\%) & 85.1 & 83.2 \\
impeller pressure ratio & 3.62 & 2.24 \\
stage pressure ratio & 3.33 & 2.01 \\
\hline
\end{tabular}

The overall polytropic efficiency of the two-stage compressor with the trimmed impeller was estimated to be $78.7 \%$ or 4.6 percentage points less than the efficiency of the NIC base 5650 compressor. Increased losses in the diffuser and exit due to a thickened boundary layer are the main contributors to the large efficiency deficit.

Both the gas-producer turbine and power turbine must be rebladed based on the new compressor pressure ratio. Decreasing the pressure ratio from 6.37 to 4.0 while holding compressor speed and flow constant lowers the work needed by the compressor from the gas-producer turbine. The new gas-producer-turbine blading, therefore, will extract less energy from the flow leaving a larger proportion of energy available for the power turbine. The blading of the power turbine must be redesigned to take advantage of the added energy in the flow.

The preliminary design of the turbine blading was carried out with the help of Tampe's TURBINE program [19]. The new annul is dimensions for the gas-producer turbine are compared to the base 5650 cylindrical annulus dimensions in Table 8.3. 
TABLE 8.3 GAS-PRODUCER TURBINE GEOMETRY FOR TRIMMED-IMPELLER OPTION

\begin{tabular}{lllll}
\hline & \multicolumn{2}{c}{ base 5650} & \multicolumn{2}{c}{ redesign } \\
& vane & blade & vane & blade \\
\hline$d_{h}(\mathrm{~mm})$ & 463.6 & 463.0 & 447.0 & 447.0 \\
$\mathrm{~d}_{t}(\mathrm{~mm})$ & 589.3 & 589.3 & 527.0 & 548.0 \\
$\mathrm{~A}_{\mathrm{n}}\left(\mathrm{m}^{2}\right)$ & 0.104 & 0.104 & 0.061 & 0.079 \\
\hline
\end{tabular}

Likewise, the new geometry for the power turbine is shown with the base 5650 dimensions in Table 8.4.

TABLE 8.4 POWER-TURBINE GEOMETRY FOR TRIMMED-IMPELLER OPTION

\begin{tabular}{lllll} 
& \multicolumn{2}{c}{ base 5650} & \multicolumn{2}{c}{ redesign } \\
\hline$a_{h}(\mathrm{~mm})$ & 468.6 & 468.6 & 558.3 & 558.3 \\
$a_{t}(\mathrm{~mm})$ & 688.2 & 688.2 & 705.5 & 738.9 \\
$A_{n}\left(\mathrm{~m}^{2}\right)$ & 0.1996 & 0.1936 & 0.146 & 0.184 \\
\hline
\end{tabular}

The mean-diameter velocity-diagram data for the redesigned blading of the two turbines are shown in Table 8.5 .

TABLE 8.5 MEAN-DIAMETER TURBINE VELOCITY-DIAGRAM DATA FOR TRIMMED-IMPELLER OPTION

\begin{tabular}{lcccc}
\hline & \multicolumn{2}{c}{$\begin{array}{c}\text { gas-producer } \\
\text { inlet }\end{array}$} & $\begin{array}{c}\text { turbine } \\
\text { exit }\end{array}$ & \multicolumn{2}{c}{$\begin{array}{c}\text { power turbine } \\
\text { inlet }\end{array}$} & \begin{tabular}{c} 
exit \\
\hline $\mathrm{Rn}$
\end{tabular}$-^{--}$ & 0.51 & -- & 0.52 \\
$\psi$ & -- & 1.63 & -- & 1.04 \\
$\phi$ & 0.85 & 0.90 & 0.46 & 0.55 \\
$\mathrm{C}(\mathrm{m} / \mathrm{s})$ & 538 & 326 & 411 & 203 \\
$\alpha_{\mathrm{C}}$ & 58 & -17 & 66 & 1 \\
${ }_{\mathrm{W}}$ & 312 & 541 & 167 & 419 \\
$\alpha_{\mathrm{W}}$ & -22 & 55 & -6 & 61 \\
\hline
\end{tabular}

The overall performance of the NIC exhaust-heated 5650 with the trimmed stage-1 impeller and re-bladed turbines is not as good as the overall predicted performance of the optimal-pressure-ratio NIC exhaust-heated 5650 engine (see Table 8.6). The lower efficiency of the compressor with the trimmed impeller is the reason for the poor overall performance. The turbines are assumed to reach their predicted efficiency levels. 
TABLE 8.6 OVERALL PERFORMANCE COMPARISON--TRIMMED VS OPTIMAL

optimal NICEH trimmed-impeller

5650

NICEH 5650

thermal efficiency

38.5

34.6

power output (kW)

2491

2239

specific fuel consumption

0.273

0.303

$(\mathrm{kg} / \mathrm{kW}-\mathrm{hr})$

\subsection{NICEH 5650 OPTION 2 - REDESIGN ALL TURBOMACHINERY}

A second alternative to achieve the optimal pressure ratio for the exhaust-heated 5650 involves redesigning all of the turbomachinery. The efficiency of the redesigned turbomachinery will. be maximized at the low-pressure-ratio design point and presumably will result in better overall engine performance.

The capital cost of more turbomachinery modifications will be weighed against savings from performance improvements on a life-cycle basis in chapter nine. In an effort to keep the flowpath and overall size of the engine as near to the base 5650 design as possible, the mass-flow rate and turbine-inlet temperature were held constant. The compressor rotational speed was allowed to vary from the base 5650 design speed. The preliminary design of the turbines was again accomplished using Tampe's TURBINE computer program. The compressor design parameters are shown in Table 8.7. Tables 8.8 and 8.9 contain a comparison of the redesigned compressor geometry and the base NIC 5650 engine, and the velocity-diagram data for the redesigned compressors, respectively. A schematic of the two stages is shown in Figures 8.2 and 8.3 .

TABLE 8.7 COMPRESSOR DESIGN PARAMETERS

\begin{tabular}{lrr}
\hline & stage 1 & stage 2 \\
\hline speed (rpm) & 10,000 & 10,000 \\
pressure ratio & 2.1 & 1.9 \\
polytropic efficiency $\left(\frac{\circ}{6}\right)$ & 88.0 & 82.0 \\
$\phi_{1}$ & 0.42 & 0.34 \\
$\phi_{2}$ & 0.54 & 0.43 \\
$\psi$ & -0.9 & -0.9 \\
\hline
\end{tabular}




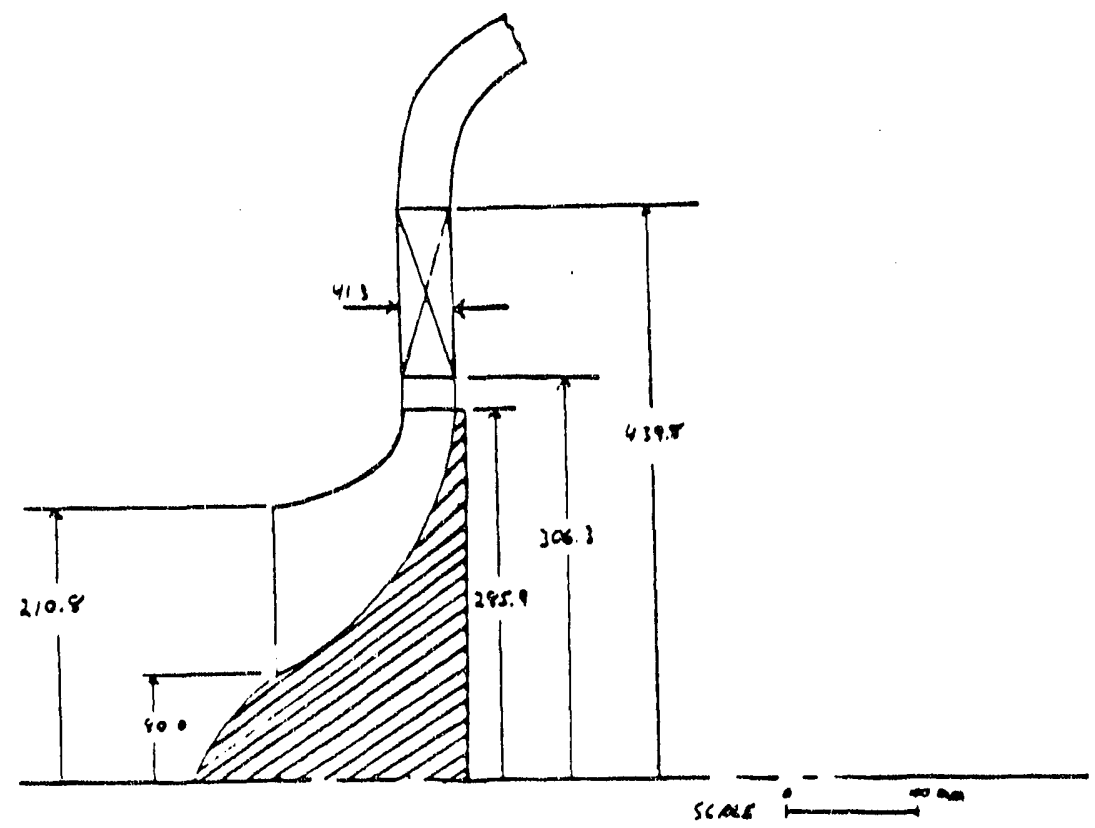

FIGURE 8.2 NICEH 5650 COMPRESSOR STAGE 1 SCHEMATIC

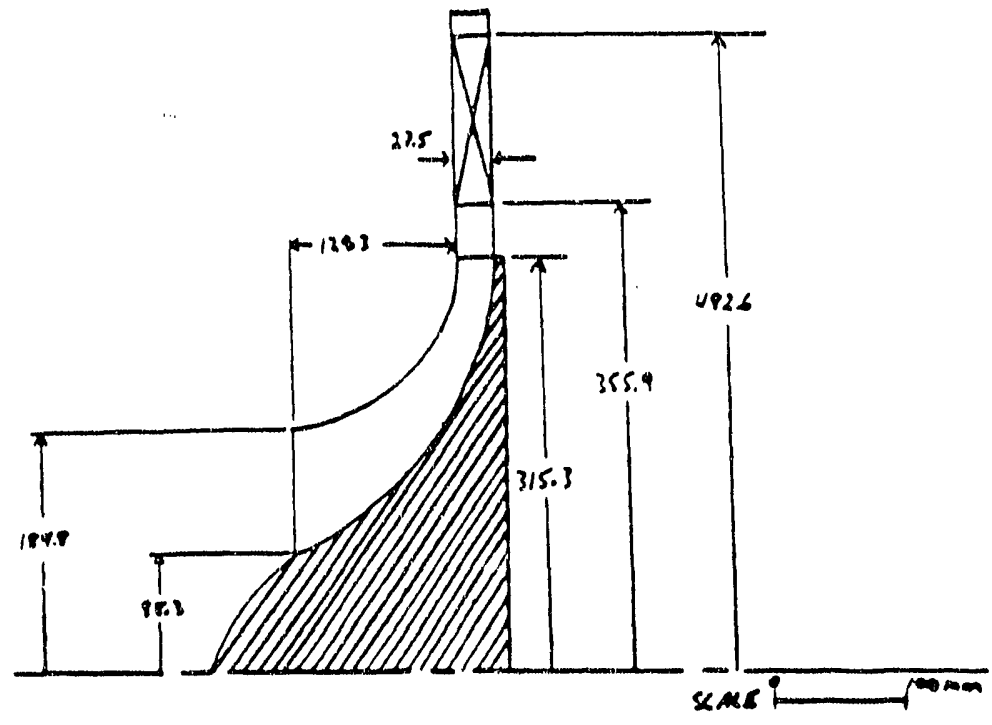

FIGURE 8.3 NICEH 5650 COMPRESSOR STAGE 2 SCHEMATIC 
TABLE 8.8 COMPARISON OF REDESIGNED COMPRESSOR GEOMETRY FOR NICEH 5650

\begin{tabular}{llrrrr}
\hline & & \multicolumn{2}{c}{ stage } & \multicolumn{2}{c}{ stage 2} \\
\hline$d_{1 h}(\mathrm{~mm})$ & 193.1 & 160.1 & 171.4 & 176.6 \\
$\mathrm{~d}_{1 \mathrm{~s}}(\mathrm{~mm})$ & 410.4 & 421.6 & 350.0 & 369.5 \\
$\mathrm{~d}_{2}(\mathrm{~mm})$ & 673.8 & 571.7 & 616.8 & 630.6 \\
$\mathrm{~b}_{2}$ & $(\mathrm{~mm})$ & 29.0 & 41.3 & 24.1 & 27.5 \\
$\mathrm{~d}_{3}$ & $(\mathrm{~mm})$ & 743.5 & 612.6 & 675.9 & 711.8 \\
$\mathrm{~b}_{3}$ & $(\mathrm{~mm})$ & 35.0 & 41.3 & 29.0 & 27.5 \\
$\mathrm{~d}_{4}(\mathrm{~mm})$ & 1042.8 & 879.5 & 952.3 & 965.2 \\
$\beta_{2}$ & & 40.0 & 0.0 & 50.0 & 0.0 \\
$\mathrm{z}^{2}$ & 26 & 20 & 26 & 20 \\
\hline
\end{tabular}

TABLE 8.9 REDESIGNED NICEH 5650 COMPRESSOR VELOCITY-DIAGRAM DATA

\begin{tabular}{lrrrrrr}
\hline & \multicolumn{2}{c}{ inlet stage 1} & \multicolumn{2}{c}{ inlet } & stage 2 & exit \\
& hub & shroud & exit & hub & shroud & \\
\hline $\mathrm{u}_{\mathrm{C}(\mathrm{m} / \mathrm{s})}$ & 84 & 221 & 299 & 92 & 193 & 330 \\
$\alpha_{\mathrm{C}}$ & 127 & 127 & 315 & 112 & 112 & 329 \\
${ }_{\mathrm{W}}(\mathrm{m} / \mathrm{s})$ & 152 & 0 & 59 & 0 & 0 & 65 \\
$\alpha_{\mathrm{W}}$ & 33 & 255 & 165 & 145 & 224 & 145 \\
\hline
\end{tabular}

The design-point performance of each centrifugal compressor stage was verified using Dallenbach's performance-predicticn method. The resulting polytropic efficiency and pressure-ratio prediction for the new geometry compared reasonably well. with the design intent, as can be seen from Table 8.10.

TABLE 8.10 COMPRESSOR DESIGN INTENT VS PREDICTION

\begin{tabular}{lcccc}
\hline & $\begin{array}{c}\text { polytropic } \\
\text { design }\end{array}$ & $\begin{array}{c}\text { efficiency } \\
\text { predicted }\end{array}$ & $\begin{array}{c}\text { pressure ratio } \\
\text { design }\end{array}$ & predicted \\
\hline stage 1 & 88.0 & 91.6 & 2.1 & 2.1 \\
stage 2 & 82.0 & 86.6 & 1.9 & 2.0 \\
\hline
\end{tabular}

The preliminary design of the turbines was completed in a similar manner as the turbine designs for option 1 . The constant-

1. It would be preferable to use Impeller blades with outlet

angles having a considerable degree of backsiopel perhaps

relatively ow pressure ratios proposed. They confer greatly

acceptable the efficlencies as sumed here. 
hub-diameter geometry for the gas-producer turbine is compared with the base 5650 cylindrical annulus design in Table 8.11.

TABLE 8.11 GAS-PRODUCER TURBINE GEOMETRY FOR REDESIGNED TURBOMACHINERY OPTION

\begin{tabular}{lcccc}
\hline & \multicolumn{2}{c}{ base 5650} & \multicolumn{2}{c}{ redesign } \\
& vane & blade & vane & blade \\
\hline$d_{h}(\mathrm{~mm})$ & 463.6 & 463.6 & 558.3 & 558.3 \\
$\mathrm{~d}_{t}(\mathrm{~mm})$ & 589.3 & 589.3 & 649.8 & 674.0 \\
$A_{n}\left(\mathrm{~m}^{2}\right)$ & 0.104 & 0.104 & 0.087 & 0.112 \\
$\mathrm{z}$ & -- & -- & 82 & 107 \\
\hline
\end{tabular}

The geometry for the power turbine is shown compared with the NIC base 5650 dimensions in Table 8.12. Since the power-turbine speed, pressure ratio, efficiency, and mass flow are the same values as those used in the option 1 design, the power-turbine dimensions and velocity diagram are exactly the same as the previous design but are listed here for convenience. A schematic of the redesigned turbines is presented in Figuire 8.4 .

TABLE 8.12 POWER-TURBINE GEOMETRY FOR REDESIGNED TURBOMACHINERY OPTION

\begin{tabular}{llcccc}
\hline & \multicolumn{2}{c}{ base 5650} & \multicolumn{2}{c}{ redesign } \\
& vane & blade & vane & blade \\
\hline$d_{h}(\mathrm{~mm})$ & 468.6 & 468.6 & 558.3 & 558.3 \\
$d_{t}(\mathrm{~mm})$ & 688.2 & 688.2 & 705.5 & 738.9 \\
$A_{n}\left(\mathrm{~m}^{2}\right)$ & 0.1996 & 0.1996 & 0.146 & 0.184 \\
$\mathrm{z}$ & -- & -- & 83 & 81 \\
\hline
\end{tabular}

The mean-diameter velocity-diagram data for the redesigned turbines are shown in Table 8.13 .

TABLE 8.13 MEAN-DIAMETER TURBINE VELOCITY-DIAGRAM DATA FOR REDESIGNED TURBOMACHINERY OPTION

\begin{tabular}{lcccc}
\hline & \multicolumn{2}{c}{$\begin{array}{c}\text { gas-producer } \\
\text { inlet }\end{array}$} & $\begin{array}{c}\text { turbine } \\
\text { exit }\end{array}$ & \multicolumn{2}{c}{$\begin{array}{c}\text { power } \\
\text { inlet }\end{array}$} & $\begin{array}{c}\text { turbine } \\
\text { exit }\end{array}$ \\
\hline $\mathrm{Rn}$ & -- & 0.50 & -- & 0.52 \\
$\psi$ & -- & 1.82 & -- & 1.04 \\
$\phi$ & 0.56 & 0.65 & 0.46 & 0.55 \\
$\mathrm{C}(\mathrm{m} / \mathrm{s})$ & 497 & 243 & 411 & 203 \\
$\alpha_{\mathrm{C}}$ & 69 & -29 & 66 & 1 \\
$\mathrm{~W}$ & 230 & 495 & 167 & 419 \\
$\alpha_{\mathrm{W}}$ & -38 & 64 & -6 & 61 \\
\hline
\end{tabular}




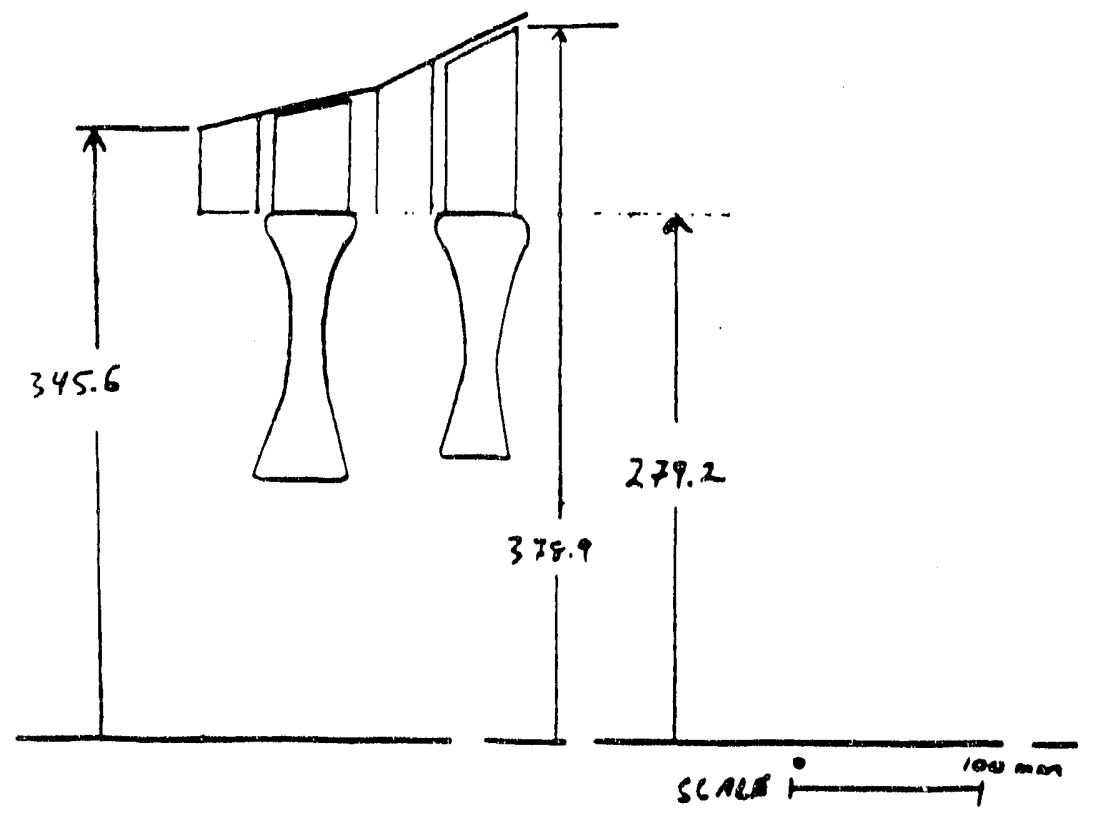

FIGURE 8.4 NICEH 5650 REDESIGNED-TURBINE SCHEMATIC 
The design-intent efficiency of both turbines was verified using the three turbine efficiency-prediction techniques previous1y described. The results obtained, shown in Table 8.14, agree well with the design-intent polytropic efficiencies used in the calculations.

TABLE 8.14 DESIGN INTENT VS PREDICTED EFFICIENCY FOR TURBINES

\begin{tabular}{lcccc}
\hline & design intent & Wilson's Exact & Trim. Binom. & GE \\
\hline gas-producer & & & & \\
turbine & 91.1 & 89.4 & 91.5 & 91.2 \\
power turbine & 90.4 & 91.6 & 94.5 & 93.0 \\
\hline
\end{tabular}

\subsection{NICEH 5650 OPTION 3 - RUN EXISTING TURBOMACHINERY AT REDUCED-SPEED OPERATION}

The reduced-speed operation of the NICEH 5650 with no turbomachinery modifications is the last option considered to arrive at the optimal pressure ratio for high thermal efficiency and specific power. This exercise was divided into two major tasks: determining the reduced-speed (or off-design) performance of the NIC base 5650 turbomachinery and predicting the off-design characteristics of the rotary regenerator sized for the optimal NICEH 5650 .

The reduced-speed performance of the NIC base 5650 turbomachinery was determined from actual test data shown in Figures 8.5 and 8.6 [52]. The data were extrapolated down to lower pressure ratios based on the assumption that the slopes stayed constant.

The off-design-point characteristics of the rotary regenerator were estimated using techniques documented in Hagler [32] and Frenkel [20]. The variation of effectiveness with mass flow through the regenerator is assumed to be linear based on analysis by Frenkel [20].

The reduced-speed engine performance was calculated for a range of pressures from 3.0 up to 6.37 using a computer program which merged elements from Tampe's CYCLE program and Frenkel's regenerator off-design calculations. The program requires interactive input from the test data in Figures 8.5 and 8.6 for each pressure ratio.

The thermal-efficiency-versus-specific-power characteristic for the reduced-speed operation of the NICEH 5650 is shown in Figure 8.7. Each point on this graph, then, represents a different speed of the same engine. This is in contrast to the other similar graphs that have been presented in the report where each point represents a different engine at design point (each engine is operating at a different pressure ratio). The peak thermal efficiency was not reached but the power output at such low pressure ratios is too small to be useful. An overall performance 


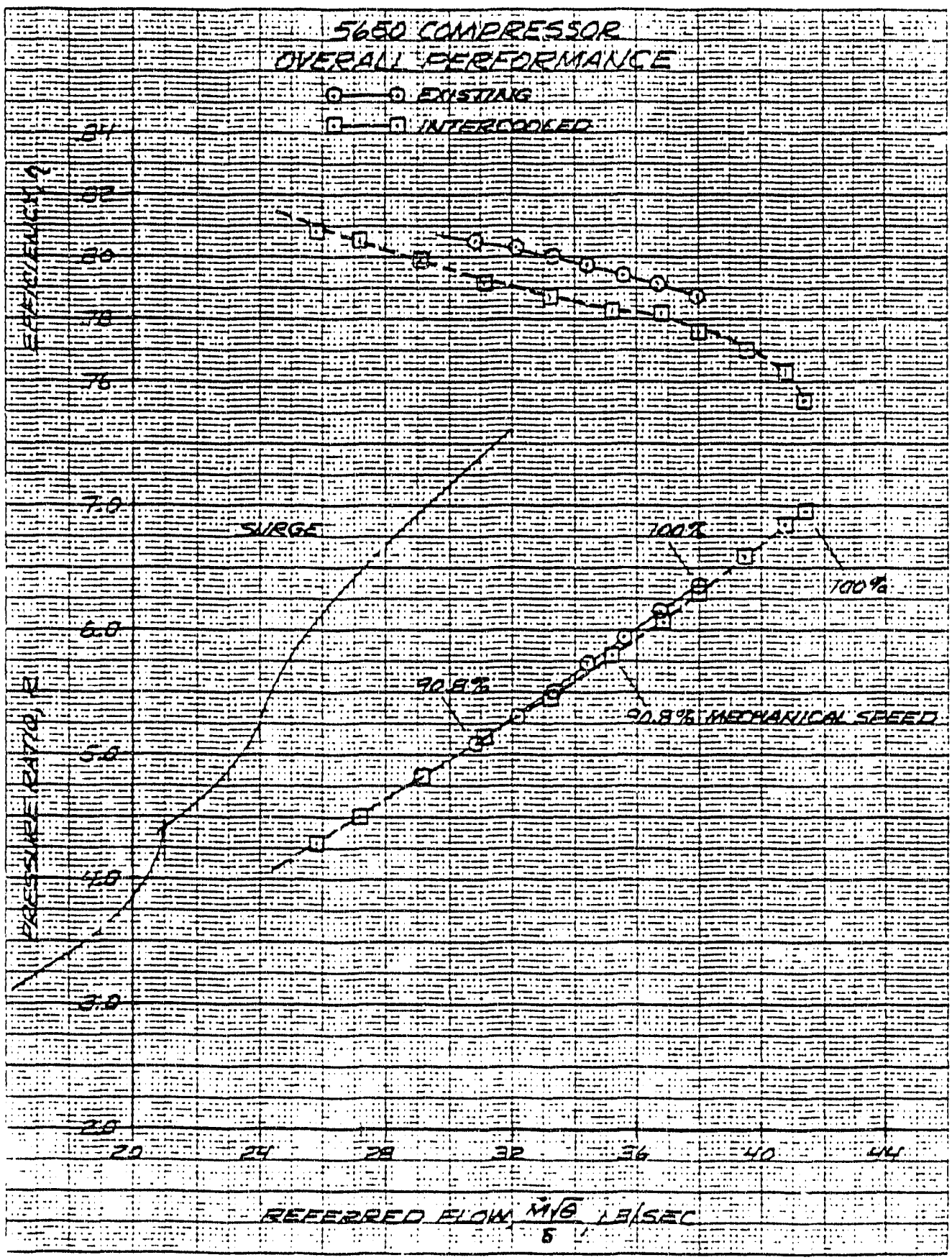

FIGURE 8.5 SOLAR 5650 COMPRESSOR OPERATING LINE [52] 


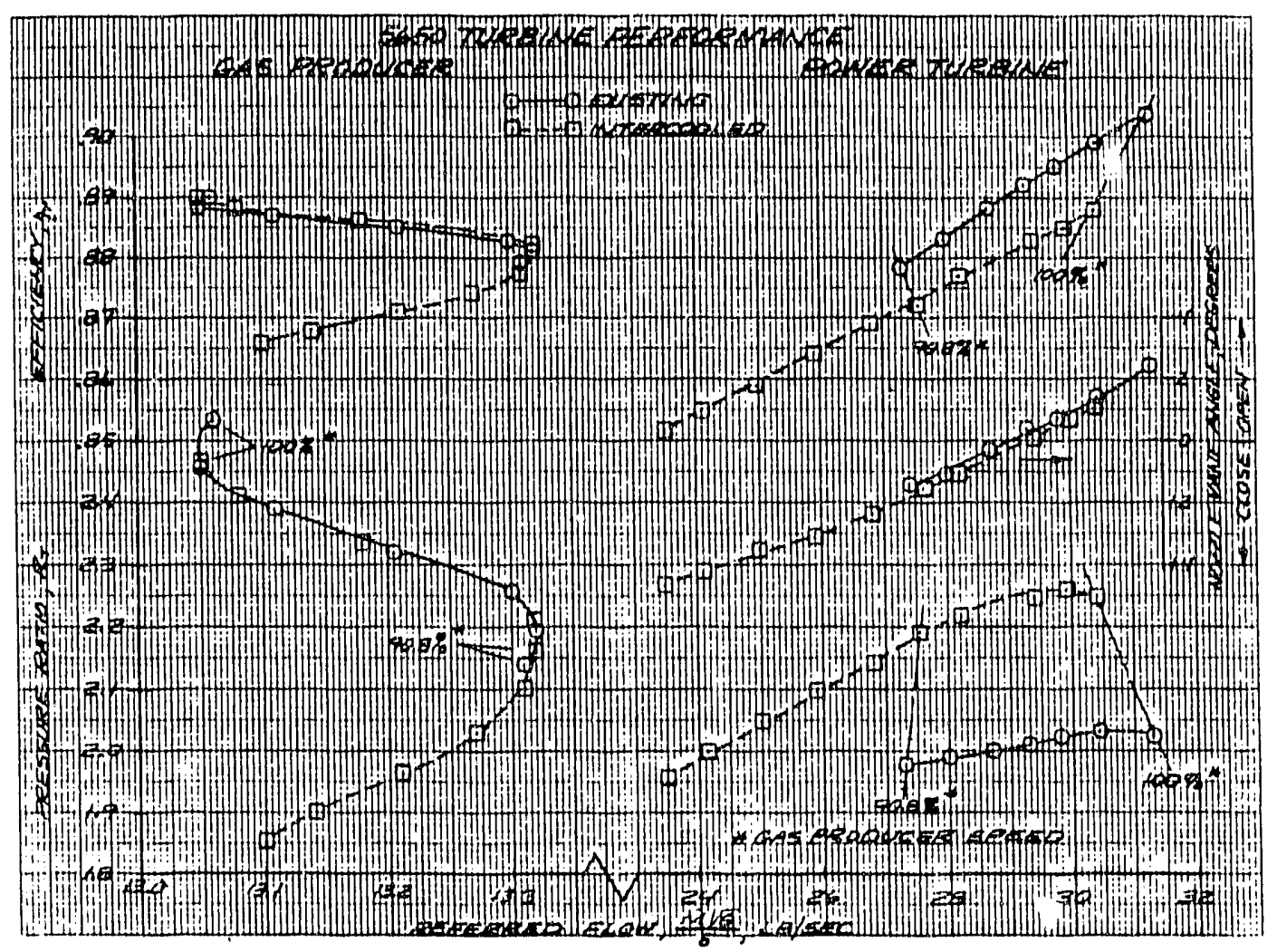

FIGURE 8.6 SOLAR 5650 TURBINE OPERATING LINE [52] 


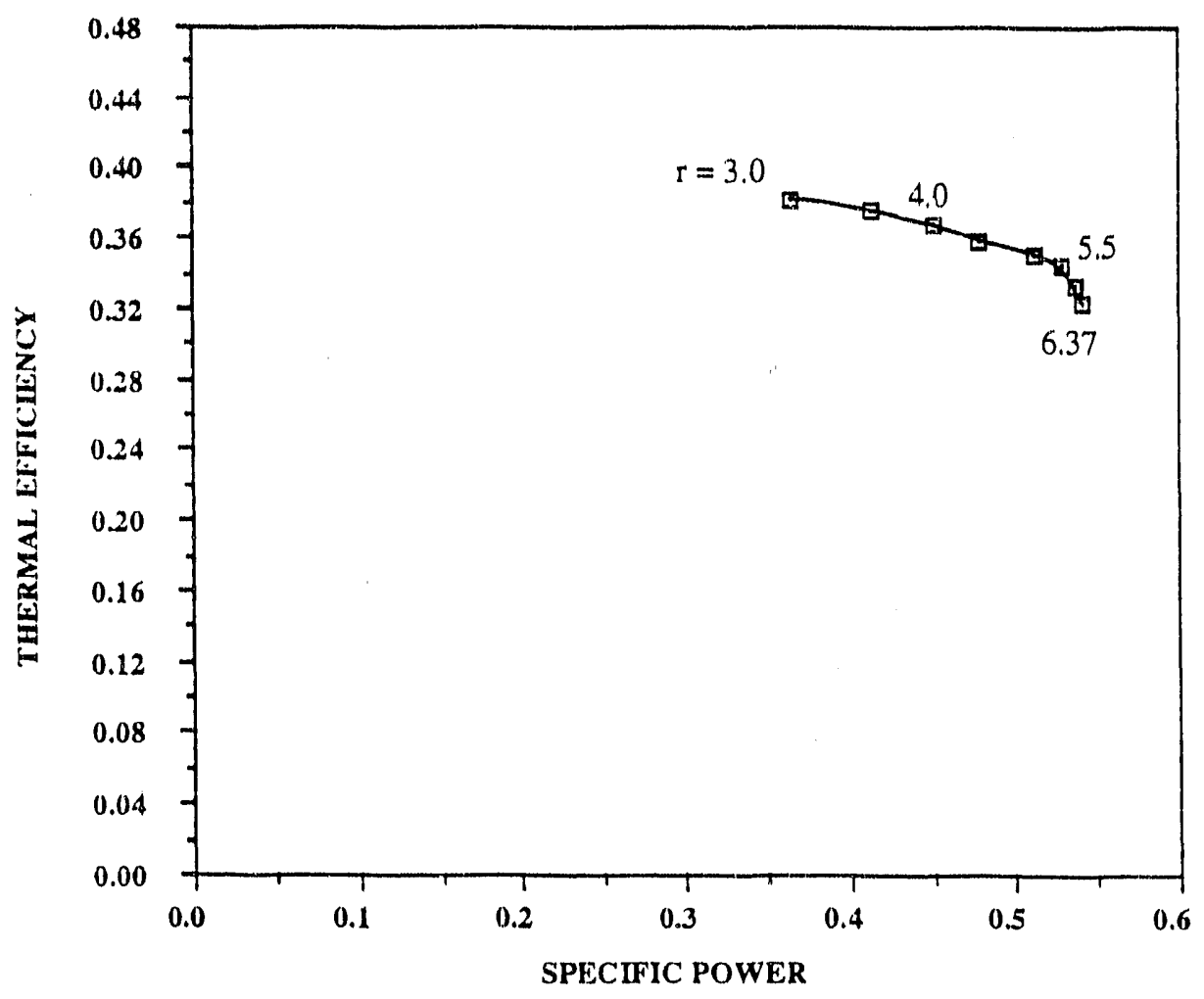

FIGURE 8.7 NICEH 5650 REDUCED-SPEED OPERATION

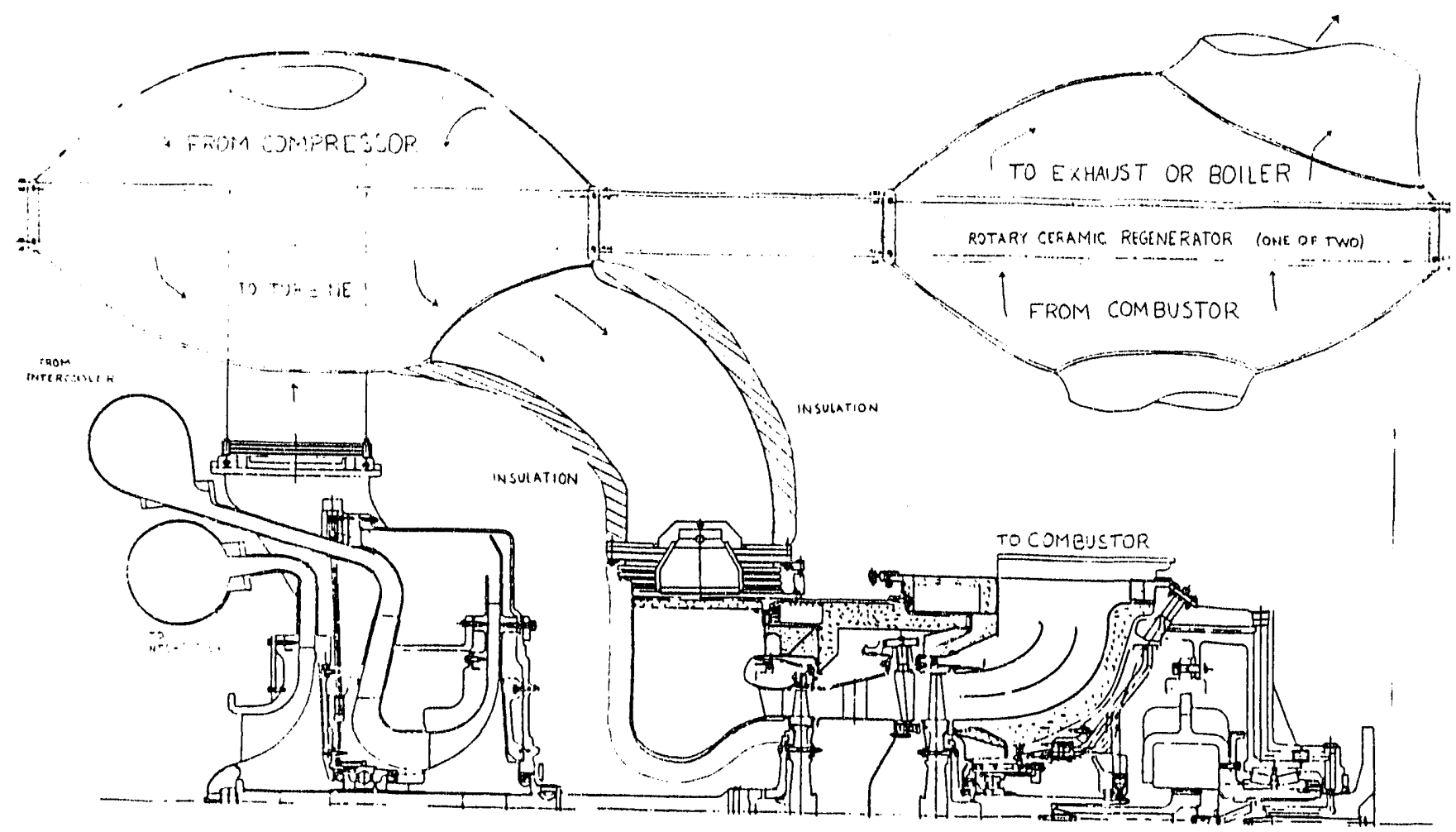

IHTEFGOOLED EXHAUST HEATEL SOLAR 5650

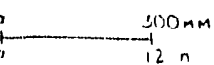

FIGURE 8.8 ICEH 5650 ENGINE CROSS SECTION 
comparison of the optimal NICEH 5650 and the reduced-speed NICEH 5650 at a pressure ratio of 4.0 is shown in Table 8.15 .

TABLE 8.15 OVERALL PERFORMANCE COMPARISON OPTIMAL VS REDUCED-SPEED DESIGN

\begin{tabular}{lcc}
\hline & $\begin{array}{c}\text { optimal } \\
\text { design }\end{array}$ & $\begin{array}{c}\text { reduced-speed } \\
\text { design }\end{array}$ \\
\hline thermal efficiency $(\%)$ & 38.5 & 36.8 \\
power output (kW) & 2490 & 1479 \\
pressure ratio & 4.0 & 4.0 \\
mass flow (kg/s) & 17.22 & 11.34 \\
\hline
\end{tabular}

The net power output of the reduced-speed model is over 40 percent less than the net power of the optimal design-point model. The reduced mass flow at lower pressure ratios is the primary reason for the power output deficit.

\subsection{IC EXHAUST-HEATED 5650 ENGINE}

Figure 8.8 is a schematic drawing of the IC exhaust-heated 5650 using a core 503A (designed with an effectiveness of 0.975 ) for the regenerator matrix. The list below summarizes the major dimensions of this regenerator.

$\begin{array}{ll}\text { Diameter : } & 3.5 \mathrm{~m} \\ \text { Thickness: } & 0.14 \mathrm{~m} \\ \text { Cold-side annular area : } & 1.86 \mathrm{~m}^{2} \\ \text { Hot-side annular area : } & 5.40 \mathrm{~m}^{2} \\ \text { Mass : } & 809 \mathrm{~kg} \\ \text { Rotation : } & 1.85 \mathrm{rpm} \\ \text { Motor Power : } & 12.0 \mathrm{~kW} \\ \text { Radial seal leakage : } & 0.37 \mathrm{~kg} / \mathrm{s} \\ \text { Circumferential seal leakage : } & 0.16 \mathrm{~kg} / \mathrm{s}\end{array}$

Table 8.16 below describes the data obtained at design-point for the three different regenerator core types.

TABLE 8.16 REGENERATOR SIZE FOR DIFFERENT CORE TYPES

\begin{tabular}{lc|c|c|c}
\hline core No. & $(--)$ & $503 \mathrm{~A}$ & $504 \mathrm{~A}$ & $505 \mathrm{~A}$ \\
\hline mass & $(\mathrm{kg})$ & 809 & 441 & 1120 \\
diameter & $(\mathrm{m})$ & 3.5 & 3.6 & 3.3 \\
thickness & $(\mathrm{m})$ & 0.14 & 0.06 & 0.30 \\
time of rotation & $(\mathrm{s})$ & 32 & 18 & 45 \\
\hline
\end{tabular}

The following sections describe the results obtained in examining the three different options mentioned earlier for obtaining an ICEH 5650 . 


\subsection{ICEH 5650 OPTION 1 - RUN ENGINE AT ORIGINAL PRESSURE RATIO}

Although this option may seem trivial, it should provide an economic alternative to the redesign of all turbomachinery. Table 8.17 below compares this option with the IC base 5650 engine.

TABLE 8.17 OVERALL PERFORMANCE COMPARISON IC 5650 VS ICEH 5650

\begin{tabular}{lcc}
\hline & IC 5650 & ICEH 5650 \\
\hline thermal efficiency $(\%)$ & 36.3 & 35.8 \\
power output (kW) & 3520 & 3257 \\
compressor pressure ratio & 6.96 & 6.96 \\
\hline
\end{tabular}

\subsection{ICEH 5650 OPTION 2 - REDESIGN ALL TURBOMACHINERY}

The second alternative to achieve the optimal pressure ratio for the IC exhaust-heated 5650 involved redesigning all of the turbomachinery. The efficiency of the redesigned turbomachinery was maximized at the low-pressure-ratio design point.

In an effort to keep the flow path and overall size of the engine as near to the base 5650 design as possible, the mass-flow rate and turbine-inlet temperature were held constant. The compressor rotational speed was allowed to vary from the IC base 5650 design speed but was constrained by the existing dimensions of the compressor turbine in order to simplify the alteration of this turbine. The preliminary design of the turbines was again accomplished using Tampe's TURBINE computer program.

The compressor-design parameters used are presented in Table 8.18. The final compressor performance and dimensions are compared with the IC base 5650 parameters in Table 8.19. The velocity-diagram data for each stage are contained in Table 8.20 and a schematic of the two stages is shown in Figures 8.9 and 8.10 .

TABLE 8.18 COMPRESSOR DESIGN PARAMETERS

\begin{tabular}{|c|c|c|}
\hline & stage 1 & stage 2 \\
\hline $\begin{array}{l}\text { speed (rpm) } \\
\text { pressure ratio } \\
\text { polytropic efficiency }(\%) \\
\phi_{1}\end{array}$ & $\begin{array}{r}12,500 \\
2.26 \\
87.0 \\
0.47\end{array}$ & $\begin{array}{r}12,500 \\
2.04 \\
82.0 \\
0.38\end{array}$ \\
\hline$\phi_{2}$ & 0.62 & 0.49 \\
\hline$\psi$ & -0.9 & -0.9 \\
\hline
\end{tabular}




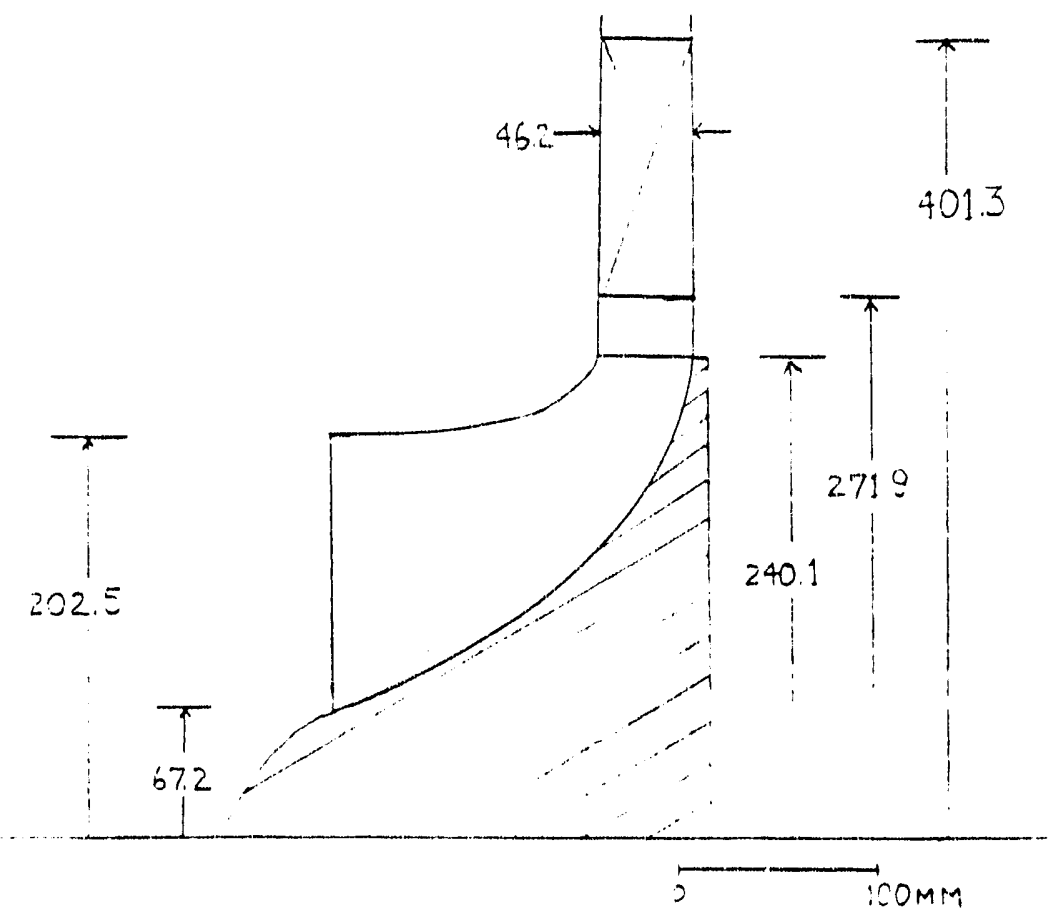

FIGURE 8.9 ICEH 5650 COMPRESSOR STAGE I SCHEMATIC

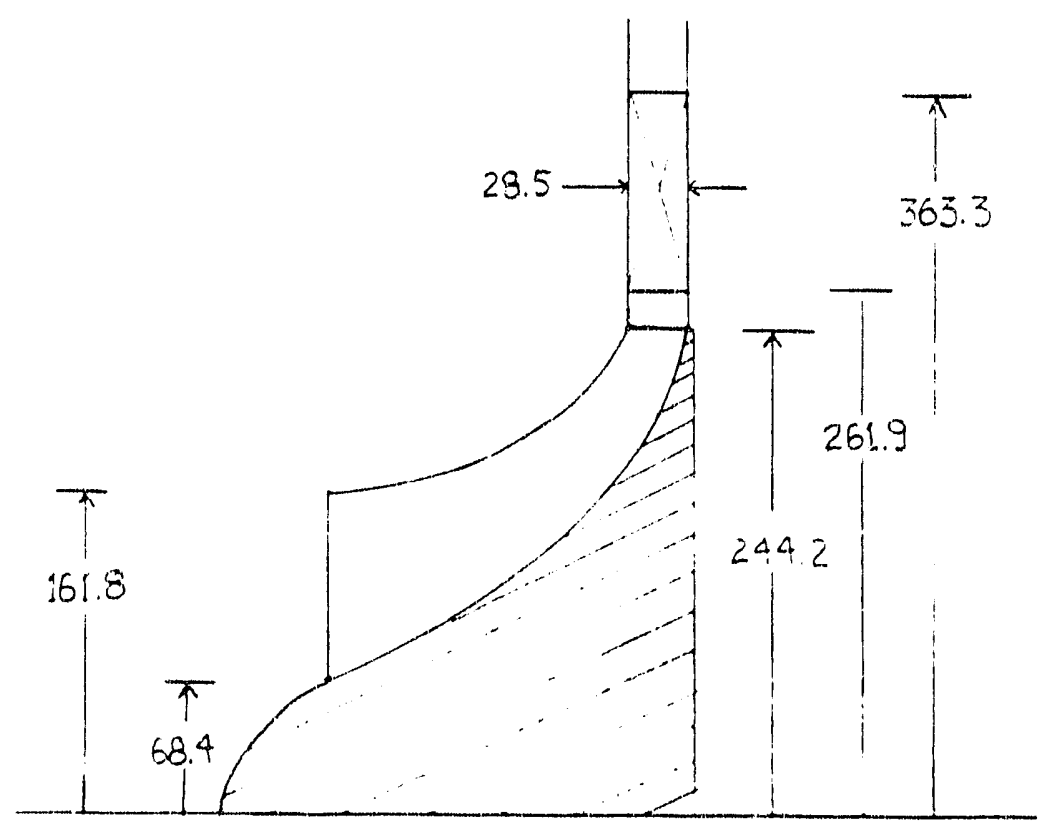

FIGURE \&.10 ICEH 5650 COMPRESSOR STAGE 2 SCHEMATIC 
TABLE 8.19 COMPARISON OF REDESIGNED COMPRESSOR GEOMETRY FOR ICEH 5650

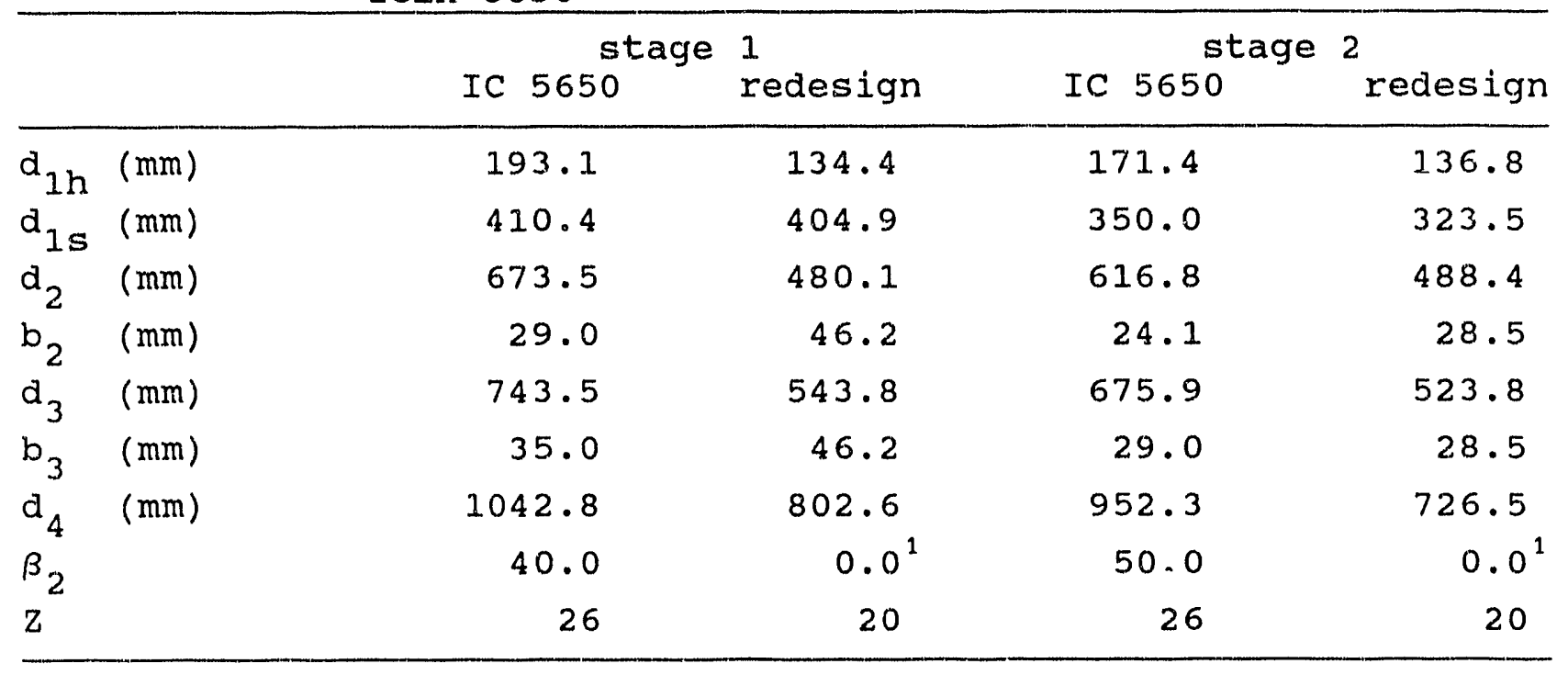

TABLE 8.20 REDESIGNED NICEH 5650 COMPRESSOR VEIOCITY-DIAGRAM DATA

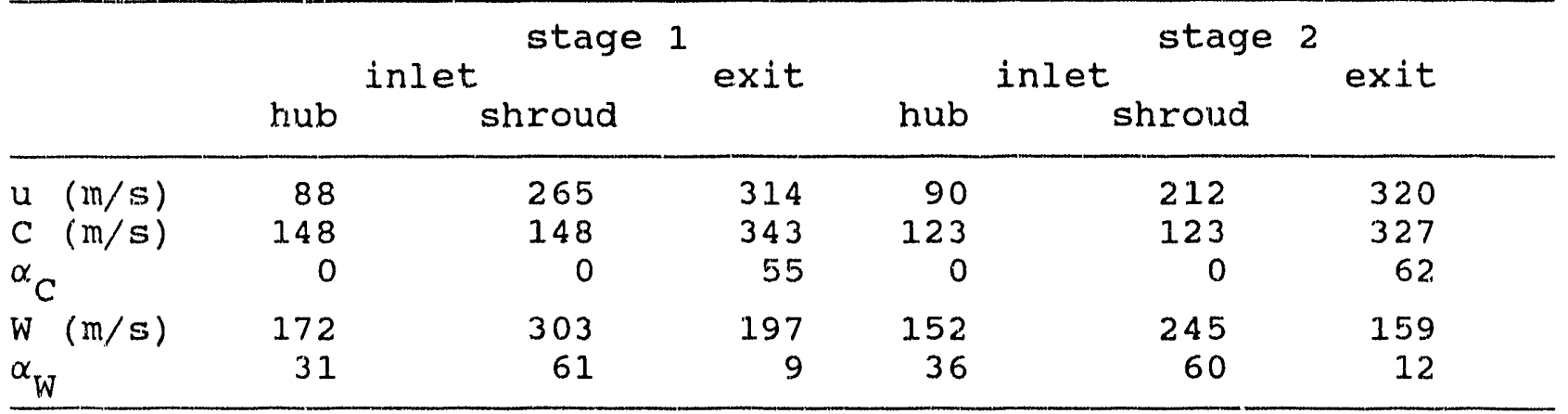

The design-point performance of each centrifugal compressor stage was verified using Dallenbach's performance-prediction method. The resulting polytropic efficiency and pressure-ratio prediction for the new geometry compared reasonably well with the design intent, as can be seen from Table 8.21 .

TABLE 8.21 COMPRESSOR DESIGN INTENT VS PREDICTION

\begin{tabular}{lcccc}
\hline & $\begin{array}{c}\text { polytropic } \\
\text { design }\end{array}$ & $\begin{array}{c}\text { efficiency } \\
\text { predicted }\end{array}$ & $\begin{array}{c}\text { pressure ratio } \\
\text { design }\end{array}$ & predicted \\
\hline stage 1 & 87.0 & 89.6 & 2.21 & 2.11 \\
stage 2 & 82.0 & 85.3 & 2.04 & 2.16 \\
\hline
\end{tabular}

The constant-hub-diameter geometry for the gas-producer turbine is compared with the IC base 5650 cylindrical annulus design in Table 8.22. The chosen compressor speed of $12,500 \mathrm{rpm}$ resulted

1. See footnote on page 124 
from seeking to minimize the changes to the gas-producer turbine when running at its modified pressure ratio.

TABLE 8.22 GAS-PRODUCER TURBINE GEOMETRY FOR REDESIGNED TURBOMACHINERY OPTION

\begin{tabular}{lllll} 
& \multicolumn{2}{c}{ base 5650} & \multicolumn{2}{c}{ redesign } \\
& vane & blade & vane & blade \\
\hline$d_{h}(\mathrm{~mm})$ & 463.6 & 463.6 & 463.7 & 463.7 \\
$d_{t}(\mathrm{~mm})$ & 589.3 & 589.3 & 535.3 & 555.6 \\
$A_{n}\left(\mathrm{~m}^{2}\right)$ & 0.104 & 0.104 & 0.056 & 0.074 \\
\hline
\end{tabular}

The geometry for the power turbine is shown compared with the IC base 5650 dimensions in Table 8.23. The power-turbine speed remains the same as the base engine but the pressure ratio has now been changed due to operation at the chosen optimal pressure ratio. A schematic of the redesigned turbines is presented in F.gure 8.11 .

TABLE 8.23 POWER-TURBINE GEOMETRY FOR REDESIGNED TURBOMACHINERY OPIION

\begin{tabular}{llcll} 
& \multicolumn{2}{c}{ base } & 5650 & \multicolumn{2}{c}{ redesign } \\
\hline$a_{h}(m m)$ & vane & blade & vane & blade \\
$d_{t}(m m)$ & 468.6 & 468.6 & 500.0 & 500.0 \\
$A_{n}\left(m^{2}\right)$ & 688.2 & 688.2 & 614.7 & 644.7 \\
\hline
\end{tabular}

The mean-diameter velocity-diagram data for the redesigned turbines are shoin in Table 8.24 .

TABLE 8.24 MEAN-DIAMETER TURBINE VELOCITY-DIAGRAM DATA FOR REDESIGNED TURBOMACHINERY OP'TION

\begin{tabular}{lcrrr}
\hline & \multicolumn{2}{c}{$\begin{array}{c}\text { gas-producer } \\
\text { inlet }\end{array}$} & $\begin{array}{c}\text { turbine } \\
\text { exit }\end{array}$ & power turbine \\
inlet & $\begin{array}{r}\text { exit } \\
\hline \mathrm{Rn}\end{array}-_{\psi}--$ & 0.51 & -- & 0.55 \\
$\phi$ & -- & 1.63 & -- & 1.49 \\
$\mathrm{C}(\mathrm{m} / \mathrm{s})$ & 0.86 & 0.90 & 0.80 & 0.86 \\
$\alpha_{\mathrm{C}}$ & 534 & 322 & 474 & 294 \\
$\mathrm{~W}$ & 57 & -17 & 57 & -15 \\
$\alpha_{\mathrm{W}}$ & 309 & 536 & 268 & 498 \\
\hline
\end{tabular}

The design-intent efficiency of both turbines was verified using the three turbine efficiency-prediction techniques previousIy described. The results obtained, shown in Table 8.25 , agree 


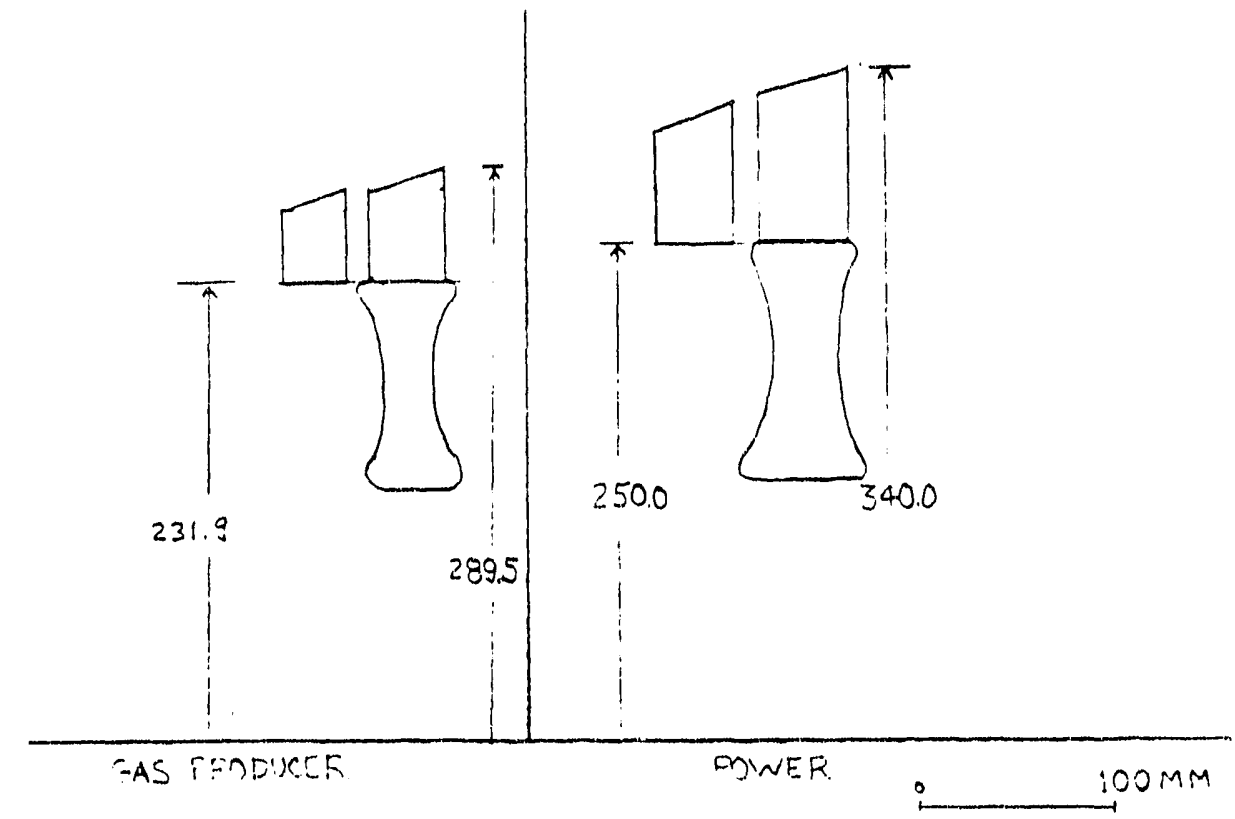

FIGURE 8.11 ICEH 5650 REDESIGNED-TURBINE SCHEMATIC

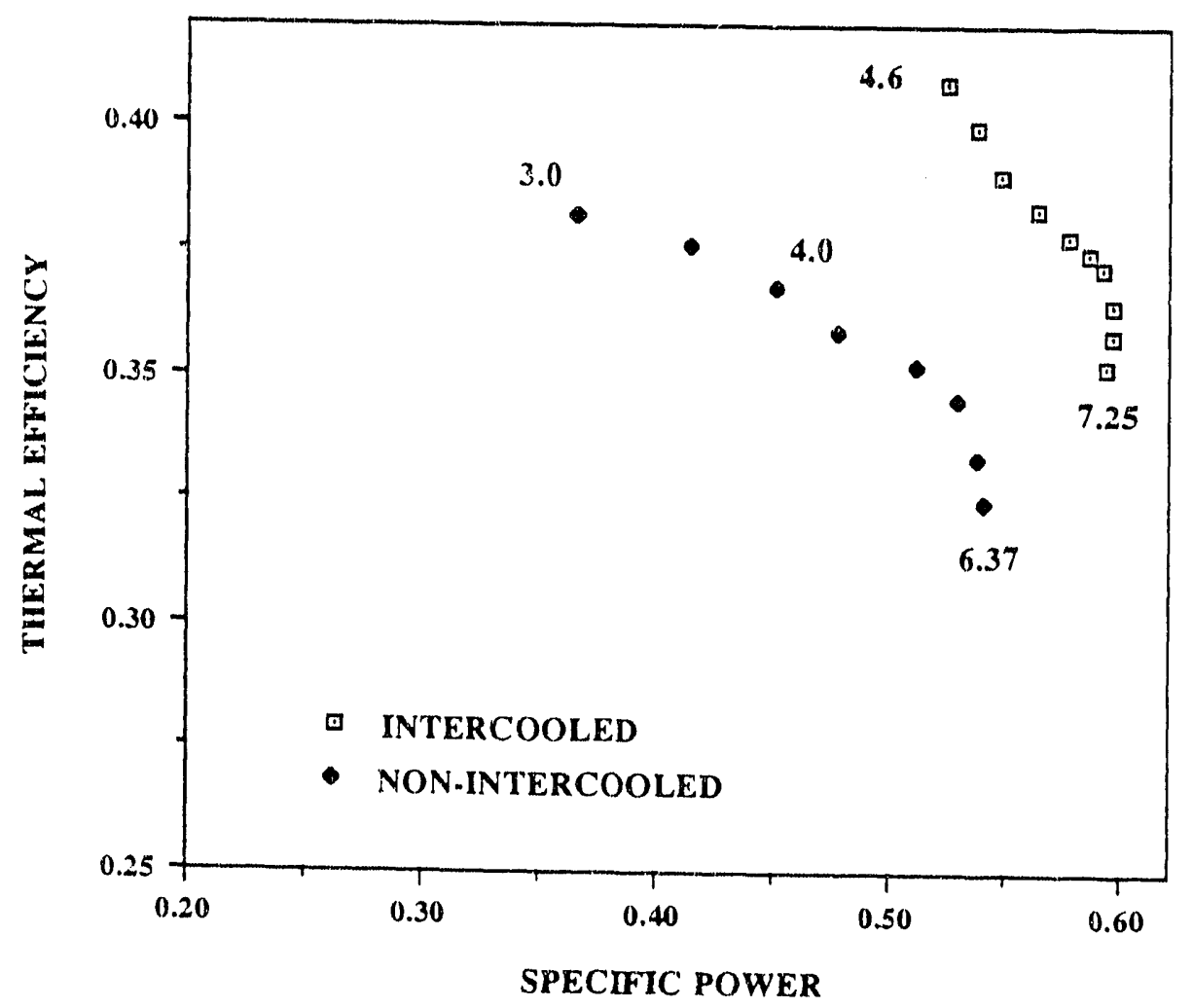

FIGURE 8.12 REDUCED-SPEED OPERATION OF ICEH AND NICEH 5650 
well with the design-intent polytropic efficiencies used in the calculations.

TABLE 8.25 DESIGN INTENT VS PREDICTED EFFICIENCY FOR TURBINES design intent Wilson's Exact Trim. Binom. GE

gas-producer

turbine

power turbine

88.7

87.9

90.1.

89.8

87.7

89.5

91.7

91.6

\subsection{ICEH 5650 OPTION 3 - RUN EXISTING TURBOMACHINERY AT REDUCED-SPEED OPERATION}

The reduced-speed operation of the IC exhaust-heated 5650 with no turbomachinery modifications was the last option considered. The analysis follows the same procedure described in section 8.4, therefore pertinent results and comparisons will only be presented. Figure 8.12 compares the reduced-speed operation of the two exhaust heated cycles (the NICEH and the ICEH 5650 cycles). As expected, intercooling provides a marked increase in the reduced-speed performance of the exhaust-heated cycle.

Table 8.26 provides a performance comparison between options 2 and 3 for the ICEH engine. Although the reduced-speed thermal efficiency matches that of the turbomachinery redesign option, this is achieved at a great sacrifice in net power.

TABLE 8.26 OVERALL PERFORMANCE COMPARISON OPTIMAL VS REDUCED-SPEED DESIGN

\begin{tabular}{lrc}
\hline & $\begin{array}{c}\text { optimal } \\
\text { design }\end{array}$ & $\begin{array}{c}\text { reduced-speed } \\
\text { design }\end{array}$ \\
\hline thermal efficiency $(\%)$ & 40.8 & 40.9 \\
power output $(\mathrm{kW})$ & 2961 & 1875 \\
pressure ratio & 4.5 & 4.6 \\
mass flow $(\mathrm{kg} / \mathrm{s})$ & 18.77 & 12.34 \\
\hline
\end{tabular}

\subsection{INCREASED TURBINE-INLET TEMPERATURE}

The exhaust-heated 5650 models were run at the optimal pressure ratio with increased turbine-inlet temperatures to determine the potential beriefit to the overall cycle performance. solar maintains that more effective gas-producer turbine-blade cooling would allow the turbine-inlet temperature (TIT) of the engine to climb from $1241 \mathrm{~K}$ to $1339 \mathrm{~K}$. Although solar does not mention any other changes, the cooling flow to the the gas-producer turbine was increased from $2.5 \%$ to $3.5 \%$ and the power-turbine cooling was increased from $0.8 \%$ to $1.5 \%$ to be conservative. The resulting overall performance is compared to the optimal pressure-ratio exhaust-heated 5650 models in Table 8.27 and 8.28 . 
TABLE 8.271339 TIT CYCLE COMPARISON - NICEH ENGINE

\begin{tabular}{lcc}
\hline & $\begin{array}{c}\text { optimal } \\
\text { design }\end{array}$ & $\begin{array}{c}133 \text { K TIT } \\
\text { design }\end{array}$ \\
\hline thermal efficiency $(\%)$ & 38.5 & 41.0 \\
power output $(\mathrm{kW})$ & 2490 & 2850 \\
\hline
\end{tabular}

TABLE $8.28 \quad 1339$ TIT CYCLE COMPARISON - ICEH ENGINE

\begin{tabular}{lcc}
\hline & $\begin{array}{c}\text { optimal } \\
\text { design }\end{array}$ & $\begin{array}{c}1339 \text { K TIT } \\
\text { design }\end{array}$ \\
\hline $\begin{array}{l}\text { thermal efficiency } \\
\text { power output }(\mathrm{kW})\end{array}$ & 40.8 & 43.3 \\
\hline
\end{tabular}

The potential performance benefit from this cycle is enormous. both power output and efficiency increase while specific fuel consumption decreases. There could also be some disadvantages to this cycle. The life of some of the uncooled engine parts may be compromised and the increased coal-firing temperature could lead to a significant rise in the stickiness of the coal ash which would have an adverse effect on the regenerator operation. Nevertheless, the prospect of running a more efficient and powerful cycle is noteworthy.

The increase in performance of the intercooled exhaust-heated cycle is very similar to the increase obtained with the nonintercooled exhaust-heated cycle with TIT raised to $1339 \mathrm{~K}$. A composite plot of the performance of the various options and cycle modifications for each off-the-shelf engine model compared with a Caterpillar 3516 diesel engine is shown in Figure 8.13.

\subsection{SUMMARY}

This section presented the three prinary design options for the NICEH 5650 and the ICEH 5650 engines. The last section presented the performance of the optimal. design for both engines if the TIT were increased from $124 \mathrm{~K}$ to $1339 \mathrm{~K}$. More detailed information on the off-the-shelf designs can be found in $[22,23]$. 


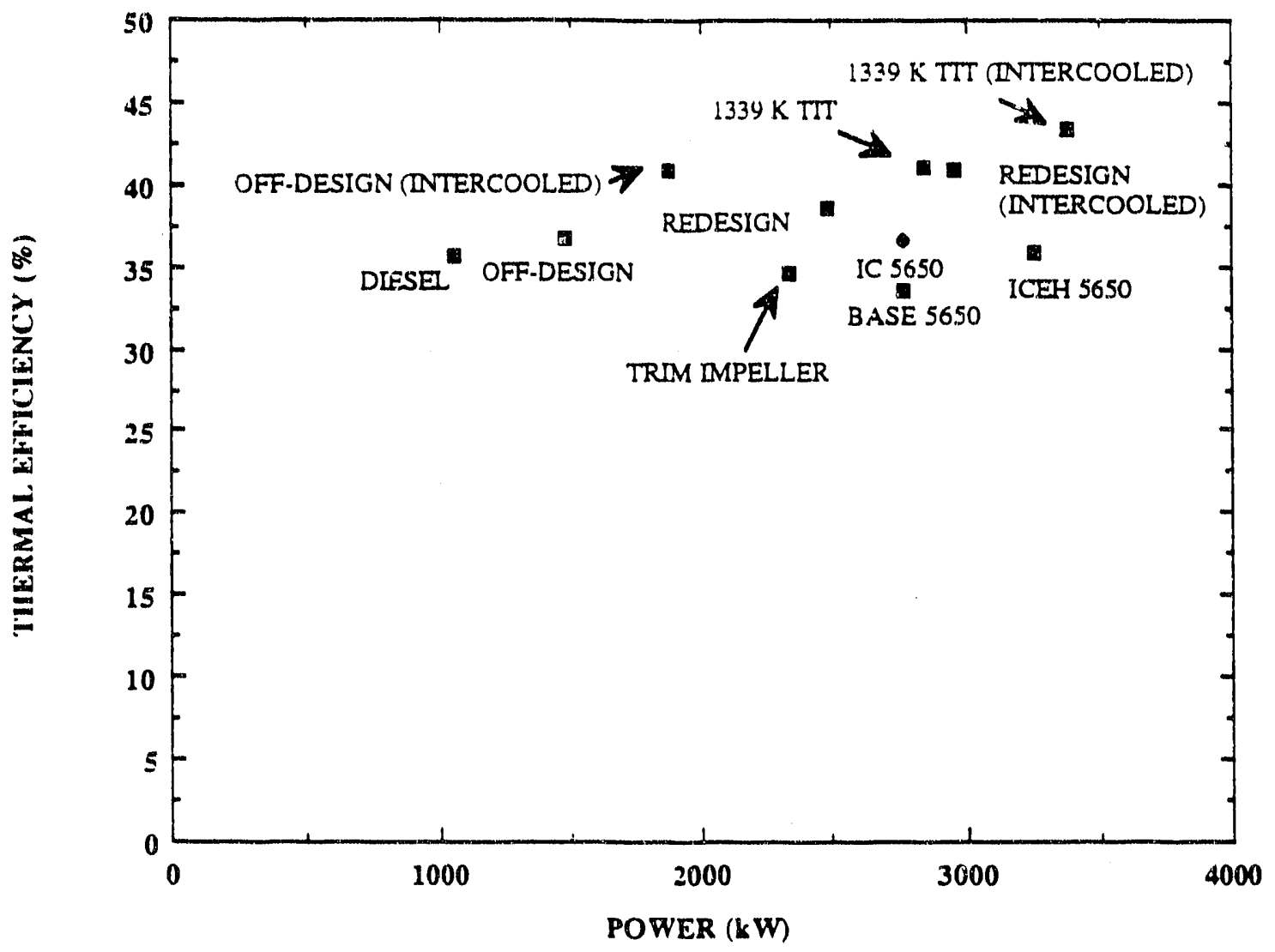

FIGURE 8.13 DESIGN PERFORMANCE OF ALL OPTIONS 


\subsection{ECONOMIC ASSESSMENT}

This section makes a thorough life-cycle-cost assessment of the blue-sky and off-the-shelf designs. Consistent fuel and maintenance costs have been used for all the engines in order to facilitate comparisons. The first two sections explain the method used in the life-cycle-cost assessment and in determining the prices of the various engines, respectively. Later sections provide the life-cycle costs for the blue-sky and off-the-shelf engines.

\subsection{LIFE-CYCLE-COST METHOD}

The life-cycle-cost model used in this analysis was developed by R.B. Spector [64] to evaluate the relative merits of varying types of industrial gas turbines. The following elements are considered in the model: initial investment cost, cost of financing, variations in equipment availability, cost of fuel, cost of fuel treatment and/or preparation, direct operating labor costs and spare parts for preventive and corrective actions. These elements are contained in the three terms which comprise the production cost: annual investment cost, annual fuel cost, and annual maintenance cost. The life-cycle-cost equation (9.1) calculates the average present value cost per kilowatt-hour of electricity generated over the life of the unit.

$$
C=I \frac{\left[\frac{i}{1-(i+1)^{-n}}\right]}{(A)(k W)(8760)(G)}+\frac{F}{(293)(E)}+\frac{M}{k W}
$$

Here the following may be defined.

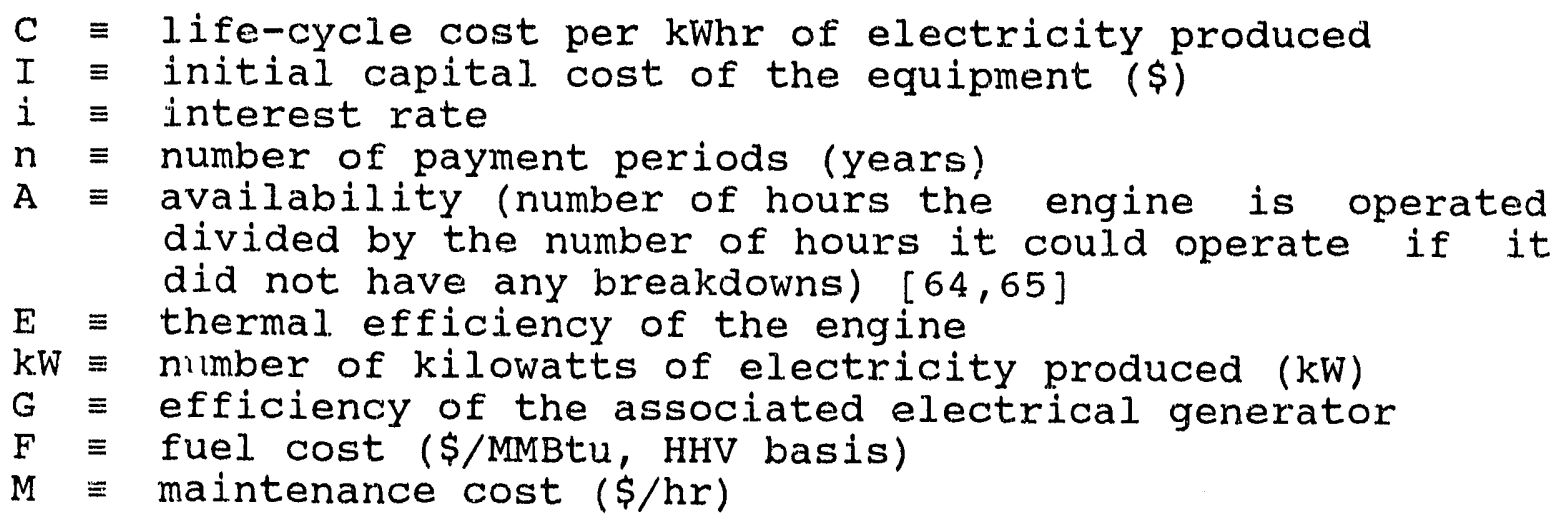

The accuracy of the method is adequate for the purpose of evaluating the relative costs of the different options but spector does not advocate its use to calculate absolute costs. 
Some of the parameters in Equation 9.1 were set equal to conitant values for all the different engines: $G$ was set equal to $0.98, \mathrm{n}$ was set equal to 20 years, and $i$ was set equal to 0.075 . Some of these values were changed, however, when the economic sensitivity study was performed as will be explained later.

\subsection{ENGINE COMPONENT AND FUEL COSTS}

A modified version of an equation found in [66] was used to obtain the capital cost in 1990 dollars of the different regenerators. The form of the equation is shown below.

capital cost of regenerator $=a_{1} M+a_{2} P+a_{3} A_{h}+a_{4}(V)^{0.5}$

Here the following can be defined.

$$
\begin{aligned}
& M \equiv \text { mass of regenerator in } \mathrm{kg} \\
& \mathrm{P} \equiv \text { perimeter of seals on one side in } \mathrm{m} \\
& \mathrm{A}_{\mathrm{h}} \equiv \text { total heat-transfer area in } \mathrm{m}^{2} \\
& \mathrm{~V} \equiv \text { total volume of the regenerator in } \mathrm{m}^{3}
\end{aligned}
$$

The following values for the coefficients were obtained based on preliminary information obtained from a regenerator-core manufacturer.

$$
\begin{aligned}
a_{1} & =14.49 \$ / \mathrm{kg} \\
a_{2} & =1.32 \$ / \mathrm{m} \\
a_{3} & =34.15 \$ / \mathrm{m}^{2} \\
a_{4} & =1000.00 \$ / \mathrm{m}^{3 / 2}
\end{aligned}
$$

Table 9.1 below summarizes the capital cost, obtained using Equation 9.2, of the different regenerator cores for the blue-sky designs. The costs shown are in 1990 dollars and to the nearest thousand.

TABLE 9.1 REGENERATOR CAPITAL COST FOR DIFFERENT CORE TYPES

\begin{tabular}{lrr}
\hline Core No. & CXEB & CICXEB \\
\hline $503 A$ & $\$ 75,000$ & $\$ 60,000$ \\
$504 \mathrm{~A}$ & 56,000 & 46,000 \\
$505 \mathrm{~A}$ & 82,000 & 65,000 \\
\hline
\end{tabular}

Based on information in [52] it is possible to estimate the price of the intercooler for the blue-sky and off-the-shelf engines as about $\$ 20,000$. Information obtained from issues of Turbomachinery International (1985 through 1990) as well as from conversations with a gas-turbine engine manufacturer indicates that a reasonable conservative estimate of the price of the blue- 
sky gas-turbine engines (installed with a generator) is around $\$ 900,000$. The price of the combustor and any heat exchangers is not included and must be added separately.

The initial cost of the solar 5650 with the exhaust-heated modifications is difficult to estimate. The cost of the base 5650 unit is not well established because solar has leased them, not sold them, and then only to a limited number of pilot sites. A "rough" price of $\$ 890,000$ for the Solar NIC base 5650 engine without the recuperator but including installation and generator cost was obtained Erom solar. The price of the turbomachinery modifications were scaled using sample engine data supplied by a gasturbine engine manufacturer. The prices obtained are for production and do not include development costs.

A cost of $\$ 250,000$ was added to the price of the exhaustheated engines (blue-sky and off-the-shelf) based on information obtained from a private communication with Professor Janos Beer of MIT. The breakdown of the components that are included in this cost are as follows. A pulverizer, a pit (supply of two to three days of coal), a hopper (eight-hour supply), the fan providing the secondary air for combustion, and the induced-draft fan could be acquired for $\$ 200,000$. The remaining $\$ 50,000$ would be allocated for a bag-house stack-gas cleaner.

The cost of the atmospheric-pressure slagging combustor, fuel system and extra ducting was simply estimated. The estimates will be included in other sections of this chapter.

Based on data in [67] the prices for the fuels used in the various engines studied were as follows (in 1990 dollars): $\$ 1.86 /$ MMBtu for coal, $\$ 4.34 /$ MMBtu for diesel and other distillate fuels, and $\$ 2.97 / \mathrm{MMBtu}$ for natural gas. The price of coal used is that for raw coal since it would be pulverized on location. The effects of different coal-price levels are discussed in the sensitivity analysis below. The thermal efficiency and the power output obtained for the various exhaust-heated engines were reduced by one percent in the economic model to account for the power requirements of the pulverizer and the fans.

Along with the blue-sky engines and the various off-the-shelf options six different systems were also priced for comparison purposes. The six other engines include a small gas-fired cogeneration plant [67], an open-cycle internal-combustion locomotive engine (burns diesel fuel) $[9,68]$, a coal-fired open-cycle externalcombustion gas-turbine locomotive engine $[9,68]$, a coal-fired closed-cycle locomotive engine [9,68], a diesel engine [69], and the Solar 5650 base engine [23].

\subsection{MAINTENANCE COST}

The maintenance cost of a gas-turbine engine can be taken as $\$ 0.005 / \mathrm{kW}-\mathrm{hr}$, and as $\$ 0.01 / \mathrm{kW}-\mathrm{hr}$ for a diesel engine [69]. These values were used if no other information concerning the maintenance cost of the engine was available. 
The maintenance cost of the exhaust-heated engines (both blue-sky and off-the-shelf) was set at double the base-gas-turbine figure to account for the extra components of the exhaust-heated cycle plus additional costs related to the handling of the coal fly ash and the purchasing of hydrated lime for sulfur removal. The cost of handling the fly ash is approximately $\$ 30$ per ton of ash produced and the cost of the lime is approximately $\$ 70$ per ton of lime $\mathrm{i}^{2}$. In the exhaust-heated engines these two extra costs amount to approximately an additional $\$ 2 / \mathrm{hr}$ in maintenance costs. Therefore, $\$ 0.01 / \mathrm{kW}-\mathrm{hr}$ was used to get the "base" maintenance cost for all the exhaust-heated engines and an additional $\$ 2 / \mathrm{hr}$ was added to the "base" maintenance cost to obtain the actual maintenance cost.

An alternative to this approach would be to set the maintenance cost of the exhaust-heated engines equal to that of a gas turbine ( $\$ 10 / \mathrm{hr}$ for a 2 MW unit) and add the cost of changing the regenerators a certain number of times per year. When a regenerator is changed it is assumed that a new regenerator must be purchased and installed into the engine. If both regenerators of the CXEB engine were changed once a year the maintenance cost, using this method, would be about $\$ 29 / \mathrm{hr}$. The corresponding cost in the CICXEB engine would be approximately $\$ 25 / \mathrm{hr}$. Having both regenerators replaced four times per year would increase the maintenance cost of the CXEB engine to $\$ 85 / \mathrm{hr}$ and of the CICXEB engine to $\$ 69 / \mathrm{hr}$. As will be shown in the economic sensitivity analysis, the last two maintenance costs are far too large to allow the engines to compete with other systems.

However, the frequency with which the regenerators would have to be replaced is unknown, nor is it known whether they could be cleaned and reused. Additionally, this analysis was based on telephone prices of the sized regenerator cores, prices which are usually high to establish a bargaining position and to cover contingencies and which may be drastically reduced by competition and mass production. Finally, other heat exchangers have been identified that probably would require a far smaller maintenance cost.

For the analysis the first method described was used to model the maintenance cost. The economic sensitivity analysis studied the effects higher maintenance costs would have on the attractiveness of these engines.

\subsection{ECONOMIC ASSESSMENT OF BLUE-SKY ENGINES}

Table 9.2 below summarizes the values of the remaining unspecified parameters of Equation 9.1 used for the economic assessment of the blue-sky engines.

\footnotetext{
1. From a private communication between Dave w1lson and a power

2. From a private communlcation between Luls Tampe and Frofessor
} 
TABLE 9.2 LIFE-CYCLE CALCULATION PARAMETERS

\begin{tabular}{|c|c|c|c|c|c|c|}
\hline engine & $\begin{array}{c}\mathrm{I} \\
\left(\times 10^{3} \$\right)\end{array}$ & $\begin{array}{l}\mathrm{kW}^{1} \\
(\mathrm{~kW})\end{array}$ & $\begin{array}{c}E^{1} \\
(---)\end{array}$ & $\begin{array}{c}F \\
(\$ / M B t u)\end{array}$ & $\begin{array}{c}M \\
(\$ / h r)\end{array}$ & $\begin{array}{c}A \\
(--)\end{array}$ \\
\hline CXEB & 1339.0 & 1980 & 0.495 & 1.86 & 22.00 & 0.95 \\
\hline CICXEB & 1328.0 & 1980 & 0.505 & 1.86 & 22.00 & 0.95 \\
\hline TRAIN ENGINE 1 & 1022.8 & 2237 & 0.420 & 4.34 & 22.37 & 0.98 \\
\hline TRAIN ENGINE 2 & 1413.0 & 2237 & 0.250 & 1.86 & 37.62 & 0.95 \\
\hline TRAIN ENGINE 3 & 1486.7 & 2237 & 0.300 & 1.86 & 37.62 & 0.95 \\
\hline COGENERATION, GAS & 34.5 & 30 & 0.260 & 2.97 & 0.47 & 0.95 \\
\hline DIESEL & 1900.0 & 2000 & 0.400 & 4.34 & 20.00 & 0.95 \\
\hline 5650 BASE ENGINE & 1140.0 & 2770 & 0.336 & 2.97 & 13.85 & 0.98 \\
\hline NGINE 1 & YYCLE, & INTERNAL & COMBU & ION & & \\
\hline TRAIN ENGINE $2 \equiv$ & OPEN CYCLE, I & EXTERNAL & COMBUS & TION $\quad(\mathrm{C}$ & L FIRED) & \\
\hline TRAIN ENGINE $3 \equiv$ & CLOSED CYCLE & , EXTERNA & AL COMB & USTION $\quad(\mathrm{CC}$ & OAL FIREL & D) \\
\hline
\end{tabular}

The break down of the capital cost of the two blue-sky engines is shown in Table 9.3 below.

TABLE 9.3 CAPITAL COST OF BLUE-SKY ENGINES

\begin{tabular}{lcc}
\hline component & $\begin{array}{c}\text { CXEB } \\
\text { (in thousands) }\end{array}$ & $\begin{array}{c}\text { CICXEB } \\
\text { (in thousands) }\end{array}$ \\
\hline engine & 900.0 & 900.0 \\
ducting & 5.0 & 8.0 \\
intercooler & -20.0 & 20.0 \\
Combustor & 20.0 & 20.0 \\
regenerators & $2 \times(82.0)$ & $2 \times(65.0)$ \\
miscellaneous & 250.0 & 250.0 \\
$\quad$ (see section 9.2) & & \\
total & 1339.0 & 1328.0 \\
\hline
\end{tabular}

Table 9.4 below compares the data obtained from Equation 1 for the six engines analyzed.

TABLE 9.4 LIFE-CYCLE COST SUMMARY $\left(\$ / \mathrm{kWhr} \times 10^{2}\right)$

\begin{tabular}{lcccc}
\hline engine & $\begin{array}{c}\text { capital } \\
\text { cost }\end{array}$ & $\begin{array}{l}\text { fuel } \\
\text { cost }\end{array}$ & maintenance & $\begin{array}{c}\text { Iife-cycle } \\
\text { cost }\end{array}$ \\
\hline CXEB & 0.8134 & 1.282 & 1.111 & 3.207 \\
CICXEB & 0.8067 & 1.257 & 1.111 & 3.175 \\
TRAIN ENGINE 1 & 0.5331 & 3.527 & 1.000 & 5.060 \\
TRAIN ENGINE 2 & 0.7597 & 2.539 & 1.682 & 4.981 \\
TRAIN ENGINE 3 & 0.7994 & 2.116 & 1.682 & 4.597 \\
COGENERATION, GAS & 1.3832 & 3.899 & 1.567 & 6.849 \\
DIESEL & 1.1426 & 3.703 & 1.000 & 5.846 \\
5650 BASE ENGINE & 0.4798 & 3.017 & 0.500 & 3.997 \\
\hline
\end{tabular}

1. The power output and thermal efflclency of the exhaust-heated
engines has been reduced by one percent (see sectlon 9.2 ). 
The lowest iffe-cycle cost is given by the CICXEB engine, despite the high heat-exchanger costs specified.

The Iife-cycle-cost model used also confirmed the findings in [68] that engine 3, the closed-cycle gas turbine, was the most economically attractive unit among the locomotive engines followed by engines 2 and 3 , in that order. The authors of [68], from the Jet Propulsion Laboratory (JPL) of the california Institute of Technology, used a life-cycle-cost model developed at the JPL. This adds a great deal of confldence to the life-cycle-cost model used here.

The economic sensitivity study performed indicates that varying the thermal efficiency produces the largest change in the Iife-cycle cost, as compared to the other parameters in the lifecycle cost model.

Figure 9.1 shows the life-cycle (L.C.) cost versus the thermal efficiency for both blue-sky engines. Figure 9.2 is the lifecycle cost versus the fuel cost of the blue-sky engines. Figure 9.3 is the life-cycle cost versus the maintenance cost, and Figure 9.4 is the life-cycle cost versus the availability of the blue-sky engines. Finally, Figures 9.5 and 9.6 show the life-cycle cost of the CXEB and the CICXEB engines versus the capital cost and interest rate, respectively. In the economic sensitivity study the base case for both blue-sky engines is as described in Table 9.2.

Table 9.5 below shows the effect changing the thermal efficiency (E), the fuel cost (F), the maintenance cost (M), the availability (A), the capital cost (I), and the interest rate (i) individually by 20 percent has on the life-cycle cost of the CXEB and CICXEB engines. Two sets of data are shown for the availability and the thermal efficiency since these parameters do not produce linear changes in the life-cycle cost as do the other variables.

TABLE 9.5 SUMMARY OF ECONOMIC SENSITIVITY STUDY

\begin{tabular}{|c|c|c|c|c|}
\hline \multirow{2}{*}{$\begin{array}{l}\text { parameter } \\
(--)\end{array}$} & \multicolumn{2}{|c|}{ CXEB } & \multicolumn{2}{|c|}{ CICXEB } \\
\hline & $\begin{array}{c}\text { change in } \\
\text { parameter } \\
\left(\begin{array}{l}(0) \\
0\end{array}\right)\end{array}$ & $\begin{array}{c}\text { change in } \\
\text { L.C. cost } \\
\left(\frac{\circ}{\sigma}\right)\end{array}$ & $\begin{array}{c}\text { change in } \\
\text { parameter } \\
\left(\frac{q}{6}\right)\end{array}$ & $\begin{array}{c}\text { Change in } \\
\text { L.C. cost } \\
\left(\frac{q}{\%}\right)\end{array}$ \\
\hline $\mathrm{E}$ & $\begin{array}{l}-20.0 \\
+20.0\end{array}$ & $\begin{array}{l}+10.0 \\
-\quad 6.7\end{array}$ & $\begin{array}{l}-20.0 \\
+20.0\end{array}$ & $\begin{array}{l}+10.0 \\
-\quad 6.6\end{array}$ \\
\hline $\mathrm{F}$ & +20.0 & +8.0 & +20.0 & +7.9 \\
\hline M & -20.0 & -6.9 & -20.0 & -7.0 \\
\hline$A$ & $\begin{array}{l}-20.0 \\
+\quad 5.3\end{array}$ & $\begin{array}{l}+6.3 \\
-1.3\end{array}$ & $\begin{array}{l}-20.0 \\
+\quad 5.3\end{array}$ & $\begin{array}{l}+6.4 \\
-1.3\end{array}$ \\
\hline$I$ & -20.0 & -5.1 & -20.0 & -5.1 \\
\hline$i$ & +20.0 & +3.0 & +20.0 & +3.0 \\
\hline
\end{tabular}




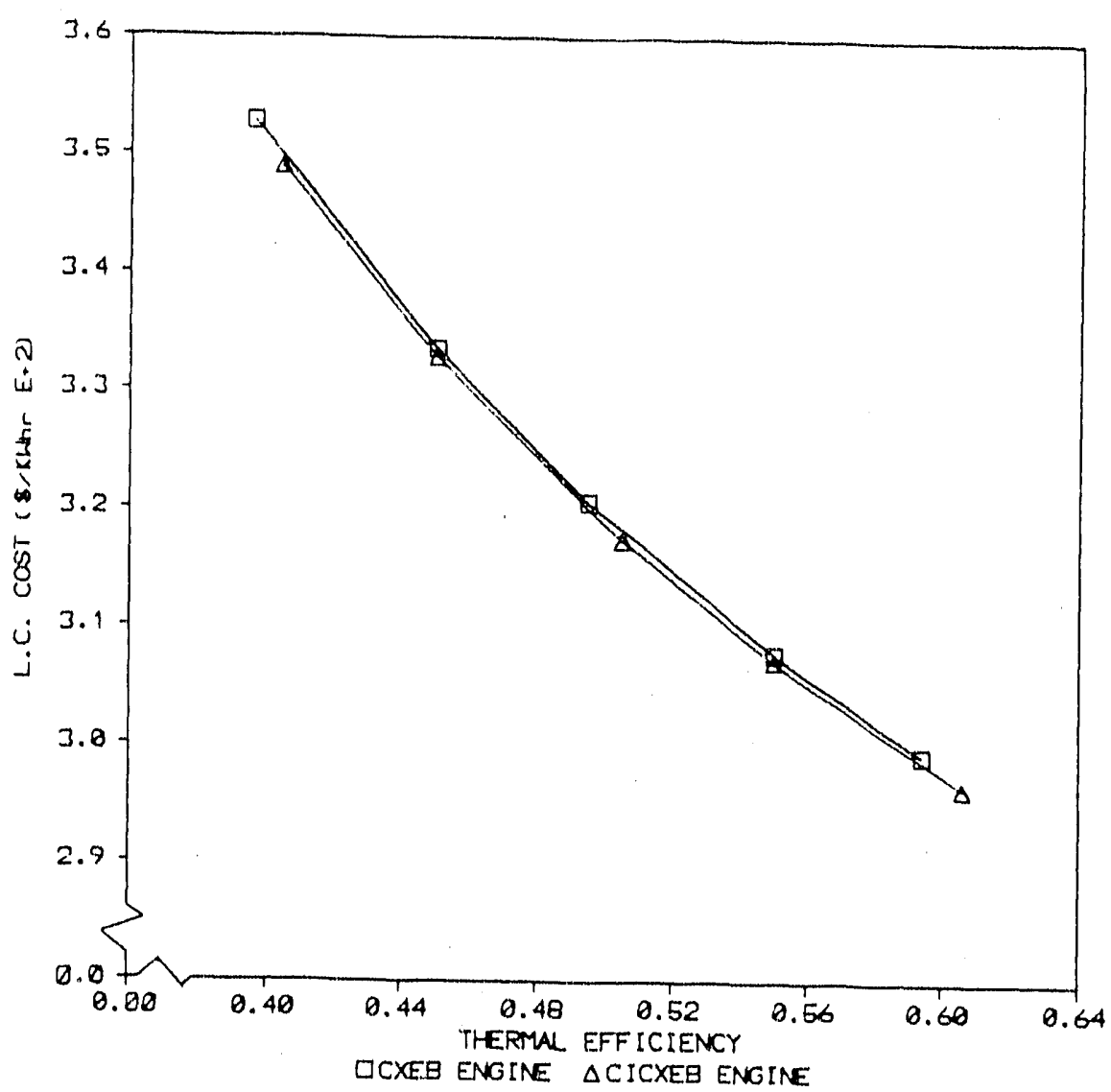

FIGURE 9.1 LIFE-CYCLE COST VS THERMAL EFFICIENCY

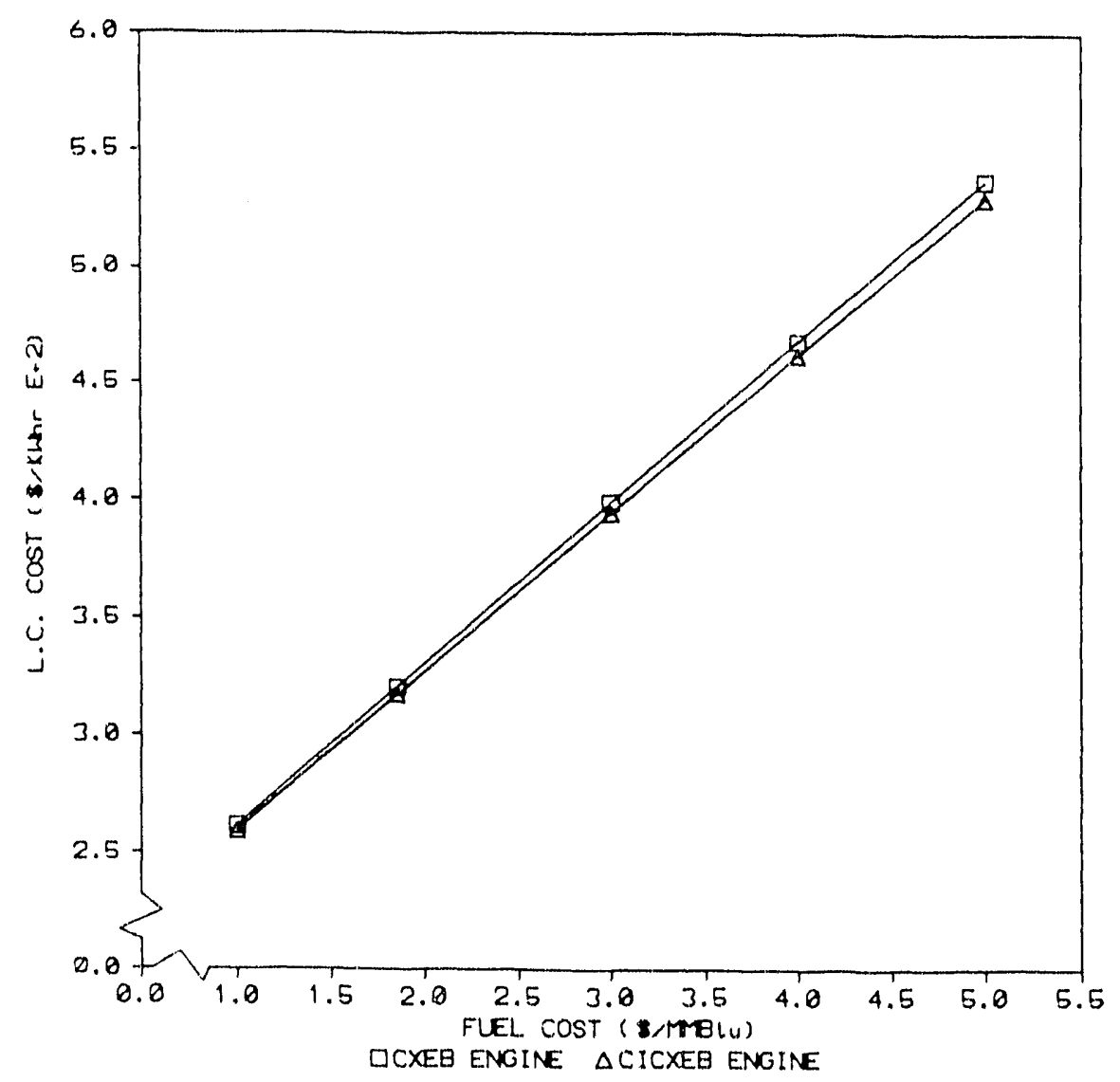

FIGURE 9.2 LIFE-CYCLE COST VS FUEL COST 


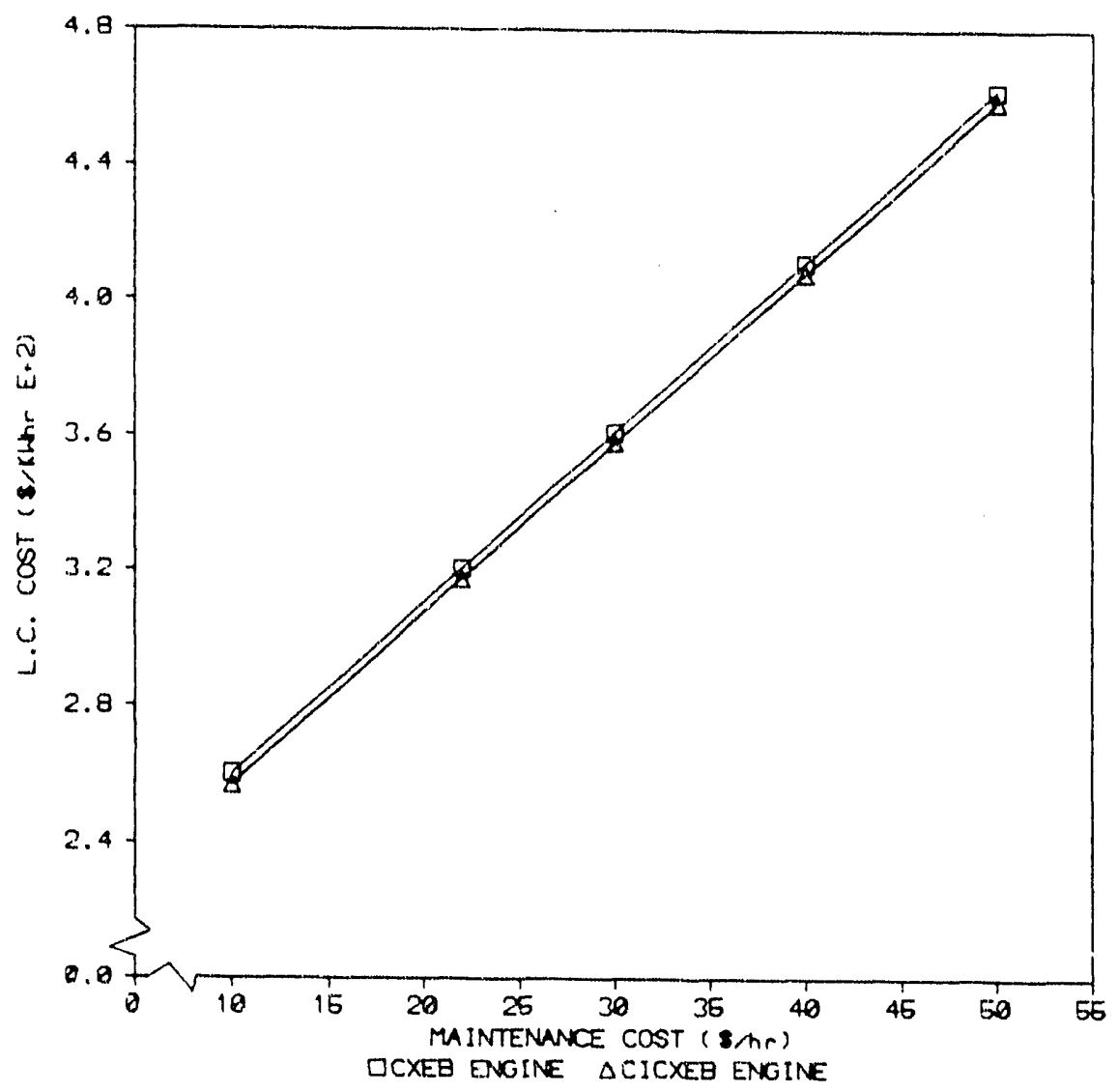

FIGURE 9.3 LIFE-CYCLE COST VS MAINTENANCE COST

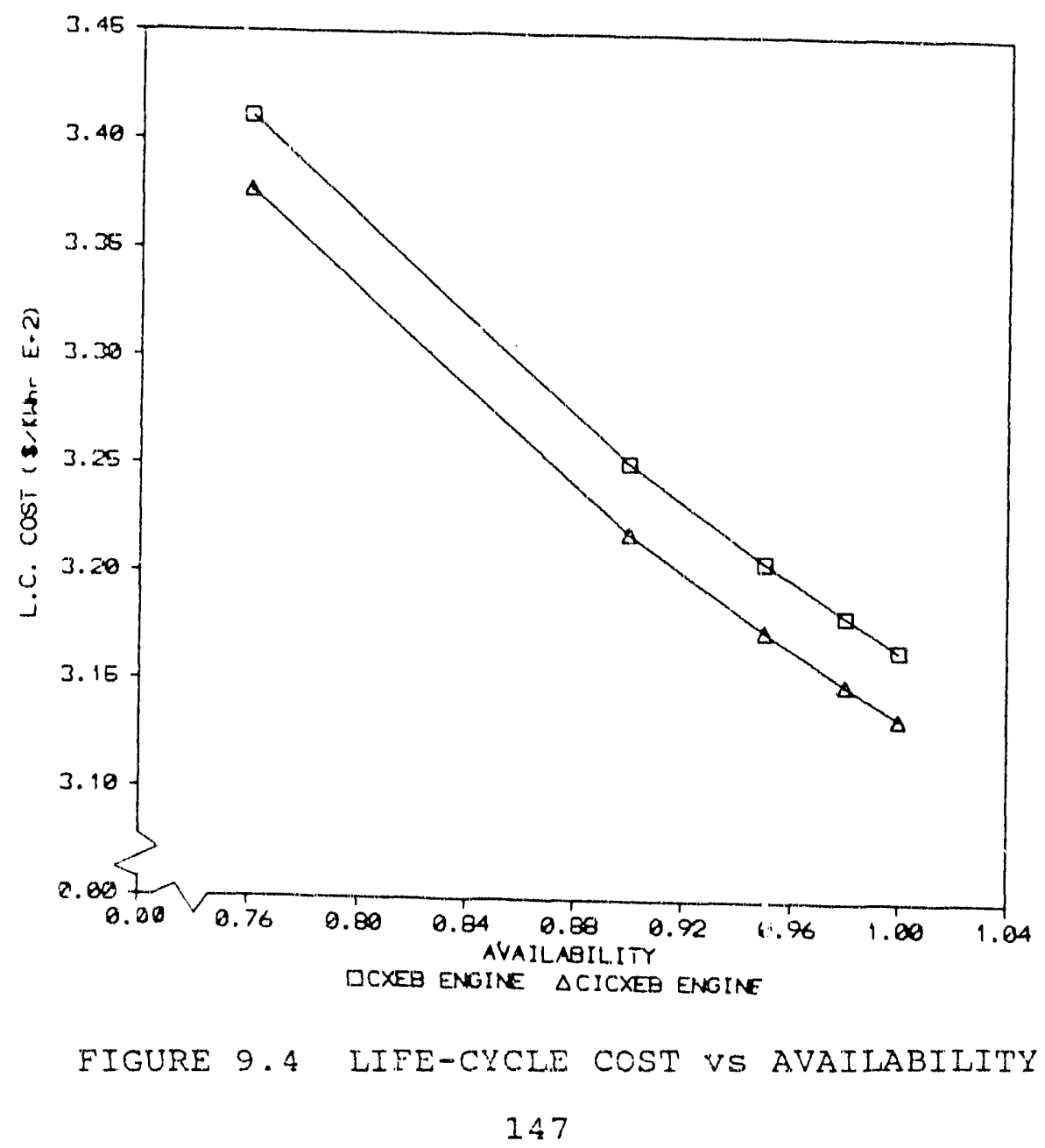




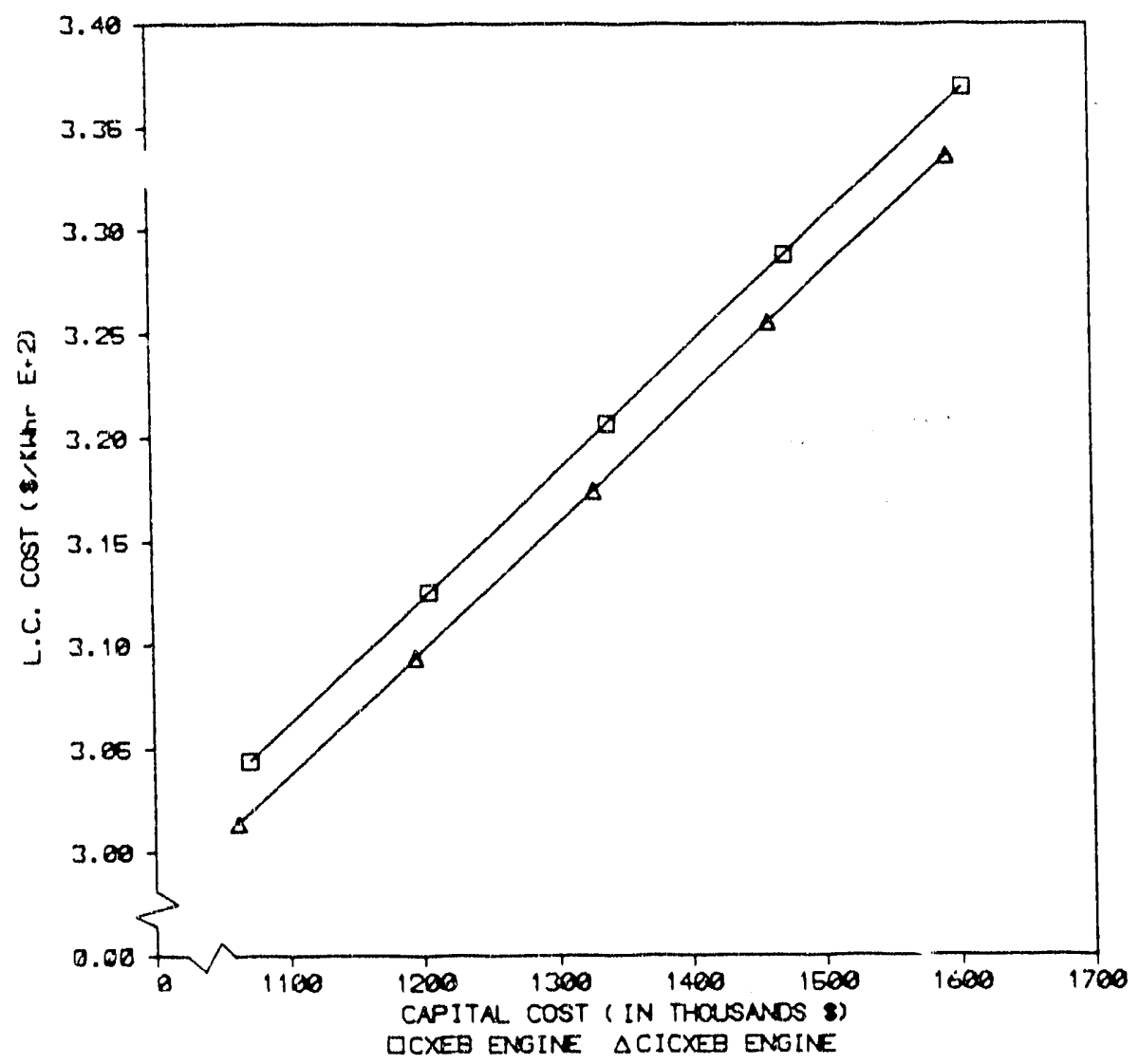

FIGURE 9.5 LIFE-CYCLE COST VS CAPITAL COST

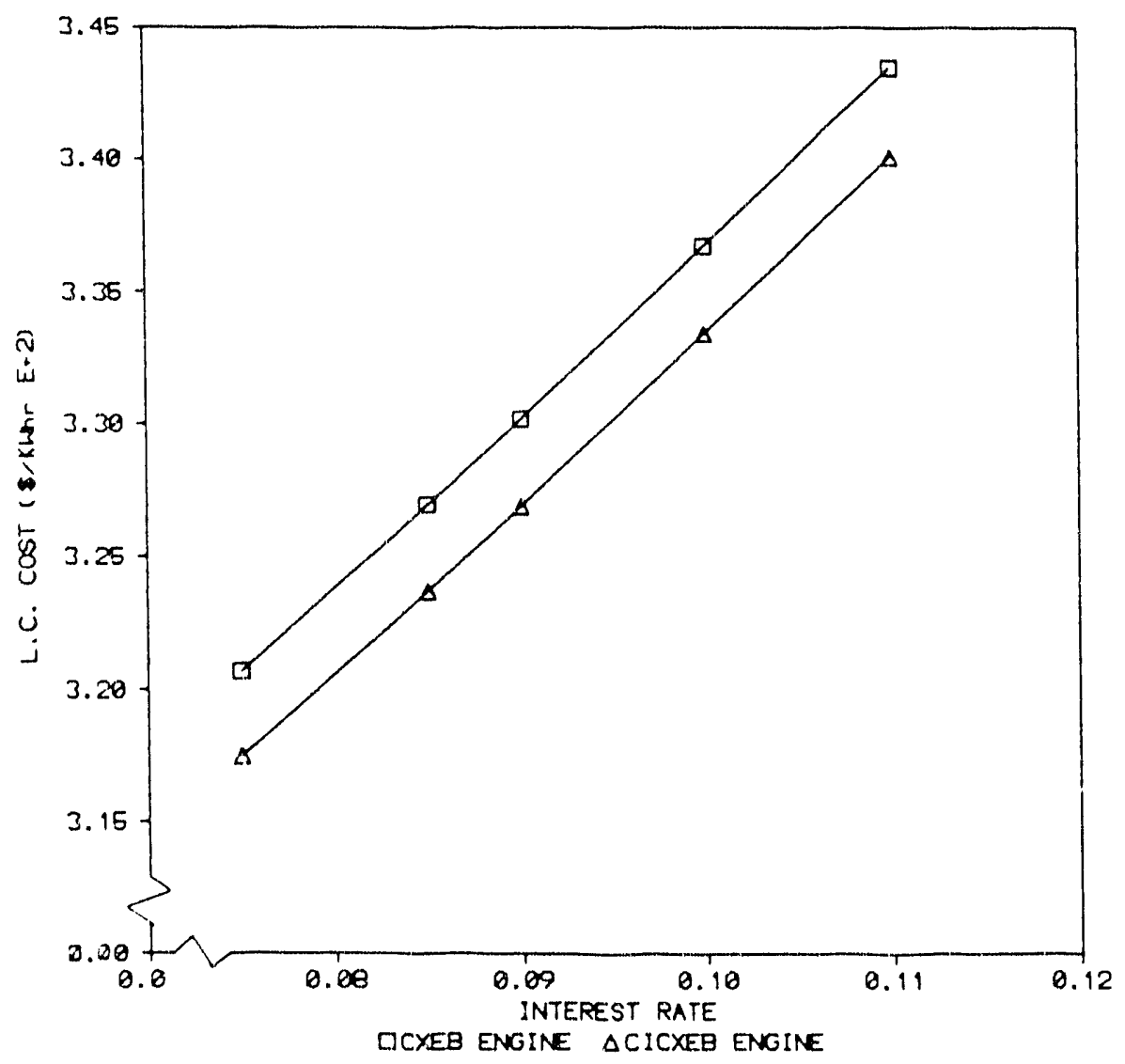

FIGURE 9.6 LIFE-CYCLE COST VS INTEREST RATE 
The parameters in Table 9.5 are listed so that those producing the largest change in the life-cycle cost of the engines appear at the top. Therefore, as mentioned before, the thermal efficiency has the greatest impact on the life-cycle cost followed by the fuel cost, the maintenance cost, the availability, the capital cost, nd the interest rate, in that order.

Comparing Table 9.4 (as well as the other off-the-shelf units) with Figuro 9.3 suggests that a maintenance cost no greater than $\$ 32$ per hour is desirable for the blue-sky engines to keep them competitive with other units. The parameter which affects the life-cycle cost of the engines the most after the thermal efficiency is the price of the coal used as fuel. The price of the coal would be dictated, of course, not only by mining and transportation costs, but also by any cleaning and grinding done prior to burning. The life-cycle cost for varying coal prices for both blue-sky engines (with a maintenance of $\$ 22$ per hour) is shown in Table 9.6 below.

TABLE 9.6 LIFE-CYCLE COST FOR VARYING COAL PRICES

\begin{tabular}{lcc}
$\begin{array}{l}\text { coal price } \\
(\$ / \text { MMBtu })\end{array}$ & $\begin{array}{c}\text { Iife-cycle cost } \\
\text { CXEB }\end{array}$ & $\begin{array}{c}\left(\$ \mathrm{kWhr} \times 10^{2}\right) \\
\text { CICXEB }\end{array}$ \\
\hline 1.00 & 2.614 & 2.594 \\
1.86 & 3.207 & 3.175 \\
3.00 & 3.993 & 3.945 \\
4.00 & 4.682 & 4.621 \\
5.00 & 5.372 & 5.297 \\
\hline
\end{tabular}

The CICXEB appears to be the best engine examined followed by the CXEB. The slight decrease in the life-cycle cost of the CICXEB as compared with the CXEB may not be large enough to justify the added complexity of the intercooled engine. Be that as it may, the comparison of the two blue-sky engines with the others examined indicates a very favorable advantage of the former over the latter.

\subsection{ECONOMIC ASSESSMENT OF OFF-THE-SHELF ENGINES}

The initial-cost break-down of the various options studied in the nonintercooled and the intercooled off-the-shelf designs are included in Tables 9.7 and 9.8 , respectively. 
TABLE 9.7 CAPITAL COST OF NICEH 5650 OPTIONS

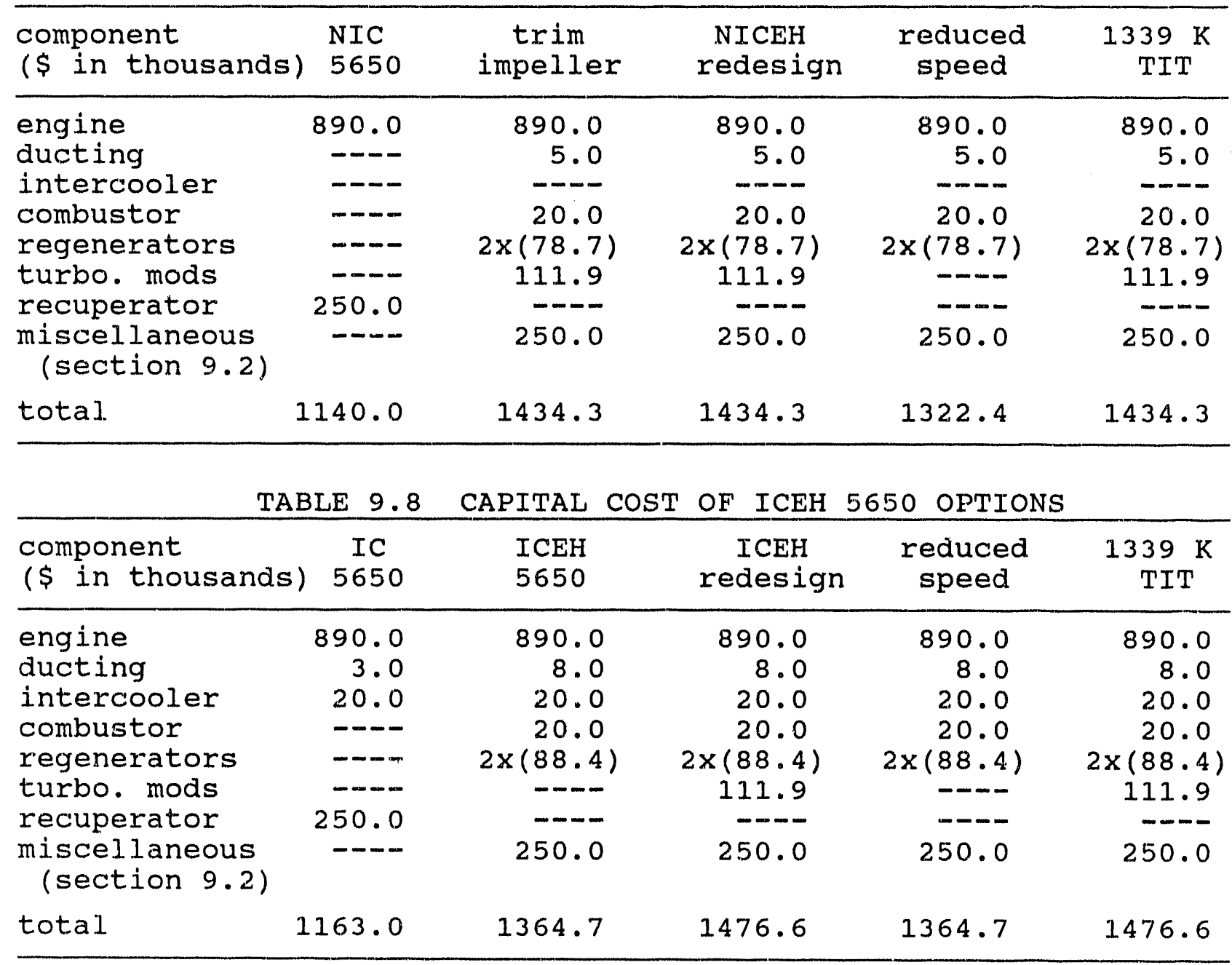

The costs for the regenerators are for core 505A. The turbomachinery-modifjcation costs are added to the base engine cost. This assumes, therefore, that the base 5650 engine is purchased and then modified.

A summary of the variable life-cycle-cost inputs is shown in Table 9.9. 
TABLE 9.9 LIFE-CYCLE CALCULATION PARAMETERS

\begin{tabular}{|c|c|c|c|c|c|c|}
\hline engine & $\begin{array}{c}I \\
\text { (thous) }\end{array}$ & $\begin{array}{c}k W^{1} \\
(k W)\end{array}$ & $\begin{array}{c}E^{1} \\
(---)\end{array}$ & $\begin{array}{c}F \\
(\$ / M B t u)\end{array}$ & $\begin{array}{c}M \\
(\$ / h r)\end{array}$ & $\begin{array}{c}A \\
(--)\end{array}$ \\
\hline base NIC 5650 & 1140.0 & 2770 & 0.336 & 2.97 & 13.85 & 0.98 \\
\hline base IC 5650 & 1163.0 & 3520 & 0.363 & 2.97 & 17.60 & 0.98 \\
\hline NICEH trim impeller & 1434.3 & 2217 & 0.342 & 1.86 & 24.39 & 0.95 \\
\hline NICEH redesign & 1434.3 & 2466 & 0.381 & 1.86 & 26.91 & 0.95 \\
\hline NICEH reduced speed & 1322.4 & 1464 & 0.364 & 1.86 & 16.79 & 0.95 \\
\hline NICEH 1339 K TIT & 1434.3 & 2822 & 0.406 & 1.86 & 30.50 & 0.95 \\
\hline ICEH 5650 & 1364.7 & 3224 & 0.352 & 1.86 & 34.57 & 0.95 \\
\hline ICEH redesign & 1476.6 & 2931 & 0.404 & 1.86 & 31.61 & 0.95 \\
\hline ICEH reduced speed & 1364.7 & 1856 & 0.405 & 1.86 & 20.75 & 0.95 \\
\hline ICEH 1339 K TIT & 1476.6 & 3343 & 0.429 & 1.86 & 35.77 & 0.95 \\
\hline
\end{tabular}

The results of inserting the appropriate terms from the above table into Equation 9.1 are summarized in Table 9.10 below.

\begin{tabular}{lcccc} 
& TABLE 9.10 & LIFE-CYCLE & COST & SUMMARY \\
engine & $\begin{array}{c}\text { capital } \\
\text { Cost }\end{array}$ & $\begin{array}{c}\text { fuel } \\
\text { Cost }\end{array}$ & maintenance $\left.\times 10^{2}\right)$ & $\begin{array}{c}\text { Iife-cycle } \\
\text { cost }\end{array}$ \\
\hline base NIC 5650 & 0.4798 & 3.017 & 0.500 & 3.997 \\
base IC 5650 & 0.3852 & 2.792 & 0.500 & 3.678 \\
NICEH trim impeller & 0.7781 & 1.856 & 1.100 & 3.734 \\
NICEH redesign & 0.6996 & 1.666 & 1.091 & 3.457 \\
NICEH reduced speed & 1.0864 & 1.744 & 1.147 & 3.977 \\
NICEH 1339 K TIT & 0.6113 & 1.564 & 1.081 & 3.256 \\
ICEH 5650 & 0.5091 & 1.803 & 1.072 & 3.385 \\
ICEH redesign & 0.6059 & 1.571 & 1.079 & 3.256 \\
ICEH reduced speed & 0.8844 & 1.567 & 1.118 & 3.570 \\
ICEH 1339 K TIT & 0.5313 & 1.480 & 1.070 & 3.081 \\
\hline
\end{tabular}

Despite having the highest initial cost, the intercooled exhaust-heated engine possesses the lowest life-cycle cost of all the configurations considered in the off-the-shelf-design study (it is also better than the blue-sky engines considered). The turbomachinery redesign, option 2 , is the most cost-effective solution to running the nonintercooled exhaust-heated engine at the optimal pressure ratio. The trimmed-impeller option, although relatively inexpensive initially, does not pay off in the long run. The reduced-speed option has the highest life-cycle cost due to the low power output at the optimal pressure ratio. Running the intercooled exhaust-heated 5650 at its original design pressure ratio (ICEH 5650 option in the tables) presents a favorable comparison to the redesign of turbomachinery due to its lower initial capital cost. For both exhaust-heated engines, increasing the turbine inlet temperature produces great economic benefits over the life-cycle of the engines, if initial capital and maintenance costs are not increased greatly.

1. The power output and thermal efflclency of the exhaust-heated
englnes has been reduced by one percent (see section 9.2 ). 


\subsection{SUMMARY}

The best engine, based on the economic model used, is the intercooled exhaust-heated 5650 with the increased turbine-inlet temperature. This engine is followed closely by the two blue-sky designs and all of the off-the-shelf designs except options one and three of the NICEH 5650 (the trimmed-impeller and the reducedspeed options, respectively). The result obtained for the offthe-shelf designs with a higher turbine-inlet temperature may be a bit optimistic since it was assumed that the maintenance of the 5650 did not change substantially. All of the exhaust-heated engines studied compare well with the other units examined. Naturally, the comparison made is only as good as the data obtained and the consistency of the model. 


\subsection{HEAT-EXCHANGER FOULING TESTS}

A test-rig was designed and built to study the behavior ashladen, room-temperature air has on an actual ceramic matrix core, as specified in [5]. Before the testing began we had expected to see rapid formation of deposits on the small matrix pores $\left(d_{H} \cong\right.$ $500 \mathrm{~mm})$. This was due in part to the fact that we anticipated the fly ash to behave like wet sand. The actual results obtained from the test rig show that the fly ash at velocities above $15 \mathrm{~m} / \mathrm{s}$ passes through the pores unimpeded leaving no deposits behind. Tests were also performed on a drop-tube furnace where ceramic tubes (alumina $\mathrm{Al}_{2} \mathrm{O}_{3}$ ) were inserted; products of coal combustion were then passed through them. Deposits of ash were found to be extremely dependent on the combustion temperature.

\subsection{TEST OBJECTIVES}

The feasibility of the exhaust-heated cycle rests entirely on the performance of the selected heat exchanger. The problems associated with corrosion, erosion, and deposition are transferred to the regenerator in this cycle from the turbine blades in direct-fired engines. Hot corrosion by alkali sulfates in fly ash has not received as much attention as has deposition [11], and long-term data at high temperatures are scarce and often conflicting [70]. It appears that ceramics containing silica are seriously corroded by alkalis; however, other forms, such as oxide ceramics, do appear to withstand alkalis [71]. Deposition of fly ash can potentially be controlled through fuel additives (such as kaolin), improvements in the combustor design, the use of separators, and by operating below the ash-stickiness temperature [10]. The problems associated with erosion should be reduced in the exhaust-heated cycle since the average air speeds drop from 300 to $400 \mathrm{~m} / \mathrm{s}$ in turbine blades to between 5 and $20 \mathrm{~m} / \mathrm{s}$ in the ceramic matrix, and ceramics are as hard or harder than the ash in the air stream [9].

The statements in the previous paragraph are educated suppositions or conclusions based upon very limited data that, as mentioned before, are sometimes conflicting. This makes it necessary for us to investigate the effects fly ash may have on the ceramic regenerator we are proposing for the exhaust-heated cycle. We have identified the pebble heater and the flexible-band regenerator, among others, as possible substitutes for the ceramic regenerator in the past [4], so it is important to determine if one or more of these alternatives needs to be investigated.

The room-temperature tests were our first attempt to understand the behavior of fly ash in a ceramic matrix core. The tests were meant to give new insight into a phenomenon no one else, it. appears, has researched. Should the DOE fund the second phase of 
this project we would be adding needed information on the performance of the regenerator with ash-laden air at combustiontemperature conditions to the room-temperature data obtained in these first preliminary tests.

\subsection{TES'T-RIG DESIGN}

Figure 10.1 is a schematic diagram of the test rig and Figure 10.2 is an actual photograph of the unit. The ceramic matrix, having a geared circumference, rests on three vertical rollers and is held in place by three horizontal rollers. The regenerator is rotated by a pinion attached directly to a small $124 \mathrm{~W}$ ( $1 / 6 \mathrm{hp}$ ) electric motor. The entire structure is supported by three aluminum struts $2.1 \mathrm{~m}$ (7 ft) in height. The three aluminum supports are held in place by two triangular trusses (at the top and at the bottom) and by two circular hoops (on top of and under the matrix).

The air supply was provided by a large compressor in the: Heat-Transfer Lab where the test rig was located. The flow of air was controlled by a valve located upstream of the first contact with the ceramic core. The transparent pipes were clear PVC with an inner diameter of about 6 inches. The transparent seal in contact with the ceramic matrix was acrylic with an inner diameter of 7.5 inches. O-rings were inserted into the clear PVC to provide sealing between them and the acrylic. Each acrylic pipe was pressed lightly against the matrix by means of three compressed springs.

The ash was kept in a small vessel and was injected into the throat region of the circuit by neans of high-pressure aix. The high-pressure air was controlled with a small valve. The vessel can hold about $0.5 \mathrm{~kg}$ ( 1 l lb) of fly ash at a time.

The test rig was designed and built by seth silverstein and Luis Tampe from the summer of 1989 until early 1990. Most of the tests were performed between February and March of 1990.

\subsection{ASH SAMPLES}

About $23 \mathrm{~kg}$ (50 Ib) of coal fly ash for the tests were obtained from the salem Harbor Power station in Salem, Massachusetts. The fly ash was heated at $191 \mathrm{C}(375 \mathrm{~F})$ for a minimum of six hours in order to dry it (fly ash tends to absorb humidity very quickly). The heated ash was allowed to cool down for about ten minutes and then blended. Blending the ash prior to injection permitted a more efficient dispersion into the air stream.

The fly ash used in the test rig was analyzed and found to have a mean diameter of about 5 microns. The largest particle found in the sample was 30 microns. This compares extremely well with information given to us by Professor Janos Beer of MIT [72]. professor Beer stated the mean size of ash resulting from coal 


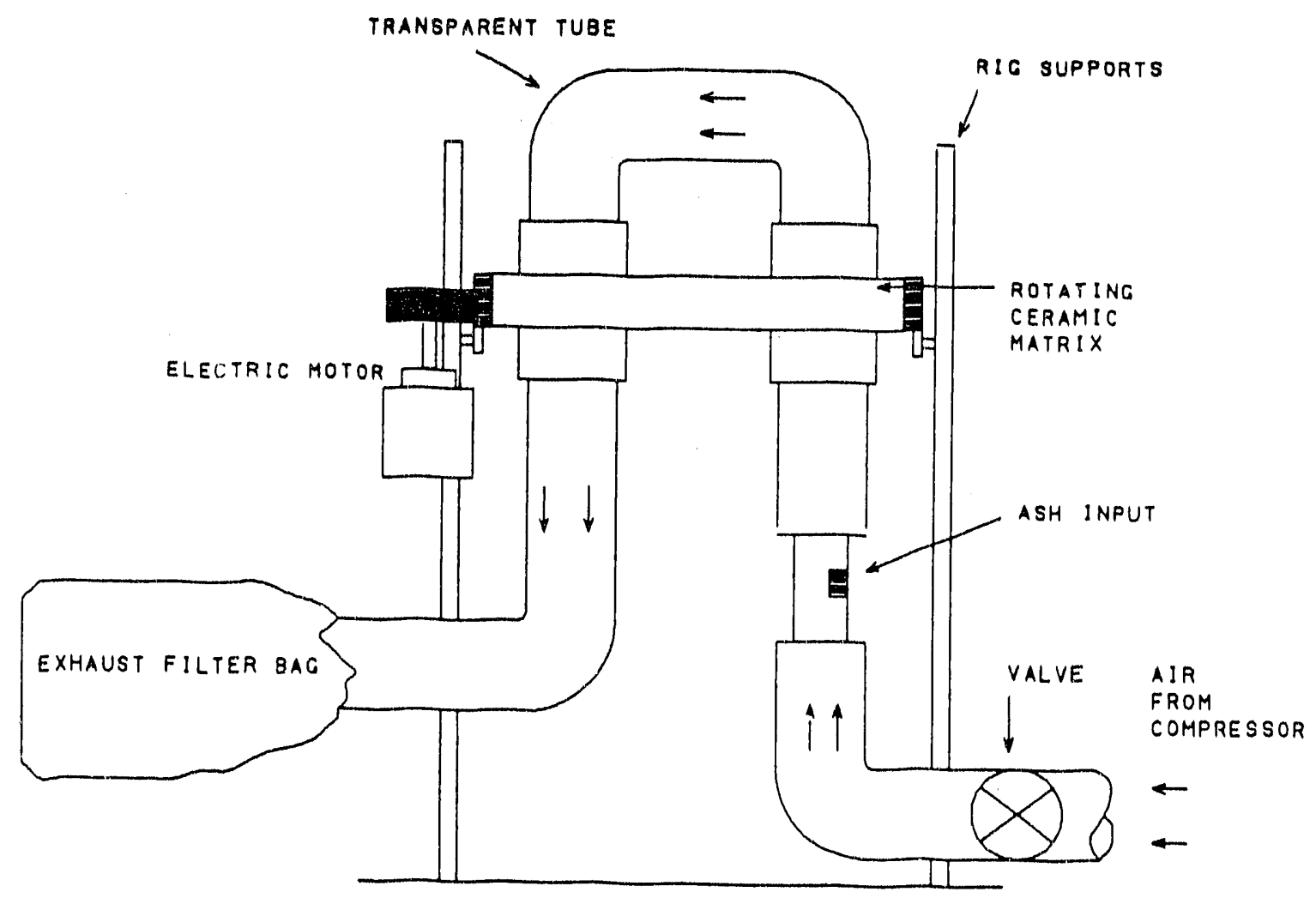

FIGURE 10.1 TEST-RIG SCHEMATIC DRAWING 


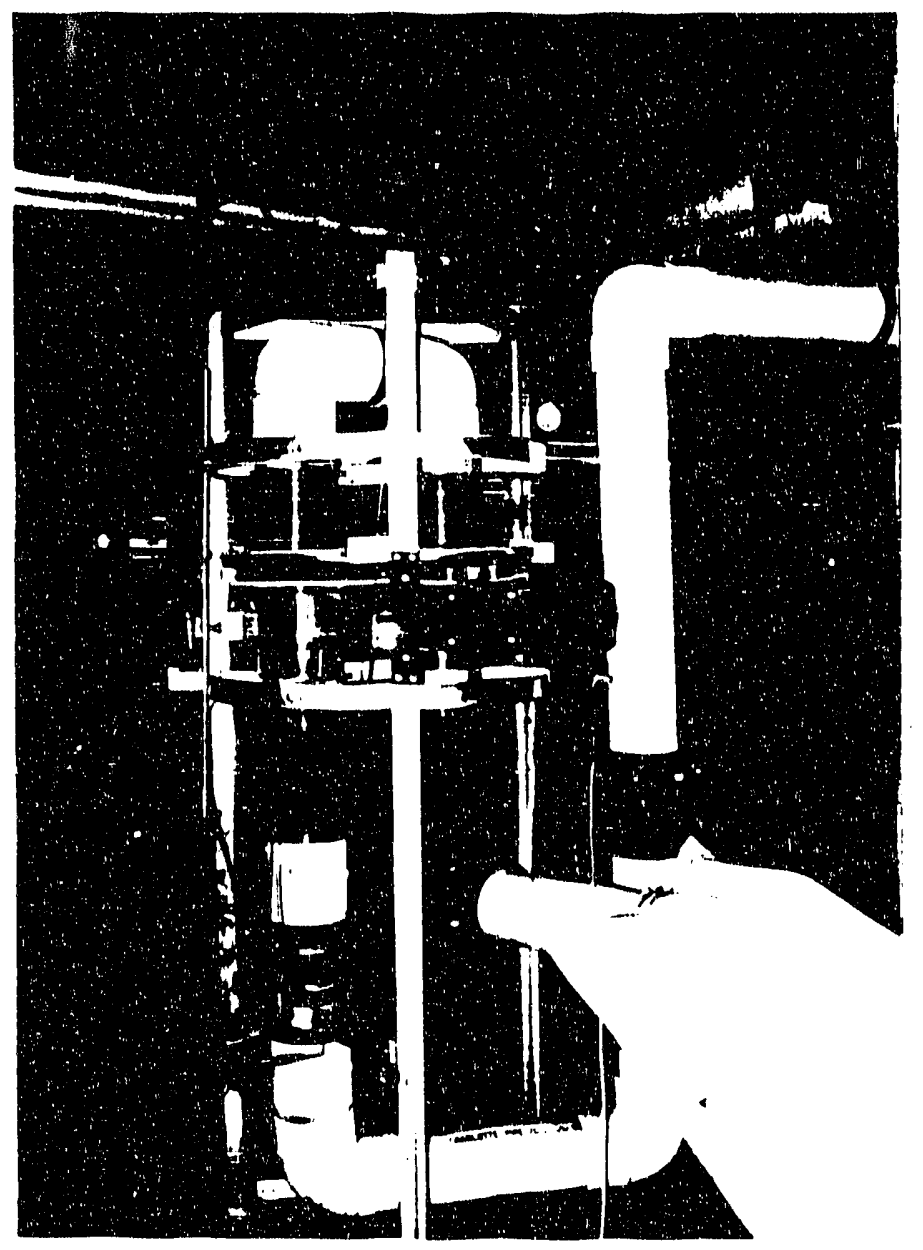

FIGURE 10.2 TEST-RIG PHOTOGRAPH 
combustion in gas turbines is between 5 and 10 microns, and the largest size is around 40 microns. Information obtained from Professor A. Self [73] of Stanford University states the mean ashparticle size of coal-burning power plants is about 10 microns. Table 10.1 below summarizes the information obtained by Self.

TABLE 10.1 SIZE DISTRIBUTION PARAMETERS OF FLY ASHES [73]

\begin{tabular}{l|c|c}
\hline source of ash & $\begin{array}{c}\text { mean diameter } \\
\text { by volume } \\
(--)\end{array}$ & standard deviation \\
\hline Kentucky \#9 (baghouse) & 10.64 & $(--)$ \\
Kentucky \#9 (cyclone) & 15.67 & 2.26 \\
Upper Freeport (baghouse) & 9.25 & 2.02 \\
Ilinois \#6 (baghouse) & 9.70 & 2.80 \\
Illinois \#6 (cyclone) & 14.72 & 3.02 \\
Beulah (baghouse) & 12.80 & 2.14 \\
Beulah (cyclone) & 11.63 & 2.95 \\
San Miguel & 32.23 & 2.34 \\
Eagle Butte & 13.68 & 3.45 \\
\hline
\end{tabular}

The fly-ash sizes are important because they confirm that the ash used in our tests is typical of what would be expected in a coal-burning gas turbine. Furthermore, a recent model developed at MIT for predicting the size and composition of fly ash which successfully uses only the description of the mineral inclusions in the coal seems to suggest the size of the original coal particles (i.e., the extent to which the coal was ground) has little or no impact on the nature of the fly ash formed [74]. This is extremely important since it means that smaller fly ash particles (which can potentially be less harmful to gas-turbine components such as the rotating blades) would not be obtained were the coal to be ground more finely.

As mentioned before, the pore size of the ceramic matrix is around $500 \mu \mathrm{m}$. This is 100 times larger than the mean fly-ash particle and nearly 17 times larger than the largest particle found in the sample. It is clear that, geometrically speaking, there should not be any difficulties in forcing the fly ash through the matrix.

\subsection{TEST PROCEDURE}

In order to use a dynamically equivalent speed in the test rig as that obtained during the sizing of the regenerator in the CXEB cycle, the Reynolas numbers (based on the core hydraulic diameter) were equated. This, however, resulted in an extremely small air speed (less than $0.5 \mathrm{~m} / \mathrm{s}$ ) which would not have been enough to lift some of the larger fly ash particles and entrain them in the flow. Instead, the minimum velocity required to en- 
train an ash particle $500 \mathrm{~mm}$ in diameter was used. An ash particle of such a large size was used in the calculation since most of the ash has not aispersed properly when it is first injected into the air stream and will consequently travel as clumps. The calculated velocity was about $3 \mathrm{~m} / \mathrm{s}$.

The clogging of the regenerator was monitored by measuring the pressure drop across the matrix with a water manometer. As the matrix pores became clogged the pressure drop across the regenerator naturally increased. A pitot tube attached to a magnehelic pressure-differential gage was used to monitor the air speed and maintain it constant.

Two endurance tests were performed. In the fjist, the regenerator was not rotated in order to maintain a "dirty" area in the ceramic matrix which could be compared to the "clean" section. In the second test the regenerator was rotated.

The testing began by turning on the air compressor in the lab and then adjusting the main valve to the test rig until the appropriate reading on the magnehelic gage was obtained. The pressure drop across the regenerator was recorded at this time. The prepared fly ash sample (about $0.5 \mathrm{~kg}$ ) in the vessel was injected into the air stream. The pressure drop was monitored during the ash injection and its final value, after all the ash had been injected, was recorded. The air speed was checked again with the magnehelic gage and the main valve was adjusted as needed.

\subsection{TEST RESULTS}

A total of about $6 \mathrm{~kg}$ were injected into the system with a stationary regenerator. The first $2 \mathrm{~kg}$, however, were injected at an air speed of about $15 \mathrm{~m} / \mathrm{s}$ which is far more than what is required. This high speed kept the pores very clean and prevented us from detecting any clogging. Table 10.2 below summarizes the results obtained with the remaining $4 \mathrm{~kg}$.

TABLE 10.2 RESULTS OBTAINED FROM TEST RIG

\begin{tabular}{|c|c|c|c|}
\hline \multicolumn{2}{|c|}{$\begin{array}{c}\text { cumulative amount of } \\
\text { ash injected }\end{array}$} & \multicolumn{2}{|c|}{$\begin{array}{l}\text { pressure drop } \\
\qquad\left(\mathrm{N} / \mathrm{m}^{2}\right)\end{array}$} \\
\hline STATIONARY & ROTATING & STATIONARY & ROTATING \\
\hline 0.00 & 0.00 & 302 & 311 \\
\hline 0.45 & 0.41 & 341 & 331 \\
\hline 0.95 & 0.83 & 468 & 341 \\
\hline 1.45 & 1.24 & 418 & 360 \\
\hline 1.94 & 1.58 & 468 & 360 \\
\hline 2.46 & 1.99 & 477 & 360 \\
\hline 2.86 & 2.43 & 517 & 370 \\
\hline 3.43 & 2.73 & 574 & 370 \\
\hline 3.98 & --- & 589 & -- \\
\hline
\end{tabular}


The data in Table 10.2 are graphed in Figure 10.3. As can be seen the pressure drop increased almost linearly as more ash was injected into the system in the stationary test. Upon inspection of the core it was noticed that about eighty percent of the pores were covered with fly ash. The air speed was increased to about $15 \mathrm{~m} / \mathrm{s}$ for some ten seconds and the pressure drop went back down to almost its initial value.

About $3 \mathrm{~kg}$ of coal fly ash were injected in the rotating endurance test. Since the surface area through which the fly ash would pass was larger, we expected the pressure drop to increase linearly as more ash was injected into the air stream, but with a smaller slope than in the stationary test. The data obtained shows that the curve appears to approach a plateau. This effect may be explained by the flow reversal in the matrix (i.e., the self-cleaning nature of the regenerator).

This result suggests that periodic increases in the air flow speed (increased by five to six times) may be enough to keep the pores unclogged. The tests performed, of course, do not take into consideration the effects sticky ash particles would have on the bonding strength of the deposits.

During the testing, especially with air speeds above $10 \mathrm{~m} / \mathrm{s}$, the ceramic core accumulated large electrostatic charges probably due to the viscous drag of the fly ash in the air stream. We are uncertain as to the possible beneficial or deleterious effects this would have upon a hot system (i.e., the charge on the regenerator surface could help prevent or induce ash deposition and fouling of the heat exchanger). This is a question that most probably can be answered through hot tests on the regenerator.

\subsection{DROP-TUBE FURNACE TESTS}

Seth silverstein [75] used a drop-tube furnace to combust. coal in an oxygen-nitrogen combustion gas. The furnace was altered in an effort to force products of combustion through alumina tubes. Temperature gradients along the tubes inserted in the furnace resulted in condensation on the tube walls of some of the constituents of the exhaust. Five ceramic tubes were inserted in the furnace; products of coal combustion were passed through four of them and a temperature profile of the tube was made on the fifth.

A bituminous Upper-Freeport coal with a size distribution ranging from 65 to 73 microns was used. This coal is composed of approximately ten percent ash. The water-cooled probe of the furnace, shown in Figure 10.4, was removed and the ceramic tubes were inserted in its place. Details of the design modifications made to the furnace as well as the experimental procedure used may be found in Silverstein [75]. 


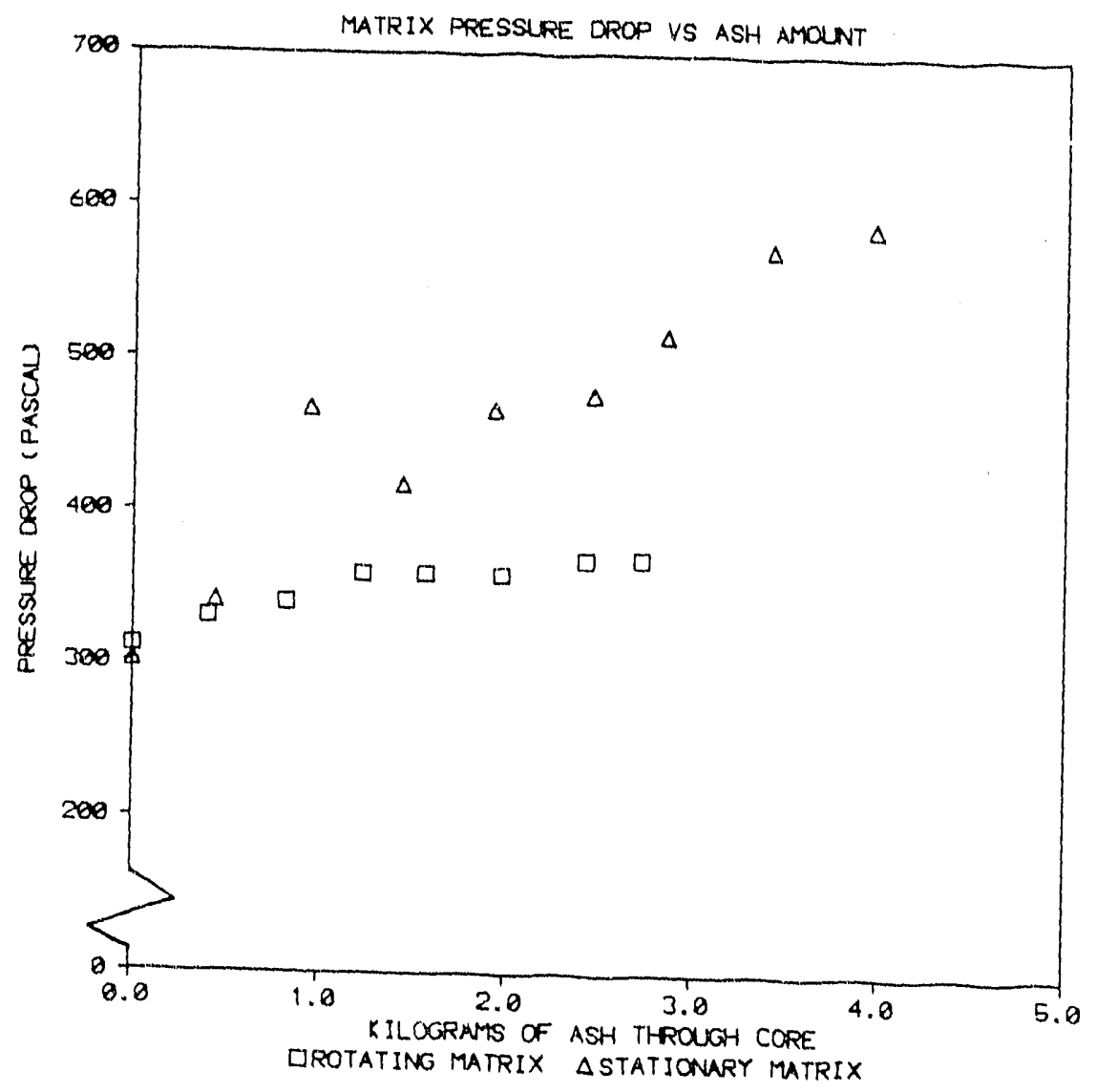

FIGURE 10.3 MATRIX PRESSURE DROP VS ASH AMOUNT 


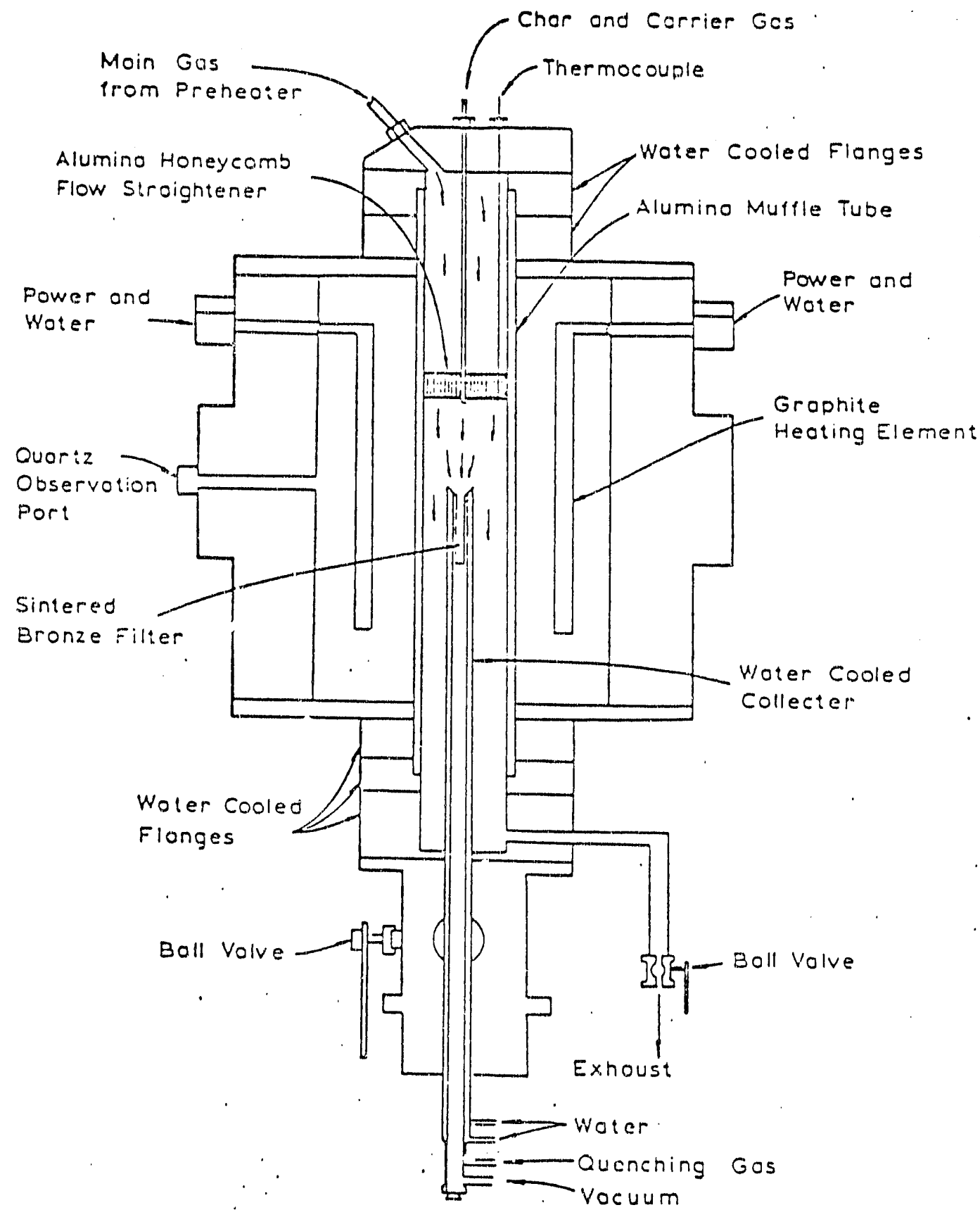
FIGURE 10.4 DROP-TUBE FURNACE WITH WATER-COOLED
PROBE IN PLACE [75] 
In all the experiments the furnace temperature was set at $1750 \mathrm{~K}$. The furnace temperature setting did not affect the gas temperature at the entrance to the specimen tube (the specimen was moved to a position within the furnace where the gas temperature entering the tube was at a desired value); however, it did influence combustion. A higher temperature setting allowed the specimen to be moved farther away from the heating elements, giving the coal more time in the furnace before entering the tube. Furthermore, a higher temperature in the furnace served to heat the coal to combustion temperatures faster. Also constant during these experiments was a combustion-gas flow rate of six liters-perminute, chosen upon the recommendation of Tony Modestino (the furnace technician). Finally, a coal-feed rate of two grams per hour was used in all experiments (except the temperature-profilemeasurement test in which no coal was burned).

Inspection of the deposits found in the alumina tubes revealed glass-like condensation at temperatures higher than about 1280 C. Based on a conversation with MIT Professor Janos Beer (May 10, 1990), we believe this deposit to be slag. This condensate is very thick and clumpy; it is so thick in one of the specimens that i.t would have clagged the tube if more coal. would have been fed into the furnace.

Below the slag there is what appears to be the cooled condensation of a vapor on the walls. Between $1280 \mathrm{C}$ and $1200 \mathrm{C}$ this condensation has what appears to be ash particles trapped in it. Below $1200 \mathrm{C}$, however, the coating is fairly uniform. Visual inspection indicates that this layer is composed of bands that vary in color. An electron microprobe allowed a photograph of the thickness of the deposits on the tube walls to be taken. The thickness appears to be less than one micron.

Ash stickiness from melting does not seem to occur below 1280 $C$, and fly ash stops being trapped by the molten alkalis below $1200 \mathrm{C}$. The results obtained from these tests are very preliminary, but we have developed a protocol to perform tests and to inspect samples and laid the ground work for more exact experiments.

We would recommend exploring the variables in the experiments. For example, only one form of coal was used. It is possible that other coals include constituents which are less or more harmful in terms of alkali condensation. Consequently, some experiments with artificial coal could be very informative. Similarly, we used only one type of ceramic in the experiments; other ceramics, such as mullite which has similar properties to alumina but is more resistant to thermal shock, should be tested.

\subsection{SUMMARY}

The results obtained from the test rig show that, at least for low enough temperatures, there should not be any problems with clogging of the pores even for holes as small as $500 \mu \mathrm{m}$. The air speed needs to be increased only by five to six times periodically 
to maintain the pores clean. This would allow a low-pressure type of "soot blower" to be used on the matrix. The pressure drop across the regenerator increased linearly as more ash was injected into the system. The self-cleaning property of the rotating regenerator was confirmed since the ash deposition seemed to reach a constant level when the matrix was rotated (this, of course, for air at room temperature). Some preliminary results were obtained from a drop-tube furnace having ceramic tubes as targets and burning coal. 


\subsection{CONCLUSIONS AND RECOMMENDATIONS}

\section{CONCLUSIONS}

1. The exhaust-heated gas-turbine cycle has great potential for burning coal in an environmentally benign manner, with control over pollutants and, because of its high efficiency, with minimum production of carbon dioxide.

2. Design-point efficiencies can be over 50 percent if moderate maximum cycle temperatures $(1373 \mathrm{~K}$ or $2011 \mathrm{~F})$ can be used, and over 45 percent if the heat-exchanger-inlet temperatures must be held to lower values, such as $1145 \mathrm{~K}(1600 \mathrm{~F})$.

3. The highly regenerated low-pressure-ratio version of the exhaust-heated cycle has a very favorable part-load performance, giving efficiencies better than those of current Diesel engines of similar power output down to at least fifteen percent of design power.

4. The second lowest life-cycle cost of the engines examined is given by a "blue-sky" or "clean-sheet" engine having an intercooled axial-flow six-stage compressor of four-to-one overall pressure ratio; a rotary ceramic matrix regenerator having an effectiveness of 0.975; a three-stage axial-flow turbine with an inlet temperature of $1373 \mathrm{~K}$ (about $2011 \mathrm{~F}$ ); and a combustor burning dry micronized coal with a hot-gascleanup system. An engine that would require less investment but that would result in a life-cycle cost a little higher would involve modifying the Caterpillar solar 5650 gasturbine engine to work on the intercooled exhaust-heated cycle (with the current turbine-inlet temperature of the solar $5650)$.

5. Cold-flow and coal-combustion experiments on a ceramic regenerator and on alumina tubes give preliminary favorable indications that a ceramic-matrix regenerator would operate successfully and with an acceptable life in the harsh environment of cooling coal-combustion gases. However, considerable testing (recommended below) is required before this indication can be confirmed.

\section{RECOMMENDATIONS}

1. Ceramic passages should be tested carrying coal-combustion products at temperatures realistic for regenerative heat exchangers. The rate of condensation of any alkali, of particulate capture and buildup; and the rate of any material removal by corrosion should be recorded for a range of passageentrance temperatures. 
2. The coal-combustion products should be representative of those coming from a combustion system equipped with hot-gascleanup devices.

3. The effects of various getters and dopants in decreasing any deleterious effects of alkalis and other constituents should be studied.

4. The resistance of different materials used for the walls for the passages in resisting the hostile environment should be investigated.

5. If the results of the above tests are favorable, a test of an actual ceramic-matrix rotary regenerator in a coal-combustion loop should be carried out.

6. If any of the above tests are uncertain or unfavorable, or to provide a backup whether or not the tests are favorable, development of one or more of several innovative low-leakage self-cleaning heat exchangers should be followed. one of these was suggested in MIT's initial proposal to DOE, but was rejected. Improvements on it, and some other alternative approaches currently being considered by MIT for patenting, could well offer longer life and lower maintenance requirements at lower first cost compared with the ceramic rotary regenerator. 


\section{REFERENCES}

1. Byam, John W. and Nelson Rekos, "US Department of Energy Coal-Fueled Gas Turbine Program: A Status Report", ASME paper $88-\mathrm{GT}-86$.

2. Mordell, D.L., "The Exhaust-Heated Gas Turbine Cycle", ASME Transactions, v72, n3, pp. 323-329, 1950.

3. McGee, James P. and Richard C. Corey, "Bureau of Mines CoalFired Gas Turbine Research Project", Combustion, v31, n10, pp. 67-72, April 1960.

4. Tampe, Luis A. and David Gordon Wilson, "Proposed Cycles for the Coal-Fired Exhaust-Heated Gas Turbine", eport prepared for US DOE on August 11, 1989, contract DE-AC21-89MC26051.

5. Tampe, Luis A. and D.G. Wilson, "Management and Detailed Program Plan", report prepared for the DOE, METC under contract DE-AC21-89MC26051, Feb 15, 1989.

6. Wilson, David Gordon, The Design of High-Efficiency Turbomachinery and Gas Turbines, MIT Press, Cambridge, MA 1984 .

7. Boyd, G.L. and D.M. Kreiner, "AGT 101/ATTAP Ceramic TechnologY Development", Transactions of the ASME, Journal for Gas Turbines and Power, v111, p158, Jan 1989.

8. Fitton, A. and R.G. Voysey, "Solid-Fuel-Fired Gas Turbines in Great Britain", Engineering, v180, n4673, pp. 239-243, August 1955.

9. Liddle, S.G., et al., "The Coal-Fired Gas Turbine Locomotive-A New Look", ASME paper 83-GT-2.42.

10. Ahluwalia, R.K. and K.H. Im, "Fouling of Gas Turbine Passages", Argonne National Laboratory, ANL/FE-89/2.

11. Logan, Ronald G., et al., "Ash Deposition at Coal-Fired Gas Turbine Conditions: Surface and Combustion Temperature Effects", US DOE, METC draft report, Feb 1990, to be published in Transactions of the A.SME.

12. Logan, Ronald G., et al., "A study of Techniques for Reducing Ash Deposition in Coal-Fired Gas Turbines", US DOE, METC draft report, Feb 1990, to be published in progress in Energy and combustion science.

13. Wisdom, J.C., "Brown Coal Burning Gas Turbines", Engineering, v206, n5353, pp. 328-331, August 29, 1958 . 
14. "Closed-Cycle Gas Turbine Engines", Automotive Engineering, v83, n11, pp. 46-50, Nov 1975.

15. Bammert, K. and G. Groschup, "Status Report on closed-Cycle Power Plants in the Federal Republic of Germany", Journal of Engineering for Power, v99, nl, pp. 37-46, Jan 1977 .

16. Mordell, D.L., "Experimental Coal-Burning Gas Turbine", Engineer, v198, n5155, pp. 665-669, Nov 12, 1954.

17. Mordell, D.L., "McGill Coal Burning Gas Turbine Project", The Engineering Journal, v40, n4, pp. 404-408, April 1957.

18. Wilson, D.G. and T.P. Korakianitis, "High-Efficiency BraytonCycle Engines for Marine Propulsion", MIT Sea Grant Program, MIT, 1985.

19. Tampe, Luis Alberto, Preliminary Design of a Regenerative Low-Pressure-Ratio Exhaust-Heated Coal-Fired Gas-Turbine Engine, MS Mechanical Engineering Thesis, MIT, Cambridge, MA, May 1990.

20. Frenkel, Richard G., An Analysis of the off-Design Performance of a Low-Pressure-Ratio Coal-Burning Gas-Turbine Engine, MS Mechanical Engineering Thesis, MIT, Cambridge, MA, May 1990 .

21. Frenkel, R.G., L.A. Tampe and D.G. Wilson, "Blue-sky Design and Performance Analysis of an Intercooled and NonIntercooled Coal-Burning Exhaust-Heated Gas Turbine", report prepared for the DOE, METC under contract DE-AC21-89MC26051, Feb 9, 1990.

22. Nahatis, Harry, Conversion of an Existing Gas Turbine to an Exhaust-Heated Coal-Burning Engine, MS Mechanical Engineering Thesis, MIT, Cambridge, MA, May 1990.

23. Nahatis, H.M., D.J. Kowalick, and D.G. Wilson, "Off-The-Shelf Design, Performance Analysis, and Econornic Assessment of an Intercooled and Nonintercooled Coal-Burning Exhaust-Heated Gas Turbine", report prepared for the DOE, METC under contract DE-AC21-89MC26051, Jan 1990.

24. Turton, R.K., principles of Turbomachinery, E. \& F.N. Spon Lta, New York, 1984.

25. Logan, Earl, Turbomachinery Basic Theory and Applications, Marcel Dekker Inc., New York, 198..

26. Cohen, H., G.F.C. Rogers, and H.I.H. Saravanamuttoo, Gas Turbine Theory, Longman Group Limited, UK 1987. 
27. Wilson, D.G., "New Guidelines for the Preliminary Design and Performance Prediction of Axial-Flow Turbines", Proc. Instn. Mech. Engrs., v201, nA4, p279, 1987.

28. Rohsenow, W.M. and A.D. Carmichael, 2.601J "Thermal Power Systems" class notes, MIT, Cambridge, MA, Spring 1989.

29. Ganley, R.J., solution to MIT course $2.601 \mathrm{~J}$ project No. 1, Cambridge, MA, 1987.

30. Kays, W.M. and A.I. London, Compact Heat Exchangers, McGrawHill Book Co., 2 ed, NY, 1964.

31. London, A.L., et al., "Glass-Ceramic Surfaces, Straight Triangular Passages--Heat Transfer and Flow Friction Characteristics", Journal of Engineering Power, p381, October 1970 .

32. Hagler, C.D., The Design of a Ceramic Rotary Regenerator for a Regenerated Low-Pressure-Ratio Gas-Turbine Engine, M.S. Mechanical Engineering Thesis, MIT, Cambridge, MA, April. 1987.

33. Hagler, C.D. and D.G. Wilson, "Considerations for the Design of High-Effectiveness Ceramic Rotary Regenerators for Regenerated, Low-Pressure-Ratio Gas-Turbine Engines", paper presented at the joint propulsion conference, Boston, MA, July 1988 .

34. Linehard, John H., A Heat Transfer Textbook, 2nd ed., Prentice Hall, Inc., 1987.

35. Bazan, Anne, Analysis of Wilson's Method for Predicting the Efficiency of Axial-Flow Turbines, MS Mechanical Engineering Thesis, MIT, Cambridge, MA, March 1988.

36. Benoit, Jeffrey A., Axial-Flow Turbine Performance: An Assessment of an Efficiency-Prediction Methodology, MS Mechanical Engineering Thesis, MIT, Cambridge, MA, May 1989.

37. Craig, H.R.M. and H.J.A. Cox, "Performance Estimation of Axial Flow Turbines", Proc. Instn. Mech. Engrs., v185, p407, 1970-71.

38. Wilson, D.G., FORTRAN computer code for calculating turbine performance, developed while at $\mathrm{GE}, 1986$.

39. Dunham, J. and P.M. Came, "Improvements to the AinleyMathieson Method of Turbine Performance Prediction", ASME Journal of Engrn for Power, pp. 252-256, July 1970.

40. Moustapha, S.H., S.C. Kacker, and B. Tremblay, "An Improved Incidence Losses Prediction Method for Turbine Airfoils", ASME paper 89-GT-284. 
41. Ainley, D.G. and G.C.R. Mathieson, "A Method of Performance Estimation by Reducing Pressure Ratio in Regenerative GasTurbine Engines", ASME paper 85-GT-147.

42. Korakianitis, T.P. and D.G. Wilson, "Improvements in PartLoad Efficiency by Reducing Pressure Ratio in Regenerative Gas-Turbine Engines", ASME paper 85-GT-147.

43. Horlock, J.H., Axial Flow Compressors, Krieger Publishing Co., Huntington, NY 1973.

44. Korakianitis, T.P., Introduction of a Low-Pressure-Ratio, Highly-Regenerative, Advanced Brayton-Cycle Engine for Marine Propulsion and Problems of its Integration in the Fishing Industry, MS Mechanical Engineering and Ocean Systems Management Joint Thesis, MIT, Cambridge, MA 1985.

45. Szanca, E.M. and H.J. Schum, "Experimental Determination of Aerodynamic Performance", in NASA SP-290 v3 (Turbine Design and Application, ed. by Arthur J. Glassman), 1975, pp. 103139 .

46. Cotroneo, J.A., "Centrifugal Compressor Performance Prediction", MIT course 2.996 project, unpublished, May 1984.

47. Casey, M.V. and F. Marty, "Centrifugal Compressors - Performance at Design and Off-Design", Proc. of the Inst. of Refrigeration, v82, 1985-86.

48. Kenny, D.P., "A Novel Correlation of Centrifugal Compressor Performance for off-Design", AIAA paper 79-1159.

49. Herbert, M.V., "A Method of Centrifugal Compressor Performance Prediction", Performance prediction of centrifugal Pumps and Compressors, ASME, NY 1979.

50. Davis, R.C. and J.L. Dussourd, "A Unified Procedure for the Calculation of off-Design Performance of Radial Turbomachinery", ASME paper 70-GT-64.

51. Dallenbach, F., "Simplified Off-Design Performance Prediction", unpublished notes, 1963.

52. Karstensen, K.W., "Intercooled Gas Turbine", Publication No. 86/0166, The Gas Research Institute, Chicago, 1986.

53. Wilson, David Gordon, personal communication, 1989.

54. Combustion Engineering, otto de Lorenzi editor, Combustion Engineering, Inc., NY, 1957.

55. Turbornachinery International Handbook 1989-90, Business Journals Inc., Norwalk Conn., 1989. 
56. Diesel and Gas Turbine Catalog, v54, Diesel \& Gas Turbine Publications, Brookfield, WI, 1989.

57. Mills, R.G. and K.W. Karstensen, "Intercooled/Recuperated Shipboard Generator Drive Engine", ASME paper 86-GT-203.

58. Karstensen, K.W. and J.O. Wiggins, "A Variable-Geometry Power Turbine for Marine Gas Turbines", ASME paper 89-GT-282.

59. "Advanced Gas Turbine Engine for Marine/Industrial Service", Solar Turbines Inc., San Diego, 1983.

60. Tampe, Luis Alberto, May 4, 1990 memo to REHCBGT group on a method for generating matrix-core geometries theoretically, MIT.

61. Gerend, R.P. and J.P. Roundhill, "Correlation of Gas Turbine Engine Weights and Dimensions", AIAA paper 70-669.

62. Korakianitis, T.P. and D.G. Wilson, memo "estimates of future high-temperature-engine performance" to the Institute for Defense Analyses, January 21, 1989.

63. Aicher, W. and S. Schnyder, "Revamp of Turbocompressors", Sulzer Technical Review, March 1988.

64. Spector, R.B., "A Method of Evaluating Life Cycle Costs of Industrial Gas Turbines", ASME paper 88-GT-324.

65. Jackson, J.A., "Reliability, Availability, and Maintainability of the General Electric LM2500 System", ASME 85-GT-140.

66. Demetri, E.P., "Heat-Exchanger Optimization for a Regenerative Small-Gas-Turbine Cycle", ASME paper 68-GT-18.

67. Holtberg, P.D., et al., "1989 GRI Baseline Projection of U.S. Energy Supply and Demand to 2010", Gas Research Institute, Chicago Ill, December 1989.

68. Liddle, S.G., et al., "Economic Aspects of Advanced CoalFired Gas Turbine Locomotives", ASME paper 83-GT-241.

69. Staudt, J.E., "High Performance Intercooled and Recuperated Gas Turbine", publication No. 88/027, The Gas Research Institute, Chicago Ill, 1988.

70. Bakker, W.T. and D. Kotchick, "Development of Ceramic Heat Exchangers for Indirect Fired vas Turbines", ASME paper 82GT-182.

71. Wilson, David Gordon, January 16, 1990 memo to REHCBGT group on viability of ceramics in coal-combustion environments. 
72. Private conversation between Janos Beer and REHCBGT group in october of 1989 at MIT.

73. Self, Sydney A., "Optical Properties of Fly Ash", report submitted to DOE, contract DE-AC22-87PC79903, october 1989.

74. "Coal Combustion: Predicting Ash Deposits Inside Utility Boilers", E-Lab, p4, Jan-March 1989, MIT, Cambridge, MA.

75. Silverstein, seth M., "Examination of the Deposition of Products of Combustion on Ceramic Surfaces", B.S. Thesis, MIT, Cambridge, MA, May 1990.

76. Mellor, George L., the NACA 65-series cascade data, the GasTurbine Laboratory charts, MIT, Cambridge, MA, 1956.

77. Wylen, G.J. and R.E. Sonntag, Fundamentals of classical Thermodynamics, 3rd ed, John Wiley \& Sons, Inc., 1985.

78. Itoh, Takane, "Vehicular Gas Turbines in Japan", Bulletin of the Gas Turbine Society of Japan, 1987. 


\section{NOMENCLATURE}

A a

$A_{f}$

$A_{h}$

b

$\mathrm{b}_{\mathrm{C}}$

$\mathrm{c}$

C

$\mathrm{C}_{\mathrm{S}}$

$c_{p}$

d

$d_{H}$

$d T$

$f$

$g_{\mathrm{C}}$

HHV

$\mathrm{h}$

h

$\mathrm{h}_{\mathrm{t}}$

j

$\dot{\mathrm{m}}$

M

MinBtu

O

$P$

$\dot{Q}$

$\mathrm{R}$

$r$

$\mathrm{Re}$

$\mathrm{Rn}$

$s$

$T$

TIT

U annulus area

flow area

heat transfer area

axial chord

backbone length

chord

absolute velocity

free stream velocity

specific heat at constant pressure

diameter

hydraulic diameter

differential change in temperature

friction factor

constant in Newton's law

higher heating value

enthalpy

blade height

heat transfer coefficient

colburn factor

mass flow rate

Mach number

million-Btu

throat opening

pressure

rate of heat transfer

gas constant

pressure ratio

Reynolds number

stage reaction

pitch or space between blades

temperature

turbine inlet temperature

overall heat transfer coefficient $\left[\mathrm{m}^{2}\right]$

$\left[m^{2}\right]$

$\left[\mathrm{m}^{2}\right]$

[m]

[m]

[m]

$[\mathrm{m} / \mathrm{s}]$

$[\mathrm{m} / \mathrm{s}$ ]

$\left[\mathrm{kJ} / \mathrm{kg}^{\circ} \mathrm{K}\right]$

[m]

$[\mathrm{m}]$

$\left[{ }^{\circ} \mathrm{K}\right]$

$[--]$

$[--]$

$[\mathrm{kJ} / \mathrm{kg}]$

[ $\mathrm{kJ} / \mathrm{kg}$ ]

[m]

[ $\mathrm{kW} / \mathrm{m}^{\mathrm{O}} \mathrm{K}$ ]

[--]

[ $\mathrm{kg} / \mathrm{s}$ ]

[--]

[--]

[m]

$\left[\mathrm{N} / \mathrm{m}^{2}\right]$

[kJ/s]

[ $\mathrm{kJ} / \mathrm{kg}^{\circ} \mathrm{K}$ ]

[--]

[--]

[-- ]

[m]

[K]

[K]

[ $\mathrm{kW} / \mathrm{m}^{\circ} \mathrm{K}$ ] 


$\begin{array}{lll}t_{c l} & \text { tip clearance } & {[\mathrm{m}]} \\ t_{\text {te }} & \text { trailing-edge thickness } & {[\mathrm{m}]} \\ \mathrm{u} & \text { blade speed } & {[\mathrm{m} / \mathrm{s}]} \\ W & \text { relative velocity } & {[\mathrm{m} / \mathrm{s}]} \\ \dot{W} & \text { rate of work transfer } & {[\mathrm{kJ} / \mathrm{s}]} \\ \dot{W}^{\prime} & \text { specific power } & {[--]} \\ Z & \text { number of blades in a row } & {[--]}\end{array}$

\section{Greek symbols}

$\begin{array}{lll}\alpha & \text { fluid angle } & {[0]} \\ \alpha_{c 1} & \text { stator's fluid outlet angle } & {[0]} \\ \alpha_{C 2} & \text { stator's fluid inlet angle } & {[0]} \\ \alpha_{w 1} & \text { rotor's fluid inlet angle } & {[0]} \\ \alpha_{w 2} & \text { rotor's fluid outlet angle } & {[0]} \\ \Delta & \text { change } & {[--]} \\ \phi & \text { flow coefficient } & {[--]} \\ \eta & \text { efficiency } & {[--]} \\ \lambda & \text { stagger angle } & {[0]} \\ \lambda & \text { hub-to-tip ratio } & {[\mathrm{kg} / \mathrm{m} \cdot \mathrm{s}]} \\ \mu & \text { viscosity } & {\left[\mathrm{kg} / \mathrm{m}^{3}\right]} \\ \rho & \text { derisity } & {[--]} \\ \psi & \text { loading or work coefficient } & \end{array}$

\section{Subscripts}

$\begin{array}{llr}h & \text { hub } & {[--]} \\ m & \text { mean } & {[--]} \\ p, c & \text { polytropic, compressor } & {[--]} \\ p, e & \text { polytropic, expander } & {[--]} \\ \text { Re } & \text { Reynolds number } & {[--]} \\ \text { st } & \text { static condition } & {[--]} \\ \text { T } & \text { total condition } & {[--]} \\ t & \text { tip } & {[-]} \\ z & \text { axial-fiow direction } & {[--]} \\ \theta & \text { tangential flow direction } & {[--]} \\ 1,2, \ldots & \text { station in thermodynamic cycle } & {[--]}\end{array}$



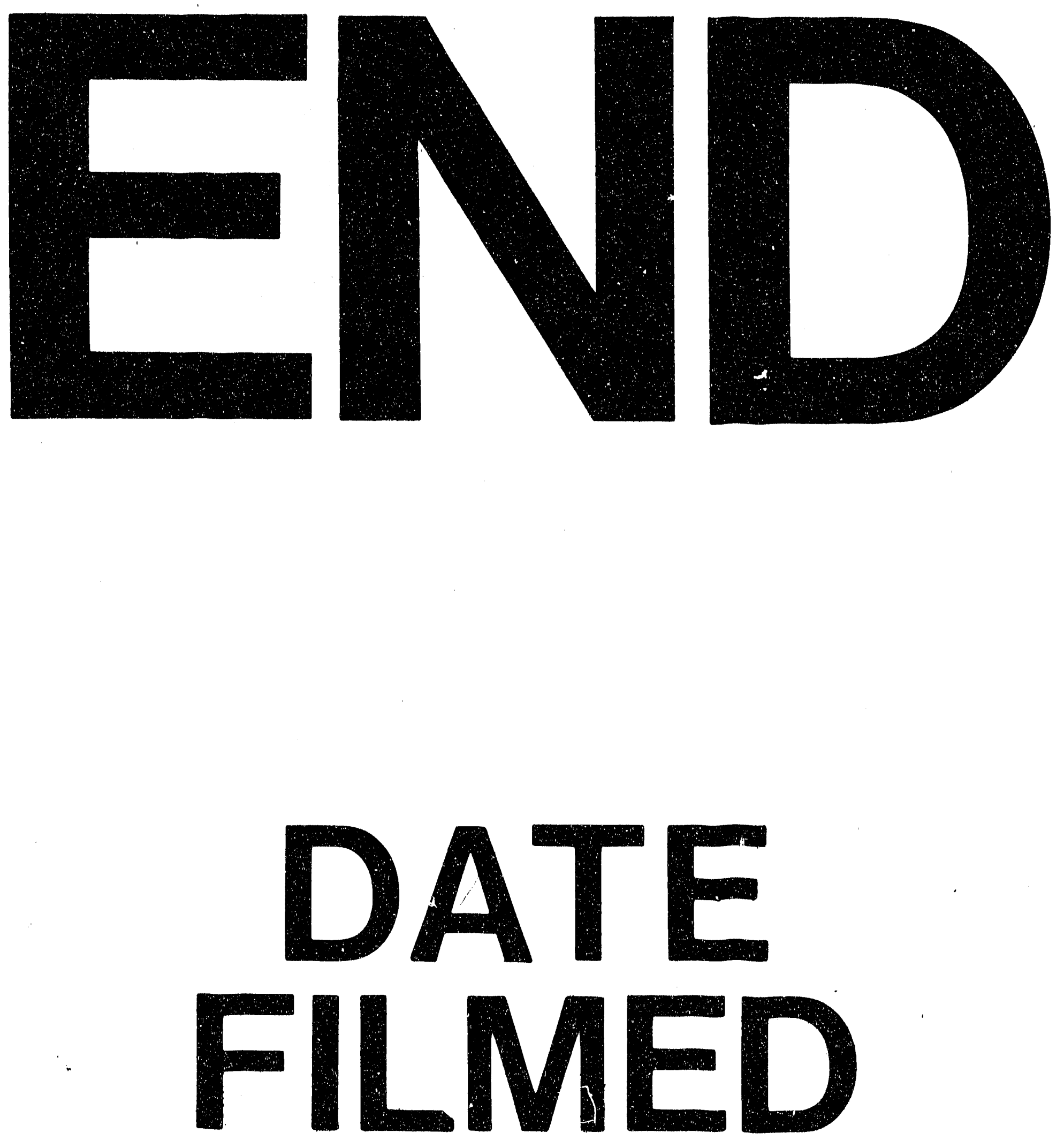

疌

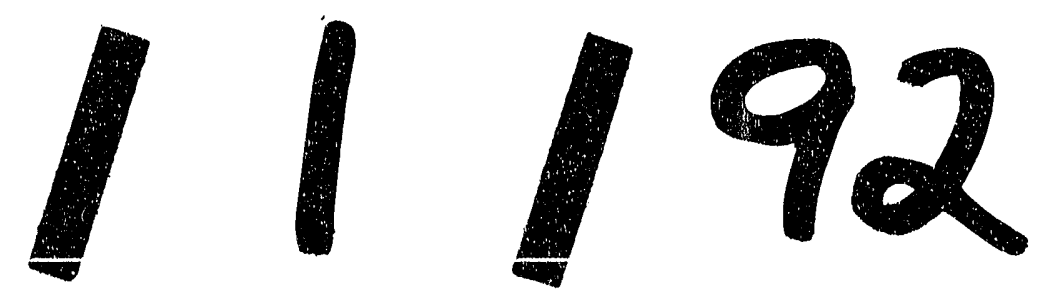

